\title{
Understanding Processes
}

\section{of Ethnic Concentration}

and Dispersal

\section{South Asian Residential \\ Preferences in Glasgow}

JENNIFER LEIGH MCGARRIGLE 
Understanding Processes of Ethnic Concentration and Dispersal 


\section{IMISCOE}

International Migration, Integration and Social Cohesion in Europe

The IMISCOE Network of Excellence unites over 500 researchers from European institutes specialising in studies of international migration, integration and social cohesion. The Network is funded by the Sixth Framework Programme of the European Commission on Research, Citizens and Governance in a Knowledge-Based Society. Since its foundation in 2004, IMISCOE has developed an integrated, multidisciplinary and globally comparative research project led by scholars from all branches of the economic and social sciences, the humanities and law. The Network both furthers existing studies and pioneers new research in migration as a discipline. Priority is also given to promoting innovative lines of inquiry key to European policymaking and governance.

The IMISCOE-Amsterdam University Press Series was created to make the Network's findings and results available to researchers, policymakers and practitioners, the media and other interested stakeholders. High-quality manuscripts authored by IMISCOE members and cooperating partners are published in one of four distinct series.

IMISCOE RESEARCH advances sound empirical and theoretical scholarship addressing themes within IMISCOE's mandated fields of study.

IMISCOE REPORTS disseminates Network papers and presentations of a time-sensitive nature in book form.

IMISCOE DISSERTATIONS presents select $\mathrm{PhD}$ monographs written by IMISCOE doctoral candidates.

IMISCOE TEXTBOOKS produces manuals, handbooks and other didactic tools for instructors and students of migration studies.

IMISCOE Policy Briefs and more information on the Network can be found at www.imiscoe.org. 


\section{Understanding Processes of Ethnic Concentration and Dispersal}

South Asian Residential Preferences in Glasgow

Jennifer Leigh McGarrigle

IMISCOE Dissertations 
Cover design: Studio Jan de Boer, Amsterdam Layout: The DocWorkers, Almere

ISBN 9789053566718

e-ISBN 978904850 I34 2

NUR 74I/763

(C) Jennifer Leigh McGarrigle / Amsterdam University Press, Amsterdam 20IO

All rights reserved. Without limiting the rights under copyright reserved above, no part of this book may be reproduced, stored in or introduced into a retrieval system, or transmitted, in any form or by any means (electronic, mechanical, photocopying, recording or otherwise) without the written permission of both the copyright owner and the author of the book. 


\section{Table of contents}

List of figures and tables 9

$\begin{array}{ll}\text { Acknowledgements } & 13\end{array}$

$\begin{array}{lll}\text { I Introduction } & 15\end{array}$

2 Processes of settlement: Residential segregation and ethnic $\begin{array}{ll}\text { clustering } & 23\end{array}$

Introduction $\quad 23$

Spatial segregation: Defining the concepts 24

Early processes of settlement: Changing patterns and practices 27

The minority population in Britain $\quad 32$

Competing explanations for segregation 36

Politicisation of segregation since 2000 in the UK 42

Conclusion 49

3 Urban migration, residential mobility and suburbanisation 51 Introduction $\quad 51$

Defining the suburbs $\quad 52$

A brief overview of the growth of the suburb in Britain 55

The social life of the suburbs $\quad 56$

'Why people move?' $\quad 58$

Conclusion $\quad 62$

4 Methodology $\quad 65$

Introduction: Research aims and objectives $\quad 65$

A triangulated approach $\quad 69$

Quantitative analysis of the Glasgow Metropolitan Area 69

$\begin{array}{ll}\text { Qualitative phase } & 75\end{array}$

Conclusion $\quad 83$ 
$5 \quad$ Through the national lens to the city: The housing position and experiences of South Asians in Scotland and Glasgow 85 Introduction $\quad 85$

South Asians in Scotland and Glasgow $\quad 85$

Minority ethnic populations in Scotland $\quad 87$

The minority ethnic population in Glasgow $\quad 92$

Housing conditions $\quad 96$

Tenure patterns in Glasgow $\quad 98$

Housing purchase and finance $\quad 106$

Housing need, preference and location $\quad 108$

$\begin{array}{ll}\text { Conclusion } & 110\end{array}$

6 South Asian settlement in Glasgow: Changing patterns of residence

Introduction $\quad 113$

Clustering in the inner city: Localised change $\quad 114$

Moving out: Suburbanisation and new locales 119

Local neighbourhoods and microscopic clusters $\quad 125$

Relative distributions: Segregation and exposure 129

$\begin{array}{ll}\text { Case study areas } & 131\end{array}$

South Asian housing transactions: Nam Pehchan results 152

Conclusion $\quad 152$

7 The role of the neighbourhood in residential choice and $\begin{array}{ll}\text { relocation } & 155\end{array}$

Introduction $\quad 155$

Moves between neighbourhoods: Paths through the city 156

The suburbs: Aspirations, identity and 'peace and quiet' 162

$\begin{array}{ll}\text { Conclusion } & 167\end{array}$

8 Housing, households, families and safe places 169

$\begin{array}{ll}\text { Introduction } & 169\end{array}$

The family, proximity, space and changing cultural ideas $\quad 170$

$\begin{array}{ll}\text { Housing issues } & 173\end{array}$

Safety and area reputation $\quad 177$

Conclusion $\quad 182$

9 Residential outcomes: Settling in or moving on again? 185 Introduction $\quad 185$

Settling into the suburbs: Privacy or inclusion? 185

The social environment, safety, fear of crime and lifestyle 193

$\begin{array}{ll}\text { Future aspirations } & 199\end{array}$

Conclusion 203 
IO Conclusions 205

Patterns of relocation $\quad 205$

$\begin{array}{ll}\text { Motivations and resources } & 207\end{array}$

The role of the core settlement area and community 215

Drawbacks of the research and future research 218

Appendix $1 \quad$ Semi-structured interview schedule (core residents) 221

Appendix 2 Semi-structured interview schedule (suburban residents) 225

$\begin{array}{lll}\text { Appendix } 3 & \text { Interviewee characteristics } & 229\end{array}$

Appendix 4 Coding categories $\quad 235$

Appendix 5 Parent nodes 239

$\begin{array}{ll}\text { Notes } & 241\end{array}$

$\begin{array}{ll}\text { References } & 243\end{array}$ 



\section{List of figures and tables}

Figure 4.I Case study areas 73

Figure 4.2 Migration flows within and between areas of core settlement and the suburbs (moves of interviewees) $\quad 75$

Figure 5.I Glasgow neighbourhoods

Figure 6.I Distribution of South Asian population (\% of the total postcode sector population), I99I 115

Figure 6.2 Glasgow neighbourhoods 116

Figure 6.3 Distribution of South Asian population (\% of the total postcode sector population), $200 \mathrm{I}$

Figure 6.4a Change in the South Asian population (\% of the total postcode sector population), I99I-200I

Figure 6.4 $\mathrm{b}$ Close view of changes in South Asian population (\% of the total postcode sector population), I99I-200I 119

Figure 6.5 Distribution of the Pakistani population (\% of the total postcode sector population), I99I

Figure 6.6 Distribution of the Pakistani Population (\% of the total postcode sector population), $200 \mathrm{I}$

Figure 6.7 Change in distribution of the Pakistani population (\% of the total postcode sector population), I99I-200I

Figure 6.8 Distribution of the Indian population (\% of the total postcode sector population), I99I

Figure 6.9 Distribution of the Indian population (\% of the total postcode sector population), $200 \mathrm{I}$

Figure 6.Io Change in distribution of the Indian population (\% of the total postcode sector population), I99I-200I

Table 4.I South Asian population of the area of study at council area level and \% of national population, 200 70

Table 5.I Scottish population by ethnic group, 200I

Table 5.2 Age profile by ethnic group, all people in Scotland, 200I (\%)

Table 5.3 Tenure by ethnic group in Scotland, I99I (\% of households) 
Table 5.4 Tenure by ethnic group in Scotland, 200I (\% of households)

Table 5.5 Household structure by number of families and ethnic group, Scotland, 200I (\%)

Table 5.6 Occupancy rating by number of families and ethnic group, Scotland, 200I (\%)

Table 5.7 BME population in Scotland's major cities, I99I-200I (\%)

Table 5.8 Population of Glasgow City by ethnic group, 200I

Table 5.9 Tenure by ethnicity in Greater Glasgow, 200I (\% of households)

Table 6.I Postcode sectors with over ro per cent of the total population comprised of South Asians, 200I

Table 6.2 Clustering within neighbourhoods (postcode sectors with largest South Asian \% of total population), $200 \mathrm{I}$

Table 6.3 Clustering in neighbourhoods (postcode sectors with highest proportionate increase in South Asian population), I99I-200I

Table 6.4 Indices of dissimilarity Greater Glasgow, I99I-200I (postcode sector)

Table 6.5 Index of segregation for Greater Glasgow by South Asian ethnic group, I99I-200I (postcode sector)

Table 6.6 Ethnic populations in case study areas, I99I and 200I

Table 6.7 Population by ethnicity, Strathbungo/Pollokshields

Table 6.8 Population by age structure (\% of all people), Strathbungo/Pollokshields

Table 6.9 Population by tenure (\% of all people),

Strathbungo/Pollokshields

Table 6.Io Population by accommodation type (\% of all people), Strathbungo/Pollokshields

Table 6.II Occupancy rating by household (\%), Strathbungo/ Pollokshields

Table 6.I2 Household amenities by household (\%), Strathbungo/Pollokshields

Table 6.I3 Social grade, all people over i6 (\%), Strathbungo/ Pollokshields

Table 6.I4 Qualification by ethnic group, all people aged I6-74 (\%), Strathbungo/Pollokshields

Table 6.I5 Economic indicators, Strathbungo/Pollokshields

Table 6.I6 Population by ethnicity, Woodlands

Table 6.I7 Population by age structure (\% of all people),

Woodlands 
Table 6.I8 Population by tenure (\% of all people), Woodlands

140

Table 6.I9 Population by accommodation type (\% of all people), Woodlands

Table 6.20 Occupancy rating by household (\%), Woodlands

Table 6.2I Household amenities by household (\%), Woodlands

Table 6.22 Social grade, all people over I6 (\%), Woodlands

Table 6.23 Qualification by ethnic group, all people aged I6-74 (\%), Woodlands

Table 6.24 Economic indicators, Woodlands

Table 6.25 Population by ethnicity, Bearsden East

Table 6.26 Population by age structure (\% of all people), Bearsden East

Table 6.27 Population by tenure (\% of all people), Bearsden East

Table 6.28 Population by accommodation type (\% of all people), Bearsden East

Table 6.29 Occupancy rating by household (\%), Bearsden East 146

Table 6.30 Household amenities by household (\%),

Bearsden East

Table 6.3I Social grade all people over I6 (\%), Bearsden East

Table 6.32 Qualification by ethnic group, all people I6-74 (\%), Bearsden East

Table 6.33 Economic indicators, Bearsden East 147

Table 6.34 Population by ethnicity, Giffnock

Table 6.35 Population by age structure (\% of all people), Giffnock

Table 6.36 Population by tenure (\% all people), Giffnock 149

Table 6.37 Population by accommodation type (\% all people), Giffnock

Table 6.38 Occupancy rating by household (\%), Giffnock 149

Table 6.39 Household amenities by household (\%), Giffnock 150

Table 6.40 Social grade, all people over I6 (\%), Giffnock 151

Table 6.4I Qualification by ethnic group, all people aged I6-74 (\%), Giffnock

Table 6.42 Economic indicators, Giffnock

Table 6.43 Percentage of South Asian buyers in study areas, I99I-2003, with breakdown by religious origin of name

Table 6.44 Percentage of South Asian buyers in study areas, I99I-2003, with breakdown by language origin of name 



\section{Acknowledgements}

There are numerous people to whom I am indebted and without whom my doctoral studies and the preparation of the current version of my thesis would have been next to impossible.

First thanks are due to Professor Ade Kearns, my supervisor, for his enthusiasm, inspiration, support, expert advice and kindness throughout my studies. I had the privilege of a second supervisor, Dr. Rowland Atkinson. I would like to thank him for his insight, generosity and kind support.

This research was supported by an ESRC and Scottish Executive case studentship, for which I am grateful. I would like to thank my supervisor at the Scottish Executive, Dr. Laura Turney, for her understanding ear and kind words of encouragement. I would also like to thank my viva examiners, Dr. Deborah Phillips, from the School of Geography at the University of Leeds and Keith Kintrea, Deputy Head of Department of the Department of Urban Studies at the University of Glasgow, for their valuable insights and detailed comments on how this work in its original form could be improved. I would also like to thank Professor Maria Lucinda Fonseca, from CEG at the University of Lisbon, for her support in bringing my thesis to its present form.

There are various other people at the Department of Urban Studies at the University of Glasgow who deserve thanks, especially Caroline Hoy and my fellow students Carlos and Nafoumi. My dearest friend Marcia Gibson, who shared an office with me and walked and talked me through the process, is due all the thanks in the world. There are others who helped me in the field; my sincere thanks go to Dr. Gil at Radio Rhamadam for introducing me to his friends at the mosque and for showing me kind hospitality. I am deeply indebted to the people I interviewed. They shared part of their lives with me and many welcomed me into their homes, offering good food and inspiring stories.

I would like to thank the publishers at Amsterdam University Press and IMISCOE for supporting and making this publication possible. In particular, I would like to thank Karina Hof for her support and understanding whilst I was preparing this manuscript.

For their support, constant encouragement and pleasurable distractions whilst I was in Glasgow, I thank my dear friends Tanja Tonjes, 
Mhairi Taylor, Anna Hart, Wai Fun Wong, Claire Peacocke and April Hopkins. Very special thanks are due to my parents, who supported me unconditionally and faithfully.

Finally, I am indebted to Joaquim Montezuma, my husband, for giving me more inspiration and support than he is probably aware: this book is dedicated to him and the little ones with all my love. 


\section{Introduction}

Processes of urban change and growth in Britain have seen the population take flight from the inner city with suburbanisation representing the most significant part of this urban de-concentration. Outward migration to the suburbs has often signified social aspiration and has been seen as an indicator of social mobility resulting in what Pacione (200I: 84) refers to as the 'modern message of difference'. As outward movement from the city gained momentum in the post-war period the working classes suburbanised and a large proportion of public sector residents through slum clearance programmes were re-housed on the periphery as well as the inner city. This exodus from the inner city concentrated deprivation and left many inner-city neighbourhoods in decline. Contrary to this 'exodus' minority ethnic groups often settled in inner-city areas. The literature on this topic relates minority ethnic movement into poor housing in the inner city to the economic and social conditions in which their early migration was rooted (Phillips \& Karn I991; Smith I989; Peach I998; Miles I982). These conditions were characterised in terms of their labour market position, often in unskilled jobs to meet labour shortages, were they acted as a 'replacement population' for the upwardly mobile majority population. This has been further complicated by difficult-to-access council housing and a weak position in the market. Despite their reasonably long history of settlement in Britain, the residential differentiation of South Asian households, in areas of core settlement in the inner city, has been maintained. It is only in recent times we have seen the small-scale movement of some South Asian households into the suburbs. It is with both these patterns of residence, inner-city clustering and suburbanisation, that this thesis is concerned.

These residential patterns, of course, have a wider political context. In an era when social exclusion is a major policy concern, increased emphasis has been placed upon understanding its determinants and the dynamics of isolation from mainstream society. In the light of this, it is important that the in-group dynamics of the South Asian community are understood in order to address both the deficits in our knowledge of minority ethnic residential behaviour and choices and the limitations in the evidence base of existing policies and political debates. 
Past literature has focussed more on the housing conditions and segregation of minority ethnic groups and much less on exploring minority ethnic housing careers, mobility and residential preferences. Despite the fact minority ethnic residential mobility has been given attention more recently (Phillips, Ratcliff \& Davis 2003; Ozuekren \& Van Kempen 2002; Bowes, Dar \& Sim 2002), to the best of our knowledge, and apart from some sparse evidence on South Asians in Glasgow in the I970 and I980s, this thesis is the first attempt to address this topic in Scotland in recent history and with an in-depth approach. Therefore, it tackles an important gap in the Scottish and, indeed, wider literature.

Glasgow is a distinct city, with some of the highest levels of poverty in the UK, high rates of economic inactivity and welfare dependency as well as the backdrop of sectarianism, which is seen spatially in the city. The city is facing major population changes with a steady and selective population loss, which has led to subsequent skills loss and an over supply of housing. Responses to population changes highlight clear differences in the policy context between Scotland and the rest of the UK. National policies in Scotland to attract migrants are in contrast with England's tightening of border control. Furthermore, at a local level council policy to house asylum seekers, housing the largest number of dispersed asylum seekers in the UK, will see Glasgow's population become more ethnically diverse. However, the settlement patterns of South Asian groups in Glasgow reported here are largely consistent with recent literature that has documented traditional patterns of inner-city concentration and more recent evidence of dispersal in other UK cities. Despite this, locations of traditional South Asian settlement in Glasgow are in areas which are becoming more desirable in the city, reflected in increasing house prices, in contrast to the neighbourhood contexts of South Asians in other British cities. This may point to the fact that economic disadvantage and limits on housing choice may not be as severe, especially in the long term, as in other UK cities, especially those in the north of England.

In drawing attention to factors shaping residential preferences and current patterns of residence, insight is provided into the degree to which minority ethnic groups are able to achieve their residential aspirations and the extent to which changing processes represent convergence or divergence with the majority population. In addition, due to the relatively recent moves of more South Asian households into the suburbs, the emphasis in the literature has been on ethnic concentration areas rather than on processes of dispersal. Thus, we need to know how and why the latter occurs; first, ensuring that theories of minority ethnic settlement and mobility are accurate; and second, to understand the socio-political implications of new modes of migration and mobility for exclusion and patterns of urban inequality. 
Often assumptions of best practices in housing have been made without an attempt to facilitate the views of minority ethnic groups themselves. With the backdrop of the increasing South Asian population in Scotland (even if much smaller than in England) and the commitment of the Scottish Executive to encourage immigration to Scotland through the Fresh Talent Initiative (Scottish Executive 2002a) in response to population loss, it is increasingly important that minority ethnic groups are able, if they aspire to, to achieve the same social and spatial profiles as the majority. Moreover, as this research suggests, suburbanisation is an emerging preference amongst many South Asian households living in central city locations. This also has implications for the Scottish Executive's agenda for Social Justice (Scottish Executive I999), especially within their neighbourhood policy, which is committed to empowerment, neighbourhood satisfaction and the reduction of inequalities.

Furthermore, enhancing our understanding of minority ethnic patterns of settlement and the factors underpinning these is important in terms of its contribution to wider political debates. Questions relating to ethnic clustering and socio-spatial segregation have moved to the forefront of media and political discussions since 200I (Phillips 2003). Concerns relating to the so-called separatist tendencies of South Asian and specifically Muslim groups, reported as being evident spatially, have characterised government responses to the 200I riots in northern English towns and has developed into a key policy concern in the form of the Community Cohesion agenda (The Independent Review Team 200I). Subsequently, with political rhetoric shifting to a more restricted form of multiculturalism, there is a danger that the actual housing and residential preferences of minority ethnic groups have been eclipsed in the policy debate. The move towards a more assimilationist position in public policy, in general, is characterised both by a commitment to integration, based on shared values and a common sense of Britishness, and by the pledge to limit immigration, which is portrayed as a instigator of hostility and intolerance toward settled minority ethnic groups (Back, Keith, Khan, Shukra \& Solomos 2002; Robinson \& Reeve 2006). Implicit within this stance and indeed the concern with the residential segregation of minority groups, expressed within the community cohesion agenda, is that cultural diversity will be tolerated providing identities and values are not at odds with dominant norms and values. The politicisation of segregation and dominant representations of particularly Muslim identities, exacerbated in the light of responses to Islamic extremism, have been based on isolationist discourse, central to which is the accusation that British Muslims have withdrawn from participation in British society (Phillips 2006). The responsibility for integrating has thus been shifted on to the individual and actual 
settlement patterns of South Asians, the processes underpinning these and the diversity within this group have been obscured.

In response to the aforementioned, the main aim of the research was to enhance our understanding of the residential location and preferences of South Asian households and their members in the Greater Glasgow owneroccupied housing market: assessing to what extent suburbanisation is emerging as a significant residential preference and considering the wider implications for understanding these preferences on Scottish and British urban contexts.

From this central aim emerged more specific research objectives, developed along the lines of particular themes pertinent in the literature:

\section{Patterns of re-location}

- To what extent through house purchase in the private market do South Asian households relocate from core community clusters to suburban locations?

- In areas of relocation is there evidence of re-clustering along the lines of ethnicity?

- How does the extent of relocation to suburban locations compare with levels of movement within core settlement areas or into areas adjacent to traditional minority ethnic settlement areas?

\section{Motivations and resources}

- What are the push and pull factors influencing the decision to remain in core settlement areas, move into them from elsewhere or relocate to a suburban location?

- Are residential preferences reflective of the house buyers' assessment of the advantages and disadvantages of remaining spatially concentrated or of dispersal?

- What influences do members of South Asian households perceive the residential environment to have on lifestyle and quality of life?

- To what extent do social class, occupation, material resources and stage in the life course enable or constrain suburban relocation?

The role of the core settlement area and community for suburbanites and core settlers

- To what extent do core areas continue to attract new populations; reverse movers and new migrants?

- What influence does residential dispersal and suburban relocation have on community ties and social networks?

- Is community attachment or membership achieved in the new suburban neighbourhood and/or retained with the core settlement area? 
This research focuses solely upon owner occupiers for four important reasons. First, the predominant tenure in suburban areas is owner occupation. Second, for reasons described in the ensuing literature review, South Asian groups are over-represented in owner occupancy in Scotland, like the rest of the UK. Third, to conduct a study of minority ethnic mobility in the private rented sector would prove to be much more difficult due to the problems associated with records of tenancy for this sector (we use records of sales to track movers to interview). Furthermore, there is less private rented accommodation in suburban areas. Finally, Scotland specific research has tended to focus on the social rented sector, which is less about choice, with less research undertaken in the owner-occupied sector.

The research studies the South Asian population, defined as, in line with census categorisations, Pakistani, Indian, Bangladeshi and Other South Asian. Despite being small in number, fewer than 20,000 in Glasgow City, the South Asian population is the largest minority ethnic population, with the Pakistani and Indian populations being the dominant groups. There has been a significant growth in the Pakistani population in the last two census periods. Furthermore, recent anecdotal evidence from Glasgow has pointed to the dispersal of some of the South Asian population to the suburbs, of which the extent of and explanations for are unknown. In order to address the main research question and objectives it was necessary to adopt a triangulated approach. For this reason, there were two main phases to the methods adopted to explore this phenomenon. First, the quantitative phase was based on an analysis of the 1991 and the 200 I censuses and a mapping of changes in the ethnic geography of Greater Glasgow. Indices of segregation, exposure and dissimilarity were calculated to give broad indicators of segregation and integration across the metropolitan area. Finally, this phase involved sampling using data from the Land Value Information Unit, a unique data set that records housing transactions in Scotland. A name analysis software, Nam Pehchan, was used to extract the names of South Asian house buyers from this data to identify potential interviewees in four case study areas; two suburban areas and two areas of core settlement. Second, the qualitative phase involved interviews with key actors in the South Asian community in Glasgow and 40 in-depth interviews with South Asian households in the four case study areas.

This thesis is structured as follows. Chapter 2 presents a review of the literature on residential processes and patterns of settlement of previous immigrant influxes into the UK, mainly, from the Caribbean, India, Pakistan and Bangladesh. It is important, in the light of changing geographies, outlined in the chapter, and current debates, to understand the processes that have sustained and underpinned the residential segregation of minority ethnic groups in British cities in 
predominantly deprived inner-city areas. Traditional debates centred upon the choice constraint model of explaining segregation are reviewed in the light of new perspectives that see these elements as interactive and highlight diversity and difference as central components to any explanation of segregation. The politicisation of segregation and the role of social identity as an explanation of segregation, in more recent times, and responses to this are also discussed.

Chapter 3 presents a review of the literature on residential mobility, the suburbs and suburbanisation. This chapter examines definitions of the suburbs, from a historical perspective, exploring their role, development and form in the urban area. It also explores the meanings of suburban change and the socio-cultural values and aspirations associated with the massification of suburbanisation. Lifestyle, psychological and behavioural approaches to understanding suburban living are also considered in the light of the diversification of the suburbs. In order to understand more general explanations of patterns of changing residence, the discussion turns to the models in the literature that explain residential mobility and the factors that instigate residential change.

Chapter 4 is concerned with outlining the methodological framework used to conduct the fieldwork.

Chapter 5 provides a review of the Scottish literature relating to minority ethnic groups and housing/neighbourhood issues, the literature is updated when out of date with our own analysis of the 200I Census to provide the reader with a more current picture. The Scottish literature concentrates, in the majority, on tenure patterns, specifically the social rented sector and issues relating to access, dwelling types and housing condition. However, there is less written on residential choice, housing careers and settlement patterns of minority ethnic groups, a gap that this research attempts to bridge. An overview of the South Asian population nationally is presented to provide context for both the Scottish literature reviewed, which in the majority pertains to Glasgow, and our own study on the ethnic geography of Glasgow.

Chapter 6 presents the findings of the census analysis which provide an up-to-date study of the ethnic geography of Greater Glasgow documenting changing patterns of residence, including changes in innercity concentration areas and patterns of dispersal. This chapter also provides a rationale for the selection of the four case study areas in which the qualitative fieldwork is conducted and provides descriptive profiles of these neighbourhoods based on analysis of census data and the Register of Sasines. Thus, Chapters 5 and 6 present a comprehensive narrative of South Asian groups in Scotland from the national level, to the city level, to the smaller scale of the neighbourhood. This provides context for the interview data examined in the following three chapters. 
Chapter 7 is the first of three chapters based on an examination of the qualitative interviews. This chapter presents detailed discussion on the role of neighbourhood factors, the neighbourhood context and place in influencing residential mobility. The findings of this chapter enable us to consider neighbourhood factors that have seen suburbia emerge as a residential preference for South Asians. The discussion considers the impact of issues relating to cultural obligations, religion, family, constraint, housing need, identity, socio-cultural and socio-economic factors on household decision-making processes and mobility. More generally, it enables us to comment on the diverse experiences and strategies involved in residential processes, as well as the meaning attributed to it.

Chapter 8 presents a discussion of three issues found to be decisive in shaping the residential motivations of the interviewees; the role of family, the impact of housing issues and perceptions of safety. This chapter considers the role that changing traditional family structures, familial obligations and generational roles play in housing choices. It also considers the often complex relationship between household composition and housing needs. After which, housing issues that may influence residential choice, such as space, overcrowding, housing condition, affordability and house type, are considered. As well as structural necessities, a critical feature addressed in the housing literature specific to minority ethnic groups has been the importance of safety in contributing to housing outcomes. Thus, its relationship with location and its influence on where people live is considered, allowing us to comment on the racialisation of space in the city.

Chapter 9 differs from the previous two chapters in that it explores the outcome of residential decisions and moves, rather than the motivations shaping them. The ease of settling in and the respondents sense of inclusion in their new area (be it a core area or a suburb) are explored as well as experiences of transition. This chapter also examines the impact of the new area on the respondents' quality of life and lifestyle as well as considering future residential plans and aspirations.

Finally, Chapter io summarises and draws together the main findings of the thesis. It provides clear discussion based around the research questions, outlined at the beginning of this chapter, and discusses the relevance of the findings in relation to current policy debates. The findings of this thesis shed new light on several important issues relating to debates on integration, community cohesion and social identity, including the role of place and interpretations of community, ethnicity and culture. Critically, the findings also show residential segregation to be less straight forward than has been previously assumed in policy debates. 



\section{Processes of settlement: Residential segregation and ethnic clustering}

\section{Introduction}

In spite of the lengthy history of settlement in Britain, minority ethnic groups are still disproportionately represented in deprived urban areas. The processes shaping patterns of segregation have been well documented in the literature. These processes have been sustained by, on the one hand, constraints - namely institutional discrimination, weak labour market positions and prolonged disadvantage - and, on the other hand, the attraction of the core as a place that maintains ethnic ties and protects against outsider hostility. The existence of segregation need not always be seen as negative per se, but rather for its continued association with deprivation, poor housing and marginalisation in the labour market. Phillips (I998) argues that there are forces for minority ethnic exclusion and inclusion at play, producing differential outcomes for different minority ethnic groups, varying dependent on individual experiences according to gender, age, class and personal resources. While given little attention in the I990s, issues related with segregation and minority ethnic clustering came to the forefront of political and media attention after the $200 \mathrm{I}$ disturbances in the northern English mill towns, adding new dimensions to the debate. In particular, discourse has been isolationist and government responses have been based around desegregation in terms of mainstreaming values and promoting spatial mix. This has propelled questions related to the factors that cause and sustain segregation to the forefront of debate once more. This chapter attempts to address some of these issues, beginning by defining spatial segregation, considering its perceived advantages and disadvantages and discussing the most common methods by which it is measured. The processes underlying patterns of segregation will be considered in the second section. The third section will turn to actual patterns of spatial concentration and the changing ethnic geography of the UK. The fourth section outlines and discusses the competing explanations for residential segregation. Finally, the last section considers the politicisation of segregation post 2000 . 


\section{Spatial segregation: Defining the concepts}

Johnson et al. (198I) define spatial segregation as the residential separation of groups within the broader population, whereby some areas show an over-representation and other areas an under-representation of members of a group. Spatial divisions between groups cannot be explained in simple terms but rather occur due to a complicated matrix of forces. The interpretation of spatial segregation is underpinned by the assumption that there is a mutual relationship between spatial distance and social difference (Murdie \& Borgegard I998). Of course, this could be between rich and poor groups, not only ethnic populations. Thus, the value in researching segregation lies in the study of the social significance of people living apart, considering the social, economic and cultural effects. As Park (1926: 26) writes:

In society we not only live together, but at the same time we live apart and human relations can always be reckoned with more or less accuracy in terms of distance.

To some extent, however, with increasing mobility and movement between diverse spaces in our daily lives this assumption might be reckoned with.

\section{Advantages and disadvantages}

Spatial segregation in its most general sense has been assumed as negative, justified by the contention that it is representative of lack of choice and opportunity in the housing market and in other domains. Pacione (I997) and Van Kempen and Ozuekren (I998: 1634) write of the existing 'negative image among the urban populace' of residents of segregated areas, relating it to the segregation of the urban poor and their treatment as the 'underclass'. Assumptions are made that negative types of behaviour and beliefs will be, 'reinforced by the social milieu' (Van Kempen \& Ozuekren I998: I633) leading to the stigmatisation of such areas (Pacione I997). Sennett (1970) asserts that segregated areas can lead to the absence of empathy between groups, thus further legitimising fear and hostility (Van Kempen \& Ozuekren I998).

Despite these negative factors, authors such as Peach (1998) and Phillips (1998) question the traditional premise of research on segregation, contending that there are positive and negative factors present. Clustering may have many positive outcomes, evident in extended social and cultural relations and networks (Phillips et al. 2003). Pacione (I997) underlines the relationship between the segregation of minority 
ethnic groups and strong communities, which act as a coping mechanism against inequality and discrimination. Solely negative views of segregated communities fail to recognise the positive support networks that these places facilitate. Van Kempen and Ozuekren (I998: I635) highlight the benefits of clustering in nurturing social contacts, which can lead to the, "preservation of a culture that is not based on the norms and values' of wider society. Furthermore, religious institutions and specialist retail outlets are practical aspects to preserve culture. The concentration of minority ethnic groups allows these to exist and remain economically viable, thus helping to overcome, to some extent, marginalisation in the labour market. Nonetheless, the aforementioned authors also recognise that there is a relationship between residential segregation and hostility, deprivation, poor housing, and marginalisation in the labour market.

\section{Measures of segregation and concentration}

There are long-standing debates and considerable controversy over the best way to measure segregation. Largely as a result of Massey and Denton's review paper (I988), measurements of segregation are, in general, linked conceptually to five different dimensions of segregation - unevenness, exposure, centralisation, clustering and concentration. The two most commonly used indices in both the US and Europe are the index of dissimilarity (ID), a measure of evenness and the index of isolation (P*), a measure of exposure. This is in the backdrop, however, of an ongoing debate, known as the 'index wars', in relation to which index might provide the best measurement of spatial segregation.

The index of dissimilarity is a measure of evenness which measures the distribution of minority and majority groups across sub-areas of a city (for example, if all of the sub areas of a city were found to be 90 per cent white and Io per cent black, the black population would be considered to be evenly distributed). It measures the percentage of a minority population that would have to move to create an even distribution by computing the sum total in a larger area of the differences in the relative populations in sub areas. A figure of ' $O$ ' would denote no pattern of segregation, since the distribution is exactly the same between the two groups being compared. A figure of ' $I$ ' indicates total segregation, where the residential distribution between the two populations being compared is totally uneven. In-between these two values, an Index of Dissimilarity (ID) less than 0.4 is considered low, $0.4-0.59$ moderately high, and 0.6-0.69 high and above 0.7 is considered very high.

$I D=\frac{1}{2} \cdot \sum_{i=1}^{k}\left|x_{i}-y_{2}\right|$ 
$k=$ the total number of sub-areas in the city

$x_{i}=$ the proportion of the city total of the $x$ population in area $i$

$y_{i}=$ the proportion of the city total of the $\gamma$ population in area $i$

The index of dissimilarity is measured as half the sum of the difference between the proportions of the two populations living in each individual $K$ areas of the city (Peach \& Rossiter 1996: II2).

The reliability of this measure has been questioned due to two main weaknesses. First, it only measures two groups at a time, so when there are more than two groups it is a less reliable indicator. This is problematic as most cities today are multi-ethnic; however, it may be good for cities where there are only two ethnic groups. The second problem is that of scale, since the index is aspatial it measures the degree of segregation, but not its spatial patterns. For instance, if the measured ID is $O$, which denotes no segregation, then it could mean that half of area is black and the other half white, however, we are unable to tell if the black and white residents are mixed or if they are each occupying a separate half of a particular area. One further weakness may be pointed out relating to compositional variance; if the total population size of the sub areas being employed decreases, the segregation index tends to increase (Stearns \& Logan I986). Gorard and Taylor (2002) describe this in more detail and argue that, despite being an unlikely scenario, if the number of the black population changes as a proportion of the city population, but in such a way that the relative distribution of the black population remains unchanged, then the ID varies. This would suggest that segregation is higher when in fact the distribution has not changed the black population has simply grown (known as compositional invariance).

In response to this, Gorard and Taylor (2002: 887) propose the segregation index, which separates the overall change/growth of the population with changes in its distribution. The segregation index (IS) compares the city-wide proportion of the minority in each subarea with the proportion of the total city-wide population in the subarea, rather than comparing two populations or pairs of groups in a subarea together. The index is asymmetric as it only deals with the distribution of the minority ethnic group.

$\mathrm{S}=0.5 * \sum\left(\left|\mathrm{A}_{i} / \mathrm{A}-\mathrm{T}_{i} / \mathrm{T}\right|\right)$.

$\mathrm{A}_{i}=$ number of the minority group in the subarea

$\mathrm{A}=$ the total number of the minority group in the whole area

$\mathrm{T}_{i}=$ the total population in the subarea

$\mathrm{T}=$ the total population in the whole area 
Indices of exposure or isolation measure the degree of potential contact between minority and majority group members within the area of the city that they live. The measure is dependent upon the extent to which they live in the same sub-area of the city. It attempts to measure the 'experience of segregation' rather than being based on an assumption of ideal distribution (Massey \& Denton I988: 287). The most commonly used measure of exposure is $\mathrm{P} *$, an interaction index. This measures the potential exposure of the minority group with the majority group (Peach \& Rossiter 1996). P* is also used to ascertain the group from whom and to whom the exposure is directed. It takes into consideration the size of the groups being compared, as there will be greater probability that a member of a smaller group will come into contact with a member of the larger group (Pacione 200I).

$\left.\mathrm{P}^{*}=\sum\left\{\left(x_{1} / X\right) y_{1} / t_{1}\right)\right\}$

$\mathrm{X}=$ the total number of group $\mathrm{X}$ in the city

$x_{1}=$ the total number of group $\mathrm{X}$ in a given subarea

$y_{1}=$ the total number of group $\mathrm{Y}$ in a given subarea

$t_{1}=$ the total population in a given subarea

(Peach \& Rossiter 1996: 126).

Simpson (2005) highlights the fact that measures of isolation, based on proportions of ethnic groups, are at a loss to assess changing levels of segregation over time because different populations are growing at different rates.

\section{Early processes of settlement: Changing patterns and practices}

The early migration of minority ethnic groups to Britain was primarily due to a short supply of labour. Their position in the labour market, the subsequent restructuring of the economy and the difficulties they faced in accessing social rented housing influenced their presence in poor owner-occupied housing, in decaying inner-city neighbourhoods. At the present time, while disproportionately represented in deprived areas and low socio-economic positions, there are clear variations between ethnic groups, pointing to differential achievements and social trajectories.

The labour market and the changing economy

Phillips and Karn (I99I) and Phillips (I998) argue that segregation patterns in Britain reflect both the material and ideological conditions that existed at the time of South Asian and Afro-Caribbean migration. 
The expanding industrial economy in post-war Britain was threatened by a labour shortage, which immigrants from the New Commonwealth and Pakistan were recruited to fill. This 'replacement population' (Peach 1998: 1658 ) represented, and indeed facilitated, white prosperity and upward social mobility. Miles (1982) refers to the racialised division of labour that emerged as a consequence of this. Employment opportunities tended to comprise low-skilled jobs in the textile industry, which where located primarily in the East Midlands and North-west England. In Scotland, at this time, South Asians were encouraged to fill public sector vacancies, working mainly on trams and buses in Glasgow. In the I96os, job opportunities became available in growing industries, such as motor manufacturing, leading to new concentrations of minority ethnic groups in towns such as Luton (Bowes \& Sim 2002). These types of employment were conducive to clustering in inner-city areas where housing was less expensive and of poor quality (Peach 1998). Direct labour recruitment programmes from specific areas in the New Commonwealth led to the further clustering of ethnic minorities from the same locales (even villages) with similar religious and cultural affiliations (Phillips I998). These clusters became ethnic centres that maintained the social, cultural and economic life of the immigrants. This emerging pattern of ethnic segregation in deprived areas was further reinforced by white suburbanisation. In due course, the inner city, as highlighted by Phillips and Karn (I99I), functioned as a constraint to spatial and social mobility.

The demand for labour was not to last and the weak position of minority groups in the economy rendered them particularly vulnerable (Peach 1998: 1659). Indeed, the economic restructuring that began after the I973 oil crisis and the subsequent 'jobless' economic recovery negatively impacted this population. Processes of residential segregation are closely related to the effects of the economic restructuring of society, which has taken place since the mid-I97os, and its subsequent impact on integration, fragmentation (Musterd \& Ostendorf 1998) and increasing social polarisation (Lee I998). The 'drive' toward flexible labour markets has resulted in long-term unemployment or insecure employment leading to polarisation and exclusion (Somerville I998).

Unemployment has traditionally been higher for minority ethnic groups than for the white population, in the early I990s the rates of unemployment for young minority ethnic men were overwhelmingly high. In general terms, despite decreasing during the I990s, higher rates of unemployment have been maintained, as shown in the report by the Cabinet Office Strategy Unit 'Ethnic Minorities in the Labour Market' (2003). Indeed, with the exception of Indian and Chinese men, high unemployment rates have persisted for minority ethnic groups over a long period of time. The unemployment rates for 
Bangladeshi, Pakistani and Black Caribbean men, in I992, were I5 to 20 per cent higher than for white men (ibid.: 20). This disparity had decreased by 2002, however, remained high at around Io to I5 per cent; similar disparities are reported for minority ethnic women (ibid.: 20). Moreover, the comparative labour market attainment of minority ethnic groups in Britain is poor when one considers further indicators such as employment rates, levels of self employment, earnings levels and occupational attainment (ibid.: I9) In short, as Peach puts it, this is evidence that, 'the economic tide that had drawn immigrants to Britain's inner cities ebbed and left many members of the minority communities stranded in a workless environment' (Peach I998: I66I). Effectively, as Phillips (I998: I685) argues, ethnic minorities who sustained now declining industries in the I970s and onwards became 'casualties' of their early geography, as economic restructuring caused job losses in the manufacturing regions of Britain. This has and continues to have obvious effects on spatial concentration and deprivation.

\section{Housing, housing policy and the housing market}

The early distribution of new migrants mirrored the structure of unskilled job opportunities, affording them little power in the housing market (Phillips \& Karn I99I). Their disadvantaged position was exacerbated by weak housing policy that denied them full access to property and welfare rights (Smith I989). Indeed, previous research has shown that minority groups were unaware that full welfare rights, including entitlement to social housing, as stipulated in The Nationality Act of I948, accompanied full citizenship. Smith (I989) contends that central to the racial differentiation of residential space was the decision not to link immigration with housing policy after the Second World War. She concedes, however, this is more likely to be a result of unanticipated outcomes of housing policy and the omission of minority ethnic needs rather than a defined policy objective. As a consequence, immigrants did not benefit from urban restructuring and lost out on welfare rights associated with social renting and subsidised ownership (Smith I989; Sarre, Philips \& Skellington I989).

Earlier studies on race and housing in Britain documented inequalities in council housing related to differential access, treatment and quality of properties allocated when compared to white applicants (Smith I989; Sarre et al. I989; Phillips 2005). This was largely a result of ageing stock and the incomprehensiveness of modernisation as well as overt discriminatory practices (Smith I989; Sarre et al. I989). The ability of local authorities to house minorities has met additional difficulties with the restructuring of the social rented sector. The 'right to buy policy', introduced in the I980s, whereby local authorities sold off 
council housing, further hampered the possibility of minority ethnic groups finding appropriate housing, as larger good quality housing, most suitable to minority ethnic needs, has been most likely to sell. Residualisation of the housing stock led to the majority of general housing allocations being made in less popular estates, where minority ethnic households were reluctant to live due to fears of racial harassment and isolation (Ratcliffe 2002). Furthermore, ethnic monitoring in local authority housing allocation has been accused of being both ineffective and inconsistent (Bowes \& Sim 2002).

Despite the significant downfalls and overt discriminatory practices, which have served to limit the housing options of minority ethnic groups, Harrison (2005) argues that practices and policies within the social housing sector have developed to become manifestly different from those documented in earlier studies up to the end of the I980s. He argues that practice environments in the UK are 'probably more developed in terms of equality, monitoring and diversity practice than in some of the other large EU countries' (Harrison 2005: 15). He observes that overt discriminatory practices are unlikely to occur in social renting in the UK today due to two factors. First, the decision-making environment is much more regulated and monitored and second, the onset of new initiatives, including, to name a few, strategies for Positive Action, mentoring schemes and the development of BME housing associations. Indeed, at the national level, the 200I Census shows Black Caribbean and Bangladeshi households to be well represented in either local authority housing or in housing associations, 40 per cent and 48 per cent, respectively (Phillips 2005: 26). Nonetheless, there are clear downfalls within the sector and possible new forms of discrimination that require a note of caution here. Harrison specifically refers to the possibility of discrimination toward young people. There is evidence that, despite a preference for owner occupation, social housing may become a vital source of housing or a transitional option for young Asian households (Ratcliffe et al. 200I; Phillips 2005). More generally, BME tenants continue to be over-represented in poor quality neighbourhoods, less is known about state of repair and the quality of dwellings they are living in (Phillips 2005). Furthermore, Phillips (2005: 37) highlights the fact that performance by housing providers continues to appear 'patchy'. Finally, there are new ethnic equality issues to be considered in the light of stock transfer, choice based lettings and changing needs related with new household formation and the growing numbers of refugees and asylum seekers.

Research by Ratcliffe et al. (200I) on South Asian access to the social rented sector in Bradford provides more recent insight into why tenancy levels of particular South Asians groups in council housing are low, offering a useful comparison with older analyses of this sector. 
The respondents felt there was a stigma related to living in social housing and to living in the areas in which the housing was located, namely, estates with poor reputations. The undesirability of these areas was further exacerbated by the fear of abuse, racial harassment and postcode discrimination. Furthermore, it was problematic when housing was located too far away from family, community and places of worship. As in past research, lack of knowledge on how to apply for housing was found to be an inhibiting factor. In addition, the study reported a suspicion of discrimination in the working of the points system used to allocate council housing. There were also fears about the cost of, particularly housing association, housing and concerns about the size.

The aforementioned obstacles have traditionally left minority ethnic groups with two choices: the declining private rented sector or owner occupancy (Phillips 1998). Research suggests that access to both was hampered by direct and indirect discrimination on the part of landlords and estate agents, often leaving minority ethnic groups with limited options in the private housing market (Ratcliffe 2002). Phillips and Karn (I99I) argue that the role of the market contributed to disadvantage since normal market mechanisms worked to keep areas white through inflated prices. Sarre et al. (1989) draw attention to the weak position that minorities held when considering the attributes needed to compete in the housing market, including obstacles such as low socioeconomic capital, language barriers, access to information and influence over providers. This was reinforced by racist practices such as redlining perpetrated by private market institutions, building societies, estate agents and landlords. As a result, moves were often restricted to private exchanges between those living in the inner city. The experience of owner occupancy, shown both in recent and earlier research, has been a difficult one for minority ethnic households with many struggling to meet costs beyond their means.

There is more recent evidence, as in social housing, that these early factors that shaped processes of settlement have begun to change for some. This is largely due to the fact that information and access to finance has improved, traditional barriers created by private institutional discrimination and 'gatekeepers' have been lowered and some households have experienced a rise in their income (Phillips 2005). Despite this, Phillips et al. (2003) found that whilst agents are unlikely to engage in overt discriminatory practices, some agents still had influence over where minority groups lived, as they used racialised stereotypes and had a racialised view of the housing market. In terms of processes of settlement, the aforementioned lowering of barriers can be best seen by the suburbanisation of some minority ethnic households (Ratcliffe I996; Phillips et al. 2003; Phillips 2005). Still, revealing the varied 
experiences of minority ethnic homeowners, there is clear evidence of households continuing to be trapped in disadvantage and poverty. Data from the English House Condition Survey (200I) shows almost three times as many black and minority ethnic people live in poor neighbourhoods as white households (Phillips 2005: 27). Similarly, across all tenures, levels of overcrowding remain high amongst the Pakistani and Bangladeshi groups, as highlighted in the 200I Census with 21 and 39 per cent, respectively, living in overcrowded conditions compared with only 4 per cent of white British (Phillips 2005: 28). Moreover, ONS statistics from 2000 revealed almost 25 per cent of Pakistani and Bangladeshi households to be living in unfit dwellings, compared to 6 per cent of white and around 7 per cent of Indian households (Phillips 2005: 28).

Today, both policy and practice is considerably different from the earlier periods as already discussed. Harrison (2005) highlights how the understanding of minority ethnic needs and experiences, reflected in specific policies and legislation, has changed considerably over the last decade and a half. Policy has moved beyond assimilationist goals through different stages, namely the development of anti-racist strategies based around monitoring and restricting direct or overt discrimination to the equality agenda. As Harrison puts it, several factors have led to the 'agenda gradually becoming more complex' (2005: 62). Prominence has been given to issues related to institutional racism within housing bodies, the recognition of the diversity within minority groups and the need for cultural sensitivity in service provision. These are clearly aspects which have fed into the multicultural agenda that developed in the UK.

\section{The minority population in Britain}

The non-European minority ethnic population in the UK grew rapidly in the post war era. In I95I, the population numbered 80,000, growing to 500,000 in I961, I.5 million in I97 and increasing further in I98I to 2.2 million (Peach I998: 1658 ). The majority of primary migration occurred between I948 and I974. Since then, most growth in this population has been due to natural increase, as over half of the Caribbean and Pakistani population in Britain are UK-born (ibid.). By I99I, the census recorded the minority ethnic population as numbering 3.I million or 5.5 per cent of the total population, growing to 4.6 million or 7.9 per cent of the total population in 200I (The Strategy Unit 2003: I5).

The ethnic composition of England, and indeed Scotland, based on 200I Census data is more varied than ever before, as Rees and Butt 
(2004: I74) state, there has been 'a dramatic increase in ethnic diversity in all regions'. The 200I Census in England reveals the largest BME group to be Indian, followed by Pakistani, White Irish, Black Caribbean, Black African, Mixed Ethnicity, Bangladeshi and finally Chinese (Rees \& Butt 2004: I76). This differs from Scotland, as will be discussed later, where the Pakistani population is by far the largest with the Indian population third behind the Chinese. Rees and Butt (2004) point out that it is highly likely that the white British group is decreasing, as in Scotland, and that immigration from Australasia, Europe and North America is preventing a decline in the overall white population. The black population is growing rapidly, especially the Black African group which increased by I4I per cent in the period between I99I and 200I (ibid.: I77). The South Asian population in England doubled over the period from I98I-200I, growing as fast as the black group as a whole but not as fast as the Black African group. The growth in the Indian population slowed between I991 and 2001 to 27 per cent, (in the decade before it was 38 per cent), due to ageing, lower immigration and lower birth rates. The Bangladeshi group, even though experiencing high-growth rates, followed a similar pattern with a lower percentage point increase between I99I-200I (76 per cent) than in the period between I98I and I99I (96 per cent). The Pakistani group grew less than the Bangladeshi group, but its growth rose from 43 per cent between I98I and I99I to 56 per cent between I99I and 200I (ibid.: I77-I78).

\section{Levels of concentration}

At a macro-scale minority ethnic groups have concentrated in England (Owen 1992), which has remained the case in 200I. At the microscale, as Rees and Phillips (I996) highlighted, there have been a variety of sub-national changes. In I99I, minority ethnic groups were primarily concentrated in declining metropolitan areas and under-represented in prosperous growth areas (Peach I998). Rees and Butt (2004) show that between I98I and I99I BME groups were concentrating into metropolitan areas, whereas a decade later they were beginning to deconcentrate. In fact, the relative growth of minority ethnic groups was higher in non-metropolitan areas than metropolitan areas. In the decade between I991 and 2001, the growth in non-metropolitan areas was 43 per cent and 38 per cent in metropolitan areas. This represents a reversal of the previous trend between I98I and I99I, when growth was 3I per cent in non-metropolitan areas and 44 per cent in metropolitan areas. Furthermore, in this period minority ethnic groups began to grow outside their core areas (Rees \& Butt, 2004: I8I), but London remained dominant overall. Indeed, the 200I Census shows the London 
region as housing around 50 per cent of England's BME population (Rees \& Butt 2004: I8I).

On a national level in I99I, the Indian population was found to be most highly concentrated in outer London and the West Midlands. Indians were also prominent in West Yorkshire, but were below the national average in all other areas (Rees \& Phillips 1996). At the local level (district), the highest concentrations of Indians were found in Leicester, Coventry, Wolverhampton, Blackburn, Bolton and Preston. In 200I, the picture in terms of locations remains relatively unchanged and the largest concentrations of the Indian group are in East Midlands' cities, most notably Leicester, and outer London as well as the West Midlands, elsewhere the group continues to be under-represented. In the period between I99I and 200I, levels of concentration decreased in all of the aforementioned places except outer London where it increased (Rees \& Butt, 2004).

The Pakistani population is unique in that its distribution is not dominated by inner or outer London rather the highest concentrations were in Bradford and Kirkless, textile towns in West Yorkshire, with further concentrations in the North-west, Greater Manchester, Central Clydeside, Birmingham and the West Midlands. In I99I, for the first time, Glasgow was represented among the top twelve districts with the largest Pakistani populations. According to census data, there was a significant rise in the Pakistani population of Glasgow between I98I and I99I, from 7,0I5 to II,605 (a percentage increase of 65.4 per cent), which was the largest percentage increase in Pakistanis of any UK district. Simultaneously, there was a io per cent decrease in the white population of Glasgow, which was the largest decrease in any UK district (Rees \& Phillips I996). There was continued growth in $200 \mathrm{I}$ in the Pakistani population to 15,330 persons. In 200I, Rees and Butt (2004) show the Pakistani population again to have a low level of concentration in London, and higher levels of concentration in West Yorkshire, the West Midlands, Greater Manchester and the East Midlands. Increases in concentration occurred in Greater Manchester, Outer London and in non-metropolitan regions (Rees \& Butt 2004).

Of all minority ethnic groups, the Bangladeshi population is the most highly concentrated in London. In I99I, 44 per cent of the Bangladeshi population in the UK lived in inner London, primarily in Tower Hamlets and Camden (Rees \& Phillips 1996). Rees and Butt (2004) confirm this again in 200I. Black groups constituted I3.5 per cent of the population of inner London in I99I, which was the only place, except the West Midlands, that they were over-represented (Rees \& Phillips I996). In 200I, this picture was somewhat different: the Black Caribbean group are over-represented in southern and midland metropolitan regions, especially in London, however, the inner London 
concentration is decreasing whilst the outer is increasing (Rees \& Butt 2004). Black Africans are over-represented in inner and outer London, again with concentrations decreasing in inner London and increasing in outer London. They are under-represented everywhere else (Rees \& Butt 2004).

\section{Indices of dissimilarity}

Undertaking a micro-scale analysis, Peach (I996) calculated the ID and IS for the ten ethnic groups in the I99I Census for major centres of settlement in Britain, namely cities in which there were more than I,০০0 members of the respective ethnic groups. Unfortunately, this study, at the time of writing, has not been repeated using $200 \mathrm{I}$ data at the finer scale for Britain. Using a different spatial scale, Rees and Butt (2004) calculated the ID based on the division of the country into 20 metropolitan and non-metropolitan regions, for 200I; however, this is not comparable with Peach's earlier study.

In I99I, Peach found the Bangladeshi group, in eleven cities, to be highly segregated with an unweighted average ID against whites of 73 and an unweighted average IS of 69 (Peach I996: 224). The Bangladeshi population was highly segregated from every other ethnic group, not only the white population, with average rates of over 50. The lowest ID measured for Bangladeshis was with the Pakistani group. Levels of segregation among the Pakistani population were found to be on average around Io points lower, in the twenty cities in which they numbered over I,O०O, than for Bangladeshis (ibid.: 225). More specifically, the unweighted average ID against whites was 6I and the unweighted IS was 58. The ID of Pakistanis against other groups was on average around 40 , being lower than with white groups. The unweighted ID on average was lower against Indians than Bangladeshis, 39 and 46 respectively (ibid.: 225). Levels of segregation for Indians, measured across twenty cities, were lower again; the unweighted ID was 46, whereas it was 73 for Bangladeshis and 6r for Pakistanis. Likewise, the unweighted IS was 42 compared to 58 for Pakistanis. They also showed lower levels of segregation from other ethnic groups than the Pakistani group (ibid.: 225-226). Black Caribbeans were found to have lower levels of segregation than both Bangladeshi and Pakistani groups and at times the Indian group. Their average unweighted ID at ward level, across seventeen cities was 4I and against white groups 45 (ibid.: 226). In a similar vein, Rees and Phillips (I996) state that in the thirty years between the I96r and I99I Census the levels of concentration for this population decreased significantly, due to a process of suburbanisation. Rees \& Phillips (I996) maintain that little redistribution had occurred among Other South Asian groups, despite high levels of population 
growth between I98I and I99I. In their analysis, they found that Pakistani and Bangladeshi groups, when compared with the white population, had ID scores that had increased between I98I and I99I by between two and nine points. The authors maintain that this was due to two factors: first, increases in minority ethnic populations added to areas of traditional concentration; and second, due to the significant movement of whites from metropolitan to non-metropolitan areas. The authors concluded that there was clear evidence between I98I and I99I of a widening spatial gap between most minority ethnic groups, with the exception of Indians and Afro-Caribbeans. Indeed, levels of segregation among the Indian population were found to be lower than those for black groups in general (Peach \& Rossiter I996).

As referred to in the previous section, there is clear evidence of minority ethnic groups advancing in the housing market. This was reflected by evidence from the I991 Census of a small-scale local de-concentration of minority ethnic groups. Ratcliffe (I996) presented evidence of more affluent members of the Black Caribbean and Indian groups relocating outward from their traditional clusters. Similarly, local authority reports in Scotland show some dispersal of minority ethnic groups to the suburbs (Glasgow City Council 2000). Furthermore, research conducted in Bradford and Leeds by Phillips et al. (2003) found a localised dispersal of South Asian households and evidence of suburbanisation into more affluent neighbourhoods.

To go back to Rees and Butts' (2004) study on England, between I98I and I99I the ID score increased for all groups, whereas in the following decade it decreased or had a lesser increase than the period before. The ID decreased amongst Black Caribbeans, Black Africans, Indians, Chinese and Other Asians and increased slightly amongst Pakistanis, Bangladeshis and Other Groups. Dorling and Rees (2003) found that when each ethnic group was compared with the rest of the population the white group experienced an increase in the index of dissimilarity, whilst most other ethnic groups experienced a decrease. This would suggest that BME groups are spreading out, whilst whites are further spatially polarised.

\section{Competing explanations for segregation}

As Ratcliffe (2004) points out and as inferred from the past two sections, differences in housing market positions and settlement patterns suggests that explanations of segregation will not be straightforward. Over the past forty years, there have been many attempts to explain patterns of residential segregation amongst minority groups. Most have seen it as resulting from constraints faced by migrant groups, in terms 
of economic disadvantage and institutional discrimination and/or from choices made reflecting culture-based clustering trends (Ratcliffe 2004). The more pragmatic contributions to this debate have attempted to balance both ideas and recent literature has tended to emphasise the interaction of both choice and constraint in determining residential segregation. Several authors have given credence to the idea that structural constraints operate in conjunction with agency and have a dialectical relationship (Harrison \& Davis 200I; Ratcliffe 2004) creating what Phillips terms as 'bounded choices' (2003: 47). Similarly, the diversity amongst and within minority households has produced divergent tendencies and outcomes leading to the focus in more contemporary literature on the importance of diversity and other forms of difference in explanations of segregation (Ratcliffe 2004). This debate in general has become increasingly politicised in recent years in the UK and issues relating to segregation have moved up the agenda. Alongside this, there has been a shift in some circles towards the idea that particular minority ethnic groups have formed separate social identities, reflected spatially and in other domains, to resist integration into the mainstream. Each of these sometimes contested and often interrelated explanations of segregation will be discussed in the following section.

\section{Choice and constraint}

Ratcliffe (2004: 66) states that in essence this (choice constraint debate) is a reworking in a substantive context of the structure-agency dualism'. Those favouring choice based explanations argue that individual actors make informed or rational choices about where they want to live, normally related to aspects of their ethnic and cultural backgrounds. More recently, as a sub set to the choice argument, some contemporary debates have focused on the so-called separatist tendencies of particular minority ethnic groups in an attempt to preserve social, ethnic or religious identities contrary to those of the mainstream. This will be discussed in more detail later in the chapter. On the other side of the debate, it is argued that structural factors such as racism and discriminatory policies or more recently cultural factors (religious or family obligations) constrain or limit housing choices for minority groups.

Housing choice theorists have attributed much to the role of ethnicity in determining where minority ethnic groups live. Dahya (I974) referred to the spatial concentration of minority ethnic groups as voluntary segregation, which occurs through a process of rational choice. He illustrates this by arguing that the Pakistani community in Bradford created an 'ethnic village' to withdraw from British culture reflecting their identification with their homeland. Since their primary objective 
was not to stay permanently, but to earn money to send home, living in cheap inner-city housing was a rational choice. Given this, clustering with those of a similar culture and with the same language and dietary requirements was reasonable. Despite recognising the existence of discrimination and racism, he does not see them as having a direct effect on minority ethnic housing choice. This perspective was echoed more recently by Lewis (I994) and the importance and predominance of agency in this debate by Ballard and Ballard (I977, cited in Ratcliffe 2004). O’Loughlin and Glebe (I984) present a similar argument, contending that if external factors of constraint were dominant then immigrants would be segregated as a whole from the 'host' community, however, instead there is deliberate ethnic grouping or clear decisions on the part of minority ethnic individuals to live together.

In contrast, proponents of the constraint theory of segregation attribute little significance to the idea of 'voluntary segregation'. They argue that the social and spatial isolation of some minority ethnic groups reflects the white population's preference (Sarre et al. I989). Furthermore, this is dictated by their weak position in the housing market and low socio-economic position, exacerbated by fear of harassment and reinforced by discriminatory practices in housing institutions. This is illustrated by an early 'classical' study by Rex and Moore, conducted in I967 in Sparkbrook in Birmingham. The authors highlighted the structural forces that placed restrictions on the housing options of minority ethnic groups through discrimination in the allocation of social housing and the denial of mortgages to buy homes, as a result of processes of red-lining. This led to the use of high interest loans to buy large Victorian houses or 'lodging houses' in disrepair, which resulted in high rental costs for the tenants. Despite the fact that the same inequalities are faced by disadvantaged members of the white population, minority ethnic groups accrue added disadvantage, sometimes referred to as 'ethnic penalties' (Harrison 2005: I8-20). In line with this, Smith (I989) points out that culture alone cannot be used as an explanation for segregation because were people able to make decisions over where to live they would not choose to cluster in deprived areas.

\section{'Bounded choices': Dialectical relationships and diversity}

Later contributions have emphasised the dialectic relationship between the two elements of this debate, as the realities of people's experiences reflect elements of both choice and constraint and, indeed, elements of inclusion and exclusion. This interplay of structural constraints and agency or choice on the part of the individual has been seen as being increasingly complex and the importance of aspects of difference and diversity within minority ethnic groups has been given due 
recognition. Phillips (2003: 47) concedes that it is likely that patterns of settlement, rather than being an expression of self or voluntary segregation, are a reflection of 'bounded choices'. Cultural autonomy - and clustering to preserve this - is a resource for those who cannot speak the language and for new immigrants, although the obligations it imposes can also be a constraint for some (Phillips et al. 2003). At the same time, tendencies to segregate may also be a defence mechanism in response to hostility or other exclusionary processes. Many other authors have pointed out the factors that make living in an ethnic cluster attractive, while also highlighting the fact that these patterns of residence are also a response to wider exclusionary forces (Tomlins, Johnson \& Owen 2002; Ozuekren \& Van Kempen 1998; Phillips I998; Peach i998; Van Kempen \& Ozuekren I998).

Important ways of understanding and analysing the complex realties of processes of settlement and residential clustering/segregation of minority groups have been highlighted by several authors. A central theme in Ratcliffe's (2004) recent book is the recognition of the dialectical relationship between social agency and systematic processes. He argues that elements of both sides of the debate are not static but change over time due to both general social change and policy or legal interventions (2004: 68). He illustrates this using several examples, such as improvements in discriminatory practices in public and private institutions, changes in the market, including an increase in home ownership in general, as well as demographic, socio-economic and generational changes within the minority ethnic population itself. Although the choice constraint model of explaining segregation allows us to include the role that difference within minority ethnic groups, such as class, age/generation, gender and economic position, has on processes of settlement, Ratcliffe (2004: 68) argues that the analysis is too static. He asserts that the actor is assumed to be rational and rigid, whereas in reality decision-making processes are normally 'negotiated choices' (2004: 68). Rather, he makes the case for a more dynamic form of analysis, which considers the two-way interactive relationship between the agent and aspects of structure.

This is expanded upon in greater depth within the structure-agency framework by Harrison and Davis (200I: 9) whose analytical approach, rather than prioritising structure in one domain and agency in another, is about 'patterns of effects' and how they persist and change over time and space. The central theme they address within this is 'difference' (specifically in relation to disability, gender and ethnicity), exploring how this is both regulated and responded to by the welfare state. They further the idea of diversity by developing the idea of 'difference within difference', whereby individuals have strategies and experiences that are more complex than the differentiations between broad categories of 
difference such as social class, 'race' and gender. Furthermore, they draw attention to the fact that actors may experience housing in different ways as they negotiate their identities, may occupy more than one position and have more than one affiliation. The authors express this succinctly in the following way: 'diversity of household experiences, strategies and identities occurs alongside or within a broader and persisting pattern of differences' (200I: 8-9). These differences are seen as being more than choices or expressions but are rather regulated and developed through structural processes and are socially constructed. Similarly, structures or structural constraints may indeed be influenced or changed by the choices and conduct of the individual actors, highlighting what Ratcliffe (2004) and Sarre et al. (I989), building on Giddens' theory of structuration, describe as a two-way interactive process.

\section{Economic factors and occupational class as spatial constraints}

The labour market is often used as a barometer gauging minority ethnic advancement. Generally, assimilationist arguments link integration with socio-economic advancement. The assumption is that as minority ethnic groups demographically mature and as younger people do better in education and move into better employment, spatial sorting will become based on social class rather than ethnicity or 'race'. Phillips (2003: 45) argues that socio-economic advancement is a central component of facilitating and explaining models of desegregation and dispersal. She acknowledges that although there is no clear cut relationship between class and ethnicity, there are, nonetheless, some systematic effects. The 200I Census indicates varied experiences between minority ethnic groups in Britain, with some being more represented in higher occupational categories. Indians are well represented in professional or managerial positions; this has been correlated with signs of dispersal from areas of traditional settlement to more mixed neighbourhoods and suburban areas. Still, Pakistanis and Bangladeshis are significantly under-represented in both skilled manual jobs and in professional occupations. Four-fifths of Pakistanis and Bangladeshis have incomes below or at the national average, in comparison to a quarter of whites (Strategy Unit 2003).

Recent work on intergenerational social mobility by Platt (2005) reveals positive transitions between the social class of parents and their children to be highly differentiated according to ethnic group. Some groups fared much better than others; Indians did better than all other groups studied, whilst there was a particularly low instance of mobility amongst the younger Pakistani and Bangladeshi generation. Patterns of higher class retention across generations were also stronger for Indians, white non-migrants and white migrants, whilst weaker for 
African Caribbeans and Pakistanis. This would indicate that class does play a role in outcomes, but that the extent to which ethnicity matters is particularised by group. Ethnicity appears to be particularly salient for Pakistani groups as a determinant of their social and occupational class. They are less likely, even with higher levels of qualifications, to achieve the same occupational rewards as white groups, furthermore, they experience greater risks of unemployment (Platt 2005: 35). Phillips (I998) argues that this fragmented picture of occupational progress correlates accordingly with the changing local geographies for Indians and African-Caribbeans, the over-representation of Pakistanis in deprived owner-occupied housing areas, Bangladeshis in the social rented sector and the growing spatial divide between minority groups. Therefore, the relationship between socio-economic class and segregation seems clear, as marginality in the labour market can easily be translated into marginality in the housing market. Despite this, it is important to note, as highlighted by Phillips (2003: 45), that social class or economic status does not fully account for changing patterns of ethnic settlement, as fear of harassment, social and cultural ties and family obligations also keep economically successful households in the ethnic cluster. Finally, traditionally the association between class and tenure for the majority population has been inversed for Pakistani and Bangladeshi groups, as home ownership rates are higher among the semi-skilled and unskilled than among those of similar social class in the white population. However, Phillips (2005), drawing on 200 I Census results, maintains that we may be witnessing a move toward a closer relationship between socio-economic status and the housing choices of younger minority ethnic households with UK-born heads.

\section{Politics of identity: Cultural barriers and separatist tendencies}

There has been a more recent shift in contemporary debates, especially those of the current Labour government, who have turned to focus on the separatist tendencies of particular minority ethnic groups (related strongly with Islam) as the causal and sustaining factor of residential segregation. The 'so-called parallel lives phenomenon' (Ratcliffe 2004: 69) argues that in an attempt to preserve social, ethnic or religious identities, which are contrary to those of the mainstream, particular minority groups have self-segregated and created cultural barriers as a strategy to resist integration. Segregation, along with the groups seen to maintain it, has been problematised as it is perceived to result in subgroups that are at odds with the dominant moral order (Robinson 2005), reflecting a particular failing of multiculturalism. The following section will undertake an in-depth discussion on the background, policy and ideological underpinnings of this turn in rhetoric and policy. 


\section{Politicisation of segregation since 2000 in the UK}

Issues of race and ethnicity have come to the forefront of political and media attention over the past few years. In Labour's early term, this was mainly in the context of their commitment to multiculturalism and in line with an inclusion, equality and diversity agenda (Harrison 2005). There have been several central debates on these issues in response to specific events, including the Stephen Lawrence report that highlighted institutional discrimination, to the Parekh Report (Runnymede Trust 2000), which pondered belonging in a multi-cultural society. Ethnic segregation per se, however, was not at the forefront of government debates or intervention throughout the late i99os. In fact, housing was not mentioned in the Parekh Report (2000) (Phillips 2006), but with the $200 \mathrm{I}$ riots that took place in disadvantaged areas in northern English towns it was propelled onto the agenda. Several reports were commissioned to examine and make recommendations on issues related to the disturbances. The reports drew attention to the self-segregation of minority groups, and communities were described as living, working, and socialising separately (Independent Review Team 200I: 9). The response of the government altered somewhat from their previous commitment to multiculturalism with the launch of the community cohesion agenda. Furthermore, political and media debates were not slow to question the commitment of British Muslims to participating in British society as a cause of the disturbances (Phillips 2006). This rhetoric combined with responses to 9/II and the more recent London bombings has to some extent shifted the focus from the exclusion and deprivation that may exist in these communities to their so-called 'voluntary segregation'. This choice based explanation represents to some extent a shift of responsibility from the government to the minority community itself. As Amin (2002 b: 2) writes:

More recently, however, the tone has turned decidedly frosty. Yes, the street confrontations a year ago in Oldham, Burnley and Bradford served to remind the nation of continuing problems of ethnic discrimination and deprivation, but they have also led to unashamed questioning of the cultural and national allegiances of British Muslims.

\section{Background and overview of the community cohesion agenda}

The 200I disturbances have been attributed to several factors: namely the frustration amongst young minority ethnic youths; their vilification by the local media; the role of right wing political activity; tensions over policing; competition over the allocation of funds in regeneration 
programmes; poor services; the dearth of shared spaces; poor communication; and the political culture that glorified community leaders (Robinson 2005; Harrison 2005; Amin 2002; Ouseley 200I). Official reports and the media tended to represent the riots as an 'Asian problem' (Robinson 2005) which was particularly poignant during a time of increasing Islamophobia after 9/II.

In response to the disturbances, the government established an interdepartmental ministerial group on public order and community cohesion and commissioned a community cohesion review team led by Ted Cantle as well as several local and national reports. The Home Office published the various reports, Cantle (Independent Review Team 200I), Ouseley (200I) (which was actually commissioned before the disturbances) and their own report, at the same time on II December 200I. Later in 2002 the Burnley Task Force report was to come. Rather than questioning the vilification of Asian youths in the media reporting of what was termed the 'race riots', the reports emphasised the separatist tendencies and 'drift toward self-segregation' of Asian groups as being central to the fragmentation of the local communities and the conflict (Ouseley 200I: foreword). The most frequently quoted illustration of this appears in the Cantle report, where it is asserted that separate educational facilities, social and cultural networks and language as well as physical divisions mean that, 'many communities operate on the basis of a series of parallel lives' (Independent Review Team 200I: 9). It is worth noting that no detailed consideration of the relationship between residential segregation and ethnic separation in other sociospatial domains has been provided.

The tenor was decidedly alarmist and despite little evidence (Robinson 2005 ) residential segregation and its associated ills was dubbed as a process that urgently needed reversed (Ouseley 200I). The isolationist discourse employed in the reports, whilst problematising minority ethnic segregation, marked this as a difficult task complicated by the resistance of minority ethnic communities to mix, 'the fact that it is mainly self-segregation makes the task all the more challenging' (Ritchie 2002:4). Thus, community cohesion was launched as a clear challenge to segregation in all its supposed forms. Community cohesion was outlined as the development of a shared vision and common goals across the divided communities as a means to help micro-communities gel into an integrated whole (Robinson 2005).

Whilst primarily giving voice to choice based explanations as contributing to the formation of separate ethnic communities, the Cantle report also concedes that some choices are not made freely but are a result of negative factors such as poverty and threats of violence. In particular, housing (both policy and provision) was highlighted as being a causal factor in the segregation of the communities in question and as 
being key to diffusing these patterns and leading to more mixed environments in other domains. The Cantle report recommends that future housing schemes should be ethnically mixed through a review of housing agencies' allocation processes. The report urges the formation of more, 'ambitious strategies to provide more mixed housing areas and to provide supportive mechanisms for minorities facing harassment and intimidation,' whilst simultaneously taking into consideration the problem of low demand housing, the effects of poverty and the fostering of contact between communities (Independent Review Team 200I: 43). Harrison (2005: 83) provides a useful summary of some of the Cantle reports 67 proposals: the development of area plans to improve community cohesion; the development of programmes to promote understanding within and between communities; limitations placed on the 'faith intake' in schools; and thematic and needs based funding allocation avoiding separate funding for different sections of the community.

In lieu of the various reports and recommendations, community cohesion became a clear policy concern mainstreamed by central government. The Community Cohesion Unit (CCU) was developed within the Home Office, the goal of which is to support and develop good practice and act as an advisory board on creating more cohesive communities. A cohesive community, as defined on the CCU website (and in the Cantle report), has four elements:

I. There is a common vision and sense of belonging for all communities.

2. The diversity of people's different backgrounds and circumstances are appreciated and positively valued.

3. Those from similar backgrounds have similar life opportunities.

4. Strong and positive relationships are being developed between people from different backgrounds in the workplace, in schools and within neighbourhoods.

A short time later in 2003, the Community Cohesion Pathfinder Programme was launched. Fourteen pathfinder areas and fourteen shadow pathfinder areas were developed, jointly funded by the Home Office and the Neighbourhood Renewal Unit, to deliver a range of different initiatives and programmes that would promote cohesive communities and to develop best-practice guidelines for local authorities. In addition, community cohesion action plans were developed by different governmental departments (Robinson 2005). Following the general trend of New Labour's strategy of community leadership and local responsibility, local authorities shouldered the responsibly of implementing the agenda. In 2004, a consultation process was developed as a first step to establishing a government wide strategy for community cohesion and race equality (Home Office 2004). The report highlights 
challenges that must be tackled, specifically 'the impact of exclusion and racism, the rise in political and religious extremism and segregation that can divide our communities' (Home Office 2004: 3). The report, alongside the aforementioned issues, addresses the need to create a shared identity and citizenship that goes beyond the legal definition and promotes a sense of belonging and pride in being British, based on shared values and rights and responsibilities (Home Office 2004: 8). Reiterating the earlier reports, it refers to the role of choice or the separatist tendencies of minority communities in developing cultural and social barriers and subcultures of difference (Home Office 2004: I6; Harrison 2005: 84). The End of Parallel Lives?, a sequel to the first Cantle report was also published in 2004. Although there was continued emphasis on the desegregationist and isolationist speak of the previous report, there was also an encouraging move toward recognising the importance of linking the equality and the community cohesion agenda to respond to disadvantage (cf. Harrison 2005: 86), to some extent echoing the Home Office report.

\section{Community cohesion: Conceptual roots and the wider policy environment}

It is therefore clear that the community cohesion agenda developed into a key policy concern, despite the fact that before the 200I disturbances, little was known of its theoretical or conceptual moorings (Robinson 2005). Robinson argues that: 'conceptually speaking, it represented an empty vehicle into which the preoccupations of public policy were poured' (2005: I4I5). The lack of clarity and contested nature of some of the central ideological assumptions and evidence upon which this agenda is based is perhaps symptomatic of broader ambiguities in New Labour's stance on multiculturalism and citizenship.

Again drawing upon Robinson's recent paper, community cohesion, he argues, was actualised by drawing on discourses of both communitarianism, seen as a means to restore social cohesion and moral order, and changes in New Labour's stance towards multiculturalism. The definition of community cohesion in the Cantle report (as outlined in the last section) adopts precisely the description of the different elements of a socially cohesive society presented by Kearns and Forrest (2000) (Robinson 2005). Kearns and Forrest make the point that socially cohesive communities, due to the strong social ties that 'glue' them together, could potentially 'withdraw' or constitute a defence from wider society resulting in division or tension within wider areas. This was adopted in the Cantle report as a conceptual springboard to assert the need for micro-communities to gel together with other micro-communities through commonalities and shared vision (Robinson 2005). More generally, this is in line with New Labour's emphasis on rights, 
civic responsibilities and participation in other domains (such as the New Deal programmes).

In this sense, in the context of the influence of communitarianism, communities themselves 'are commonly charged with the responsibility for being the arbiters of moral worth' and places where people learn 'civilized behaviour' as highlighted by Back et al. (2002: 448). There is ambiguity between this stance and multiculturalism, as when dominant moral values are not homogenous or mono-cultural, as is the case with multi-ethnic or multi-faith communities, then the local is not considered to exemplify accepted forms of citizenship or cultural values (ibid.). To the contrary, as Back et al. express, the community, 'rather than the arbiter of moral worth, becomes a battleground of competing ethics' (2002: 448). The government's approach represents a clear move away from pluralism in public society to the idea that there is a dominant model of citizenship to be adhered to in the public sphere with diversity demoted to the private sphere (Back et al. 2002; Mitchell 2004; Robinson 2005). This accentuates a clear tension between community cohesion and multiculturalism, characteristic of New Labours more restrictive multiculturalism. Robinson (2005: I4I7) comments that segregation is problematised in this environment as it is seen to produce communities that are separated socially and culturally from the mainstream moral and value system. This so-called separatism has been represented officially as being a clear failure of multicultural policy (Phillips 2005).

The idea that the public sphere should, rather than 'achieve diversity', be neutral (with cultural difference being relegated to the private sphere) is contested by Mitchell (2004: 648), who argues that at the core of this neutrality or dominant moral order lies the nation. In the same vein, Robinson (2005: I4I8) refers to the 'hegemonic position occupied by a particular notion of Britishness'. Further problems with this public-private split are highlighted by other authors, for instance: the transcendence of the two domains by particular aspects of peoples' lives such as the role of the church and Islam (Robinson 2005); the lack of emphasis on social equalities as those who do not 'opt in' to the dominant cultural values are liable to be excluded (Mitchell 2004; Ratcliffe 2004); and the unquestioned 'cultural exclusions' of white Englishness (Phillips 2006; Amin 2002).

Several authors have documented the ambivalent and contested nature of 'multi-cultural Britain'. On one hand, there has been the promotion of diversity and difference, and very positive steps taken toward embracing, or some would argue managing, diversity and tackling institutional discrimination. On the other hand, however, there have been moves back towards 'assimilation-speak', seen through the introduction of citizenship tests, Blunkett's call for South Asians to speak English 
in the home and oaths of allegiance for new migrants (Phillips 2006; Harrison et al. 2005; Ratcliffe 2004; Back et al. 2002). Harrison (2005: 87), referring to the current political environment as being 'post-multicultural', warns that the 'clock may have been turned back at a national level' at a time when the diversity agenda appeared well developed. However, he is careful to reiterate that at the grassroots level this is somewhat different and more positive, as the practice environment is still informed by the diversity and equality agendas. Moreover, Ratcliffe (2004) also highlights the importance of grassroots activity in contributing to a more inclusive society.

The shift towards local responsibility and community leadership in New Labour's policies on racial equality is underlined by Back et al. (2002), who also highlight the degree of self-government involved, in which individuals are responsible for participating and integrating themselves. This appears to be a trend more generally across several European states, the US and Australia, where a discourse of failing multiculturalism is accompanied by a de-centralised responsibility for integration, the burden falling upon the individual (Mitchell 2004). Phillips (2006: 37) argues that, although demands for ethnic assimilation are 'more muted' than in the past and 'diluted by the language of neoliberal multiculturalism', the implication is still the same; British Muslims are expected, under the responsibilities of citizenship, to 'optin' to multi-cultural Britain. Mitchell (2004: 645) construes this as a new technology of knowledge or power in neoliberal regimes of governance that constitutes the individual as free-thinking, yet in reality there is little choice as those who 'opt-out' are cast as individuals not willing to participate in wider social life and are liable to be excluded from citizenship rights. In this sense, notions of multiculturalism in Britain today, reinforced by the community cohesion agenda, are to some extent an exercise of power from the top to control or contain diversity and difference, especially relating to Islam.

\section{Community cohesion and 'self-segregation': Contested concepts and the evidence base}

At the heart of the community cohesion agenda there are some fundamental assumptions that have been contested in the literature. First, is the central assumption that South Asian groups self-segregate. There are two aspects that need to be tested in order to validate this claim, first, is the evidence relating to actual settlement patterns and second, is the lived experience and locational preferences of minority ethnic households. There is clear evidence from both the I99I and 200I censuses that there have been significant moves by ethnic minorities on a local scale away from most of the major conurbations (Phillips 2003) 
and clear patterns of dispersal and selective suburbanisation (Phillips 2006; Peach I998; Phillips I998; Rees \& Phillips. I996). Phillips et al. (2003) and Phillips (2006), studying South Asian mobility in Bradford and Leeds, also report evidence of moves across lesser distances to the areas surrounding traditional ethnic clusters, not only as a means to find better housing but as a means, 'to occupy a social, cultural and spatial position on the margins of the community, which affords some freedom from perceived social strictures and conventions' (2006: 35). Furthermore, Simpson (2004) shows, based on research in Bradford, that the prevailing concentration of South Asians in inner-city neighbourhoods is best explained by a mixture of immigration and natural growth, rather than as a result of population inertness. He also verifies that there are fewer 'mono-racial' areas in Bradford in 200I than in I99I and that for both white and South Asian households the overall trend was to move out of the city. Johnston, Forrest and Poulsen (2002) also demonstrate that, contrary to the existence of ghettos in Britain, the majority of minority ethnic groups live in areas where the white British population is the majority. Modood, Berthoud, Lakey, Nazroo, Smith, Virdee and Beishon (I997) conducted a national survey in which they found that over half of the Bangladeshi and Pakistani respondents would be willing to live in areas where they would be the minority. In the same vein, Phillips et al. (2003) also reported a general readiness amongst the Muslim respondents in their sample for social mixing beyond the traditional areas of settlement, providing that they did not feel threatened.

Second, the discourse and debates surrounding the community cohesion agenda pay little attention to the constraints that minority ethnic groups face in both residential choice and housing outcomes. As Phillips (2006: 29) comments:

it may be argued that the political discourse of self-segregation seriously underplays the power of structural constraints (economic and structural racism) and popular racism to shape minority ethnic housing and neighbourhood choices.

Still, the differences and diversity of strategies adopted within the minority ethnic population to deal with the challenges they face are oversimplified. Robinson (2005: I420) highlights the fact that rather than representing passive agents minority ethnic groups can devise strategies of resistance, accommodation and avoidance to deal with obstacles that influence their housing outcomes, which can therefore be seen as more than a result of the housing system.

The third contested concept central to the community cohesion agenda is the idea that residential mixing is the solution to fostering a 
socially integrated society. In line with this, Amin (2002: 963) points out the fact that there are mixed neighbourhoods in different British cities that are 'riddled with prejudice and conflict between Asian, White and African-Caribbean residents', and that attempts to engineer ethnic mixing have resulted in resentment and white flight in the past. The same author (2002: 969) also argues that housing estates and urban spaces in general are not 'structured as places of interdependence', as at best they facilitate contact, rather the best places for generating cultural exchange are those where engagement between people is compulsory through common activities, such as the workplace, schools, colleges, etc. The somewhat coercive proposals to 'mix' neighbourhoods may represent a further structural constraint placed upon minority housing options. Likewise, Ratcliffe et al. (200I) found that housing managers had concerns related to what they felt was the use of coercion and preferred to focus on the widening of housing choices. Furthermore, Phillips (2006) suggests that the conditions for residential mixing and fostering subsequent notions of common identities may not currently be in place.

\section{Conclusion}

Minority ethnic segregation and its causation are complex and dynamic. The current settlement patterns of minority ethnic groups in the UK are related to early patterns of settlement, labour market opportunities, socio-economic position, social and cultural networks and discrimination faced in different domains. Explanations of segregation are not straight forward; rather they vary depending on ethnic group, economic and social class, position in the labour market and education, alongside other differentials, including different household strategies. There is evidence of changing patterns, with different trajectories and levels of achievement visible between different ethnic groups. Despite this, there is still continued disadvantage and evidence that housing and neighbourhood choices made by particular minority ethnic groups are often constrained. In the face of positive advancements in the policy arena relating to equality and diversity in different domains, issues relating to minority ethnic groups and segregation have become increasingly politicised in the climate of restricted multiculturalism in the UK. The stress which has been placed upon the separatist tendencies of particularly Muslim populations has to a large extent taken the emphasis off social inequalities and placed emphasis on the role of the individual actor to opt-in to the norms of British society, leading to new and difficult debates on citizenship and belonging. 



\section{Urban migration, residential mobility and suburbanisation}

\section{Introduction}

Suburbanisation signifies a specific form of urban de-concentration. Kramer (I972) refers to it as a ubiquitous process that represents the formation of a new urban landscape in which the outward movement of people, amenities, industry and institutions from the urban core create an extended city. The suburbanisation process is not as selective as traditionally may have been assumed, as contemporary British suburbs are not homogenous in population composition or limited to the middle classes. The reality is that only I5 per cent of the UK population live in areas with a population density high enough to be classed as inner city. The average English person lives at a low density ( 20 people per hectare compared to 50 in the inner city) (Schoon 200I). From its mass uprising the suburb has never failed to incite controversy. The flight of middle- to high-income dwellers from the city to the suburbs has been regarded as a contributing factor to the acceleration of social polarisation and segregation. The ecological development of the suburb has been correlated with new behaviours pertaining to the suburban 'way of life', based upon social conformity, competition and upward social mobility (Fishman I987). As once the rural idyll was upheld as a model form of living, in opposition to the corrupt and congested city, the diversity of the city and its cultural allure was favoured over massproduced suburbia by its critics (Thorns I972). These negative connotations have, by bringing to light the diversity and heterogeneity in the suburbs, been contested as the 'suburban myth' (Gans \& Berger 1972). Indeed, as the economic and social bases of the suburbs have grown, over the past one hundred years, so has the diversity of the suburbanites.

This chapter is structured as follows. The first section considers definitions of the suburbs in terms of their role and location in the city, ways of measuring and defining residential areas and the traditional models depicting the expanding city. The second section provides a brief overview of the origin and growth of suburbs in Britain. Following from this, the third section considers the social and cultural representation of the suburbs in the literature. Finally, in the fourth section 
attention is given to the more general models of residential mobility presented in the literature.

\section{Defining the suburbs}

The pattern of population dispersion outside the city to the suburbs emerged almost as early as the city itself (Mumford I96I). Suburbs are not a modern phenomenon, but rather a historic part of city life, visible even in the early Egyptian city. The urban values associated with the suburb have, however, changed over time; the suburbe, for example, in the pre-modern English city defies the assumptions associated with the modern suburb. Historically, cities were built assuming that the core would house the elite in close proximity to work and that the poorest, including immigrants, would be housed in the urban periphery beyond the city walls (Fishman I987). Thus the suburbe was defined between the fourteenth and mid-eighteenth century as, 'a place of inferior, debased, especially licentious habits of life' (OED cited in Fishman I987: 23). Furthermore, in the pre-modern city a prostitute was contentiously referred to as a 'suburbe sinner' (ibid.). Of course, the suburbs are no longer seen as inferior in the modern British city, albeit work conducted for JRF highlighted their decline (Gwilliam et al. I999). Fishman (I987) argues that the emergence of suburbia in the modern city, and its transition from the pre-modern form, reflects a change in urban values that goes beyond the reversal of core and periphery to include the disentangling of work and residence and the association of the suburb with a suburban 'way of life'. In the early twentieth century, there were suburban communities emerging around many central cities in North America, Western Europe, Japan and Canada (Rothblatt \& Garr I986). The influence of technology, rising real incomes, the growth in consumer power, innovative transport networks, industrial de-concentration, intensified demographic pressures on the city and planning policy accelerated and in many cases made the vigorous postwar growth of the suburbs viable.

The suburb in its modern form can primarily be defined as an outlying residential area adjacent to and usually economically and culturally dependent upon the central city; however, despite being situated outside the city, it is considered part of the urban agglomeration as a whole (Rothblatt \& Garr I986). Drawing on Thorns (I972), Clapson (I998) outlines three defining characteristics of suburbs: first, regardless of their location beyond the centre of the city, they lie within the metropolitan area; second, the urban geography of the suburb is intermediate between the city centre and the surrounding rural area and; third, they are within commuting distance of the city centre. Johnson 
et al. (I98I: 33) define the suburb as being 'usually residential or dormitory in character, being dependent on the city for occupational, shopping and recreational facilities'. Despite common points of reference, it is obvious from discussion in the international literature that definitions of the suburbs are culturally specific. For instance, in the US context Palen (I995) questions traditional definitions, arguing that definitions of suburbs that assume economic and cultural dependence upon the city are out of date. He contends that the suburb is emerging as a self-sufficient new central district with employment, cultural and social attractions and amenities, rendering it no longer sub to the central metropolitan area. In Britain, however, there is still considerable dependence on the inner city for employment, recreation and commerce. Unfortunately, however, there are few recent studies of the characteristics of British suburbia. Again, the suburbs of Continental Europe differ, with Paris being the primary example in the literature, housing the working classes, immigrants and the poorer groups in society, leaving the inner space for the economically advantaged. The diversity of the suburbs means that any attempt to define or classify them is met with difficulties. Pacione (2001: 83) contends that rather than attempting to classify the suburbs they should instead be viewed as 'dynamic entities with a diversity that reflects their role in the post-modern city'.

\section{Measuring the suburbs}

Throughout the past century, identifying residential areas and subareas both within the city and outside the city boundary has represented a long-term challenge for urban geographers. Urban definitions are an important basis for any description, analysis or social profiling of the internal structure of the wider metropolitan area and the surrounding non-metropolitan areas which employ some form of dependence on the urban conurbation. Bourne and Simmons (I982: 57) write that most governments use, 'some definition of the concept of the 'extended' city as a consistent basis for measuring the spatial extent of urban development'. They contend that any definition, statistical measurement or description encompassing residential areas must seek to include the suburbs as they are the 'living space' and often the 'market place' for a vast number of 'urban residents'.

Empirical studies conducted in I920s Chicago focusing on the city's socio-spatial organisation produced the influential model that correlated territorial organisation and the distribution of the population with social behaviour. This theoretical approach became famously known as urban or human ecology. The 'Chicago School's' urban ecologists defined geographical areas not only by considering the 'physical individuality' of an area, but also by the cultural characteristics of the people 
who live in the area (Pacione 200I: 349). The aim of the urban ecologist definition of what they termed the 'natural area' was to provide an empirical analysis that encompassed a description of the reality of urban life as experienced by residents. Its hypothetical framework led to the correlation of social distance and residential proximity i.e. the relative patterning of the city with areas of relative social homogeneity (neighbourhoods) (Thomlinson i969: 9). Urban ecological theorists attribute the evolution of the city as resulting from competition, influenced by an ecological impetus of invasion and subsequent succession by individuals, households and communities, rather than a consequence of government planning or control. Urban change is produced by the invasion of areas that urge previous occupants and purposes out, leaving space for new populations and land usage.

Burgess developed a further ecological model, the Burgess growth model, based upon the hypothesis that the spatial organisation of the city develops in concentric zones (Burgess 1925). The Burgess model stressed, as classical urban ecology, that there was no random dispersal in the urban area, but a clear pattern of spatial and social ordering based explicitly on competition, through which he contended cities grew (Burgess, 1925). In the industrial city, the most valuable land, relating to higher land use, was the city centre in which the central business district was located, thus less intensive uses were pushed out. Moving toward the periphery, land use decreased as did land value, thus what became suburban land was less valuable and more affordable, meaning single-family homes on larger plots of land became economically viable (Palen 1995). Palen (I995: I7) highlights the, 'inverse relationship between the value of land and the economic status of those occupying it'. This concentric zonal hypothesis has underpinned many assumptions regarding the relationship of the suburb to the central city (Palen I995).

The urban ecology method was influential and formed the basis for more in-depth statistical methods that defined areas through the use of more extensive social indicators. Pacione (200I) argues that the main weakness of the urban-ecological definition of the 'natural area' was that the typifying of social areas was based on a very limited number of key variables, which were not informed by theory or wider social change. With the same objective, Shevy and Bell (I955) used a multivariate analysis informed by a theory of social change. They adopted three 'constructs' as indicators of social change: social rank and economic status; urbanisation and family status; and segregation and ethnic status. Using measures of each, they standardised each of the individual indices merging them to produce a score on an index of I to IO०, forming a construct score for every census tract in the city. These scores led to the production of sixteen typologies used to classify all 
areas in the city. The subsequent development of factorial ecology in the I960s was based on more rigorous mathematical principles and employed more variables than those previously utilised by Shevy and Bell in their social area analysis. Rather than select constructs based on deductive theory, factorial ecology selects constructs inductively, by exploring a data set (Pacione 200I). By measuring a more extensive set of variables a smaller set of diagnostic factors are identified. The factors educed are composed of multiple correlated variables and once they are scored and then mapped it is possible to observe areas delineated by their social and demographic characteristics. Often, suburban locations are identified using this technique through observation of tenure and type of house, by the density of the area or by the distance from the city centre.

\section{A brief overview of the growth of the suburb in Britain}

Between the eleventh and eighteenth centuries, suburbs in Britain developed in two ways: first, to accommodate the villas and country houses of wealthy city dwellers and professionals with careers in the city; and secondly, to house the urban poor, composed mainly of immigrants and traders (Thorns I972). Thorns (I972) highlights the increasing importance of the upper-class suburb in the eighteen and nineteenth centuries, which was situated at greater distances away from the city. Thompson (I985: 2) refers to the 'decisive social upgrading' that changed the economic and social characteristics of the suburb from being a 'mere dumping ground for the unfortunates unable to live in town houses' to a much sought after residential area. With the rise of the Romantic Movement, cities were progressively considered undesirable and the impetus to leave grew, so that select suburbs emerged as exclusive places to live, whilst industrial city centres became increasingly reserved for commerce. The exclusiveness of suburban living was perpetuated by limits to transport, with accessibility being restricted to carriage use (Clapson I998).

Initially in the inter-war period and later in the post-war period, the suburbs were to grow rapidly, namely due to development in transport and communications, increased housing need and land shortage in the city centre. Post-war suburban growth was based on the premise of urban dispersal as the answer to the problems of the inner city and industrial de-concentration was encouraged in order to lessen population densities (Clapson I998: 39). The building of local authority housing and slum clearance programmes led to significant suburban expansion. The majority of English and Scottish cities were extended by these types of suburbs. Clapson (1998: 33) argues that these early 
peripheral council estates, arising mainly in answer to working-class housing needs and from a desire for improved housing 'laid the legislative foundations of post-war housing developments'. Private building prior to this was specified as being largely middle-class; however, during this period the economic and social base of the suburb began to expand. The establishment of building societies, in the post-war period, led to a growth in mortgage lending and a subsequent rise in owner occupation. Mortgage deposits fell from around 30 per cent to 5 per cent, meaning that the most affluent of the working classes could afford to partake in the housing market (Thorns I972). Thus, the suburb emerged during the last century as the dominant residential form, representing rising prosperity and changing urban values.

\section{The social life of the suburbs}

Despite evidence of early suburban development in the industrialised world, it was not until the late nineteenth century that suburbia emerged as a model of the 'good life' (Rothblatt \& Garr I986). The suburb and its association with pastoral life and traditional family values dominated Anglo American planning ideology and it came to be seen as an ideal in residential terms. Prominent authors when writing about the attractiveness of the suburbs have pointed to the dominance of the 'housing needs and aspirations of the family' (Champion 2001: I48), as well as to the provision of 'closer contact with nature' and an increased sense of privacy (Harris \& Larkham i999: I0; Mumford I96I). In her recent study of English culture, Fox (2004: 209) also argues that 'our love-affair with our homes and gardens is ... directly related to our obsession with privacy'. Many would say that this 'love-affair' was particularly suburban.

Harris and Larkham (I999) assert that depictions of the suburbs place emphasis not only on the retreat from the city and city life, but from wider economic and political engagement. Furthermore, they argue these depictions of suburban living comprise a gendered dimension with emphasis placed upon the male breadwinner family. The stereotype perceives the male as commuting to work, playing a greater role in public life, whilst the female retreats to the private sphere, both to raise her children and to focus on home improvements. The latter is in line with what Newby and Turner (I999) refer to as 'suburban taste' that arose with the mass consumption of design. This ideal has encapsulated, if at times somewhat reductively, the white Anglo American middle-class dream. In reality, the suburbs have evolved into a symbol of success and status, which to some degree continues to inform 
cultural and social aspirations associated with the child rearing stage in life.

Subsequent to discussions of the suburban ideal, writers and critics have emphasised the suburban way of life as being devoid of culture. In popular culture the suburb has been represented satirically; elegant families have been depicted as playing the role of new suburbanites, adhering to the contrivances of the suburban social network and moral commons. An obvious example being Rockwell's depictions of the suburbanites mingling with cocktails around the poolside and barbecuing on the manicured lawn. The extent to which suburbanites believed in or were committed to this new image or 'way of life' was satirised in films like The Graduate. Later, we were to see the same conformity disrupted in, amongst others, American Beauty.

Academic literature added to the process of maligning suburbia and its facilitation of the suburban way of life. Mumford (I96I) subscribed to the idea that suburbia was socially and aesthetically void. Contrary to creating a new synthesis, he contended it was the physical representation of the further deterioration of a dysfunctional society (Baxandall \& Ewen 2000). Relationships were drawn between architectural and behavioural conformity, with the suburbanite being characterised as the mass-produced man. Fishman (I987: 2I) argued that suburbia was an expression of bourgeoning values and a monument to the bourgeoisie, based on mass production, consumption, conformity and compliance.

However modest each house might be, suburbia represents a collective assertion of class, wealth and privilege as impressive as any medieval castle. Most importantly suburbia embodies a new ideal of family life, an ideal so emotionally charged that it made the home more sacred to the bourgeoisie than any place of worship. (ibid.)

He argues that suburbia is an explicitly exclusive 'cultural choice' of the Anglo-American middle classes based on alienation and self-segregation (Fishman 1987: 24). In some aspects, this is evident when economic status and 'race' are considered, as self-segregation, white flight and institutional discrimination have been shown to be contributing factors to the growth of the white American suburb. Recent trends of black suburbanisation have rendered it as a significant demographic pattern representative of the advancement of black groups in the housing market. Nevertheless, early work by Dorbiner (I963) and more recent work from Palen (I995) suggest that, rather than being an endorsement of increased racial integration and equality, this movement is a sign that black groups have become differentiated by class. Pacione (200I) substantiates this by presenting evidence of the growing class 
divide within the black population. Black suburbanisation, then, is symptomatic of increasing polarisation in American cities, leaving the most disadvantaged further isolated and excluded in marginal 'outcast ghettos' (Pacione 200I: 37I). Similarly, in the UK suburbanisation has largely been a white phenomenon with only very recent emergence of small-scale and selective minority ethnic suburbanization.

\section{Dispelling the myth}

Blaxandall and Ewen (2000) argue that there is little evidence that being a suburban dweller is conducive to a certain way of life. Thorns (I972) draws attention to the heterogeneity of the suburban dweller and argues that lack of research throughout the twentieth century resulted in the adoption of stereotypes. Gans (1972: 33), on the basis of his infamous study of the 'Levittowners', questions the mutual exclusiveness of the concepts of the city and suburb and the extent to which spatial organisation, residential location and other ecological concepts are useful for explaining behaviour and ways of life. He argues that social phenomena cannot be understood entirely as a consequence of the ecological environment. Contending rather that such explanations fail to add meaning to legitimate choices, which, even if influenced by the socio-economic and political environment, can only be understood according to individual characteristics. Thus, he argues that ways of life are functions of class and lifestyle rather than of environmental factors of the neighbourhood, concluding that 'the sociologist cannot therefore speak of an urban or a suburban way of life' (I972: 48). Furthermore, despite the assumed exclusivity of suburbia, the suburbanisation process is not as selective as traditionally may have been assumed, as contemporary suburbs are not limited to the middle classes.

\section{'Why people move?'}

The degree to which the suburbs represent a way of life can be contested, nevertheless, the symbol of achievement and social distinction associated with them is still prevalent in forming an impetus to move, leading us in this section to consider the residential mobility literature more generally. The residential mobility literature has been influenced by seminal works in the I950s and I960s.Broadly speaking, residential mobility studies can be classified into three types, namely area studies, household studies and motivational studies, but in most cases a study will encompass all three of these factors. In the I960s, Lee developed a model that has influenced our manner of speaking about residential mobility. He contended that certain characteristics of the place of origin 
act as push factors, encouraging the individual to migrate, whilst simultaneously attributes of the new residential neighbourhood act in unison as pull factors, attracting individuals to the new location (Lee I966). Further to this, he acknowledges that some processes of migration have restrictions placed on them relating to factors other than just push and pull forces. For instance, he uses the example of the restriction of cultural or language differences. Champion, Fotheringham, Rees, Boyle and Stillwell (I998) contend that the push and pull factors of the area of origin and the new location are perceived in different ways and are influential in varying capacities depending upon the population sub group.

Among early attempts at theorizing or explaining residential mobility, one of the most influential was Rossi's (1955) Why Families Move, which saw movement as a result of rational decisions based on personal and environmental factors. In his study, Rossi used three modes of analysis: characteristics of mobile and stable areas; the characteristics that distinguished mobile from stable households; and the reasons given by households for making particular moves. He found mobility potential to be related to the age of the head of household, number of persons in the family and tenure preference. The findings of his study showed the social characteristics of the mobile to be related very significantly with the family's stage in the life cycle. Mobility was greatest in the period when families were experiencing greater growth, with younger people being more mobile. Migrating households took into consideration housing needs, space, neighbourhood context, and costs, more so than journey to work or distance from friends and relatives, so overall mobility decisions were found to have less to do with social networks. He concluded that specific pull factors to a new home included a desirable amount of space, particular dwelling design features and dwelling location. Furthermore, he also found that the more moves made in and out of an area the less inter-personal ties people had and the more likely people were to think the area was unattractive. In the same vein, the stronger a person's ties with an area or the longer they had lived there, the more likely they were to be aware of the amount of mobility there.

Wolpert (I966) built on this by developing a systematic behavioural theory of how environmental factors interacted to encourage people to move. He measured both structural opportunities and individual determinants to determine the households' ability to fulfil their residential aspirations. He contends that even if an individual makes a negative evaluation of their surroundings, this may not be a sufficient condition for residential change; rather people may adjust to this in ways that may diminish their inclination to move. Thus, he introduced the notion of a 'threshold effect', whereby a negative evaluation must be of a 
particular strength before the household begins to think about moving. Contrary to Rossi, he also stressed that an evaluation of the community makes the most significant contribution to the process of deciding to migrate and that the absence of community ties is what allows people to migrate often. Consequently, the principal conclusion, reverberated later by Speares (I974), was that a key component in any decision to move was the evaluation of the community, and that satisfaction with the area was significant when it interacted with expecting to migrate.

Later studies moved on to consider neighbourhood effects (which included the community) in greater depth than before. Although Rossi (I955) undoubtedly emphasised the impact of stage in the life cycle on propensity to move, he also concluded that the socially mobile are concerned more with neighbourhood location and prestige. Lee, Oropesa and Kanan (1994) conducted an interesting study on the neighbourhood context and residential mobility. They built on an earlier study by Fernandez and Kulik (198I) that found features of neighbourhoods and local areas significantly influence residents' life satisfaction. The main research objective was to explore which properties of urban neighbourhoods determine whether inhabitants move or stay. In critical response to the fact that earlier studies were overly focused on neighbourhood deterioration, they attempted to take into consideration all aspects of the neighbourhood context which might potentially affect mobility. For instance, they assert that there is a duality of community context where the residents' more subjective perceptions of their neighbourhood and community (which may be temporal) are just as important as the objective characteristic upon which much of urban research is based. In conclusion, the authors confirmed that life cycle and housing circumstances are important factors influencing mobility behaviour (older, home-owning and longer length of residency reduces mobility). This is supported by recent work conducted on the determinants of migration flows in England by Champion et al. (1998). Secondly, the former authors found that aspects of the neighbourhood context play a role in mobility decisions, but interestingly that only one of the subjective neighbourhood measures had an impact on mobility, namely the residents perceived level of turnover in the neighbourhood, which was different from actual mobility.

Other studies on propensity to migrate, albeit not directly concerned with suburbanisation, are relevant due to the focus upon the factors that compel households to leave deprived neighbourhoods in the inner city in search of a more desirable or suitable location. Mumford and Power (I999) outline an extensive range of factors that influence people's movement from inner-city neighbourhoods, mainly those suffering from low demand housing and depopulation. They argue, alongside the aforementioned push factors, that lack of 
job opportunities relating to low income, poverty and demoralisation increase the impetus to relocate outside of the city. Champion et al. (1998) argue that labour markets have a significant influence on people leaving the city as industry and institutions have increasingly decentralised. Mumford and Power (I999) found that the unpopularity of an area, a poor quality environment and accelerated decay led to a low value being placed upon the neighbourhood by the residents, therefore, weakening the 'sense of place' and leading to a gradual breakdown of social stability. They also concluded that indicative of the desire to relocate was the failure of mainstream services, most significantly education. Simultaneously, the impetus to move out of inner-city neighbourhoods was fuelled by availability of employment, accessibility to improved services, namely education, and easy access to and availability of housing supplies. These destinations represented a better standard of living and quality of life, therefore, the attractiveness of a place emerges as a significant factor in forming the aspirations of households to move. Champion et al. (I998) argue that environmental factors are hugely important push and pull factors in understanding why individuals move out of the city. They found that individual aspirations to fulfil the desire for a 'good quality of life' are undeniably linked to the desire to be as close as possible to the countryside. They assert, therefore, that push factors include the social and environmental deficits of the city in comparison to the country. Amongst the reasons that inform decisions to move out of the city, two appeared most significant: first, the advantages of living in an attractive neighbourhood; and second, the search for a different type of community and lifestyle than that of the city. A study undertaken by MRAL (1995) looked at the reasons why people moving house left their neighbourhood. The results reported that 67 per cent of people moving from busy over-populated urban areas did so for environmental reasons, including traffic related concerns such as congestion, mentioned by 39 per cent of respondents, and poor parking facilities, mentioned by I7 per cent. Crime was a push factor for 20 per cent of respondents and street disturbances and troublesome neighbours for I2 per cent. Concern regarding the suitability of an area for children constituted a determinant for 26 per cent, whilst the poor standard of local schools was a push factor for only 8 per cent of the sample population. Champion (I999) highlights the greater impact that migration from inner-city neighbourhoods is having upon the composition of the population not only on the number of residents in the area. He accentuates the fact that the 'exodus' from the city is biased towards those with higher socio-economic status, underlining material resources, class and occupation as important explanatory variables. 
Indeed, 'ability' to migrate is affected by personal circumstances which at times may be constraining (Champion, Atkins, Coombes \& Fotheringham I998).

\section{Conclusion}

The suburb has emerged as the dominant location of urban residence in UK cities. The mass exodus from the city has been associated with social achievement and dominant social aspirations. The influence of technology, innovative transport networks, industrial de-concentration, intensified demographic pressures on the city and planning policy has contributed to and facilitated the rigorous post-war growth of suburbia. There is a clear bias in the UK literature on the suburbs towards documenting the actual processes (economic, social and political) that made their growth viable and their social role, but less is written on the actual volume and extent of suburbanisation in Britain. Each of the aforementioned processes and the continued attraction of suburban areas have contributed to the emergence of different types of suburbs, reflecting the need to expand the kind of imagery that should be associated with suburbia. This is illustrated through the emergence of the working-class suburb, the growth of black suburbanisation in the US, and by evidence of suburbanisation amongst Britain's minority ethnic population. Despite concerns about suburban decline and recent innovations to encourage people to move into the inner city, the extent to which moving to suburbia represents a search for the 'good life' appears to remain significant. Keeping this in mind, it is important to know whether minority ethnic individuals share the same aspirations for status and lifestyles of the white majority and if they see these things as attainable in the suburbs. Furthermore, the residential mobility literature suggests that push and pull factors for moving house have changed over time, with more recent emphasis on the pull of better services and better environments, rather than on household/lifestage factors in creating a move. It also suggested, however, that these factors vary for particular groups, so we need to know about motivations for minority ethnic households/individual movers. For example, do minority ethnic households move to get space for family growth as for the white majority, given their past experience of living at higher densities (which could suggest not)? Does distance to family and friends matter more for ethnic minorities, given our knowledge about close communities and extended families in areas of traditional minority ethnic settlement? Are motivations for better housing and improved services, particularly education, significant pull factors (as they are 
identified for the majority population), given minority ethnic over-representation in the inner city? 



\section{Methodology}

\section{Introduction: Research aims and objectives}

The previous chapters, through reviews of the literature, served both to contextualise the current study and to develop the research questions and objectives that this research seeks to address. The current chapter advances to discuss the methodological framework upon which the thesis is based. Then the actual fieldwork itself is described and the process of analysis. First, however, before outlining the research methods, it seems appropriate to revisit the aims of the research, discussed in the introduction, and consider how these were derived from the literature.

The established literature on settlement patterns of minority ethnic groups in the UK clearly points to their disproportionate representation in ethnic clusters, which are normally also deprived or run down areas in the inner city. This pattern has been attributed to several factors, including the pull of the ethnic core, structural barriers and discrimination as well as fear of harassment. More recently, as documented in Chapter 2, the settlement patterns of the minority ethnic population, which previously represented a more static geography, have begun to change. There is clear evidence of dispersal on a local level to locales where they were previously absent, particularly traditional white middle-class neighbourhoods and a growth in non-metropolitan areas (Robinson 2005; Rees \& Butt 2004; Phillips et al. 2003; Ratcliffe I996). This is significant as it suggests that some of the factors maintaining residential clustering or the characteristics and factors influencing the choices of individuals are changing. This trend of dispersal out of the inner city has been suggested to be occurring in Glasgow amongst the South Asian population (Glasgow City Council 2000). However, to date it has yet to be researched in depth, which is also the case at the time of writing for ethnic geographies, patterns of settlement and neighbourhood choice in general. The main research question seeks to address this gap in our knowledge through enhancing our understanding of the residential location and preferences of South Asian households and their members in the Greater Glasgow owner-occupied housing market: 
assessing to what extent suburbanisation is emerging as a significant residential preference.

As a subset to this main research question, additional research objectives along the lines of three particular themes pertinent in the literature have been developed.

\section{Patterns of re-location}

- To what extent through house purchase in the private market do South Asian households relocate from core community clusters to suburban locations?

- In areas of relocation is there evidence of re-clustering along the lines of ethnicity?

- How does the extent of relocation to suburban locations compare with levels of movement within core settlement areas or into areas adjacent to traditional minority ethnic settlement areas?

The first theme, relating to wider patterns of relocation and residence across the city region, enables us to contextualise suburbanisation as well as explore the wider ethnic geography of Greater Glasgow. A key feature of the residential location and choice of South Asian groups, as highlighted in the literature, is that of clustering, but it is not known whether households are re-clustering in the suburbs. This will be explored as a means to understand the different components of settlement and to investigate the links between clustering and the preservation of culture and safety in a different neighbourhood context, as well as determining if these aspects still matter in shaping residential choice. Moves to the areas adjacent to the areas of core settlement were also highlighted in Phillip et al.'s (2003) study of Bradford as being an important means to access better housing and to overcome particular constraints relating to social and familial obligations. Thus, this is an element that will be explored in the research as a potential driver of mobility. Furthermore, movement within the area of core settlement may be important as this may be an expression of choice.

\section{Motivations and resources}

- What are the push and pull factors influencing the decision to remain in core settlement areas, move into them from elsewhere or relocate to a suburban location?

- Are residential preferences reflective of the house buyers' assessment of the advantages and disadvantages of remaining spatially concentrated or of dispersal?

- What influences do members of South Asian households perceive the residential environment to have on lifestyle and quality of life? 
- To what extent do social class, occupation, material resources and stage in the life course enable or constrain suburban relocation?

The second subset of research objectives, related to motivations and resources, has been developed to explore the central factors that compel South Asians to cluster or suburbanise. Chapter 3 sets out some of the main factors in the residential mobility literature that have been used to explain the triggers that compel people to move. To a large extent, minority ethnic groups have been excluded from these more general discussions of residential mobility, partly due to the fact that they tended to live in inner-city clusters and research on minority ethnic groups focused on explaining this phenomenon of clustering or segregation (this is less so in the US literature). The current research, however, tries to bridge this gap between these two bodies of literature and seeks to assess the degree to which broader motivations, documented in the general residential mobility literature, are reflected in the mobility decisions of minority ethnic groups, whilst also assessing the degree to which ethnicity matters.

Recent political debates have brought segregation to the forefront of discussion; elements of this debate have clearly problematised ethnic clusters and sparked debates over the negative aspects of segregation. Still, there are few studies in the literature or evidence in public debates that draw on the perspective of the minority ethnic individual on this issue. A key objective is to address the extent to which an assessment of clustering or dispersal is reflected in residential decision-making. Likewise, referring back to the chapter on segregation, it is important to consider if minority ethnic groups are attracted to the suburbs as a means of socially and spatially integrating, as this has implications for the self-segregation debate. This also gives opportunity to explore the explanations of minority ethnic segregation in the literature relating to personal choices, barriers and constraints and social identities.

The general literature on suburbanisation highlights the importance of moving out to improve living conditions and environments, to access better job opportunities and schools, to accommodate changes in the life cycle and to meet general housing needs, as well as being a result of low worth and a weakened sense of place having developed in the inner-city neighbourhood. It also suggested, however, that these factors vary for particular groups, so we need to know about motivations for minority ethnic households. There are certain issues that are pertinent in the literature on majority motivations that raise questions given our knowledge of minority ethnic settlement to date, such as whether or not minority ethnic households move to get space for family growth as the white majority, given their past experience of living at higher densities (which could suggest not). Also, the literature 
suggests proximity to family and friends is not important for white movers, yet given our knowledge about close communities in areas of traditional minority ethnic settlement it is significant to explore the importance of this for minority ethnic groups. Importantly, motivations in general are clearly related to increasing resources and aspirations, thus the extent to which neighbourhood choice for South Asian groups reflects these factors relating to quality of life and advancement and differentiation in other domains will be explored.

\section{The role of the core settlement area and community for suburbanites and core settlers}

- To what extent do core areas continue to attract new populations; reverse movers and new migrants?

- What influence does residential dispersal and suburban relocation have on community ties and social networks?

- Is community attachment or membership achieved in the new suburban neighbourhood and/or retained with the core settlement area?

The final subset of research objectives developed relate to the role of the core settlement area and community for suburbanites and core settlers. In debates about explanations of segregation reviewed in Chapter 2, living in an ethnic cluster has been highlighted as having positive and negative consequences. The benefits of clustering relate to the preservation of culture, the defence it provides against hostility, the social and cultural capital that can be developed there and the role that the community and social networks play as important resources. The extent to which these benefits are still sought and realised in the context of growing ethnic dispersal and suburbanization have yet to be researched.

Assessing the attractiveness of and attachments to the ethnic cluster, in the light of new residential patterns, is important to help us understand the changing dynamics within the core areas as a result of mobility. The impacts that population turnover and new forms of mobility have on close knit neighbourhoods may be significant, as suggested in Rossi's early seminal study (I955). The extent to which the core area may continue to attract new residents and the degree to which needs are met and choices are able to be realised within the area are important, bearing in mind the well-documented evidence in the literature of poor housing conditions and lack of housing choices (Sarre et al. 1989; Phillips 2005). Furthermore, the extent to which community attachment and a sense of belonging is achieved in the suburbs is important in overcoming some barriers that have been documented as maintaining clustering, such as hostility and fear of harassment. In line with 
the role that the core plays in attracting new populations, it is also important to understand its role for those who leave, and the extent to which it continues to be an important place to preserve identity, give support and meet particular needs. This may also give some insight into the influence that particular ethnic amenities and social networks have on residential choice. Understanding strategies of interaction in the new suburban areas is essential to respond to the discourses that have portrayed South Asian groups as insular and isolationist. In line with desegregationist proposals linked with the community cohesion agenda, it is important to understand if residential mixing actually results in more cultural understanding, or social interaction, and if these new mixed neighbourhoods become places of engagement.

\section{A triangulated approach}

In order to explore these research objectives and define both the changes in South Asian residence and the processes and factors shaping these changes, a triangulated or 'mixed methods' approach was adopted, combining quantitative and qualitative methods. Traditionally, quantitative and qualitative approaches were often assumed to be polar due to their contrasting epistemological, ontological and methodological foundations (Barbour I998). However, now it is more commonly agreed that there are no principled grounds for adopting a qualitative or quantitative approach; rather, if the specific research questions call for it both methods can compliment each other (Silverman I997). A purely quantitative approach to the question of ethnic segregation or clustering would be, whilst providing detail on the distribution of the ethnic population, unable to explore the factors underlying these processes and patterns of settlement. Thus, after establishing the ethnic geography of Glasgow through quantitative analysis, qualitative research (semi structured in-depth interviews) was required to investigate the causal factors of these patterns of residence. In this sense, the qualitative and quantitative methods used corroborated each other. This section describes both stages of the research.

\section{Quantitative analysis of the Glasgow Metropolitan Area}

The first stage of the research provided a detailed picture of the broader ethnic geography of the Greater Glasgow conurbation over the I99I200I census period. There were five steps to this phase of the research, each discussed below: 
Step one: Selecting the area of study

The first step of the metropolitan study was to define the boundaries of the relevant study area. This was defined as Glasgow City itself and the six surrounding council area districts: East Dunbartonshire, West Dunbartonshire, North Lanarkshire, South Lanarkshire, East Renfrewshire and Renfrewshire. The delineation of the case study area can be justified by two studies which previously defined the Greater Glasgow conurbation (Bailey, Turok \& Docherty I999; CRU 2002). Glasgow's suburbs are located within these areas. Beyond these council areas, the South Asian population is known to be extremely small, suggesting that few have moved from the urban area into rural areas.

A significant per cent (59 per cent) of Scotland's South Asian population live in the study area (Table 4.I) and 40 per cent in Glasgow City. Two other council areas, East Dunbartonshire and East Renfrewshire, in the study area have South Asian populations above the Scottish average, which is significant in terms of our concerns with suburbanisation. The other three council areas in the study area have South Asian populations below the Scottish average.

In terms of the different South Asian groups identified by the census, 66 per cent of all of those who classified themselves as Pakistani on census night in Scotland lived in the study area and 53.3 per cent of those who categorised themselves as Indian. Only I7.4 per cent of those who categorised themselves as Bangladeshi lived in the area, as did 46.6 per cent of those who categorised themselves as Other South Asian.

Table 4.1 South Asian population of the area of study at council area level and \% of national population, 2001

\begin{tabular}{lrrrrrrrr}
\hline & $\begin{array}{l}\text { All } \\
\text { persons }\end{array}$ & Indian & Pakistani & $\begin{array}{l}\text { Bangla- } \\
\text { deshi }\end{array}$ & $\begin{array}{l}\text { Other } \\
\text { South } \\
\text { Asian }\end{array}$ & $\begin{array}{l}\text { Total } \\
\text { South } \\
\text { Asian }\end{array}$ & $\begin{array}{l}\text { South } \\
\text { Asian } \\
\text { (\%) }\end{array}$ & $\begin{array}{l}\text { South } \\
\text { Asian \% } \\
\text { of national } \\
\text { population }\end{array}$ \\
\hline Scotland & & & & & & & & \\
Glasgow City & $5,062,011$ & 15,037 & 31,793 & 1,981 & 6,196 & 55,007 & 1.09 & NA \\
East & 577,869 & 4,173 & 15,330 & 237 & 2,020 & 21,760 & 3.76 & 39.6 \\
Dunbartonshire & 108,243 & 1,533 & 504 & 38 & 192 & 2,267 & 2.094 & 4.12 \\
East Renfrewshire & 89,311 & 686 & 1,769 & 13 & 153 & 2,621 & 2.93 & 4.8 \\
North Lanarkshire & 321,067 & 527 & 1,756 & 19 & 213 & 2,515 & 0.78 & 4.6 \\
Renfrewshire & 172,867 & 461 & 497 & 8 & 103 & 1,069 & 0.62 & 1.94 \\
South Lanarkshire & 302,216 & 536 & 968 & 29 & 165 & 1,698 & 0.56 & 3.08 \\
West Dunbartonshire & 93,378 & 103 & 180 & 1 & 43 & 327 & 0.35 & 0.59 \\
Total & & & & & & & & 58.73 \\
\hline
\end{tabular}




\section{Step two: Spatial analysis}

In the current study, three key spatial units of analysis were used: council area, postcode sector and output area (OA). The main building blocks for census areas are output areas from which all higher geographies are built. The boundaries of the council areas in Scotland changed in I996 creating some difficulties regarding the comparability of I99I and 200I data. To ensure comparability, as far as possible, the new unitary council area boundaries were recreated in the I99I data by matching 200I output areas to I99I postcode sectors. In the study area there were 239 postcode sectors, the majority of which had over I,००० people with the largest containing I9,000 people. These were built, in the current research, in I991 with 13,78I OAs and in 200I with I2,723 OAs. Output areas unfortunately could not be compared between I99I and 200I as they had changed significantly, with I,000 more in the study area in 200I than there had been in I99I, but higher geographies were compared and could be constructed as the same. Nonetheless, the output area data was very useful later to study at the concentration of South Asians within the case study areas.

As with all census data, there are limitations to the data that complicate comparisons over time, such as changes made to population bases, changes in the wording of questions asked or changes in the definition of variables/response formats used. In addition to the aforementioned limitations, some caution needs to be taken with regards to the ethnicity variable in the census. Categories are set in advance in the survey design process, so ethnic categories, although selected in the data collection process by the respondent, cannot be thought of as having a fixed cultural definition that is generalisable, nor exhaustive of a persons expressed self-identity (Simpson 2004). Despite this, and although being reductive, the ethnic categories are the best we have for the purpose of the research.

Once the data had been adjusted to ensure comparable spatial units, a comparison was made between the population by ethnicity in I99I and $200 \mathrm{I}$ and the data was mapped. This analysis was done at postcode sector level. Unfortunately, the local authority areas could not be compared between I99I and 200I due to the change in their geography. The South Asian (classified in the census as Pakistani, Bangladeshi, Indian and Other South Asian) areas of concentration were identified in I99I and changes in these areas (proportionate growth and decline) were uncovered by analysing the 200I Census. Proportions of the population were then calculated in order to identify population shifts and areas of new growth. This resulted in a detailed overview of the city structure by ethnicity. From the cross-sectional census data it was not possible to conclude changes in location definitively, as population shifts may not have necessarily been made by the same people. For 
instance, if the Pakistani population decreased in the inner city and the suburban proportions increased, clearly it could not be suggested that they were the same people who moved, as such an inference is muddied by people making other moves and by births and deaths. Rather, we are looking at two snapshots of density. Despite this, we can have confidence in interpreting these patterns of movement from the census, as the qualitative data was used to confirm the nature of the population flows inferred from the census data.

\section{Step three: Calculation of segregation, concentration and exposure indices}

The next stage, continuing with the use of the census data, was to measure concentration, or degrees of evenness, and exposure for each of the South Asian groups from the majority white population using segregation indices at the extended city level (Glasgow City and the surrounding districts). Three indices were calculated: the index of dissimilarity (ID), the index of segregation and the index of exposure. For a full explanation and discussion of these indices see Chapter 2's section 'Measures of segregation'.

\section{Step four: Identification of core settlement and suburban case study areas}

From the analysis of the census four areas were identified as case studies in which in-depth qualitative study was undertaken. Two inner-city areas with established South Asian communities and religious and cultural infrastructures were chosen using the following criteria: their identification as ethnic cores in the literature and social history studies of Glasgow; their high percentage of South Asian residents when compared to other areas in the city; and their developed community infrastructures. The analysis of the census revealed very different population changes to the north and south of the River Clyde, with population loss in the ethnic core to the north and growth in the core area to the south. In order to understand the processes behind this a core area was chosen in each part of the city. To verify this selection, preliminary interviews were carried out with four key actors who worked in city centre mosques and multicultural centres and many observational visits made. Interviews were also carried out with some residents in the core areas to try to explore peoples' sense of where the suburbs were and where they thought people were moving to.

The suburban areas were chosen primarily on the basis of having higher than average proportions of South Asian residents. Other criterion was also used to select the suburban case study areas, namely their location outside the city boundary and the results of preliminary interviews with key actors and residents. As with the areas of core settlement, a suburban area was chosen in the west of the city, north of the River Clyde and one in the south of the city. 
Figure 4.1 Case study areas

\begin{tabular}{l|l} 
North \\
Core & Suburb \\
\hline Woodlands & Bearsden \\
\hline Strathbungo/Pollokshields & Giffnock \\
\hline &
\end{tabular}

\section{South}

Step five: Sampling using the Land Value Information Unit (LVIU) property sales data (Sasines) and Nam Pehchan (South Asian name-finding software) The bridging step between the quantitative and qualitative phases of the research was the extraction of South Asian names from Glasgow's property sales database, as the basis for contacting prospective interviewees. The property sales database is compiled by and held at the Land Value Information Unit at the University of Paisley. This register is unique to Scotland and is the most comprehensive source of data recording property transactions. It is compiled by extracting information (addresses, dates, sale prices and names of transacting parties) from the Register of Sasines (which holds title deeds) and the Land Register (which holds titles) provided by the Registers of Scotland and attaching it to full postcodes and transaction codes.

Data was extracted from the LVIU database for each of the four local case study areas from I991 to the end of 2003 (at the time of obtaining the data this was the most recent available). In order to identify South Asians in each of the case study areas, a name analysis computer programme called Nam Pehchan, developed by Bradford City council, was used. It is possible to match both surnames and up to two forenames using the programme. It also identifies the specific religious and language origin of the name as well as matching it with gender. All elements of the names under analysis are matched against a lookup database and given character codes. For example, if the character codes 5, $\mathrm{U}, \mathrm{M}$, and $\mathrm{C}$ appear beside a name then it is inferred that there is a definitive match on the name (5) and that the name is associated with the Urdu language (U) and Islam (M), but that the gender (C) could not be determined from the name.

This output provided a database of South Asian names and addresses, which was used later as a sampling frame to contact the interviewees. One hundred names were randomly picked from this new database of South Asian names over different years from each case study area, creating a new list of four hundred names. Religion was used as 
a proxy to distinguish between Indian and Pakistani households. This was primarily due to the fact that there was also reliable census information relating to ethnic group and religion, whereas this was not the case with language. To identify potential Indian respondents names associated with the Sikh and Hindu religion were selected, and to identify potential Pakistani respondents names associated with the Muslim religion were identified. This is justified by the fact that the 200I Census revealed the Indian population in Glasgow to be in the vast majority Sikh or Hindu, 5I per cent and 24 per cent, respectively, 4.4 per cent are also Muslim with affiliation to all other religions being below 3 per cent. The Pakistani population was shown in the 200I Census to be 84 per cent Muslim with affiliations to all other religions being below I per cent (200I Census: author's own analysis). This was a proxy measure and not always accurate due to the fact language and religious origin of a persons name does not automatically denote their culture or religious affiliation.

Nam Pehchan is estimated to be almost 97 per cent accurate by Bradford City Council (Nam Pehchan programme instructions, Bradford City Council). Harding, Dews and Simpson (I999) and Fieldhouse and Cutts (2006) both assert Nam Pehchan to be highly reliable. Some have questioned this contending that there are quite high misclassifications of names (Cummings, Winter, Cheng, Maric, Silcocks \& Varghese I999). Cummings et al. (I999) found in their study that tested Nam Pehchan I (not 2 which was used in the current study), that 36.8 per cent of all names identified by Nam Pehchan on a disease register were false positives and that 9.5 per cent not identified were indeed South Asian names. They concluded that it was not good to use Nam Pehchan as a single strategy. Nam Pehchan I focused more on names related with the Urdu speaking Muslim population of Bradford and less on Hindi and Gujerati names. However, the second version of Nam Pehchan, which was used in this study, has an updated name directory that has been expanded using names from throughout Britain, rather than just Bradford, to widen the places in which Nam Pehchan could be used. It has also been extended to cover more non-Muslim names. Furthermore, names and their religious associations were checked by a panel of language specialists. Nam Pehchan 2 has greater precision due to the fact that it can now assign names with one or two languages and religions, meaning it is more flexible (Fieldhouse \& Cutts 2006). Nanchchal, Mangtani, Alston and Dos Santos Silva (200I) contend it is the most reliable method for identifying South Asian names. However, this does not guarantee precision and any study using Nam Pehchan must be aware of the possibility of the misclassification of names (Fieldhouse \& Cutts 2006). Furthermore, it would be 
inaccurate to assume that the names database fitted Glasgow as well as it did Bradford, despite the wider coverage of Nam Pehchan 2.

\section{Qualitative phase}

The spatial analysis provided a picture of residential patterns in the study area and enabled the selection of case study areas that best captured the dynamics of these patterns for further qualitative analysis. Semi structured in-depth interviews were conducted to explore the motivations and rationales of household migration from and to these areas. Figure 4.2 is a schematic representation of the flows of the interviewees.

Figure 4.2 Migration flows within and between areas of core settlement and the suburbs (moves of interviewees)

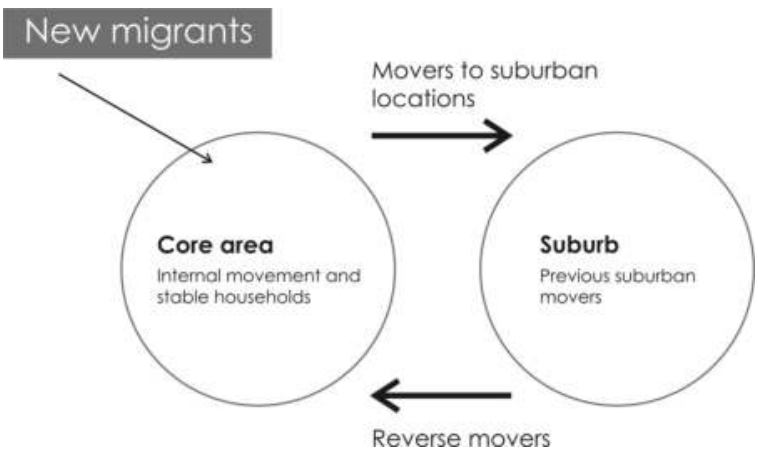

Ten interviews where conducted with house movers in each of the four case study areas (40 interviews in total). This seemed a reasonable number of interviews given the time available after conducting the quantitative phase. This phase of the research had six main steps described in detail below.

Step one: Building contacts and interviews with key community actors

Whilst choosing the case study areas in the quantitative phase of the research, it was important to define core areas and suburban areas in the city. In order to validate the choice of the earlier case study selection and the patterns of South Asian residence, (from the mapping of census data) interviews were conducted with key community actors. This gave supplementary information that confirmed the inferences made regarding patterns of settlement and changes within areas from the census. Two interviews were conducted with imams in local 
mosques, one with a representative of the Sikh temple, and one with a University professor who was also the director of an international Muslim radio station broadcast from Glasgow.

The style of these interviews was open and conversational; rather than using a schedule broad topic areas were used to generate discussion. As well as verifying the choice of the case study areas and confirming patterns of movement, advice was sought on how to conduct the interviews with sensitivity. Instructions were given regarding appropriate appearance and behaviour (for example, to keep hair and arms covered and to wear shoes that could be easily removed when entering an interviewee's home). Specific advice was also given regarding interactions with men, especially older men, taking into consideration cultural differences in the roles of women. Advice of this nature was given by the key actors in the Muslim community and less by the representative of the Sikh temple. The key actors also read the interview schedules for the core and suburban residents, though none of the interviewees advised any changes to be made.

\section{Step two: Development of semi-structured interview schedule}

The principal concern was the importance of being clear about the purpose of the interview in order to ensure the questions asked in the survey would elicit the kind of information desired. This involved revisiting the literature reviews, the research objectives and thinking about the patterns of residence inferred from the census analysis. Furthermore, it was important to work on the suitable wording of questions to make sure they were easily understood and unambiguous, however, as with the question order, this was flexible to a certain extent and as needed was adapted to suit each respondent. The initial drafts of the schedules were long, which meant questions had to be collapsed together and prioritised. To test that each of these specifications were met, some preliminary interviews were carried out, described in the next step.

During the primary stages of designing the schedule the broad aims and objectives of the research were translated into topic areas. Two interview schedules were developed; one for residents in the areas of core settlement and one for suburban residents (see Appendices I and 2). These themes were then translated into five topic areas around which the interview schedule was structured. The first, which was common to both, was housing histories. The main aim of this was to characterise the respondents' residential and housing histories in order to place their current residence and future aspirations in a life context. This also provided information on past household structures and the means by which they had moved, chosen and financed their current home. The second area, also common to both, focused on residential motivations, which explored 
the push and pull factors attracting and repelling people to and from their past and current place of residence. This area also explored factors that had made a move possible and others that had inhibited or constrained preferences from being achieved. In discussing the pull factors of the current area of residence it was also possible to raise questions surrounding peoples' sense of safe, desirable and hostile places in the city, and thus of residential areas that were considered open to them. The third area looked at views on current neighbourhoods. This addressed issues of both neighbourhood satisfaction and the residential outcomes of the interviewees' choices. This, as the last area, also provided an opportunity to probe for details relating to other members in the household, and for the influences that age, class, occupation, resources and ethnicity had on residential location and preferences.

Each of these areas were addressed in both schedules, however, the fourth area in each schedule was varied around issues relating to community and social networks. In the schedule for the residents of the area of core settlement the fourth area considered the role of the core. The aim was to explore the attraction of the core and the extent to which and, indeed, why it attracted new migrants and reverse movers from the suburbs, whilst retaining long-term residents. Questions were added that explored reasons behind neighbourhood attachment and the nature of social networks in the area. It also aimed to explore the influence residential dispersal and suburban relocation had on community ties and social networks and to get a sense of the nature of relationships with those who had suburbanised from the core. This also aimed to elicit information surrounding the perceived motivations behind suburban moves, again, from the perspective of the interviewee who had remained in the core.

The fourth area addressed in the suburban schedule explored the development of community attachment or membership in the new suburban neighbourhood and examined the extent to which people had settled in and achieved a sense of belonging. Also, the purpose of this area was to examine the extent to which attachments and ties were retained with the core settlement area and the established community there.

The fifth area, included in both of the schedules, was future aspirations. This aimed to explore people's ideal residential locales and housing, even if they thought they would not be able to realise them. It aimed to obtain information regarding future changes in people's residence, relating to differentials and needs. It also aimed to explore the household decision-making process, barriers to achieving these preferences or any future opportunities that may help to realise them. 


\section{Step three: Contacting interviewees}

After creating the database of South Asian names of movers from the Register of Sasines, one hundred people from each case study area were randomly selected at three points in time between I99I and 2003. Each potential interviewee was contacted by letter. The letters were sent in four phases by case study area a few weeks before I was going to interview in each area. Letters were sent to the first area in April 2004. The letter specified that interviews should be conducted with someone who was key in making household decisions, rather than the head of the household, as there was a possibility that, for example, a son could have been decisive in making housing decisions, as was indeed the case in a few households. It informed the recipient of the period in which the interviews would be taking place in their neighbourhood. It stipulated that I might call on them, as there was the possibility that the list of one hundred people (in each case study area) would not be exhausted. There was also an opt-out option, by which the recipient of the letter could telephone, write or email to say they did not want to take part in the research. Included in the letter was an information sheet about the research that broadly outlined the objectives of the research. Consent forms were not used, as it was felt that conducting the interview was consent enough without the signing of a form that recorded the names of the interviewees and further compromised confidentiality.

\section{Step four: Complementary snowball sampling}

The main means of sampling was purposive (identifying South Asians and contacting them directly), however, there was a degree of uncertainty as to how well this method would work. So by way of precaution, in the event that it was unsuccessful, contacts were built with key actors, so that snowball sampling could be used if needed. The main difficulty I faced was identifying households who had reversed moved from the suburbs to the core, making it necessary to rely on the 'snowball effect' rather than purposive sampling to encounter some of these movers. However, due to the overall success of the purposive sampling, contacts with only a small number of the 40 interviewees were generated by snowball sampling.

\section{Step five: Conducting the interviews}

Two weeks after the first phase of letters were sent to Pollokshields I began interviewing (May 2004). I aimed to interview during the day or later in the evening, after dinner, following the advice of the key actors, as mosque school ran from 3.30-6.00 pm. Also, on Fridays I only contacted Indian interviewees. Often, in the first visit the purpose of the research was explained to supplement what had been outlined in the 
letter and another time was arranged for the actual interview. Personal contact before the actual interview was very beneficial in fostering a sense of rapport with the interviewees. Responses to the research varied greatly between case study areas. People most eager to be interviewed were in Strathbungo/Pollokshields and Giffnock. In Woodlands and Bearsden, it took a much longer time to arrange interviews.

\section{The nature of the interviews}

The topics to be addressed in the interviews were specified using a topic guide; however, the questions were open-ended making the interviews discursive and providing the interviewee with the opportunity to develop their responses. Being an 'outsider', contrary to that highlighted in the literature on 'researcher matching', was often beneficial. Some interviewees, especially those living in the core, felt that the interview gave them an opportunity to discuss sensitive issues, such as the burden of family and cultural responsibilities and obligations, which they had been unable to broach with their family and neighbours.

One of the most distinct benefits of using semi-structured interviews in the research was that they could be adapted to individual interviewees, a benefit highlighted by Leonard (2003). For instance, the building of rapport between women that I interviewed and older men called for a different approach. When interviewing the older men, it was necessary to make questions more specific to encourage them to elaborate, as in the first instance they were most likely to give very general and vague answers. However, with more specific questions they were able to provide richer detail. These interviews took more time. The open format also enabled me to seek clarification as well as confirmation of the interviewees' response and importantly to clarify any ambiguities or misinterpretations of the questions, this was particularly important when the interviewee had language difficulties. In the two cases were people could not speak English fluently another member of the household translated. One male interviewee had arrived in Scotland a few years before and had difficulty understanding questions, so a simplified version of the interview schedule was used, resulting in less detailed answers and at some points his younger son had to translate. This had an impact upon the richness of the data, as time was spent on translation and the more complex processes of decision making were not properly explored in the interview.

The majority of the interviews were recorded and pseudonyms were used to label the cassettes, to ensure confidentiality as promised to the interviewees. All of the interviews were long, ranging in length between one-and-a-half to three hours, and included many stories about the family that deviated to varying degrees from the schedule (even 
one that was conducted in the small kitchen of a corner shop). Hence, it was necessary both to leave plenty of allowances for improvisation, but also to draw the interviewees back to the broad topics on the schedule. It was unusual for an interviewee, especially Pakistani interviewees, to let me leave without some form of additional socialising, usually eating or drinking something, sometimes this even included dinner. One interviewee from Kashmir taught me how to make a traditional Kashmiri fish dish after the interview had finished. Several times I was invited back for dinner and entertained as a special guest. This meant that the interviews were time-consuming and sometimes a couple of visits to each house were made, so no more than two interviews could be arranged in one day.

Often, in a household where the members were Muslim, women retired if an interview was taking place with a man. An effort was made to talk to women when possible, in fact, in transnational marriages when the female was born in Britain she often steered the housing decisions and I was shown to her when I called to the house, rather than the male partner. The household was barely ever a fixed unit or at least one that matched with my notion of a household and an important part of each interview was actually trying to work out who lived in the house and their relationship to one another. During many of the interviews in the core there were many interruptions as relatives visited unexpectedly or phoned, giving a sense of the closeness of social and family ties in the area.

Some social researchers, for instance Hyman (1954), argue that the demographics of both interviewer and interviewee should be matched. Primarily, he focused on 'race' arguing that if interviewees were black and the interviewer white the answers of the respondents would be inhibited. Of course, there is only a certain extent to which the interviewer has control over this, as certain characteristics are fixed and matching researchers with similar backgrounds and appearances as interviewees is costly. However, less definitive characteristics such as dress and manner can be changed. In line with this, it was decided before beginning the interviews that certain respectful gestures be made and cultural sensitivities adopted. There were times, however, when the interviewees were confused about my religious and cultural identity by my behaviour. For instance, several times when I had covered my hair, a few interviewees assumed I was Muslim. This produced the opposite effect than that initially intended, as some the interviewees thought it was strange that I should adopt particular cultural behaviours which were not my own. These incidents lead to me feeling that I had somehow belittled cultural practices by partaking and not understanding or ascribing to the reasons underpinning them. In response to this, a more open approach was taken with most of the interviewees, 
whereby I acknowledged my position as student who was eager to understand more of their culture and religious background. Furthermore, it was necessary to possess an awareness of the potential influence that my personal characteristics may have had upon interviewees and of the possibility of producing gender biased research, considering any crosscultural differences in roles of women.

An important aspect in conducting the interviews was the timing of when the actual interviews took place; it was important to assess whether or not events that took place around the same time influenced respondents. In line with this, it was clear that the closeness of the interviews in this study to the trial of two young Asian boys for murdering a white youth in the neighbourhood most likely affected the interviewees' feelings about their neighbourhood and the youth of the community. Similarly, it may have influenced the feelings toward the area and community of those households who had moved out of the area.

\section{The interviewees}

As mentioned previously, there were 40 interviews carried out in four case study areas. Of these interviewees thirteen were female, 24 were male and three were carried out with married couples. There were more Pakistani than Indian respondents, 27 and thirteen, respectively, which was reflective of their weight in the total population. In terms of religious background, although several did not practise, the largest number with 29 were Muslim, seven were Sikh and four Hindu. See Appendix 3 for a summary of the characteristics of each of the interviewees.

\section{Step six: Transcription and analysis}

The interviews were fully transcribed, twenty personally and twenty by a professional transcription service. NVivo qualitative software was used as an aid to analyse the data. It was thought that NVivo would be a useful tool as the interviews were long and generated a large amount of data that needed to be organised in an effective way. There are distinct benefits and drawbacks to using software for the analysis of qualitative interviews. Qualitative data is easily stored, retrieved and manipulated; however, it is merely a practical means alongside the methodological and theoretical underpinnings of the research and cannot be a substitute for learning data analysis methods (Weitzman 2000). In this instance, using NVivo was a useful organisational tool and fast way to extract and search the data according to themes and labels that had been attributed to it. The speed and the organizational qualities of NVivo were especially useful due to the importance of what Weitzman (2000: 8I3) calls 'poking around in your data' for a more inductive 
approach. It was also very useful to store aides mémoires and keep organised notes and ideas as the analysis process began to unfold.

Despite its benefits, there were some drawbacks to using NVivo, as without continuous reading of the individual transcripts it was easy to search for themes and nodes across all of the interviews stored in the NVivo database project, but to lose a sense of the context in which individuals were speaking. This is the case more so with NVivo than paper based methods as NVivo extracts lines of texts adhering to a particular node/code meaning that particular quotes were not presented within the text of the interview. This potentially created susceptibility to over generalise and to lose the separate voices in their appropriate contexts.

To begin with, once the interviews were successfully transcribed and checked, attributes were created for each of the interviewees (age, gender, ethnic group, religion, place of residence, household type, economic status and previous place of residence). These attributes were used to search the text and analyse responses according to specific interviewee characteristics, as relationships started to develop between particular categories and attributes. There were several different stages to recording ideas and developing the themes arising from the interviews. First, extensive personal notes were made on the qualitative data whilst transcribing. These notes were early thoughts on the interviews and were cumulative, including the experience of the actual interview process. They also began to identify the main themes arising from the interviews, which formed the basis for analytical coding categories that were used later in coding the data. Secondly, coding categories were developed whilst working through the interviews. At this stage, although the analysis was led, to a certain extent, by the content of the data, the research questions and the rationale behind the development of the interview schedules were also used to guide the reading and analysis of transcripts. As Schmidt (2000: 254) notes:

The researchers own theoretical prior knowledge and the research questions guide his/her attention in the reading of the transcripts. The aim is to note, for every single interview transcript, the topics that occur and individual aspects of these which can be related in a very broad sense - to the context of the research question(s).

Furthermore, Schmidt (2000: 254) highlights the importance of taking, 'account of the openness of the interviews', rather than simply using the:

formulations from the questions that were asked but considering whether the interviewees actually take up these terms, what the terms mean to them, which aspects they supplement, which they 
omit and what new topics, which are not foreseen in the guide, actually turn up in the collected data (ibid.).

The coding was done using mainly a free form method as themes arose, rather than rigidly following distinct analytical categories that had been previously devised. Care was taken, however, to ensure that the coding developed uniformly throughout the analysis of the interviews. To ensure this, it was necessary to make detailed notes providing a rationale for each of the codes within the overall main aim of the research. A third set of memos were written that linked specific pieces of text and codes together. This was useful were themes overlapped and led to the building of a more cohesive sense of the overall findings of the interviews. The memos were useful in the retrieval of text and helped in networking, linking and finding relationships between different codes or concepts.

The most difficult stage in the analysis was refining and editing the coding categories that had been created as the data was rich and there were multiple labels or codes attached to it (over Ioo). An early version of the coding categories is appended (see Appendix 4). To move to the next stage of analysis, these free codes (referred to as free nodes in NVivo) were collapsed into broader nodes and then transferred into 'tree' nodes, organising them into overall themes and giving them a coherent structure. Tree nodes are nodes that are hierarchically organised in such a way that makes them meaningful for the research objectives and the voices of those interviewed. Some of these tree nodes were predefined from the research questions and aims before this process. In each tree there is a parent node and several codes nestle under each of these (see Appendix 5). This brought greater clarity and structure to the analysis. It also facilitated the ongoing process of writing. Reports were generated from each of the free nodes that made up the tree nodes. Searches were also conducted, most commonly of keywords, relating to specific themes as they arose in the analysis process and node reports created according to different interviewee attributes. This was done throughout the writing and analysis process as certain questions and curiosities began to arise around particular themes.

\section{Conclusion}

The adoption of a triangulated approach to the research was a logical response to the research objectives and provided a valid assessment of both the residential location of South Asians in the Greater Glasgow metropolitan area and the causal factors driving these patterns of residence. The use of techniques from quantitative and qualitative 
paradigms allowed patterns of residence that could only be inferred from the study of the census to be confirmed and explained by the qualitative interviews. Thus, a clear strength of the methodological framework is its validation and robustness arising from the complementary viewpoints and techniques from both quantitative and qualitative paradigms.

There were clear challenges in the research process, relating mainly to comparability between the I99I and 200I censuses, however, this was largely resolved through the rebuilding of geographies of 'best fit' using the smallest geographical unit of output areas. There were also difficulties gaining access to the Register of Sasines, which held up the research process. This data set proved, when used with Nam Pehchan, to be an extremely effective way of tracing South Asian homeowners. Despite the problems expected in gaining access and consent to interview people, contact with prospective interviewees was largely met with enthusiasm. There were aspects of the interviews that challenged the advice given by the key actors and the literature, regarding issues around cultural sensitivities and the necessity of matching interviewee and interviewer characteristics. This is an interesting methodological consideration and perhaps a useful addition to the literature. 


\section{Through the national lens to the city: The housing position and experiences of South Asians in Scotland and Glasgow}

\section{Introduction}

People of South Asian origin have lived in Scotland since the late nineteenth century. Despite this, their settlement is commonly regarded as a more recent phenomenon as the population was small until after the Second World War. There has been a focus for many years in England and in the US on the experiences of minority ethnic groups in various domains; however, it is a slightly more recent research phenomenon in Scotland. Prior to the late I980s and early I990s, there was a scarcity of research that considered minority ethnic communities, which may be partly due to what some authors have referred to as a lack of racialisation of the political process since I945 in Scotland (Hopkins 2006; Miles \& Dunlop I987). The experience of minority ethnic groups in Scotland and the rest of Britain may generate some useful comparisons; however, this must be seen within a wider framework of difference between the two countries, particularly in the legal and housing systems and in the composition of the minority ethnic population. There has also been a long-standing perception in Scotland, relating to Scottish nationalism, that Scotland is exempt from the race-relations problems seen to exist in England. This idea of 'Scottish tolerance' has often contributed to the notion that racism, or racist practices, are not perpetrated north of the Border (MacEwen, Dalton \& Murie I994; Maan I994; Audrey 2000); however, recent research has challenged these assumptions. The housing experiences of minority ethnic groups in Scotland are significant to gaining an understanding of the patterns of minority ethnic settlement and housing aspirations at the city level. This chapter begins by providing an overview of the national picture in Scotland and moves to outline the housing experiences of minority groups in Glasgow at the city level.

\section{South Asians in Scotland and Glasgow}

Migration to Scotland from Asia has its origin in the British Empire. As trading relations developed between Scotland and India, Scotland's 
industry prospered often at the expense of the Indian economy. One example being the development of the jute trade in Dundee's looms in the I830 at the expense of Bengali hand weavers (Audrey 2000). However, the first main juncture in the process of migration from South Asia to Scotland was the later recruitment of Indian seamen by companies like Glasgow's East Indian Sea Company and Anchor Line (Maan I992). Subject to frequent harsh treatment, unequal labour conditions and pay, many exited ships and took temporary and some permanent residence in the UK. The Glasgow Corporation funded the opening of a home in 1930 to house some of these men, whilst others resided in a variety of seamen's hostels near the docks. Despite this early migration, by 1940 there were still only 400 Indians in Glasgow who mostly owned or rented from fellow country men in the Gorbals, an inner-city locale on the south bank of the River Clyde (ibid.). Despite their common nationality at the time, they were not a homogenous group (ibid.): 35 per cent were Sikh and 65 per cent were Muslim (Audrey 2000). These differences became increasingly apparent in 1947, during the time of repartition, when India was granted independence and the new state of Pakistan was formed. At this stage, there was large-scale migration to Britain and, between 1950 and I960, the number of South Asians in Scotland rose from approximately 600 to 4,000. Audrey (2000) contends that whilst demand for labour was a pull to migrate to England this was not so for Scotland as many of Scotland's indigenous population emigrated throughout this period due to Scotland's economic decline. This may be a slight misrepresentation as other historical research shows that there were in fact labour shortages in some of the unskilled occupations in Scotland at this time.

Unlike England's direct recruitment from the New Commonwealth, recruitment happened in Scotland through established immigrants passing word of opportunities to their countries of origin and through internal migration from England to Scotland. The majority of South Asians were employed in factories or the transport industry. In the I960s and I970s, a process of family reunification occurred making it necessary to obtain larger properties. These were bought outside the Gorbals, mainly due to slum clearance at the time. The previous minority ethnic inhabitants of the Gorbals spread to Govanhill, Pollokshields, Garnethill/Woodside or to the West End (Kearsley \& Srivastava I974). New areas of family settlement began to emerge as permanent residential locations with cultural amenities and places of worship were established locally. After this period, the numbers of immigrants decreased in line with changing immigration legislation, which made a distinction between the Old and the New Commonwealth, opposition towards immigration from the latter was given credence by both Labour and Conservative policies. 


\section{Minority ethnic populations in Scotland}

Over the past twenty years, minority ethnic groups have grown in Scotland, but still comprise a small proportion of the population. Two per cent of the Scottish population, according to 200I figures, are now from a minority ethnic group, compared with I.3 per cent in I99I. Scotland's minority ethnic population as a whole increased by 62.3 per cent between the I99I and 200 censuses, the South Asian population increased by $4 \mathrm{I}$ per cent and the white population by 0.5 per cent, whilst Scotland's total population increased by I.3 per cent. Table 5.I shows that those categorised as Pakistani are the largest minority ethnic, or non-white group, followed by Chinese, Indian and those categorised as having mixed ethnic background. What can be very broadly viewed as the South Asian population, those categorised as Pakistani, Indian, Bangladeshi and Other South Asian, comprise over 50 per cent of the total minority ethnic population.

\section{Age profile}

Minority ethnic groups in Scotland have a much younger age distribution than those who categorised themselves in the white groups (see Table 5.2). The percentage of the South Asian population represented in the age groups below 50 and most especially below sixteen are between a fifth and a third more than the percentage of the white group represented in the younger age groups. In line with this, the

Table 5.1 Scottish population by ethnic group, 2001

\begin{tabular}{lrcc}
\hline Ethnic group & Population total & \% of total population & \% of BME \\
\hline Population & & & \\
White Scottish & $4,459,071$ & 88.09 & NA \\
Other White British & 373,685 & 7.38 & NA \\
White Irish & 49,428 & 0.98 & NA \\
Other white background & 78,150 & 1.54 & NA \\
Pakistani & 31,793 & 0.63 & 31.27 \\
Indian & 15,037 & 0.3 & 14.79 \\
Bangladeshi & 1,981 & 0.04 & 1.95 \\
Chinese & 16,310 & 0.32 & 16.04 \\
Other South Asian & 6,196 & 0.12 & 6.09 \\
African Caribbean & 1,778 & 0.04 & 1.75 \\
Black African & 5,118 & 0.1 & 5.03 \\
Other black & 1,129 & 0.02 & 1.11 \\
Any mixed background & 12,764 & 0.25 & 12.55 \\
Any other background & 9,571 & 0.19 & 9.41 \\
Total minority ethnic population & 101,677 & 2.01 & 100 \\
Total population & $5,062,011$ & 100 & NA \\
\hline
\end{tabular}

Source: 2001 Census; author's own analysis 
Table 5.2 Age profile by ethnic group, all people in Scotland, 2001 (\%)

\begin{tabular}{|c|c|c|c|c|c|c|c|}
\hline Ethnicity & Under 16 & $16-29$ & $30-49$ & $50-64$ & $65-74$ & 75 and over & Total \\
\hline White Scottish & 20 & 17 & 29 & 15 & 12 & 7 & 100 \\
\hline White British & 10 & 19 & 34 & 18 & 11 & 8 & 100 \\
\hline White Irish & 5 & 20 & 30 & 18 & 16 & 11 & 100 \\
\hline Other white background & 14 & 30 & 32 & 11 & 7 & 6 & 100 \\
\hline Indian & 23 & 29 & 31 & 11 & 4 & 2 & 100 \\
\hline Pakistani & 33 & 28 & 28 & 8 & 2 & 1 & 100 \\
\hline Bangladeshi & 31 & 27 & 30 & 8 & 3 & 1 & 100 \\
\hline Other South Asian & 28 & 25 & 34 & 8 & 3 & 2 & 100 \\
\hline Chinese & 22 & 32 & 32 & 8 & 4.5 & 1.5 & 100 \\
\hline Caribbean & 18 & 24 & 39 & 11 & 4 & 4 & 100 \\
\hline African & 23 & 30 & 39 & 4 & 3.5 & .5 & 100 \\
\hline Black Scottish & 30 & 23 & 26 & 10 & 6 & 5 & 100 \\
\hline Mixed background & 44 & 27 & 18 & 5 & 3.5 & 2.5 & 100 \\
\hline Other ethnic group & 22 & 26 & 42 & 7 & 2 & 1 & 100 \\
\hline
\end{tabular}

Source: 2001 Census; author's own analysis

percentage of the South Asian population over age 50 is a half to a third lower than that of the white group. The decline in the proportion of the white population is particularly marked in the younger age groups, whilst the proportion of the population in the younger age groups from minority ethnic backgrounds has grown considerably (Scottish Executive 2004).

\section{Tenure patterns}

Tenure patterns according to ethnicity appear to have changed quite significantly in the ten-year period between I991 and 2001. From the I99I Census (see Table 5.3), we can see that minority ethnic groups were disproportionately over-represented in owner-occupancy. In contrast, however, over three times as many white households lived in social rented housing as did South Asians. Between I99I and 200I, the percentage of all households owing their own home rose by 12 per cent to 64 per cent, a trend matched by white households. Interestingly,

Table 5.3 Tenure by ethnic group in Scotland, 1991 (\% of households)

\begin{tabular}{lcrrrrr}
\hline & All people & White & Black & South Asian & Chinese & Other \\
\hline Owner-occupied & 52 & 53 & 43 & 77 & 71 & 50 \\
Private rented & 6 & 5 & 24 & 10 & 14 & 27 \\
Housing association & 4 & 3 & 5 & 2 & 1 & 4 \\
Local authority & 34 & 35 & 25 & 10 & 13 & 17 \\
Scottish Homes & 4 & 4 & 3 & 1 & 1 & 2 \\
Total & 100 & 100 & 100 & 100 & 100 & 100 \\
\hline
\end{tabular}

Source: 1991 Census in Third et al. 1997: 9 
however, the proportion of Indian, Chinese and Pakistani households represented in the owner-occupied sector has fallen and is now in line with both the percentage of all households and the percentage of white households represented in the sector (see Table 5.4). Non-owning South Asian households do not appear to have shifted to the social rented sector, as may have been expected on the basis of research that reported an increasing willingness of the Pakistani population to make applications for this sector (Bowes, Dar \& Sim I997; Kearns 2002). Rather, there has been a substantial increase in the number of South Asian households residing in the private rented sector, doubling over the ten year period, most likely due to affordability reasons, the difficulties associated with social renting (suitability of properties and long waiting lists) and fear related with its location. The proportion of South Asian households in the private rented sector in I991 was Io per cent, increasing to 25 per cent of Indian households and 2I per cent of $\mathrm{Pa}$ kistani households.

This substantial increase in the private rented sector and decrease in the proportion of those in owner-occupancy may reflect constraints, as reported by Third, Wainwright and Pawson (1997) who found minority ethnic households experienced more difficulties in gaining access to the owner-occupied sector. This may be indicative of financial limitations rather than discrimination by gatekeepers and financial institutions. It is probable that the rise in the proportion of white households in owner occupancy and the increase in property prices priced lower income minority ethnic groups out of the market, pushing them into private renting. On the contrary, this may signal real preferences as Third et al. (I997) found in their study of minority ethnic homeowners that 25 per cent of those interviewed said they would have preferred not to have become a homeowner when they first bought their house. Despite this, a considerable proportion of the same survey respondents would have preferred to rent public housing as an alternative as opposed to private renting, which was noted in the same survey as the least favoured sector.

Table 5.4 Tenure by ethnic group in Scotland, 2001 (\% of households)

\begin{tabular}{lccccrr}
\hline & All people & White & Indian & Pakistani & Chinese & Other \\
\hline Owner-occupied & 64 & 64 & 65 & 63 & 65 & 42 \\
Rented from council & 23 & 23 & 6 & 10 & 9 & 18 \\
Other social rented & 5 & 5 & 4 & 6 & 4 & 8 \\
Private rented/free & 8 & 8 & 25 & 21 & 22 & 32 \\
Total & 100 & 100 & 100 & 100 & 100 & 100 \\
\hline
\end{tabular}

Source: 2001 Census, author's own analysis 


\section{Household structure and occupancy}

There are significant differences in household structure by ethnicity. On the one hand, there are almost half as many single-person households in the South Asian group as in the white group. On the other hand, there are over seven times as many South Asian households who are multiple family households than in the white group, with Pakistanis most likely to be represented in multi-family households (see Table 5.5).

Again, there are disparities in occupancy ratings ${ }^{\mathrm{I}}$ according to ethnic group. There are more Pakistani and Other South Asian households living below the occupancy rate (3I per cent), whereas the white group is the least represented (I2 per cent) (Table 5.6). It is also evident that over half of Indian households have more rooms than they require under the official standard, as do half the Chinese and over 40 per cent of Pakistanis and Other South Asian households compared to over 60 per cent of white households.

\section{Urban concentrations}

Glasgow has the highest percentage of its population comprised of black and minority ethnic residents of any other local authority area in

Table 5.5 Household structure by number of families ${ }^{2}$ and ethnic group, Scotland, 2001 (\%)

\begin{tabular}{lcccccr}
\hline & White & Indian & Pakistani & $\begin{array}{l}\text { Bangladeshi } \\
\text { and Other } \\
\text { South Asian }\end{array}$ & Chinese & Other \\
& & \multicolumn{7}{c}{$\begin{array}{c}\text { Sorrer } \\
\text { O-Couple/Lone parent families }\end{array}$} & 23.7 & 14.4 & 5.2 & 15.2 & 18.6 & 22 \\
1-Couple/Lone parent family & 75.3 & 76.5 & 79.8 & 79.7 & 78.7 & 77 \\
2-Couple/Lone parent families & 1 & 7.5 & 12.7 & 4.6 & 2.6 & 1 \\
P-Couple/Lone parent families & 0 & 1.6 & 2.3 & 0.5 & 0.1 & 0 \\
Total & 100 & 100 & 100 & 100 & 100 & 100 \\
\hline
\end{tabular}

Source: Scottish Executive 2004

Table 5.6 Occupancy rating by number of families and ethnic group, Scotland, $2001(\%)$

\begin{tabular}{lcllcc}
\hline Ethnic group & +2 or more & 1 & 0 & -1 or less & Total \\
\hline All people & 28 & 23 & 26 & 23 & 100 \\
White & 37 & 27 & 24 & 12 & 100 \\
Indian & 33 & 21 & 24 & 22 & 100 \\
Pakistani and Other South Asian & 24 & 19 & 26 & 31 & 100 \\
Chinese & 27 & 23 & 26 & 24 & 100 \\
Other & 22 & 24 & 29 & 25 & 100 \\
\hline
\end{tabular}

Source: 2001 Census, analysis Scottish Executive (2004) 
Table 5.7 BME population in Scotland's major cities, 1991-2001 (\%)

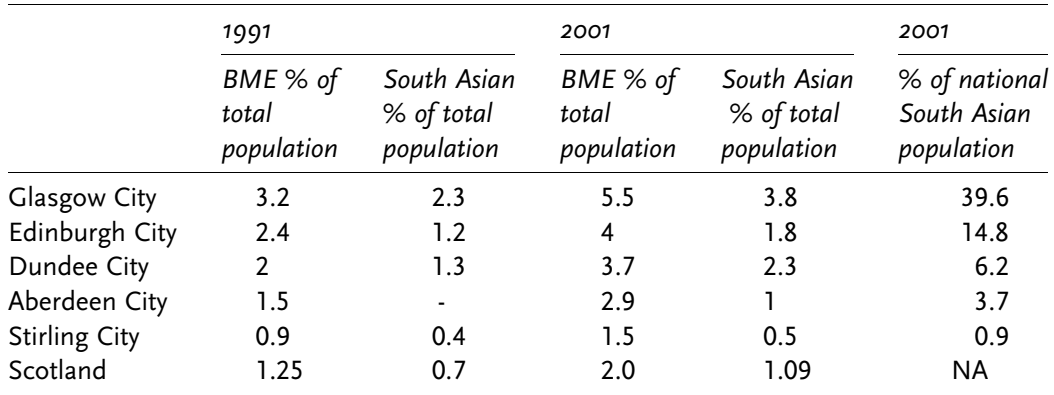

Source: 1991 and 2001 Censuses; author's own analysis

Scotland (see Table 5.7). At national level, 2 per cent of the population is black or minority ethnic, whereas minority ethnic groups in Glasgow City comprise 5.5 per cent of the population. Similarly, 3.76 per cent of Glasgow's population is South Asian, having increased by I.5 per cent of the total population during the decennial census period from I99I. There are few other areas at local authority level that have a black and minority ethnic population that exceeds the national average and as expected these local authority areas are, in the majority, comprised of the major Scottish cities. Besides the cities of Edinburgh, Dundee and Aberdeen, the only other two local authority areas in which the South Asian population exceeds the national percentage of South Asians are the Glasgow suburban local authorities of East Dunbartonshire and East Renfrewshire, whose South Asian populations are 2.I per cent and 2.93 per cent, respectively, of the total population.

To conclude this brief overview relating to age structures, housing situations and household formations by ethnic group, we can summarise by saying that the South Asian population has a much younger age profile than the white majority. Also, differences in tenure are notable with levels of Indian and Pakistani households owning their own home decreasing in line with the white group but remaining significantly higher than other minority ethnic groups, especially black groups. In a similar vein, social rented accommodation is the tenure in which South Asian groups are least likely to live, whilst ethnic minority use of the private rented sector has grown significantly. In terms of multiple occupancies and household composition, the Pakistani groups are most likely to live in multiple family households and in overcrowded dwellings. The South Asian population is also concentrated in the main metropolitan areas particularly in Glasgow City (40 per cent), followed by Edinburgh City (I5 per cent). 


\section{The minority ethnic population in Glasgow}

The minority ethnic population in Glasgow is predominantly Pakistani in origin, young and expanding (Binns 2002). Over the period between I98I and 200I, there was a significant rise in the Pakistani population, increasing by 65.4 per cent, from 7,0I5 to $\mathrm{II}, 605$ between I98I and I99I, and by 32 per cent to I5,330 between I99I and 200I. The second largest ethnic group in Glasgow is Indian (4,I73 persons), followed by Chinese $(3,876)$, those from mixed backgrounds, other ethnic backgrounds, Other South Asian and Black Africans (see Table 5.8).

\section{Traditional settlement patterns}

Traditionally, the ethnic geography of Glasgow has had a crescent shaped distribution, spanning from the South side of the city across the river Clyde intersecting the inner city to North Glasgow and spanning out to the west of the city (Dalton \& Daghlian I989; Kearns 2002). Notably, there has been an absence of minority ethnic groups in the East End working-class areas of the city, the suburban public sector housing schemes (Dalton \& Daghlian I989) and the more affluent suburbs. The core areas of settlement in Glasgow where most of the minority ethnic groups have tended to settle are: Pollokshields and Govanhill on the south side of the city and Woodlands/Charing Cross and Garnethill on the north side (Dalton \& Daghlian I989; Kearsley \& Srivastava 1974) (see Figure 5.I).

Table 5.8 Population of Glasgow City by ethnic group, 2001

\begin{tabular}{lccc}
\hline Ethnic group & Population total & $\begin{array}{c}\text { \% of total } \\
\text { population }\end{array}$ & $\begin{array}{c}\text { \% of BME } \\
\text { population }\end{array}$ \\
\hline White Scottish & 503,614 & 87.2 & NA \\
Other White British & 20,934 & 3.6 & NA \\
White Irish & 11,467 & 2.0 & NA \\
Other white background & 10,344 & 1.8 & NA \\
Pakistani & 15,330 & 2.7 & 48.7 \\
Indian & 4,173 & 0.7 & 13.2 \\
Bangladeshi & 237 & 0.0 & 0.8 \\
Chinese & 3,876 & 0.7 & 12.3 \\
Other South Asian & 2,020 & 0.3 & 6.4 \\
African Caribbean & 302 & 0.1 & 1.0 \\
Black African & 1,257 & 0.2 & 4.0 \\
Other black & 233 & 0.0 & 0.7 \\
Any mixed background & 2,046 & 0.4 & 6.5 \\
Any other background & 2,036 & 0.4 & 6.5 \\
Total minority ethnic population & 31,510 & 5.5 & 100.0 \\
Total population & 577,869 & 100.0 & NA \\
\hline Sourc: & &
\end{tabular}

Source: 2001 Census; author's own analysis 
Figure 5.1 Glasgow neighbourhoods

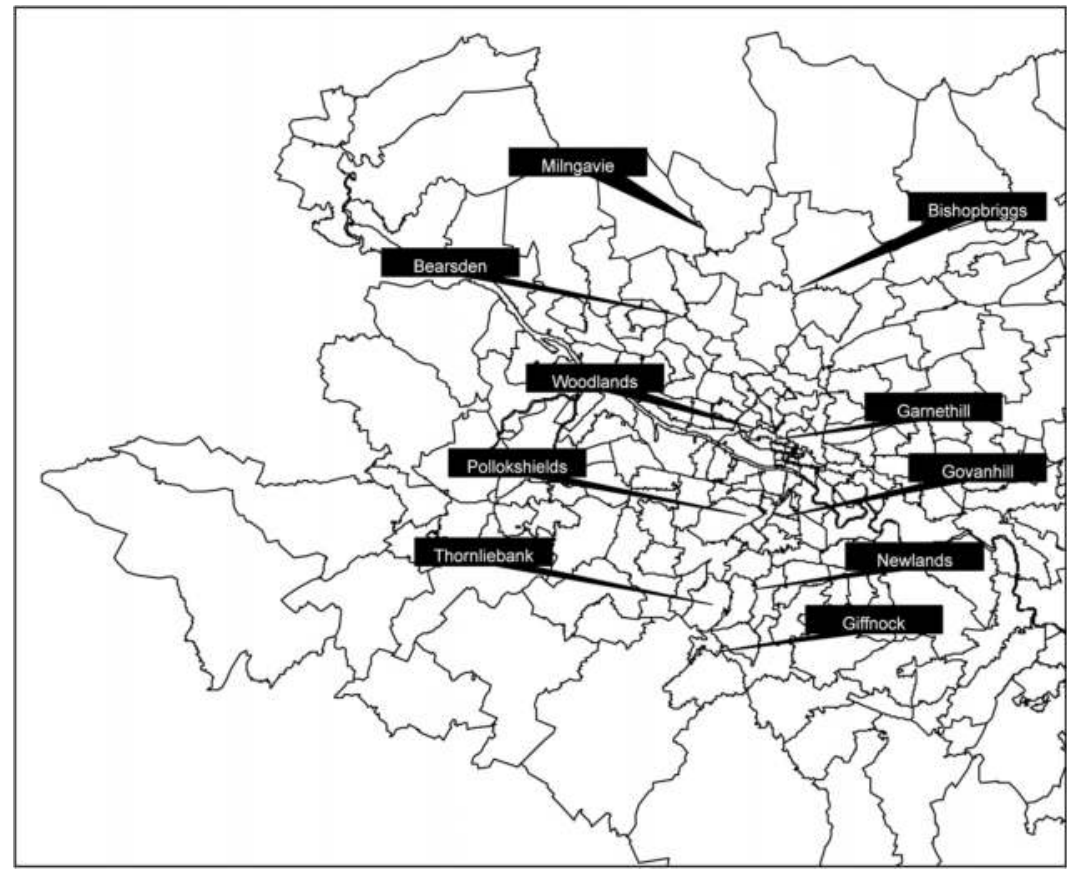

These core areas were shown in the past to be residentially stable, for instance, Dalton and Daghlian (I989) found that the majority of the population had lived in their homes for an average of twelve years. More recent evidence presented in the next chapter would suggest that these areas are becoming more dynamic. These core areas have offered a number of positive features in attracting new households and retaining well-established ones. Namely, the availability of tenement property that was at one time cheap to buy, the cultural, social and economic support networks that have developed in these areas over the last 30 years (Scottish Executive 200I) and the areas' proximity to amenities and easy access to work, schools and community facilities. High minority ethnic presence in these areas is also reflective of the barriers they have faced in gaining access to high status, high cost housing and to public housing (MacEwen et al. I994). There is also an active private rented market situated in these areas (Scottish Executive 200I) attracting in-movers.

Since the late I980s and early I990s, minority ethnic households have begun to establish themselves in Glasgow's middle-class suburbs of Bishopbriggs, Bearsden and Milngavie, to the north of the city, and Newlands and the Eastwood suburbs of Giffnock and Thornliebank, to 
the south (see Figure 5.I). However, to date the literature, albeit limited, suggests the populations of these districts are very small (Dalton $\&$ Daghlian 1989; Binns 2002). More recently, evidence of an expansion can be seen from the established core areas into adjacent postcode sectors (Binns 2002). There is also evidence that minority ethnic households have begun to establish themselves in localities such as Parkhead and Dennistoun in the East End of the city, which until recently were devoid of minority ethnic residents. This evidence of a small spread across the city to areas previously uninhabited may represent a growing confidence amongst the population. Despite this, evidence from both the I98I and I99I censuses suggests that core settlement areas have become denser and have remained residentially stable for South Asian families (Dalton \& Daghlian I989; Kearns 2002).

\section{Traditional settlement patterns by ethnic group}

There has been a significant degree of separation between the various minority ethnic communities in the city. Results from a study undertaken by Glasgow City Council in the late i980s (Bowes, McCluskey \& Sim I990a) and similar results from a study by Dalton and Daghlian (I989) revealed that 66.4 per cent or two-thirds of the Chinese population in Glasgow lived in Garnethill and Woodlands, 73.7 per cent of the Sikh Community (mostly Indian population) also lived in Garnethill and Woodlands, whilst 67.2 per cent of the Pakistani Muslim community were concentrated south of the river. Dalton and Daghlian (I989) contend that this pattern of spatial differentiation has been maintained throughout the post-war period. Current patterns will be explored in the ensuing chapter.

There have been few studies conducted in these neighbourhoods; however, a relatively recent study by Berce-Brathko (200I) attempted to undertake a culturological analysis of Garnethill providing interesting detail of the dynamics of the neighbourhood. Garnethill is situated in Glasgow's inner city and has undergone substantial social change in the past thirty years. Originally it was inhabited by the middle classes, but subsequent to their flight from the area and its rehabilitation, it is inhabited in the majority by South Asian and Chinese households $\left(6_{3}\right.$ per cent), it must be noted that this study is done on a very small scale, reflecting the high percentages. The area is known locally as Chinatown due to the presence of Chinese cultural amenities. There has been an ongoing expansion of the Chinese indoor market located near by which is a central meeting place and now encompasses a temple for worship. The Chinese living in the area make their income primarily from the catering and restaurant business. The survey uncovered that 83 per cent of the Chinese sample had a strong sense of belonging to 
the area and appreciated living there, despite the overcrowded nature of most dwellings. Simultaneously, however, 76 per cent felt that the neighbourhood was neglected. In his analysis, Berce-Brathko concluded that neighbouring was strong and social relations highly developed but found that there was no obvious desire to extend this to other ethnic groups. This was reflected in the fact that, despite many having lived in Scotland for over twenty years, a substantial number of elderly people in the community, especially women, were unable to speak English. This limited social interaction to stay within their ethnic group. Those interviewed about their housing aspirations intended to remain in the area.

By contrast, the majority of Indians and Pakistanis surveyed aspired eventually to move to areas in the South of the city such as Shawlands or to more affluent suburbs, of which Bearsden was cited. In general, those interviewed wanted to move to areas they considered to be more 'respectable'. Only 32 per cent identified strong ties with the area and 63 per cent felt that it needed to be upgraded. Community ties and the social network within this group appeared to the author to be stronger than in the Chinese community. Support between people was more pronounced extending to financial and business help and to other matters surrounding daily domestic and religious life. Cultural and social patterns among the South Asian groups were formed mainly on the basis of their regional or local place of origin, meaning that they tended to mix exclusively within their own communities. The author argues that the South Asian groups are attached locally primarily due to property ownership, thus contradicting, to some extent, prior research that outlines the pull factors of core settlement areas and the agency of cultural choice. The case study fails to explore the relationship between the desire to move and its impact on the strong social networks or the relationship between a strong sense of community amongst the members and neighbourhood satisfaction.

The Scottish people surveyed identified very strongly with the area, taking pride in its history and conservation. The majority of respondents said they were satisfied with the dynamics and ethnic make up of the population providing that their spatial and cultural identity was not 'threatened'. Nonetheless, they showed resentment and frustration towards those members of the minority ethnic communities who had not learnt English and towards those who dressed differently, some also expressed disdain at smells from the kitchens of minority ethnic households. These feelings of hostility triggered by the reproduction of or assertion of differences in language, dress and social mores coincides with Modood and Werbner's (I997) definition of cultural racism. These issues were not explored further, this study being mainly descriptive; however, it is useful in its depiction of the differential ethnic 
experiences and attempts to understand the implications of cultural and ethnic differences for the neighbourhood, as experienced by the various ethnic groups.

\section{Household structure}

The average size of households in Glasgow, in I99I, was 2.4 persons, whilst the average size of minority ethnic households was 4.6 persons (Scottish Office I99I). This has fallen on both counts over the decennial census period to two persons and 3.2 persons, respectively (200I Census; author's own analysis). A survey conducted by the Scottish Office, in I99I, revealed significant variation between ethnic groups, for example, 20 per cent of Sikh (mostly Indian) and Muslim (mostly Pakistani) households were comprised of seven or more individuals compared with only 3.I per cent of Chinese households (Scottish Office I99I). The same survey found that 60 per cent of the white group had two or fewer members, whilst the same was true for only 22 per cent of Indian and Chinese households and only 7 per cent of the Pakistani group. Research by MacEwen et al. (I994) found that only 7 per cent of the white group were made up of two or more family units in comparison to 22 per cent of the Indian community, 25 per cent of the $\mathrm{Pa}$ kistani community and I3 per cent of the Chinese community. The same survey revealed that minority households were more likely to be comprised of combinations of adults and children and less likely to contain only adults over 55 (3 per cent as opposed to 3I per cent for white households), yet they were far more likely to contain individuals from all three age bands (MacEwen et al. I994). The 200I Census shows that there is a continuing higher incidence of over-occupancy related to the larger minority ethnic household size. In Glasgow, 43 per cent of the minority ethnic population live in houses with occupancy rates of minus one or less compared to only 26 per cent of white households (Source: 200I Census; author's own analysis). This shows overcrowding to be a continuing problem and highlights the extended nature of minority ethnic households.

\section{Housing conditions}

Although there has been less research conducted in Scotland regarding minority ethnic groups and housing conditions, a few studies undertaken in the late I980s and throughout the I990s have provided us with some suggestion of the housing conditions in which minority ethnic groups live. A survey conducted by the Glasgow City Council in the late I980 established a correlation between poor tenement property in 
predominantly inner-city locales and Asian settlement (Bowes, McCluskey \& Sim I989). Later research undertaken by Third et al. (I997) also reported a preference amongst the survey respondents to live in tenement properties due to their larger size. MacEwen et al. (I994) found that minority ethnic households in Glasgow were disproportionately over-represented in property that was in severe disrepair. Despite this, Third and MacEwen (I997) reported that minority ethnic households were less likely to have carried out repairs to their home, possibly reflecting financial limitations.

Littlewood and Kearns (I998) undertook a study which specifically focused on housing conditions in five community based housing association areas of operation, within inner-city Glasgow, where there was a presence of both minority ethnic and white households living in below tolerable standard (BTS) housing. Over a quarter of occupants of BTS housing in the inner city were from minority ethnic backgrounds, the majority of whom were concentrated in owner-occupied dwellings. In particular, Pakistani households were found to be markedly over-represented in BTS households, being ten times 'more prominent as innercity BTS occupants than they were city residents' (Kearns 2002: 248). The authors reported that Pakistani and Indian households used BTS housing in the long term, and were more likely to use it as a family home in the child rearing stage of life (Littlewood \& Kearns I998). In contrast, other minority ethnic and white households were most likely to live in BTS housing during transitional periods or in the earlier stages of their housing career. The study uncovered evidence suggesting that tenure choice was constrained by the lack of large affordable accommodation to suit the larger household size. This caused frustration amongst some respondents who had aspirations to move to social rented accommodation.

Minority ethnic households in Glasgow were more likely to experience multiple housing and socio-economic problems than the white households surveyed. One-third of minority ethnic households had serious problems with affordability and were in arrears with housing payments. This was acute for Pakistani households as 40 per cent of the survey respondents were experiencing difficulty, whereas only one-fifth of the white survey group had incurred problems with more general costs. Kearns (2002) points to the seriousness of the situation faced by Pakistani households, as despite the difficulty they incurred in meeting payments, they still had the highest rate of owner occupation. Furthermore, Littlewood and Kearns (I998) found that dwellings occupied by minority ethnic households, most especially Pakistanis, were more likely to fall below tolerable standards due to reasons of lack of amenity and disrepair, whereas for white households it was more likely due to underground instability as a result of past mining activity. Overcrowding 
was the most acute housing problem faced by minority ethnic groups and was experienced by more than two-thirds of those surveyed compared to less than one-third of white households. This was more of a problem in households where there were dependent children and is accounted for in the report by extended family living. Interestingly, more survey respondents from the white population identified lack of amenities and overcrowding as a problem than minority ethnic respondents. Kearns (2002) suggests that this may indicate a lack of awareness among minority ethnic respondents that their property is in fact substandard.

\section{Tenure patterns in Glasgow}

In general, tenure patterns in Glasgow are not entirely consonant with wider patterns in Scotland (see Table 5.9). The overall total percentage of households in owner occupancy ( 56 per cent) is substantially lower than that at the national level (64 per cent). However, the proportion of Indians in owner occupation is higher, as has been the trend in the past. In particular, 7I per cent of Indian households in Glasgow are in owner-occupation, higher than the national rate of ownership for this group ( 65 per cent), whilst a lower number reside in the private rented sector (I8 per cent) than at the national level (25 per cent).

The proportion of minority households in the public sector continues to be very low indicating that perhaps the causes determining this, which have been documented in the literature, continue to be prevalent. The remainder of this section seeks to provide a review of research previously conducted in the private rented sector, the social rented sector and the owner-occupied sector.

\section{Private renting}

The private rented sector is probably the most under-researched sector in Scotland with regards to minority ethnic groups and housing.

Table 5.9 Tenure by ethnicity in Greater Glasgow, 2001 (\% of households)

\begin{tabular}{lcccccc}
\hline Tenure & All people & White & Indian & Pakistani & Chinese & Other \\
\hline Owner-occupied & 56 & 56 & 71 & 64 & 64 & 35 \\
Council & 26 & 26 & 6 & 8 & 11 & 23 \\
Other social rented & 9 & 9 & 5 & 7 & 5 & 10 \\
Private rented/free & 9 & 9 & 18 & 21 & 20 & 32 \\
Total & 100 & 100 & 100 & 100 & 100 & 100 \\
\hline
\end{tabular}

Source: 2001 Census; author's own analysis 
Results from the I99I Census revealed a larger proportion of minority ethnic households to be represented in the private sector than was average for the total population, with the Chinese group being most highly represented. Bowes et al. (I997) maintain that the higher proportion of minority ethnic groups sharing facilities or without basic amenities can be attributed to their over-representation in the private sector. However, other research revealing evidence of below tolerable standards in the owner-occupied sector (Littlewood \& Kearns I998) questions this. Research conducted in the mid-I99os in Govanhill (Dalton \& Hampton I996) revealed a substantial increase of minority ethnic groups in the private rented sector, later reflected in 200I Census figures (see Table 5.9), which showed the doubling of this group in the sector since I991. This may signify a shift in housing choices of the minority ethnic households; however, this is surprising in the light of research, mentioned earlier, which was conducted by Littlewood and Kearns (I998) that reported 48 per cent of the Pakistani respondents resident in the private rented sector expressed a desire to move to the social rented sector. This may indicate that current tenure distribution amongst minority ethnic groups is a result of constraint, though the issue merits more research.

Research conducted in the I990 by Wainwright, Murie and MacEwen (I994) found that almost all immigrants rented privately on their arrival to Scotland. They also found that minority ethnic groups' experience of the private rented sector was in general unsatisfactory, with specific difficulties in relation to the condition of the housing, the attitude of the landlord and the level of rents. Among the group surveyed, housing standards were poor, none of the respondents had central heating and several expressed concern regarding the expenses that heating the house would incur. The most severe cases relayed experiences of being exploited by landlords. The Scottish Household Condition Survey (I996) rendered the private rented sector the worst tenure, excepting the local authority sector, for dampness and condensation and for energy efficiency. Research reveals a correlation between this sector and below tolerable standard housing; it is likely that this is related to the age of the buildings themselves (GCC 2002). More generally, there has been recent evidence that the sector is improving in Glasgow. Since the de-regulation of rents in 1989, the private rented sector that had previously been in long-term decline began to grow and expand, with a 50 per cent increase in the number of properties rented between I991 and 200I (ibid.). The location of private rented stock in Glasgow is predominantly inner city with the largest concentrations being in Pollokshields, Govanhill/Mount Florida, Shawlands, Langside and the West End, amongst which include areas of core minority ethnic settlement in the city. Despite earlier findings, the Local Housing 
Strategy for Glasgow City Council (2002: 8) maintains that there has been, 'a substantial improvement in physical conditions overall'. This has largely been attributed to the appendage of a substantial amount of property to the upper end of the market, improvement by landlords, BTS treatment in Housing Action Areas, improvement and repair grants and the purchase of poor quality property by buyers who wanted to renovate for rental purposes. Overall, this suggests that the sector has become more desirable; however, more research must be conducted to ascertain the impact this is having on the growing representation of minority groups in the sector.

\section{Local authority housing}

As is characteristic of the rest of Britain, particular minority ethnic groups are seriously under-represented in social housing. This is shown by the small percentage in council lets in Glasgow City, which has actually fallen in absolute terms, from I4I households in 2000/ $200 \mathrm{I}$ to 82 in $200 \mathrm{I} / 2002$ (this figure also includes refugees and asylum seekers, which renders it problematic as a useful indicator) (GCC 2002). In the council and other social rented tenures there are a higher proportion of minority ethnic applicants than tenants, with the proportion of minority ethnic applicants being much lower for the Council than for housing associations (Binns 2002). Bowes, McCluskey and Sim (I990b: 526) found in earlier research that there appeared to be a relatively 'positive orientation' towards council housing by the younger generation of the Asian population in Glasgow; however, access was hampered by a lack of knowledge of the system. In their survey, only 42.8 per cent of the sample had any knowledge of what qualifying for a house involved. Half of the Pakistani sample had some knowledge, but amongst the Chinese and Indian communities only 30 per cent had any knowledge at all. Only I4 per cent of the sample had actually previously applied to council housing, this was highest amongst the Pakistani communities and lowest among the Indian and Chinese community. Within the core areas, where minority ethnic households have traditionally settled, there is very little social rented housing, and that which does exist is disproportionately occupied by white tenants. Much of Glasgow's public housing stock has been primarily situated in peripheral schemes, which have not been popular with minority ethnic applicants, and indeed amongst other applicants, due to their perceptions of neighbourhood safety. Wainwright et al. (I994) found that minority ethnic experiences in social renting (and to some extent in private housing) involved racial harassment and violence which tended to steer their housing preferences toward owner occupation. 
MacEwen at al. (I994: 22) argue that housing policy since I980, namely, the mandatory sale of council housing and cuts in new stock, has eroded both the 'fiscal and political autonomy of local government'. This has severely curbed the capability of public housing in promoting access for minority ethnic groups. Further attention is drawn to this by the Scottish Executive Audit (2002), which argues that policies that affect the supply of public housing have a significant bearing on the potential success of allocation policies in providing access to housing that is both desirable and suitable. The low rates of new building and simultaneous sales of council housing have resulted in a decline in the quality and quantity of dwellings available in Glasgow. The small size of existing apartments, with the majority of larger accommodations being sold under right to buy, is creating a mismatch between existing stock and minority ethnic needs (MacEwen et al. I994). Binns (2002) draws attention to a more recent survey by Glasgow City Council that found ethnic minority applicants for council housing most commonly to be families in need of larger accommodation due to larger family sizes. The same survey presented evidence to suggest that the majority of those still waiting for council housing (which was in fact the majority of the minority ethnic applicants) were often unsuccessful due to the profile and location of the stock.

In a city with a significantly high proportion of council housing, the low proportion of minority ethnic tenants is especially poignant. Bowes et al. (I990b) endorse the findings of Henderson and Karn (1987) who contend that minority ethnic households are effectively excluded from council housing as a result of discrimination in the allocation process. Legislation in both England and Scotland gave local authorities autonomy to develop both their own allocation policies and criteria upon which individuals' eligibility is determined (MacEwen et al. 1994). Evidence from previous studies outside Glasgow suggests that where there is discretion in an allocations system on the part of the housing authority it tends not to be used to favour minority ethnic applicants (Henderson \& Karn I987). This may be less so now, however, does not appear to be a practice only of the past as South Asians continue to fare badly in accessing council housing.

Bowes et al. (I990b) conducted a study examining council housing from the consumer's point of view, seeking to determine the extent of people's knowledge and their attitudes and experiences of council housing services in Glasgow. They found that the system of allocation in Glasgow seems to be coping poorly with the housing aspirations of Asians. Many minority ethnic applicants were allocated housing quite far away from family, friends, local amenities and places of worship due to a lack of sufficient points. The authors argue that this is due to the discriminatory nature of the points system itself, as it prioritises 
waiting time over housing need. Their findings were not particularly encouraging: over 50 per cent of respondents stated that families in council schemes 'were isolated and subjected to harassment' (I99ob: 525); 45.3 per cent 'agreed' or 'strongly agreed' that 'officials did not treat minorities fairly'; and 43.8 per cent agreed or strongly agreed that the housing offered to minority ethnic families was poor. The views of the Pakistani respondents were more negative than the views of the Indian and Chinese groups: 47.4 per cent had difficulties in the process of applying for council housing; 50 per cent of these respondents said they had difficulty obtaining information; 42.I per cent had difficulty completing forms and reading leaflets; whilst others had difficulty obtaining accommodation in the area of their choice.

Over the past ten years, changes in policy and practice have, however, led to the emphasis in research being shifted from discriminatory allocation policies to policies that have bearing upon the type of dwellings offered to minority ethnic households. The process of matching applicants to suitable housing has become increasingly difficult as stock has become more varied in age, design and condition. Other studies considering the role of the gatekeeper reveal that assumptions have been made about what constitutes appropriate accommodation and also about the locale in which the dwelling is situated as deemed best to suit minority ethnic needs. These judgements on the part of housing officers have been based upon both stereotypes and suppositions of the preferences of minority ethnic households, ironic in a time when housing policy aims to promote choice (Bowes \& Sim I997). MacEwen et al. (I994) maintain that this is in some measure due to the pressure placed upon housing officers to fill vacancies quickly and to the fear of how they would manage problems which may arise if minority ethnic households were housed in white areas. In an attempt to avoid such problems, the general trend of the allocation process has been to offer housing to minority ethnic groups in older estates that have a relatively higher prevalence of other minority ethnic tenants. The same authors, drawing on Henderson and Karn's study of Birmingham in the late I970s, argued that emphasis should be placed upon policy implementation, rather than upon formal housing policy as discrimination is more notable in the actual allocation process than in legislation. Attempts to diffuse the problems associated with the allocation process, in Scotland, have included strategies such as staff training to increase their awareness of stereotypes; increased ethnic monitoring; prosecutions for those perpetrating harassment; active equal opportunity programmes; and anti-racist agendas. Many of these strategies were made mandatory with the Race Relations Amendment Act 2000 , in which active inspection of public bodies is used as an incentive to increase the accountability of local authorities. Employment 
of more staff from minority ethnic backgrounds (who are still underrepresented in public sector employment), which has aimed to overcome language barriers, has been pursued to try to empower minority ethnic groups. To date, there has been no clear evaluation of the outcomes of these measures in the Scottish literature.

\section{Housing associations}

Scotland's housing associations, in comparison with England, have in the past been accused of being slow and resistant in placing issues surrounding fair access for minority ethnic groups onto their agenda (MacEwen et al. 1994). Sim (I99I) highlighted the deficiency of the Scottish Federation of Housing Associations (SFHA), stating that it has adopted a 'colour blind' approach to its work even when it is present in areas of high minority ethnic settlement. In Scotland, he maintains that any initiative was left to the Housing Corporation (later to be Scottish Homes now Communities Scotland). In response to published guidance in England for equal access and good practice in 1982, Scottish housing associations began to develop a stand-alone code of practice in 1986; however, this was rejected and instead incorporated into ongoing reviews on housing management practice. Sim (I991: 40) asserts that this is reflective of the long-standing notion that there is 'no problem', with regards to equality, in Scotland.

Despite the geographical scope that major housing associations in Glasgow have had in terms of potential to target minority ethnic groups, actual outcomes are severely imbalanced, to the detriment of minority ethnic applicants. Previous studies on this sector, in the I980s and I990s, elicited examples of institutional discrimination spanning from actual allocations criteria, lack of awareness and knowledge, waiting list exclusion policies and waiting times to local connection points. Glasgow-specific research has uncovered specific areas of bad practice with regard to access. Eligibility criteria disadvantaged home owners, which was significant considering 7 out of to of the minority ethnic residents in Glasgow's inner-city areas, at the time of this study, were home owners (Mac Ewen et al. 1994), this has since decreased to around 6 out of Io. Many of these home owners were in need of re-housing due to the state of disrepair of their homes and problems of overcrowding; evidence suggests that this is still true (Littlewood \& Kearns 1998; Kearns 2002). Advertising and marketing were found to be inefficient and exclusionary, often being informal and by word of mouth. This compounded with discretionary allocations, based on local connection points rather than need, limited the chances of minority ethnic households becoming tenants (Dalton \& Daghlian I989; MacEwen et al. 1994; Bowes et al. I990b). A further study, 
conducted for Scottish Homes, in the early I990s, found that minority ethnic interviewees perceived access to housing associations to be restricted, which may affect confidence in even making an application (Scottish Homes I994). Further criticism has been made of housing associations with respect to special needs, as many such applicants have experienced multi-faceted discrimination on grounds of ethnicity and special requirements (Scottish Office I99I). Subsequently, the law changed to take such issues into account with the Housing (Scotland) Act 200I, which promotes equality of opportunity based on need, stipulating that landlords must ensure they take into account the 'needs and circumstances of all relevant groups, including, for example, information for disabled people on the availability of suitable houses and adaptations' (Scottish Executive 2002b: 4). It was also stipulated that local authorities and registered social landlords give reasonable preference in housing allocations to those who live in below tolerable conditions, occupy overcrowded houses or have large families.

\section{The Glasgow Housing Association}

The Glasgow Housing Association (GHA) is now the largest social landlord in Glasgow as a consequence of the stock transfer of council housing. Management of the stock is planned to be devolved to 78 local housing organisations (LHOs), each are responsible for race relations and equal opportunities in their representative areas (Binns 2002). The GHA developed an Equality Action Plan that has a built in capacity to take whatever action is necessary to guarantee equal access and equal treatment. Each LHO must adopt the same equal opportunities policy, and members and managers are obliged to undergo a training programme in order to implement this. A black and minority ethnic tenant participation group has been established with the aim of recruiting minority ethnic representatives. Glasgow's Local Housing Strategy 2002 (Binns 2002), stipulates that LHOs should ensure that all tenants are treated equally and that there is access to all ethnic groups, regardless of the presence of minority ethnic households in their respective areas. The principal reason being that until minority ethnic groups are assured that they can live securely outside core settlement areas then they, 'will not gain equal access to improved housing in many parts of the city' (2000: I3). Binns outlines proposals made in a local housing strategy options appraisal seminar (October 2002), which was aimed at specifically improving services for minority ethnic households in Glasgow. He lists the four main strategies for inclusion in the local housing strategy: 
- All agencies which own or manage social rented housing should ensure that all staff undertake racial awareness training as part of their Equality Action Plan;

- City-wide social landlords should set appropriate targets for each area of the city to increase BME residence;

- BME-targeted budgets should be ring fenced within development funding programmes;

- Glasgow City Council should support the establishment of a BMEled housing association, to act either as a landlord, a service provider for other social landlords or in both capacities.

Other proposals, subsequent to the four listed above and deemed most important, included positive action to increase minority ethnic employment in public agencies, the development of an outreach team to recruit management committee members and a drive to 'equality proof' allocation offers. The latter was to ensure that minority groups are made offers in appropriate areas and that they are not penalised for refusing offers in areas that they consider lacking in security (Binns 2002). The local housing strategy also asserts that the urgency for the GHA to make its services accessible to minority ethnic households is greater, considering the higher number of minority ethnic applicants compared to council housing and due to the scale of stock transfer. The success of these measures remains to be seen, as little recent research has been conducted and only time will reveal the impact of the housing associations' new capacity.

\section{Owner occupation}

As alluded to previously, the vast majority of the minority ethnic population is represented in the owner-occupied sector. However, evidence from both England and Scotland indicates that at times minority ethnic buyers find the process of becoming and remaining an owner occupier extremely challenging. These challenges primarily relate to racial discrimination by gate-keepers, limited financial capacity, limited awareness of different types of housing, multiple deprivation, frequency of mortgage arrears, limited mobility, and both indirect and direct discrimination.

Tenure structures between ethnic groups in Glasgow are contrasting, with almost 70 per cent of the South Asian population living in owneroccupied housing compared with $5^{6}$ per cent of the white population (Table 5.9). The literature provides overwhelming evidence to suggest that minority ethnic groups in Glasgow show a preferential orientation toward owner occupation (Wainwright et al. I994; Bowes \& Sim 1997). Bowes et al. (1990b) reported that 70 per cent of minority ethnic 
respondents from their survey sample preferred to own their own home. Pawson, Third and Wainwright (I996) found the same preference in research they conducted in Leith (Edinburgh). A further study, conducted by MORI (2000), reports that this is the case due to the security it is perceived to afford.

Adding another dimension, Bowes et al. (1997) argue that, in line with a large body of literature south of the border, despite a preference for owner occupancy, choice for individuals from a minority ethnic background is substantially constrained. They contend that the preference to live in owner-occupied housing may be reflective of the limitations associated with gaining access to housing in the social rented sector. Research undertaken by Third et al. (1997) indicates that, despite preferring an alternative, one-third of minority ethnic respondents were forced into owner occupation. More than twice as many minority ethnic owners in the sample as white respondents say that they had 'not very much' or 'no choice at all'. In the same vein, research conducted for Scottish Homes (MORI 2000) negates any correlations that may be assumed to exist between the over-representation of minority ethnic groups in the owner-occupied sector and high household income. The research also concludes that any move into owner-occupied housing was done so without full knowledge of other alternatives. Despite this, the consensus of the respondents in the Scottish Homes survey was that owner occupancy was their preferred tenure choice (MORI 2000).

Indeed, evidence from other studies suggests that the experience of owner occupancy for many is an arduous one and that minority ethnic homeowners are more likely to live in homes below tolerable living standards (MacEwen et al. I994; Kearns 2002). Kearns (2002) found that the incidence of problems such as overcrowding, affordability and lack of amenities to be significant amongst the minority ethnic population in inner-city Glasgow. One in three home owners from Third et al.'s (I997) survey sample lived in overcrowded conditions, compared to one in fourteen in the white sample. In addition, minority ethnic households were found to have more difficulties in both arranging mortgages and in the upkeep of their payments, leading to mortgage arrears (Kearns 2002).

\section{Housing purchase and finance}

Third et al. (1997) found that more households from the minority ethnic population than other groups lived in the immediate locality prior to purchasing the house that they now lived in. This may be demonstrative of financial limitations and the need to stay in the inner-city 
area where housing is cheaper and not necessarily a desired end. The authors conclude that movement into owner occupation is done so within a system of structural constraints, which is not only limited to a lack of tenure alternatives, but to difficulties experienced by minority ethnic groups in purchasing. In line with this, there is substantial evidence in the Scottish literature of direct and indirect discrimination within financial bodies. Bowes and Sim (I997) maintain that particular areas, often those that are cheaper with poor quality housing, are redlined by mortgage lenders. Concomitantly, evidence suggests minority ethnic groups experience increased difficulties in arranging mortgages, exacerbated by the fact that they are more likely than the white population to be self-employed (Third et al. I997). Earlier research by Wainwright et al. (I994) established a significant correlation between housing experience and employment, emphasising the limitations that economic and employment factors placed upon housing situations and choices. Self-employed minority ethnic households were struggling to maintain their homes, as many had invested the majority and sometimes all of their available assets into their business leaving them with a meagre income (ibid.).

In response to difficulties with financial bodies and estate agents, past research has verified the existence of a housing submarket within the South Asian community. Third et al. (I997) found 23 per cent of South Asian owners and only 2 per cent of white owners in their survey bought their home from a South Asian vendor. Minority ethnic house buyers were more likely than members of the white population to have known the person from whom they bought their house (ibid.). A further study of Pakistani tenure preferences in Glasgow conducted by Bowes et al. (I997) verified this. They reported that formal methods of searching for housing were much less likely to be used, whereas personal contacts and word of mouth constituted the most common way of finding a house. Third et al. (I997) also reported that a greater proportion of the white population found it easier than the minority ethnic population to find suitable housing that was affordable.

Scottish research in this area lacks a focus upon the experiences of different occupational classes. Fenton's (I977) research on a small group of South Asian households in Manchester who suburbanised in the late I970s elicits differential experiences to those often characterised by constraints. The household characteristics of the minority ethnic households, including income, were similar to those of the white population in the area. The respondents bought their homes through estate agents and newspapers and financed the purchase using loans from building societies, paying only a small deposit. Fenton concluded that, excepting the significance of the increased prices 
South Asians paid for equivalent housing, there were few differences between the two populations.

\section{Housing need, preference and location}

Recent research seeking to uncover minority ethnic housing need and preference has overwhelmingly uncovered that propensity to move, self-assessed housing need and household preference is determined by a fine balance between space and location (Dalton \& Hampton i996; Bowes et al. I997; Sarre et al. I989). The need for both large and reasonably priced accommodation has emerged frequently in past research. Studies conducted in Scotland have related the importance of space, not only to the traditionally larger household size and the subsequent tendency for minority ethnic households to be overcrowded, but also to the need in Muslim households for separate facilities for men and women (Bowes et al. I997). Likewise, Dalton and Hampton (I996) noted the importance of having a private kitchen to provide space in which women could socialise, whilst men socialised in the main reception room.

Bowes et al. (I997), reiterating Sarre et al.'s (1989) earlier work, established the presence of a trade-off between a particular home and a particular area. In most instances, areas that were perceived as being unsafe were avoided, even if the highest quality and most desirable homes where located there. Similarly, Wainwright et al. (I994) conducted research that highlighted the correlation between neighbourhood problems and racism in Scotland, thus a high premium was placed upon safe residential areas for minority ethnic households. Areas that were perceived to be safe, in the same study, tended to be those with a prevalence of other minority ethnic households. Despite the prevalence of close proximity to family and friends informing residential preference, a survey for Scottish Homes (MORI 2000) reported a higher importance being placed upon proximity to community facilities. Contrary to this, Third et al. (I997) reported a preference among 23 per cent of their South Asian sample to live independently from their family. These findings can be compared to a recent study by Phillips et al. (2003) conducted in Bradford and Leeds, which found that the younger generation and a number of female respondents felt constrained by the close-knit nature of the ethnic community in the core. Slightly less than one-fifth of respondents thought that a preference to live out with the core community locale would be informed by the desire for increased privacy and independence. Some respondents also noted that this could only be achieved after intense negotiations with their family and others maintained that they could not move due to 
cultural obligations, despite a preference to do so (Phillips et al. 2003). Thus, in conjunction with the traditional descriptions of constraints, cultural constraints are coming to the fore in constraining residential preferences.

Littlewood and Kearns (I998) found that even though levels of neighbourhood dissatisfaction were higher among white groups the margin was very narrow. In contrast, however, more minority ethnic households than white households said they had a desire or need to move home, yet less had undertaken any course of action to do so. Neighbourhood dissatisfaction (classified as a need in the survey) was the need that was associated with the most significant level of desired mobility. Kearns (2002: 259) contends, albeit with a cautionary note against any over assertion of the importance of the core neighbourhood in the light of increased mobility, that this 'indicates how important the neighbourhood context is for residential satisfaction among ethnic minorities'. Three earlier studies (Bowes et al. I989, Wainwright et al. I994; Third et al. I997) indicate that the neighbourhood was more significant as a determinant of housing choice and satisfaction for minority ethnic households than white households. Bowes et al. (I989) also reported that neighbourhood satisfaction was related to 'good neighbours' and 'unfriendly neighbours' as being the most significant determinant of locational preference. This point is of interest as earlier we discussed the case of Pakistani and Indian households residing in Garnethill, and although a high dependence on neighbouring households and the local social network was noted, so too was a pronounced desire to move from the neighbourhood to the south side of Glasgow or to more affluent suburbs (Berce-Bathko 200I). This calls into question long-standing models of residential satisfaction. For example, Kasarda and Janowitz's (I974) model contended that residential satisfaction is dependent upon social networks, social interaction and close proximity to relatives, which they link to length of residence. It appears that one may need to separate the neighbourhood from the neighbours in any future analysis of neighbourhood satisfaction in order to ascertain the impact of environmental and structural factors and individual determinants. It is not clear from past research in Scotland to what degree the neighbourhood context in which minority ethnic people desire to live and subsequent neighbourhood satisfaction is dependent on the residential environment, neighbourhood attributes, socio-economic and class factors, presence of other ethnic minorities or other background variables. Residential satisfaction may be met by the presence of other minority ethnic groups so long as there was an absence of harassment as suggested by several studies.

Scottish studies concerned with housing aspiration have been few, although one survey by MORI (2000) for Scottish Homes revealed the 
foremost desire among minority ethnic respondents was for a large home (preferably more than four bedrooms). The house types that were considered most desirable were detached houses followed by tenement flats. Future housing aspirations also included a desire to remain in the owner-occupied sector (MORI 2000). Respondents also indicated aspirations to own a home on the outskirts of the city, and maintained that acquiring a larger house with a garden would act as an impetus to move. Three quarters of the respondents intended purchasing their next property through a mortgage lender. These factors combined with aspirations to move to the outskirts of the city may indicate an increase in purchasing power, which could possibly be linked to economic achievements in the labour market or a better negotiation position than in the past. In terms of preferred areas for potential relocation in Glasgow, those mentioned by respondents were Bearsden, Giffnock, Newton Mearns, Bishopbriggs and Milngavie; these areas are middleclass, predominantly owner-occupied suburbs. Other suburbs of the city were mentioned, albeit less frequently: Jordanhill, Newlands, Anniesland and Kelvindale. The main constraints mentioned in realising these aspirations were financial and the fear of stereotypes. These findings are similar to those of several studies in England, which have correlated occupational advancement and changing settlement patterns (Ratcliffe I996; Phillips I998). Still, these aspirations are significant as they indicate the emergence of a preference among some of Glasgow's minority ethnic community to move out of the inner city to the suburbs.

There were considerable differences in housing aspirations by age in the MORI survey. Middle-aged and elderly respondents were more likely to express a preference to remain in the core inner-city areas of settlements to be close to amenities, due to the presence of a strong social network and for reasons of security. Alternatively, those respondents aged between 25 and 30 were more likely to want to move out of the inner core settlement areas and were comfortable with living in 'mixed' areas (MORI 2000). Different housing aspirations within the minority ethnic community are not surprising, but significant in terms of their future spatial distribution and the characteristics of the population remaining in the inner city.

\section{Conclusion}

The Scottish literature paints a picture of an expanding and young minority ethnic population. There remain particular gaps in the literature, including a lack of research on the housing careers, preferences and future aspirations of minority ethnic groups and the factors and 
motivations influencing residential choice and mobility. Similarly, there has been little research into the actual process of ethnic clustering and neighbourhood attachment in these areas, rather the main body of literature has tended to focus on issues of tenure and housing condition. There are other gaps in the knowledge base, primarily relating to explanations for housing tenure and the role of the neighbourhood that we do not understand from existing research. We do not know why there has been a rise in private renting among the minority ethnic population and whether this is due to rising prices in the owner-occupied sector, rising standards in the private rented sector or changing preferences among younger households. It is also unclear as to why there has been no expansion into social renting and whether previous constraints still apply. Or, indeed, if there is increasing interest in this sector now that the stock is being transferred from the council to GHA. There are also questions left unanswered regarding the attraction of owner occupancy for minority ethnic groups, if it is for the same reasons as for whites (financial security, freedom, etc.) or due to security in other terms, such as avoidance of harassment and threats to safety in other locations or continued weaknesses in the social rented sector. In terms of explaining the role of the neighbourhood in shaping residential choices, there is lack of clarity on how several factors mentioned in past research fit together. First, whether or not local moves within the neighbourhood are due to the informal mechanisms involved in house purchase, related to the core community or due to house price constraints. Second, comes the question of whether the neighbourhood is particularly important for the aforementioned reasons or for reasons of wanting good neighbours, more than other returns from the neighbourhood, such as status and investment returns. 



\section{South Asian settlement in Glasgow: Changing patterns of residence}

\section{Introduction}

Any comprehensive attempt to understand the residential preferences of minority ethnic groups must begin by defining actual residential locations and by identifying changes which these have undergone in recent years. The last chapter highlighted the gap in the Scottish literature regarding minority ethnic residential settlement, housing choices and preferences. It set the scene by providing a summary of the housing experiences of minority ethnic households: first, with a brief overview at the national level, then more in depth at the city level. Evidence of localised settlement patterns and the question of whether they are changing have not been studied over the past ten to fifteen years in Glasgow. In response, this chapter tries to address the gap in the literature by analysing patterns of location and trends across the city region over the census period from I99I to 200I. Other primary aims of this chapter are: first, to explore the extent to which South Asian households are relocating to or establishing themselves in the suburbs, which will lead us to discussions on the significance of and motivations behind residential dispersal in later chapters; and second, to analyse how population shifts in the suburbs compare to changes within the core and within areas adjacent to the core, which will enable issues surrounding the continued attraction of the core and its neighbouring vicinities to be considered together with issues related to housing mobility. The area of study used in this analysis, as outlined fully in Chapter 4, is Greater Glasgow, i.e. Glasgow City and its surrounding districts, which encompass the suburbs. After identifying changes in the ethnic geography, this chapter will focus in at a smaller scale to look at neighbourhoods chosen as case studies in which qualitative research was conducted with individual households. Thus, in the previous chapter and in the current one we have descended from the national level to the metropolitan area to the neighbourhood.

The chapter is structured as follows. The first section draws attention to the traditional core areas of ethnic settlement, considers their geographical location in the city and details changes in these ethnic clusters over the decennial census period from I991. Section two 
concentrates on evidence of the wider dispersal and suburbanisation of the South Asian population across the study area, while section three explores settlement patterns at a smaller scale within the areas of greatest change and those areas that have the largest South Asian populations. In section four, indices of dissimilarity, segregation and exposure are computed. In light of the census analysis, section five provides a rationale for the selection of the case study areas and area profiles.

\section{Clustering in the inner city: Localised change}

The present section focuses primarily on the areas of core settlement in Glasgow's inner city. However, attention is also given to the population changes in areas adjacent to the area of core settlement, which may indicate overspill from the core or localised patterns of dispersal. Before commenting on any changes over the census period the I99I geography will be detailed.

\section{South Asian distribution 1991}

In I99I, the ethnic geography of Greater Glasgow, as seen in Figure 6.I, mirrors the pattern of that previously described in the literature presented in the previous chapter, spanning from the west of the city, broken by the River Clyde, through the inner-city areas to the south of the city. Focusing on the South Asian population, we see it to be predominantly centred in the areas surrounding the inner city to the west and the south of the city, whilst also expanding to the neighbouring suburbs. The core settlement areas identified both from the literature and by their community infrastructures, which include numerous religious and cultural facilities, are easily located on the map as the areas with the highest proportion of South Asians of the total population. There are two main clusters of South Asian groups, one on the south side of the River Clyde, in the area of Strathbungo and Pollokshields, and one directly north in Woodlands in the West End of the city, though the proportion of South Asians never exceeds 33 per cent of an area's total population (see Figure 6.2 to locate the neighbourhoods).

The area, in I99I, that had the highest percentage of South Asians was the Strathbungo/Pollokshields area to the south of the river, representing slightly over 33 per cent of the total population (predominantly Pakistani). The area with the second largest South Asian percentage of the total population, 24 per cent, was the postcode sector east of Pollokshields and Strathbungo, Crosshill. Similarly, the other postcode sectors neighbouring this area had between 5 and I5 per cent of their populations comprised of South Asian groups. 
To the north of the River Clyde in the west of the city the area with the largest South Asian population (22 per cent of the total population) was the postcode sector of $\mathrm{G}_{3} 6$, which is comprised of the areas of Woodlands and Garnethill. The main South Asian community infrastructure here is established in Woodlands, which is the only area with a wide range of cultural and religious facilities for Pakistani and Indian groups north of the river. Adjacent to Woodlands is Port Dundas, which had a similar absolute number and proportion of its population (20 per cent) comprised of South Asian groups. As with Pollokshields and Strathbungo in the South, several of the postcode sectors neighbouring Woodlands had between 5 per cent and 20 per cent of their populations comprised of South Asian groups, namely, the university area of Hillhead and Maryhill.

Outside both of the aforementioned areas, despite evidence of smallscale dispersal to the suburbs, no other areas had more than 5 per cent of their populations comprised of South Asians. This fact reveals that the I99I population was overwhelmingly resident in inner-city locales.

\section{South Asian distribution 2001}

The 200I Census, however, revealed some interesting localised changes. The areas of core settlement that are often characterised as being static and concentrated are shown to be dynamic, with notable changes on a local level and in the areas adjacent to them. Additionally, when the South Asian group is further differentiated we see interesting population shifts. As is evident from a comparison of Figures 6.I and 6.3, the areas that had the highest proportion of their overall

Figure 6.1 Distribution of South Asian population (\% of the total postcode sector population), 1991

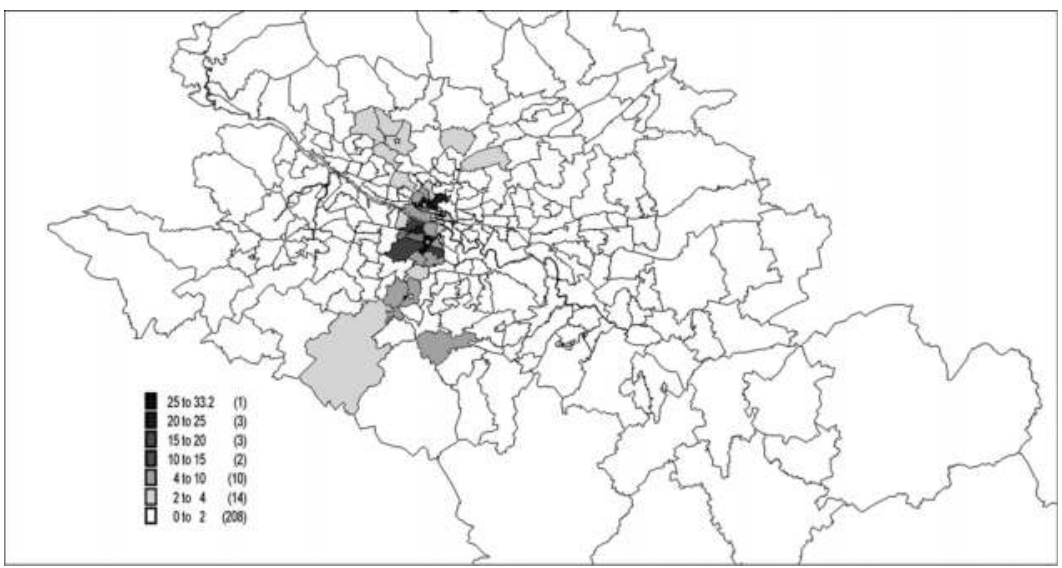


Figure 6.2 Glasgow neighbourhoods

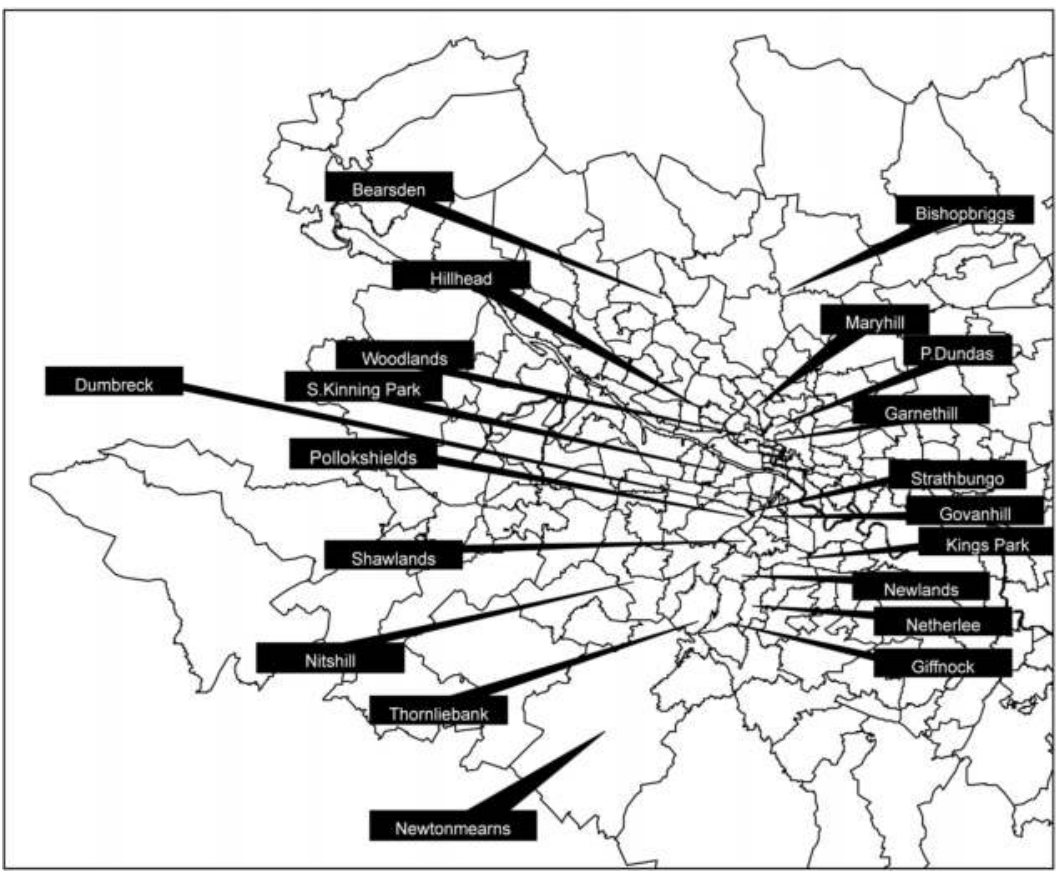

population comprised of South Asian groups in I99I remained mostly similar. However, some interesting changes can be seen across not only the whole study area, which will be discussed in depth later, but also within the main ethnic clusters to the west and south of the city.

The core settlement area of Strathbungo remained the area in the city with the largest South Asian population in both absolute terms $(3, \infty \circ)$ and as a proportion of the total population $(36$ per cent). However, the population growth over the study period was less than that of some of the surrounding localities. At 300 persons, it represents a 2.5 per cent growth in the South Asian proportion of the total population of the area. Thus, the area has remained stable rather than experiencing a large growth in its South Asian population. By contrast, the postcode sectors that are adjacent to, or on the border of, the Strathbungo area experienced substantial growth in the percentage of their populations who are South Asian (see Figure 6.4). The area in the city with the largest proportional and absolute change in its population is Dumbreck, where the South Asian population grew by almost 600 persons and by over Io per cent of the area's total population. The total population here only grew by 50 persons, with the white population decreasing. Similarly, in another adjacent postcode sector, Pollokshields East, the South Asian population grew as a proportion of the total 
population by over 9 per cent. The South Asian population grew in other postcode sectors bordering Strathbungo: in North Govanhill by 7 per cent; in Crosshill by over 4.5 per cent; and in Shawlands by almost 3 per cent as a proportion of the total population. Whilst the South Asian population grew in these areas in absolute numbers, the total population decreased.

Interestingly, a very different picture is seen north of the river in the west of the city. Woodlands and Garnethill experienced a notable decline in the proportion of their population that is South Asian. The South Asian population only grew by two persons and with the overall population increasing by more than I,০o० persons the proportion of the total population that is South Asian decreased by 5 per cent. Further change is revealed when the South Asian population is disaggregated, as the Indian population of this area decreased by 25 per cent, suggesting that they have dispersed out of the area. By contrast, the Pakistani population increased by io per cent of itself, even though overall it decreased by 2 per cent of the area's total population.

A similar trend of South Asian population decline was verified in the areas surrounding this traditional area of core settlement. Port Dundas, an area directly adjacent to Woodlands, whose South Asian population in I99I was almost equal to that of Woodlands, experienced even greater population decrease over the study period. Its South Asian population decreased by over 6 per cent of the total population or in absolute terms by 200 persons, whereas the total population grew by almost I,০o० persons. In Hillhead, the South Asian population decreased by almost 3 per cent, in Yorkhill by 2 per cent and in Anderson by over 3 per cent; each of these areas experienced absolute decreases in their South Asian populations in the context of an expanding total population.

Previously, although resident in the inner city, there was virtually no presence of South Asian groups in city centre areas. In 200I, however, there was a slight increase in the numbers of South Asians resident in these areas. Interestingly, when the South Asian category is further differentiated, it is only Indians who are represented in the city centre. This is an area for future research that may touch upon the gentrification of particular areas in the city. Wider changes across the city's South Asian population can also be seen, as there has been a slight increase in numerous postcode sectors across the city, suggesting smallscale dispersal to areas that previously had no South Asian population. The areas of growth to the north-east of the core settlement area in the north are areas of social rented housing that have absorbed recent asylum seekers.

The census analysis has uncovered population changes here to be explored further, through qualitative research, such as the population loss 
Figure 6.3 Distribution of South Asian population (\% of the total postcode sector population), 2001

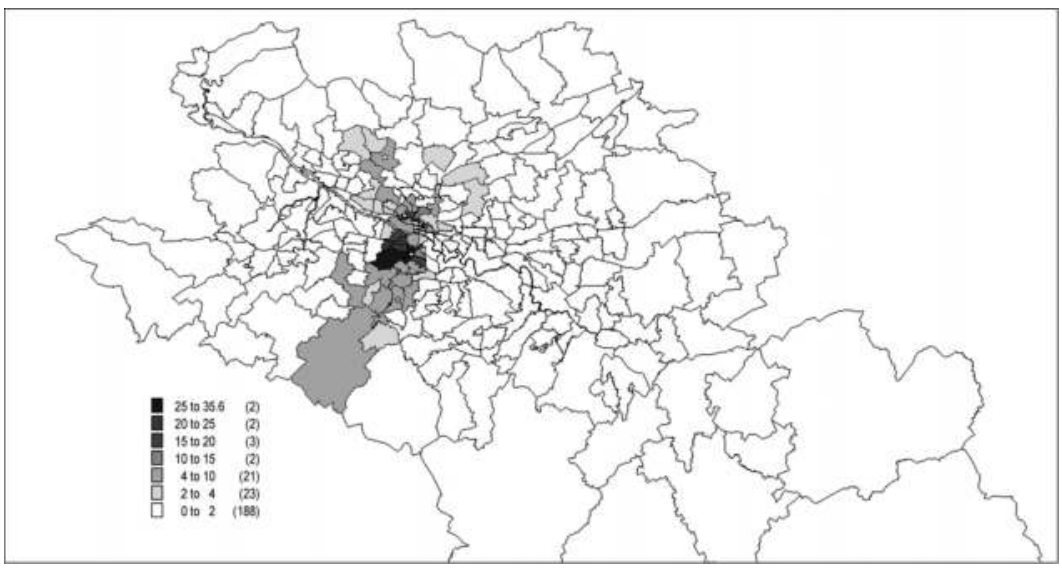

Figure 6.4a Change in the South Asian population (\% of the total postcode sector population), 1991-2001

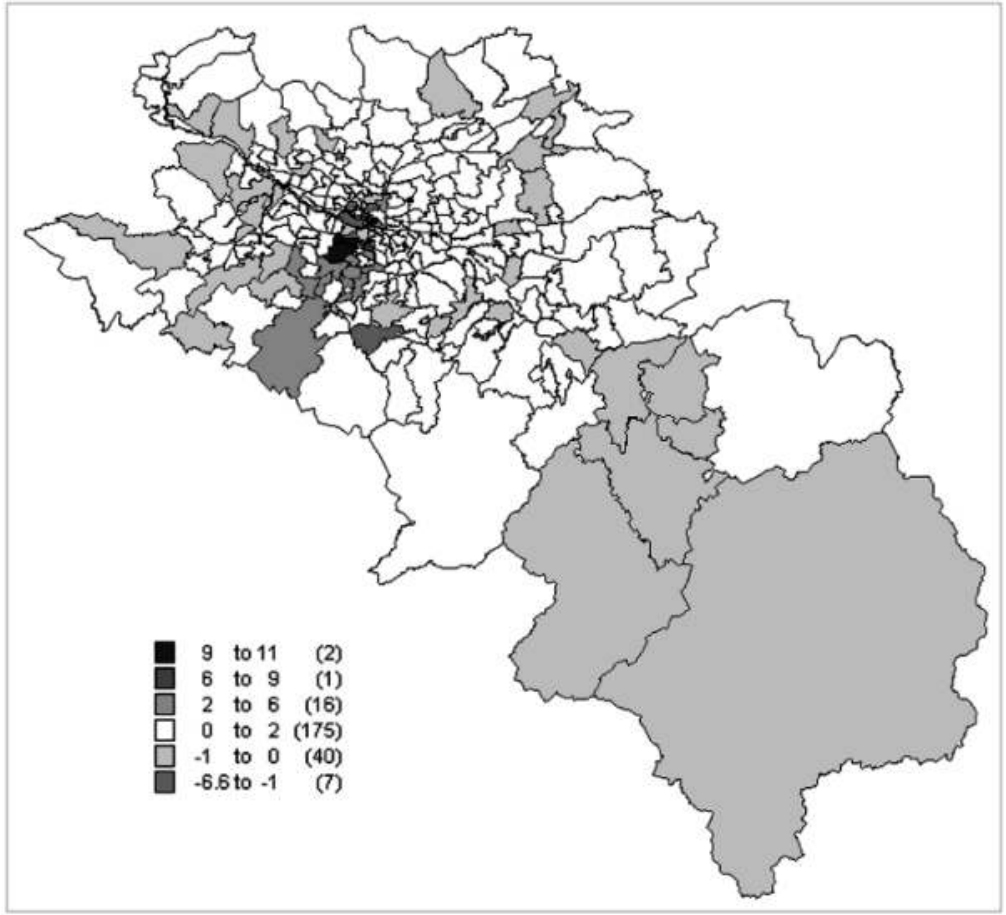


Figure 6.4b Close view of changes in South Asian population (\% of the total postcode sector population), 1991-2001

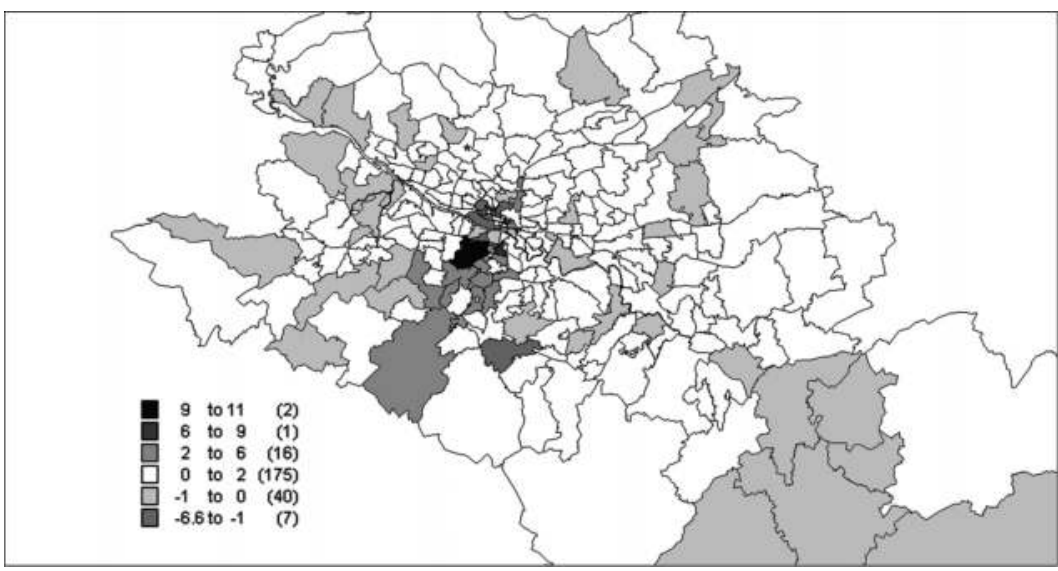

in the core area in the west of the city and the migratory trajectories of the same residents. There are also questions surrounding the reasons for growth in the core area and in the surrounding areas south of the River Clyde, and as to whether this is due to in situ growth, overspill or new migrants from elsewhere in the city or from outside it.

\section{Moving out: Suburbanisation and new locales}

While the previous section looked at changes in the areas of core settlement, this section considers evidence of South Asian suburbanisation and a wider dispersal across the conurbation. As is evident from Figure 6.3, the South Asian population is slightly more dispersed throughout the study area in 200I than it was in I991. These changes represent a small proportion of the South Asian population, but are significant none the less. We also see further growth in the majority of suburban areas that had South Asian populations in I99I (See Figure 6.4a). Before discussing changes in the ethnic geography over the study period, this section will begin by describing patterns of suburban settlement in I99I.

\section{Suburban settlement 1991}

In I99I, the South Asian population was represented in small numbers in a few of the suburbs of Glasgow, namely, those suburbs immediately adjacent (intermediate) to the core settlement area of Strathbungo/Pollokshields and just across the city boundary into East 
Renfrewshire in the south and in East Dunbartonshire to the west (see Figure 6.I). Moves, despite representing some form of dispersal, were never too far away from the main ethnic clusters; indeed, the trajectory of movement appears to be along the main transport routes out of the city that pass through the areas of core settlement.

The suburban areas with South Asian residents were primarily located in the local authority areas of East Dunbartonshire and East Renfrewshire, both of these districts being the only non-city local authority areas that had South Asian populations above the national average. The suburban areas to the south of the city in East Renfrewshire (Giffnock, Netherlee, Thornliebank and Newlands), and indeed those intermediate areas to the south of Strathbungo/Pollokshields, had the highest percentage of South Asians in I99I. These suburban areas are in the main clustered together moving due south from the core area in the south. The area with the highest percentage of South Asians (5 per cent) in I99I was Thornliebank. However, the neighbouring suburbs of Newlands, Newton Mearns, and Giffnock had South Asian populations that were comparable in size to that of Thornliebank.

North of the river Clyde, travelling west from the core settlement area of Woodlands, the South Asian population was distinctly located in the four postcode sectors that make up the area of Bearsden, comprising over 3 per cent of the total population (over 2 per cent of this was comprised of Indians). The South Asian population of the intermediate postcode sectors on the main thoroughfare between Woodlands and the suburbs of Bearsden was of a comparable size to that of Bearsden. In I99I, South Asian groups were also living in the northern suburb of Bishopbriggs, numbering almost 3.5 per cent of the total population. This was the only suburban area in which South Asians were resident which was not directly connected by a main transport route from the city centre to an area of core settlement.

\section{Suburban settlement 2001}

In 200I, there was little growth in the South Asian population in the suburbs to the west, north of the river, and notable population increases in the southern suburbs. The growth in the suburbs to the west of the city into the local authority area of East Dunbartonshire was slight. One would have expected households from Woodlands to move to this area, meaning it likely that some moved to the southern core, the areas surrounding it or possibly to the East Renfrewshire suburbs on the south of the city. South of the river, East Renfrewshire, like East Dunbartonshire, has a minority ethnic population that exceeds the national average. In the East Renfrewshire suburbs (Newton Mearns, Giffnock, Netherlee, Thornliebank and Newlands), there was 
significant overall growth in the South Asian population, from slightly over I,700 to over 3,100 persons, an increase of 82 per cent. The Pakistani population grew by 94 per cent and the Indian population grew by 60 per cent over the ten-year period between I99I and 200I. Despite what may seem to be a large growth in these populations, their proportion of the total population is still very small, comprising 3 per cent of the total population of East Renfrewshire. The Bangladeshi population still numbers under twenty and the Other South Asian category, newly added in the 200 I Census, numbers 210.

The suburbs that experienced the largest increases in their South Asian population were those where South Asians had already lived in I99I, all located in East Renfrewshire (see Figure 6.4b). Newton Mearns has both the largest absolute South Asian population and experienced the largest absolute growth, 6.4 per cent of the population categorised themselves as South Asian and 24 per cent of the districts South Asian population live in the area. Giffnock, neighbouring Newton Mearns, experienced the largest proportionate change in its South Asian population and has the second largest absolute South Asian population in the district. The South Asian population here comprises 7.5 per cent of the total postcode sectors population, and 2I per cent of the district's South Asian population live in the area. As can be seen from Figure 6.3, the suburbs moving south from the core settlement area of Pollokshields and Strathbungo have South Asian populations of between 5 and io per cent of their total populations and experienced over 2 per cent growth in the proportion of South Asian residents of their total populations. The settlement of South Asians in the areas surrounding these suburbs is evident from the 200I map, representing dispersal to wider areas, albeit on a small scale.

Overall, in East Dunbartonshire during the period I99I-200I, there was little change in the South Asian population, in absolute terms the increase was small, at less than 400 persons for the entire local authority, leaving the population at 2,300 . However, in proportionate terms the population change looks slightly different with the South Asian population increasing by 24 per cent, the Indian population by 24 per cent and the Pakistani population by 29 per cent. Overall in this local authority area, there appears to be little differentiation between Indian and Pakistani groups as regards the areas they reside in. These population changes are within the context of the total population of the district decreasing by I per cent.

The four postcode sectors that make up the suburb of Bearsden, to the north-west of the city, saw slight change in their populations (see Figure 6.4b). The largest absolute growth was in Bearsden West, the population here is still small numbering 30I including the 87-person increase in the aforementioned period. Proportionately, however, the 
South Asian population comprises slightly over 3 per cent of the total population. The largest proportionate growth occurred in Bearsden East (Kessington) where the South Asian population grew by I.5 per cent of the total population to 5 per cent (the largest percentage of the population of any locality in the district); however, absolute growth was small numbering just over 80 persons. Thus, even though South Asian households are still moving to these suburbs they are doing so in very small numbers. Bishopbriggs, mentioned earlier as being the only suburban area with a significant South Asian population along a different transport route out of the city, remained stable with no population increase.

\section{Settlement patterns by ethnic group}

The separate patterns of population change of the Indian and Pakistani groups can be seen in Figures 6.5 through 6.10. ${ }^{3}$ As is evident from the Figures 6.5 through 6.7, the Pakistani population, in both I99I and 200I, are predominantly resident in two localities: the areas of core settlement to the north of the river in the West End, mainly in Woodlands and the areas adjacent to it, but more so in the south in Strathbungo and the surrounding areas. In I99I, Pakistanis did not represent any more than I per cent of the total population in any western suburban area, whereas there were clear signs of suburbanisation to the suburbs on the south of the city into East Renfrewshire. In 200I, this is replicated, with increasing suburbanisation to the southern suburbs and a greater dispersal into adjacent suburbs on either side of the main southern transport route out of the southern core area, such as East Darnley, Darnley and Nitshill, which had few Pakistani residents in I99I. The areas with a Pakistani population are very much clustered along a straight route south out of the city. There may be several reasons for this: first, the journey to the core along one route into the city is an uncomplicated one, using familiar transport routes and the same bus services; similarly, access to services and family in the core is convenient.

The Indian population is less concentrated in the areas of core settlement and, indeed, comprise no more than 5 per cent of any postcode sector in the Greater Glasgow study area, compared to the Pakistani population who comprise up to 32 per cent of a single postcode sector's population. In Figure 6.Io, we see that the Indian population has grown in the postcode sectors to the east of the northern core adding to the small population that lives in Glasgow's recently gentrified city centre, in the suburbs and indeed throughout the whole study area in general. Their representativeness in the suburbs of Bearden equals that in the areas of core settlement. They comprise a greater proportion of 
the population in Bearsden than in the suburbs to the south that have the largest South Asian populations. To some extent, there is a differentiated pattern of suburban settlement according to ethnic group. In the majority, the South Asian population in the suburbs to the south is comprised of Pakistanis, who are represented in the northern suburb of Bearsden in small numbers, whilst there was little growth in the Indian population in the southern suburbs. Interestingly, the areas in which the Indian population grew most over the decennial census period were Crosshill (an area directly adjacent to the main core area in the south) and the newly gentrified areas of the city centre, albeit here the absolute numbers are very small.

Figure 6.5 Distribution of the Pakistani population (\% of the total postcode sector population), 1991

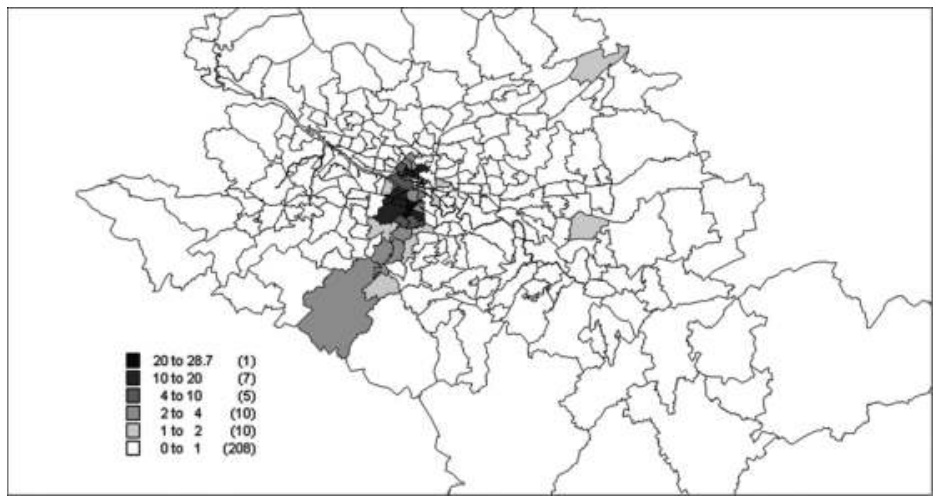

Figure 6.6 Distribution of the Pakistani Population (\% of the total postcode sector population), 2001

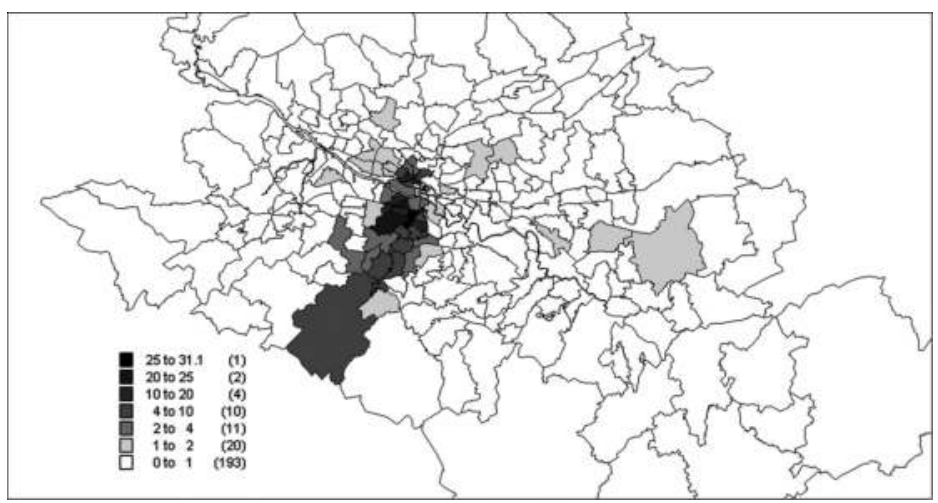


Figure 6.7 Change in distribution of the Pakistani population (\% of the total postcode sector population), 1991-2001

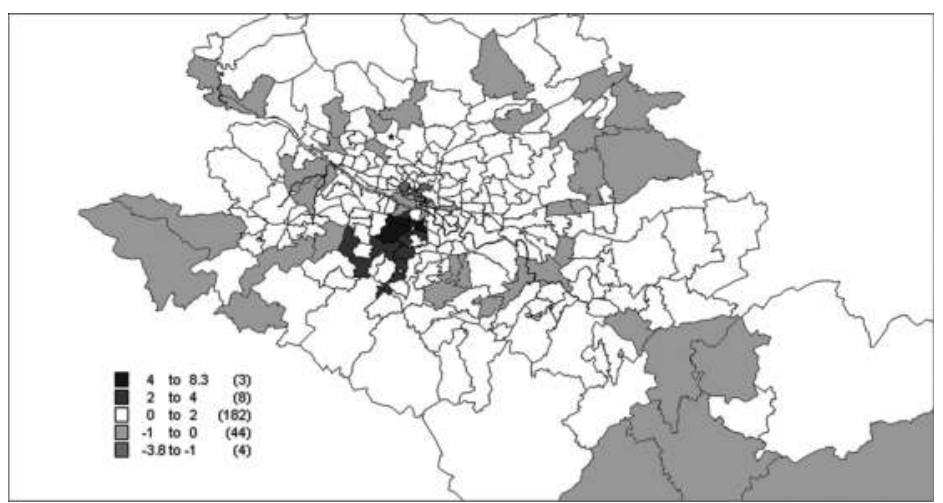

Figure 6.8 Distribution of the Indian population (\% of the total postcode sector population), 1991

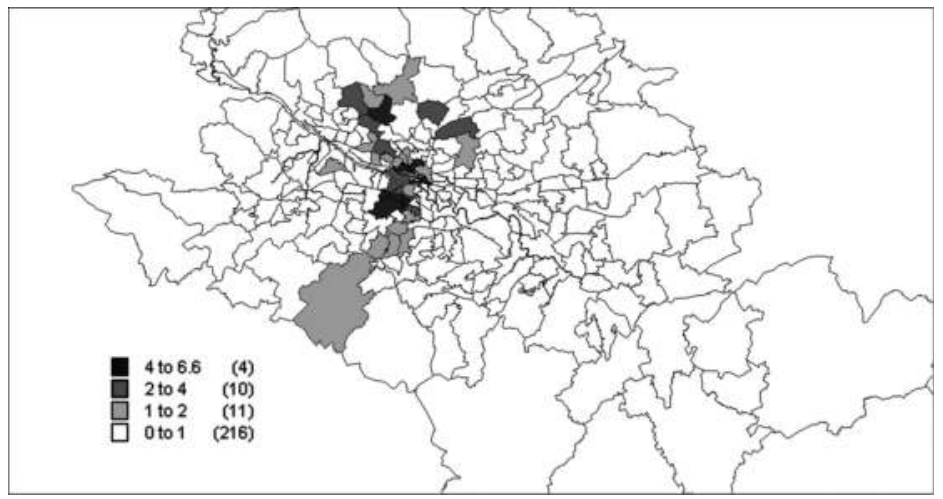

Figure 6.9 Distribution of the Indian population (\% of the total postcode sector population), 2001

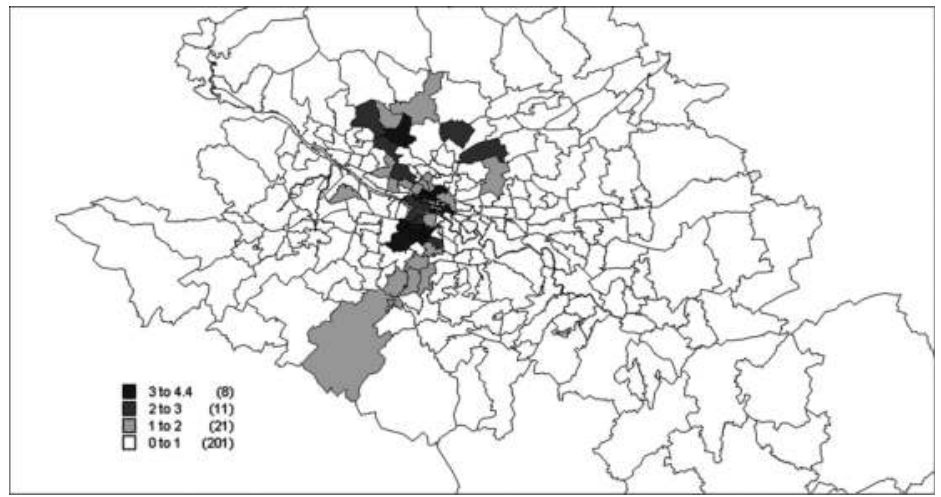


Figure 6.10 Change in distribution of the Indian population (\% of the total postcode sector population), 1991-2001

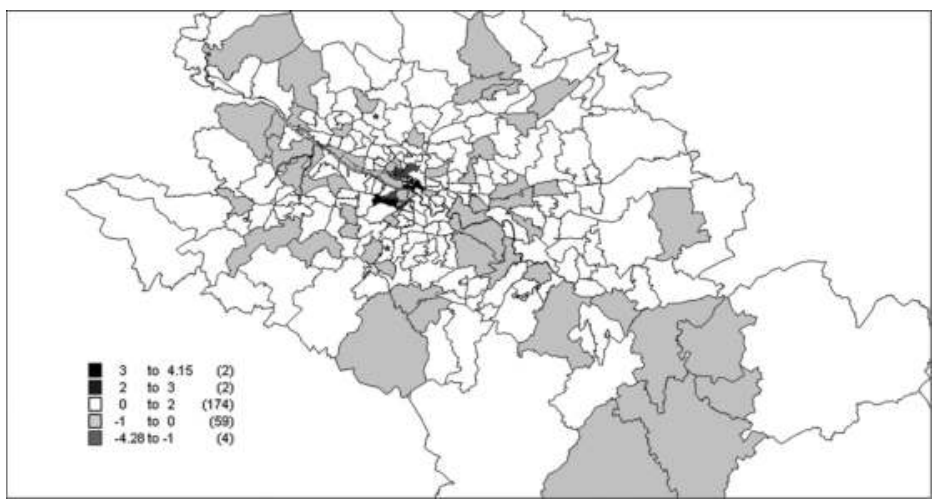

\section{Local neighbourhoods and microscopic clusters}

In the context of changing patterns of settlement across the city, including increasing ethnic clustering to the south of the city, population shifts in the north, clear evidence of suburbanisation and a wider dispersal on a very small scale to areas that in I991 had no South Asian population, it seems appropriate to look at the populations within the areas of significant change over the census period at a finer scale. This provides the opportunity to explore evidence of re-clustering or concentration within these smaller local areas. This section will therefore look at the population distribution at the smallest census area, the output area, in the areas with larger proportions of their populations comprised of South Asians, followed by those areas which experienced more notable population changes.

The South Asian population at output area, in 200I, is most concentrated within the ethnic clusters and areas of core settlement in the city, rather than in the suburban areas, as may have been expected. There are nine postcode sectors that have South Asian populations exceeding Io per cent of the total population (all of which are in the inner city), shown in Table 6.I. These areas are mainly clustered in the area of Glasgow City to the south of the river and are predominantly in the master postcode G4I (Strathbungo/ Pollokshields, South Kinning Park and Dumbreck) - see Table 6.I. There has been maintenance of these areas as areas of traditional settlement and levels of clustering on a finer scale within these postcode sectors are significant to understanding the extent of concentration, arguably more so than the index of segregation, as evenness at a very local level can be observed. 
Table 6.1 Postcode sectors with over 10 per cent of the total population comprised of South Asians, 2001

\begin{tabular}{lll}
\hline Locality & Postcode sector & \% South Asian \\
\hline Strathbungo & G41 2 & 35.56 \\
Pollokshields East & G41 4 & 25.28 \\
South Kinning Park & G41 1 & 22.93 \\
Dumbreck & G41 5 & 22.88 \\
Crosshill & G42 8 & 19.58 \\
Woodlands/Garnethill & G3 6 & 16.92 \\
North Kinning Park & G51 1 & 15.04 \\
Port Dundas & G4 9 & 13.78 \\
North Govanhill & G42 7 & 11.18 \\
\hline
\end{tabular}

Table 6.2 details the percentage of each postcode sector's South Asian population that live in smaller output areas where South Asians comprise over 50 per cent, 20 per cent, Io per cent and 2 per cent of the total output area population. As is evident, the South Asian population in some of the postcode sectors are more clustered than others at the level of output area. In three postcode sectors, Strathbungo/Pollokshields, South Kinning Park and North Kinning Park more than 40 per cent of South Asians live in output areas where they comprise over 50 per cent of the output area's population. In seven of the nine postcode sectors, over 60 per cent of the South Asian population is clustered in output areas in which they comprise over 20 per cent of the output area's population.

Table 6.2 Clustering within neighbourhoods ${ }^{4}$ (postcode sectors with largest South Asian \% of total population), 2001

\begin{tabular}{|c|c|c|c|c|c|c|c|}
\hline & Locality & $\begin{array}{l}\text { Postcode } \\
\text { Sector }\end{array}$ & $\begin{array}{l}\text { South Asian } \\
\% \text { of } \\
\text { postcode } \\
\text { sector } \\
\text { population }\end{array}$ & $\begin{array}{l}\text { South Asian } \\
\text { population } \\
>50 \% \text { of } \\
\text { output } \\
\text { area }\end{array}$ & $\begin{array}{l}\text { South Asian } \\
\text { population } \\
>20 \%<50 \% \\
\text { of output } \\
\text { area }\end{array}$ & $\begin{array}{l}\text { South Asian } \\
\text { population } \\
>10 \%<20 \% \\
\text { of output } \\
\text { area }\end{array}$ & $\begin{array}{l}\text { South Asian } \\
\text { population } \\
>2 \%<10 \% \\
\text { of output } \\
\text { area }\end{array}$ \\
\hline Core & $\begin{array}{l}\text { Strathbungo/ } \\
\text { Pollokshields }\end{array}$ & G412 & 35.6 & 71.6 & 19.5 & 6.5 & 2.1 \\
\hline Core & Woodlands & G3 6 & 16.9 & 5.8 & 57.4 & 22.9 & 3.4 \\
\hline Adjacent & $\begin{array}{l}\text { Pollokshields } \\
\text { East }\end{array}$ & G41 4 & 25.3 & 22.7 & 58.8 & 12.1 & 6.4 \\
\hline Adjacent & $\begin{array}{l}\text { South Kinning } \\
\text { Park }\end{array}$ & G411 & 22.9 & 55.2 & 27 & 15.9 & 1.8 \\
\hline Adjacent & Dumbreck & G41 5 & 22.9 & 33 & 40.6 & 20.6 & 5.7 \\
\hline Adjacent & Crosshill & G42 8 & 19.6 & 10.9 & 60.5 & 21.9 & 5.2 \\
\hline Adjacent & $\begin{array}{l}\text { North } \\
\text { Kinning Park }\end{array}$ & G511 & 15 & 43.9 & 24.6 & 18.8 & 12.1 \\
\hline Adjacent & Port Dundas & G4 9 & 13.8 & 0 & 43.1 & 42.8 & 13.9 \\
\hline Adjacent & $\begin{array}{l}\text { North } \\
\text { Govanhill }\end{array}$ & G42 7 & 11.2 & 0 & 28.8 & 46.2 & 24.8 \\
\hline
\end{tabular}


In Strathbungo, 7I.6 per cent of the total South Asian population live in 25 per cent of the output areas that comprise the sector, all of which are over 50 per cent and up to 83 per cent South Asian. In South Kinning Park, an area adjacent to the core, over half of the area's South Asian population (55 per cent) live in a single output area, making that area 73.6 per cent South Asian. In fact, 82 per cent of the postcode sector's South Asian population live in 30 per cent of the output areas that comprise the postcode sector. In Crosshill, also adjacent to the core, the South Asian population is more dispersed throughout the output areas that comprise the larger area, Io per cent live in output areas where they are over 50 per cent of the total population and 60.5 per cent in output areas where they are between 20 and 50 per cent of the total population. In Dumbreck, the area with the most significant proportionate increase in its South Asian population over the census period, the South Asian population is slightly more clustered, with the vast majority living in output areas that are between 20 and 70 per cent South Asian. In North Govanhill, the South Asian population is spread more evenly throughout the postcode sector and only io per cent of output areas have South Asian populations that exceed 20 per cent of the total postcode sector populations. Indeed, no output areas have South Asian populations that comprise over 50 per cent of the total population. In Port Dundas, adjacent to the western core, almost 50 per cent of the South Asian population live in only 20 per cent of the output areas; however, the rest of the population are largely more dispersed throughout the area, none of the output areas are over 50 per cent South Asian. Patterns of clustering to a lesser extent can be found in Woodlands, where 20 per cent of the output areas making up the postcode sector contain 63 per cent of the South Asian population, and in North Kinning Park where 68.5 per cent of the South Asian population live in 20 per cent of the output areas.

Table 6.3 is as Table 6.2 but in reference to postcode sectors where the growth in the South Asian population was most significant between I99I and 200I. Notably, all of the areas presented in Table 6.3 are in the south of the city, highlighting that the growth in the South Asian population has been greatest in a series of adjacent, intermediate and suburban areas moving south from the southern core area. Levels of concentration are highest within the core area of Strathbungo/Pollokshields, but are also pronounced within three of the four areas adjacent to the core.

Four of the five suburban areas have moderate clusters where over a fifth of the postcode sector's populations live in output areas which are over 20 per cent South Asian. Furthermore, the clustering of South Asians in output areas is often higher in the suburban areas than in the intermediate areas. In Giffnock, the majority of the South Asian 


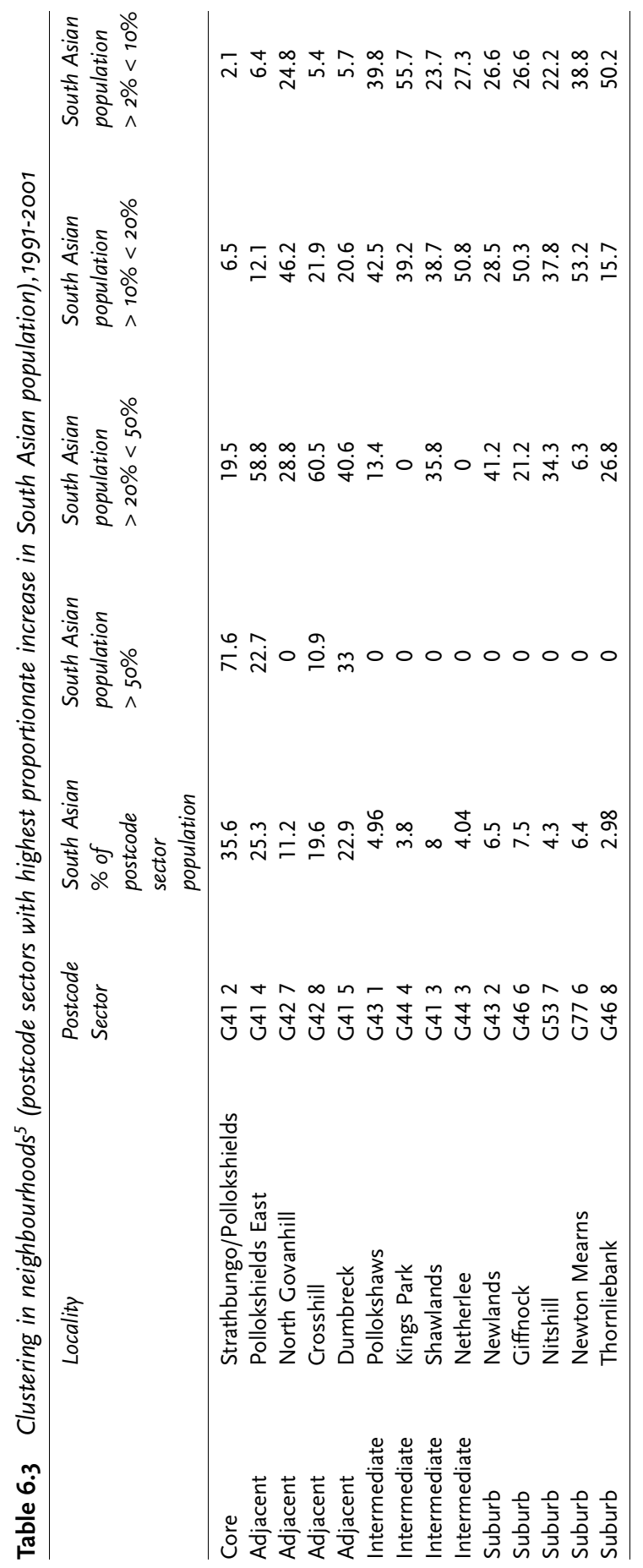


population, over 70 per cent, live in output areas that are between Io and 50 per cent South Asian, whilst a third of the output areas have no South Asian residents. In Newlands, over 40 per cent of the South Asian population live in output areas in which they comprise between 20 and 50 per cent of the output area's total population and, in general, the South Asian population appears to be slightly more dispersed throughout the postcode sector than in Giffnock. In Newton Mearns, the South Asian population is less clustered in output areas than in Giffnock, with only 6 per cent of the total population living in output areas where they comprise between 20 and 50 per cent of the total population. The same is true of Thornliebank as over 50 per cent of the South Asian population is resident in output areas that have more than 2 and less than Io per cent of their population comprised of South Asians.

\section{Relative distributions: Segregation and exposure}

After previously studying the ethnic geography of the metropolitan area at postcode sector level and briefly at output area, this section will turn attention to the distribution of the South Asian population across the study area as measured using standard segregation indices. The purpose of which is to compare the distribution of the different ethnic groups within the South Asian category both with each other and with the distribution of the white majority (all white groups are included). The index of dissimilarity, a measure of evenness, will first be computed, followed by the index of segregation and finally by the index of exposure.

\section{Index of dissimilarity}

The index of dissimilarity was calculated for both I99I and 200I at postcode sector level across the Greater Glasgow study area. The final index must be interpreted with caution as there are problems involved with comparing measures of segregation over time. Segregation is a dynamic process with numerous different causes, meaning it is impossible using measures alone to comment on social trends. For example, an increase in the level of segregation may simply be due to natural increase rather than migration into an area of concentration and may accompany a trend of slow dispersal. Therefore, these indices can be regarded only as a snap shot in time and not as being reflective of the dynamic processes involved, meaning the difference between I99I and $200 \mathrm{I}$ is not an accurate or reliable measure but rather indicative. For more detailed discussion on measures of segregation see Chapter 2. 
Table 6.4 Indices of dissimilarity Greater Glasgow, 1991-2001 (postcode sector)

\begin{tabular}{lllc}
\hline Ethnic group & 1991 & 2001 & Difference 1991-2001 \\
\hline White: South Asian & 58.1 & 53.8 & -4.3 \\
White: Indian & 59.5 & 52.5 & -7.0 \\
White: Pakistani & 64.0 & 59.1 & -4.9 \\
White: Bangladeshi & 79.5 & 64.7 & -14.8 \\
White: Other Asian & 56.3 & 49.7 & -6.6 \\
Indian: Pakistani & 42.7 & 38.9 & -3.8 \\
Indian: Bangladeshi & 62.4 & 35.2 & -27.2 \\
Indian: Other Asian & 44.0 & 35.7 & -8.3 \\
Pakistani: Bangladeshi & 71.1 & 49.8 & -21.2 \\
Pakistani: Other Asian & 44.8 & 44.9 & 0.1 \\
Bangladeshi: Other Asian & 64.7 & 45.5 & -19.2
\end{tabular}

Over the census period from I99I, we see the index of dissimilarity decline between the white group and all of the South Asian groups (Table 6.4). The highest level of segregation is amongst Bangladeshis; however, this is to be expected as they make up such a small proportion of the overall population, whilst the Indian population has the lowest level of segregation from the white group. Overall, the South Asian groups have moderately high levels of segregation from the majority white group with the vast majority scoring over 50, though this is falling, which would suggest some are becoming more spatially integrated.

\section{Index of segregation}

The index of segregation was also computed at postcode sector for I99I and 200I. Due to the fact that the index of segregation only measures the distribution of one group in an area compared to the total population levels of segregation between ethnic groups cannot be computed. The index of segregation is slightly lower than the index of dissimilarity, which is to be expected as the total population of the area is taken into account. The index of segregation has been falling to a similar degree as the index of dissimilarity between whites and other groups, namely by between five and fifteen points over a ten year period.

Table 6.5 Index of segregation for Greater Glasgow by South Asian ethnic group, 1991-2001 (postcode sector)

\begin{tabular}{lllc}
\hline Ethnic group & 1991 & 2001 & Difference 1991-2001 \\
\hline South Asian total & 0.57 & 0.52 & -0.05 \\
Indian & 0.59 & 0.51 & -0.08 \\
Pakistani & 0.63 & 0.58 & -0.05 \\
Bangladeshi & 0.78 & 0.64 & -0.14 \\
Other Asian & 0.56 & 0.48 & -0.08 \\
\hline
\end{tabular}




\section{Index of exposure}

Exposure was calculated at postcode sector level for I99I and 200I using the Liebersons $\mathrm{P} *$ Index. The probability of a South Asian person meeting someone from another ethnic group in I99I was 0.45 this increased to 0.56 in $200 \mathrm{I}$, suggesting the probability of exposure between ethnic groups was greater.

\section{Case study areas}

The quantitative study of the census depicted the changing patterns of South Asian residence over the past ten years; however, to explore the causal factors and motivations underpinning these residential patterns it was necessary to pursue in-depth qualitative research. To do this, case study areas that capture the main patterns of residence and changing trends were selected using three criteria: first, results from the census analysis; second, the literature; and third, the results of preliminary interviews with key actors in the South Asian community. In line with the fact that the main concerns of this study are to assess the extent and the drivers of suburbanisation and neighbourhood attachment, two suburban areas and two areas of core settlement were chosen as case studies.

Despite the fact the areas adjacent to the areas of core settlement saw significant changes in their South Asian populations, in order to understand neighbourhood attachment, clustering and the changes occurring in these residential patterns, it was decided to choose a case study area to the north of the river Clyde and one to the south. Pollokshields/Strathbungo was chosen to the south of the river as it has the main community infrastructures in the city, it is the largest area of South Asian concentration and also its South Asian population increased over time. Woodlands was chosen to the north of the river Clyde due to the population changes occurring in the area. Contrary to that south of the river, the area saw a decline in its South Asian population. These two areas correspond with the principal areas of core settlement identified in the literature (Dalton \& Daghlian I989; Audrey 2000; Binns 2002) and in the census analysis. They were also verified as the main areas of core settlement of South Asians in the city through interviews with key actors in the South Asian community (leaders at the mosque, Sikh temple and a main multicultural centre).

The study of the census showed clear evidence of the beginnings of South Asian suburbanisation in I99I, with a notable increase in this trend in 200I. In 200I, the greatest increases in the South Asian population were in the suburbs to the south of the river in the local 
authority district of East Renfrewshire, neighbouring Glasgow City. The South Asian population have established themselves in suburban areas surrounding those where they had already established themselves in I99I. The area to the south, in East Renfrewshire, with the largest change in the South Asian population as a percentage of the total population was Giffnock, where the South Asian population now comprises 7.5 per cent of the population. To the north of the river Clyde, in I99I, those South Asians who had suburbanised lived mainly in Bearsden. The largest proportionate growth occurred in Bearsden East (Kessington), where the South Asian population grew by I.5 per cent as a proportion of the total population to almost 5 per cent (the largest proportion of the population of any locality in the district). Absolute growth, however, is small, suggesting that even though South Asian households are still moving to these suburbs they are doing so in small numbers.

Both of these areas were selected as case study areas, primarily, due to the relative growth in the proportion of South Asians in the area. Further to this, the interviews with the key actors suggested that there were flows of movement from the core settlement area in the south to the suburbs in the south, and similarly, between the core to the north of the river and the suburbs to the north-west. Hence, one area was chosen from north of the river and another from the south to explore this further. The changes in the populations of the study areas over the study period can be seen in Table 6.6.

This section will turn to provide brief profiles of each of the four case study areas, including population, age structures, tenure and accommodation types, occupancy ratings, household amenities, car ownership, social grades, qualifications by ethnic group, amenities and services and house prices.

Table 6.6 Ethnic populations in case study areas, 1991 and 2001

\begin{tabular}{|c|c|c|c|c|c|c|c|c|}
\hline Neighbourhood & Year & $\begin{array}{l}\text { Total } \\
\text { persons }\end{array}$ & Indian & Pakistani & Bangladeshi & $\begin{array}{l}\text { Other } \\
\text { South } \\
\text { Asian }\end{array}$ & $\begin{array}{l}\text { Total } \\
\text { South } \\
\text { Asian }\end{array}$ & $\begin{array}{l}\text { South } \\
\text { Asian \% } \\
\text { of total } \\
\text { population }\end{array}$ \\
\hline \multirow[t]{2}{*}{ Woodlands } & 1991 & 3906 & 216 & 550 & 17 & 64 & 847 & 21,7 \\
\hline & 2001 & 5017 & 162 & 603 & 15 & 69 & 849 & 16,9 \\
\hline Pollokshields/ & 1991 & 7890 & 309 & 2260 & 8 & 35 & 2612 & 33,1 \\
\hline Strathbungo & 2001 & 8211 & 271 & 2549 & 5 & 95 & 2920 & 35,7 \\
\hline \multirow[t]{2}{*}{ Giffnock } & 1991 & 9455 & 97 & 306 & 0 & 5 & 408 & 4,3 \\
\hline & 2001 & 9125 & 169 & 486 & 2 & 27 & 684 & 7,5 \\
\hline \multirow[t]{2}{*}{ Bearsden } & 1991 & 6754 & 158 & 61 & 4 & 13 & 236 & 3,5 \\
\hline & 2001 & 6398 & 194 & 90 & 7 & 26 & 317 & 5.0 \\
\hline
\end{tabular}

Source: 2001 Census; author's own analysis 


\section{Strathbungo/Pollokshields}

Strathbungo/Pollokshields is a largely residential area that lies around one mile south of the River Clyde and Glasgow's city centre, with the M77 motorway to its west and the M8 to its north. It is the largest and most established ethnic cluster in the Greater Glasgow area and one of the most ethnically diverse neighbourhoods in Scotland (see Table 6.7), including small Chinese and Irish groups as well as South Asians. This is reflected by the well established ethnic infrastructure in the area. The largest minority ethnic group resident in the area is Pakistani, followed by Indians. The population of the area has a very young age structure when compared to the Scottish average (see Table 6.8) with only II. 3 per cent of the population being over 60 and 35 per cent of the population being under 24. The median age of the area is 3I, which is seven years less than the Scottish median age.

Table 6.7 Population by ethnicity, Strathbungo/Pollokshields

\begin{tabular}{lrc}
\hline All people & 8,211 & \% of all people \\
\hline White Scottish & 4,278 & 52 \\
Other white British & 423 & 5.2 \\
White Irish & 181 & 2.2 \\
Other white background & 244 & 3 \\
Pakistani & 2,549 & 31 \\
Indian & 271 & 3.3 \\
Bangladeshi & 5 & 0.07 \\
Chinese & 95 & 1.2 \\
Other South Asian & 60 & 0.7 \\
African Caribbean & 6 & 0.08 \\
Black African & 7 & 0.1 \\
Other black & 4 & 0.05 \\
Any mixed background & 49 & 0.6 \\
Any other background & 39 & 0.5 \\
Total minority ethnic population & 3,089 & 37.6 \\
\hline Souce: 2001 Censu; authors & &
\end{tabular}

Source: 2001 Census; author's own analysis

Table 6.8 Population by age structure (\% of all people), Strathbungo/Pollokshields

\begin{tabular}{ll}
\hline Age & $\%$ \\
\hline $0-15$ & 21.1 \\
$16-24$ & 13.7 \\
$25-29$ & 11.5 \\
$30-44$ & 29.7 \\
$45-59$ & 12.7 \\
$60-74$ & 6.9 \\
75 and over & 4.4 \\
\hline
\end{tabular}

Note: Population base 8,211

Source: 2001 Census; author's own analysis 


\section{Housing}

Strathbungo/Pollokshields is dominated by private housing (both owned and rented) and has significant problems of overcrowding and lack of amenities. The tenure structure of the area differs considerably from that of Glasgow $\mathrm{City}^{6}$ (see Table 6.9). The predominant house type is flats (specifically old tenement buildings), housing 87 per cent of all residents (see Table 6.Io). One quarter of households live in overcrowded conditions (i.e. below the accepted bedroom standard, see Table 6.II) compared to Ir.8 per cent at the national level and 22 per cent at the city level. Likewise, at the national level 6r.6 per cent of all households have extra space, some 20 per cent higher than in our case study area and indeed for Glasgow City as a whole. Furthermore, 25 per cent of households in the area are without central heating (see Table 6.I2). The average (median) house price of the area is $£ 84,000$, lower than the city average of $£_{109, \mathrm{I} 63}$ (GSPC), but ranging in price in some cases from under $£ 20,000$ to $£ 395,000$ (Register of Sasines 2003; author's own analysis).

Table 6.9 Population by tenure (\% of all people), Strathbungo/Pollokshields

\begin{tabular}{|c|c|c|c|c|c|c|}
\hline Owned & & Social rented & & Private re & & Live rent-free \\
\hline 70.9 & & 5.7 & & 21.7 & & 1.7 \\
\hline Of which: & & Of which: & & Of which: & & \\
\hline Owned outright & 27.4 & $\begin{array}{l}\text { Rent from } \\
\text { council }\end{array}$ & 26.4 & $\begin{array}{l}\text { Private } \\
\text { landlord/ } \\
\text { agency }\end{array}$ & 92.3 & \\
\hline $\begin{array}{l}\text { With mortgage } \\
\text { or loan }\end{array}$ & 71.3 & $\begin{array}{l}\text { Other social } \\
\text { rented }\end{array}$ & 73.6 & Other & 7.7 & \\
\hline Shared ownership & 1.3 & & & & & \\
\hline
\end{tabular}

Note: Population base 8,211

Source: 2001 Census; author's own analysis

Table 6.10 Population by accommodation type (\% of all people), Strathbungo/ Pollokshields

\begin{tabular}{ll}
\hline Accommodation type & \% of all people \\
\hline House/bungalow & 12.99 \\
Flat/maisonette/apartment & 87 \\
Caravan/mobile accommodation & 0.01 \\
\hline
\end{tabular}

Note: Population base 8,211

Source: 2001 Census; author's own analysis 
Table 6.11 Occupancy rating by household (\%), Strathbungo/Pollokshields

\begin{tabular}{lc}
\hline Occupancy rate* & \% of households \\
\hline+2 or more & 15 \\
+1 & 27 \\
0 & 33 \\
-1 & 16 \\
-2 & 9 \\
\hline
\end{tabular}

Note: Population base 3,467

Source: 2001 Census; author's own analysis

Table 6.12 Household amenities by household (\%), Strathbungo/Pollokshields

\begin{tabular}{llll}
\hline & $\begin{array}{l}\text { \% of all } \\
\text { households }\end{array}$ & Of which: & $\%$ \\
\hline $\begin{array}{l}\text { Households with } \\
\text { central heating }\end{array}$ & 75 & $\begin{array}{l}\text { With shower/bath } \\
\text { and toilet } \\
\text { Without shower/ } \\
\text { bath and toilet } \\
\text { Total }\end{array}$ & 99 \\
$\begin{array}{l}\text { Households without } \\
\text { central heating }\end{array}$ & 25 & $\begin{array}{l}\text { With shower/bath } \\
\text { and toilet } \\
\text { Without shower/bath } \\
\text { and toilet }\end{array}$ & 100 \\
Total & 100 & Total & 93.5 \\
\hline
\end{tabular}

Note: Population base 3,467

Source: 2001 Census; author's own analysis

Economic indicators, deprivation index, social grades and qualifications

The Strathbungo/Pollokshields area is generally one of relatively high economic activity and a well qualified population (compared to the city as a whole), although a lack of qualifications is widespread within the South Asian community as a whole. Twenty-five per cent of persons over age sixteen in the area are represented in social grade $A B$ compared to I4 per cent at the city level (see Table 6.I3). Likewise, there are almost half as many people represented in social class $\mathrm{E}$ in the area than at the city level. The educational qualifications of persons aged between sixteen and 74 in the area are higher than the city level: 27 per cent of the whole population have no qualifications (see Table 6.I4) compared to 40.6 per cent of the city population; 34.7 per cent have group four qualifications, which is twice that of the city population. However, these figures hide significant variations according to ethnic group as only i7 per cent of the white group have no qualifications, which is more than half 
Table 6.13 Social grade, all people over 16 (\%), Strathbungo/Pollokshields

\begin{tabular}{ll}
\hline Social grade & \% of all people over 16 \\
\hline $\mathrm{AB}$ & 25.6 \\
$\mathrm{C} 1$ & 33.5 \\
$\mathrm{C} 2$ & 11.4 \\
$\mathrm{D}$ & 12 \\
$\mathrm{E}$ & 17.5 \\
\hline
\end{tabular}

Note: Population base 6,352

Source: 2001 Census; author's own analysis

Table 6.14 Qualification by ethnic group, all people aged 16-74 (\%), Strathbungo/ Pollokshields

\begin{tabular}{|c|c|c|c|c|c|c|}
\hline & All people & White & Indian & $\begin{array}{l}\text { Pakistani } \\
\text { and Other } \\
\text { South Asian }\end{array}$ & Chinese & Other \\
\hline $\begin{array}{l}\% \text { of population } \\
\text { aged } 16-74\end{array}$ & 100 & 68 & 3 & 27 & 0.8 & 1.2 \\
\hline No qualification ${ }^{8}$ & 27 & 17 & 40 & 52 & 42 & 18.3 \\
\hline Group 1 & 15.4 & 13 & 25 & 19 & 19 & 7.2 \\
\hline Group 2 & 14.9 & 17 & 9 & 11 & 4 & 30.9 \\
\hline Group 3 & 8 & 9 & 6 & 6 & 10 & 4.2 \\
\hline Group 4 & 34.7 & 44 & 20 & 12 & 25 & 39.4 \\
\hline
\end{tabular}

Note: Population base 6,112

Source: 2001 Census; author's own analysis

that of the percentage of Indians (40 per cent) and around one-third the percentage of Pakistanis (52 per cent) in the area with no qualifications.

Likewise, twice as many white residents have group four qualifications than Indians and four times as many as Pakistani residents. The percentage of working-age people who are economically active is io per cent higher than the percentage for Glasgow City. The percentage of economically inactive people in the area is Io per cent lower than that of Glasgow City, although it is Io per cent higher than the Scottish average. The percentage of children in workless households is 43 per cent higher as a percentage of the Scottish average and the number of households with no car (40.4 per cent) is also almost 20 per cent higher as a percentage of the Scottish average.

The deprivation index for neighbourhoods in Scotland in 2004 was calculated at the scale of data zone (a new geographical area created in Scotland), which is an area significantly smaller (around one-fifth the size) than the areas described here (postcode sectors). Thus the data zones were matched to the areas described here. The Scottish deprivation index (SIMD) brings together 3I different indicators which cover specific aspects of deprivation in the domains of income, health, education, employment and access. These indicators are weighted and 
Table 6.15 Economic indicators, Strathbungo/Pollokshields

\begin{tabular}{ll}
\hline Indicator & \% of people \\
\hline Economically active* & 65.6 \\
Economically inactive* & 34.4 \\
Unemployment claimants* & 3.3 \\
Income support claimants* & 13.1 \\
Children in workless households & 26.3 \\
Households without a car*** & 40.4 \\
\hline
\end{tabular}

Source: ScotPHO (2004); Census 2001

* All people aged 16-74

$* *$ All households

combined to produce the overall SIMD score and then ranked in order of the most deprived, ranked one, to the least deprived data zone in Scotland, ranked 6505 (Scottish Executive 2005). The SIMD is not an absolute measure of deprivation but rather relative, so it cannot be used to determine how much more deprived one data zone is from another; however, it is possible to say one is more deprived than another. For instance, the SIMD score for Strathbungo/Pollokshields is 30.00 (aggregated from data zone) whilst for Bearsden it is 3.8, however, it is not possible to conclude that Strathbungo/Pollokshields is eight times more deprived than Bearsden but only that it is more deprived. Therefore, the rank of each data zone comprising the case study areas relative to other data zones in the country provides a more meaningful relative picture of their overall deprivation than a comparison of their score. There are thirteen data zones that comprise the Strathbungo/ Pollokshields area, almost a quarter of these are amongst the top I5 per cent of most deprived data-zones in Scotland. There is variation between each as they are ranked between the $600^{\text {th }}$ most deprived areas in the country to the 4,42 Ist out of 6505 in the country.

\section{Amenities and services}

The Strathbungo/Pollokshields area is well served by a wide range of amenities, with Asian specialist facilities in most sectors. In the areas immediate vicinity there are three mosques, a Sikh temple, a house of worship for all faiths operated by the Sikh community centre and the Islamic Academy of Scotland (a centre of excellence in Islamic studies). There are also two community centres, a youth centre and a multicultural centre in the area that provide classes in English and Urdu as well as other courses and specific activities for women. There is an ethnic minority enterprise centre that provides training and assistance in finding employment, which also has a newly established bilingual support service for drug and alcohol users and their families. There are 
also Asian banks, an Islamic Relief charity shop, Asian grocery stores, two halal butchers, call centres with special rates to the Middle East and Asia, Bollywood DVD rentals, an Islamic education centre, a Koran school attached to the mosque as well as fourteen Asian dress and jewellery shops attracting shoppers from all over Scotland. There are 25 restaurants, bars and hot food takeaway shops in the area, thirteen of which are South Asian restaurants or takeaways, 29 retail outlets dealing in office, electrical, telecommunication, D.I.Y, clothing, sports and musical goods, five estate agents, two florists, one launderette, five newsagents, four furniture/interiors shops, fourteen hairdressers/beauticians, two chemists, one car dealer, two banks and one money lender, two general practice doctors surgeries, one optician and five dental surgeries (Glasgow City Council retail database).

The area lies within the catchment area of two primary schools (one non-denominational and one Roman Catholic), one of which is over 90 per cent Asian. There are a further three schools in close proximity to or within the area, and two nursery schools, however, there is no pre-school day care. The area lies within the catchment area of two secondary schools. There is a library and a learning centre in the area as well as a fashionable theatre on its parameter. The residents of the area are within five minutes driving time to a general practice doctor's surgery and a dentist and less than 30 minutes to a hospital (SPHO 2004). There is also a social work office in close proximity to the area.

\section{Woodlands}

Woodlands is situated in the West End of the city, lying to the east of Hillhead, to the west of the M8 and north of the city's park district. The University of Glasgow is situated on the fringe of the area, hence the reason for it accommodating a sizable student population. The area is thriving with ethnic businesses, bars and cafes. Its proximity to the M8 makes it a congested and busy thoroughfare. Woodlands has been home to a sizeable South Asian population for over three decades. The largest minority ethnic group resident in the area is Pakistani, followed by Indian and Chinese.The population of the area has a young age structure when compared to the Scottish average with only II per cent of the population being over 60 and 44 per cent of the population being under 24; this is of course reflective of the student population (see Table 6.I7). The median age is only 27, which is eleven years fewer than that for all of Scotland. 
Table 6.16 Population by ethnicity, Woodlands

\begin{tabular}{lrc}
\hline All people & 5,017 & \% of all people \\
\hline White Scottish & 2,897 & 57.7 \\
Other white British & 517 & 10.3 \\
White Irish & 141 & 2.9 \\
Other white background & 293 & 5.8 \\
Pakistani & 603 & 12 \\
Indian & 162 & 3.2 \\
Bangladeshi & 15 & 0.3 \\
Chinese & 166 & 3.3 \\
Other South Asian & 69 & 1.4 \\
African Caribbean & 5 & 0.1 \\
Black African & 36 & 0.7 \\
Other black & 7 & 0.2 \\
Any mixed background & 52 & 1 \\
Any other background & 54 & 1.1 \\
Total minority ethnic population & 1,169 & 23.3 \\
\hline
\end{tabular}

Source: 2001 Census; author's own analysis

Table 6.17 Population by age structure (\% of all people), Woodlands

\begin{tabular}{lc}
\hline Age & \% of all people \\
\hline $0-15$ & 11 \\
$16-24$ & 33 \\
$25-29$ & 13 \\
$30-44$ & 22 \\
$45-59$ & 10 \\
$60-74$ & 7 \\
75 and over & 4 \\
\hline
\end{tabular}

Note: Population base 5,017

Source: 2001 Census; author's own analysis

\section{Housing}

The Woodlands area is dominated by rented housing (both social and private), has major problems of overcrowding and yet has house prices close to the city average. Housing in the area is heavily influenced by the student market. The tenure structure of the area is contrasting to that of Glasgow City (see Table 6.18) and indeed Scotland. The number of all people living in the owner-occupied sector is 20 per cent lower than the national percentage at 42.7 per cent. The number of people in private renting is over three times that of all people nationally, at 3I per cent and 8 per cent respectively, again due to the student population.

The predominant house type in the area is flats (specifically old redstone tenement buildings), housing 95 per cent of all residents (see Table 6.I9). Thirty-two per cent of households live in overcrowded conditions compared to II. 8 per cent at the national level and 22 per cent at 
Table 6.18 Population by tenure (\% of all people), Woodlands

\begin{tabular}{|c|c|c|c|c|c|c|}
\hline \multicolumn{2}{|l|}{ Owned } & \multicolumn{2}{|l|}{ Social rented } & \multicolumn{2}{|c|}{ Private rented } & Live rent-free \\
\hline \multicolumn{2}{|l|}{42.7} & \multicolumn{2}{|l|}{23.5} & \multicolumn{2}{|l|}{31.4} & 2.4 \\
\hline \multicolumn{2}{|l|}{ Of which: } & \multicolumn{2}{|l|}{ Of which: } & \multicolumn{2}{|l|}{ Of which: } & \\
\hline $\begin{array}{l}\text { Owned } \\
\text { outright }\end{array}$ & 33.9 & $\begin{array}{l}\text { Rent from } \\
\text { council }\end{array}$ & 18 & $\begin{array}{l}\text { Private } \\
\text { landlord/ } \\
\text { agency }\end{array}$ & 89.8 & \\
\hline $\begin{array}{l}\text { With mortgage } \\
\text { or loan }\end{array}$ & 62.7 & $\begin{array}{l}\text { Other social } \\
\text { rented }\end{array}$ & 82 & Other & 10.2 & \\
\hline $\begin{array}{l}\text { Shared } \\
\text { ownership }\end{array}$ & 3.4 & & & & & \\
\hline
\end{tabular}

Note: Population base 5,017

Source: 2001 Census; author's own analysis

Table 6.19 Population by accommodation type (\% of all people), Woodlands

\begin{tabular}{lc}
\hline Accommodation type & \% of all people \\
\hline House/bungalow & 4.9 \\
Flat/maisonette/apartment & 95 \\
Caravan/mobile accommodation & 0.1 \\
\hline
\end{tabular}

Note: Population base 5,017

Source: 2001 Census; author's own analysis

the city level.There are also half as many households with extra space than at the national level and Io per cent less than the city wide percentage, revealing households in Woodlands to be more overcrowded than in Strathbungo/Pollokshields south of the river. Again, this is also likely to reflect at least in part the student residents. Fewer households in the area when compared to Strathbungo/Pollokshields are without central heating (see Table 6.2I). The average (median) house price in the area is $£$ IIO,300 (Register of Sasines 2003; author's own analysis) compared to the city average of $£ \mathrm{IO9}, \mathrm{I} 6_{3}$ (GSPC). Prices in the area ranged from $£ 20,000$ to $£ 755$,000.

\section{Economic indicators, deprivation index, social grades and qualifications}

The population of Woodlands is well qualified on the whole, although levels of qualification are low among the South Asian population. The population over sixteen in the area have higher representation in $A B$ social grades than at the city level, although not to the same extent as Strathbungo. Similarly, there are io per cent fewer people represented in social class $\mathrm{E}$ in the area than at the city level (see Table 6.22). As in Strathbungo, the levels of qualification of the population over age 
Table 6.20 Occupancy rating by household (\%), Woodlands

\begin{tabular}{lc}
\hline Occupancy rate* & \% of households \\
\hline+2 or more & 10.3 \\
+1 & 18 \\
0 & 39.1 \\
-1 & 21.5 \\
-2 & 11.1 \\
\hline
\end{tabular}

Note: Population base 2,324

Source: 2001 Census; author's own analysis

Table 6.21 Household amenities by household (\%), Woodlands

\begin{tabular}{lclc}
\hline & $\begin{array}{l}\text { \% of all } \\
\text { households }\end{array}$ & Of which: & $\%$ \\
\hline $\begin{array}{l}\text { Households with } \\
\text { central heating }\end{array}$ & 81 & $\begin{array}{l}\text { With shower/bath } \\
\text { and toilet } \\
\text { Without shower/ } \\
\text { bath and toilet } \\
\text { Total }\end{array}$ & 1.5 \\
$\begin{array}{l}\text { With shower/bath } \\
\text { and toilet } \\
\text { Without shower/ } \\
\text { without central }\end{array}$ & 19 & $\begin{array}{l}\text { bath and toilet } \\
\text { Total }\end{array}$ & 100 \\
heating & 100 & 95 & 5 \\
Total & & 100
\end{tabular}

Note: Population base 2,324

Source: 2001 Census; author's own analysis

Table 6.22 Social grade, all people over 16 (\%), Woodlands

\begin{tabular}{lc}
\hline Social grade & \% of all people over 16 \\
\hline AB & 23.6 \\
C1 & 26.9 \\
C2 & 8.6 \\
D & 17.7 \\
E & 23.2 \\
\hline
\end{tabular}

Note: Population base 4,166

Source: 2001 Census; author's own analysis

sixteen are highly differentiated according to ethnic group with total figures hiding disparities (see Table 6.23). However, there are fewer differences between ethnic groups than in Strathbungo/Pollokshields, as only twice as many white residents as Pakistani residents in Woodlands have group four level qualifications (compared with four times as many in Strathbungo/Pollokshields). The disparity is wider when those with no qualifications are considered as three times more Pakistani residents 
Table 6.23 Qualification by ethnic group, all people aged 16-74 (\%), Woodlands

\begin{tabular}{lcccccr}
\hline & All people & White & Indian & Pakistani & Chinese & Other \\
\hline \% of population aged 16-74 & \multicolumn{1}{c}{100} & 80 & 3.1 & 10.6 & 3.7 & 2.6 \\
No qualification & 21.4 & 16 & 39.8 & 48.4 & 47.2 & 17.4 \\
Group 1 & 9.7 & 8.9 & 12 & 14.1 & 10.3 & 10.4 \\
Group 2 & 28.1 & 31.8 & 12 & 11.1 & 16.4 & 22.6 \\
Group 3 & 7.7 & 7.9 & 7.5 & 8.2 & 4.2 & 6.1 \\
Group 4 & 33.1 & 35.4 & 28.7 & 18.2 & 21.9 & 43.5 \\
\hline
\end{tabular}

Note: Population base 4,292

Source: 2001 Census; author's own analysis

and two-and-a-half times more Indian residents have no qualifications than white residents.

The area performs no better than the city overall in terms of economic activity. The percentage of working-age people who are economically active reflects the percentage for Glasgow City (55.4 per cent), as does the percentage of economically inactive people in the area $(43.5$ per cent), yet it is 23 per cent higher than the Scottish average. The percentage of children in workless households is a significant 74 per cent higher as a percentage of the Scottish average. Likewise, the number of households with no car (58.9 per cent) is also over 70 per cent higher than the Scottish average. The index of deprivation score for Woodlands is 34.I6. There are, however, significant variations in the eleven data zones that comprise this area, one is ranked the 59th most deprived data zone in Scotland, which lies within the top I per cent of most deprived data zones in the country, whilst the least deprived data zone in the area is ranked 3793rd out of 6,505. Overall, 36 per cent of data zones are represented in the top 15 per cent of the most deprived data zones in Scotland.

Table 6.24 Economic indicators, Woodlands

\begin{tabular}{lc}
\hline Indicator & \% of people \\
\hline Economically active* & 56.44 \\
Economically inactive* & 43.5 \\
Unemployment claimants* & 4 \\
Income support claimants* & 13.3 \\
Children in workless households & 32 \\
Households without a car*** & 58.9 \\
\hline
\end{tabular}

Source: ScotPHO (2004) and Census 2001

* All people aged 16-74

** All households 


\section{Amenities and services}

The reasonably lengthy settlement of the South Asian population has led to the development of a community infrastructure in the immediate vicinity to meet specific cultural and religious needs. The area is home to two mosques, the headquarters of Radio Ramadam, The UK Islamic Mission, The Islamic Society of Britain, The United Muslim Organisation of Scotland, a Sikh temple and association centre and a Hindu temple. There are also seven Asian grocery shops, a halal butchers, an Asian cash and carry, halal takeaway restaurants, Asian silk stores and jewellery shops. The area has 3I cafes, bars, restaurants or takeaway restaurants, two confectioners, six hair dressers and beauticians, fourteen grocery shops (in addition to the seven Asian grocery shops), eleven office, photographic, electrical or communications shops, two sports/clothes shops, two alternative medicine centres, three furniture shops, two hotels, two travel agents, two opticians, two estate agents, two betting offices and one car dealer (Glasgow City Council retail database).

There are seven primary schools in close proximity to the area, including one Gaelic school (the area falls within the catchment area of two of them). There are two additional special needs primary schools, one of which houses a language unit. The area falls within the catchment areas of two secondary schools, one of which is Roman Catholic and the other non-denominational. The area also has five nurseries and two pre-aged five day care centres. Proximity to health care is good in this area, as all households are at least within a five-minute drive to a general practice doctor's surgery and a dentist and within a 30-minute drive to a hospital (SPHO 2004). The area is in close proximity to three public libraries, one adult educational centre, a community centre with a well developed timetable of events for youth, the YMCA and an E-skills drop-in centre. There are no social work offices in the area. The area has access to all city centre amenities being within a fifteento twenty-minute walk.

\section{Bearsden East (Kessington)}

Bearsden East is primarily a middle-class commuter suburb located approximately six miles to the north-west of Glasgow in the local authority district of East Dunbartonshire. Interestingly, a recent survey by EuroDirect, exploring the residential location of millionaires, listed Bearsden as having the seventh highest number of millionaires of any postcode sector in Britain (EuroDirect, 2005). The population of the area is predominantly White Scottish with 6.2 per cent of the 
population comprised of minority ethnic groups, which is over 4 per cent higher than their percentage of the Scottish population. The largest ethnic minority group in the area is Indian (see Table 6.25). The population of the area has an older age structure when compared to the two case study areas in the inner city with 27 per cent of the population being over 60 and 28 per cent of the population being under 24 (see Table 6.26). The median age is 45 compared to 38 in Scotland as a whole.

\section{Housing}

The tenure structure of the area is markedly different to that of Glasgow City and indeed Scotland, as the vast majority of the population, namely 96 per cent, are living in owner-occupied housing, over 40 per

Table 6.25 Population by ethnicity, Bearsden East

\begin{tabular}{lrc}
\hline All people & 6,398 & \% of all people \\
\hline White Scottish & 5,447 & 85.1 \\
Other white British & 369 & 5.8 \\
White Irish & 93 & 1.5 \\
Other white background & 93 & 1.5 \\
Pakistani & 90 & 1.4 \\
Indian & 194 & 3 \\
Bangladeshi & 7 & 0.1 \\
Chinese & 32 & 0.5 \\
Other South Asian & 26 & 0.4 \\
African Caribbean & 0 & 0 \\
Black African & 5 & 0.08 \\
Other black & 1 & 0.02 \\
Any mixed background & 16 & 0.2 \\
Any other background & 25 & 0.4 \\
Total minority ethnic population & 396 & 6.2 \\
\hline
\end{tabular}

Source: 2001 Census; author's own analysis

Table 6.26 Population by age structure (\% of all people), Bearsden East

\begin{tabular}{lc}
\hline Age & \% of all people \\
\hline $0-15$ & 17.4 \\
$16-24$ & 11.1 \\
$25-29$ & 2.9 \\
$30-44$ & 17.9 \\
$45-59$ & 23.8 \\
$60-74$ & 17.6 \\
75 and over & 9.3 \\
\hline
\end{tabular}

Note: Population base 6,398

Source: 2001 Census; author's own analysis 
Table 6.27 Population by tenure (\% of all people), Bearsden East

\begin{tabular}{|c|c|c|c|c|c|c|}
\hline \multicolumn{2}{|l|}{ Owned } & \multicolumn{2}{|l|}{ Social rented } & \multicolumn{2}{|l|}{ Private rented } & Live rent-free \\
\hline \multicolumn{2}{|l|}{96} & \multicolumn{2}{|l|}{1.7} & \multicolumn{2}{|l|}{1.8} & 0.5 \\
\hline \multicolumn{2}{|l|}{ Of which: } & \multicolumn{2}{|l|}{ Of which: } & \multicolumn{2}{|l|}{ Of which: } & \\
\hline Owned outright & 41.95 & Rent from council & 86.6 & $\begin{array}{l}\text { Private landlord/ } \\
\text { agency }\end{array}$ & 73.5 & \\
\hline $\begin{array}{l}\text { With mortgage } \\
\text { or loan }\end{array}$ & 58 & Other social rented & 13.4 & Other & 26.5 & \\
\hline Shared ownership & 0.05 & & & & & \\
\hline
\end{tabular}

Note: Population base 6,398

Source: 2001 Census; author's own analysis

Table 6.28 Population by accommodation type (\% of all people), Bearsden East

\begin{tabular}{lc}
\hline Accommodation type & \% of all people \\
\hline House/bungalow & 89.5 \\
Flat/maisonette/apartment & 10.46 \\
Caravan/mobile accommodation & 0.04 \\
\hline
\end{tabular}

Note: Population base 6,398

Source: 2001 Census; author's own analysis

cent of which is owned outright. The house type is also distinct to that in the core areas of settlement as 89 per cent of all people live in houses or bungalows. Only 2.I per cent of households are overcrowded and almost 90 per cent of households have more space than they need (See Table 6.29). Similarly, less than two per cent of households are without central heating. The average (median) house price in the area is $£ 200,000$ ( 83 per cent higher than the Glasgow City average, reflecting both location and the predominance of houses over flats), with prices ranging between $£ 40,000$ and $£$ I, I00,000 (Register of Sasines 2003; author's own analysis).

\section{Economic indicators, deprivation index, social grades and qualifications}

Bearsden East is an area of high social class and high qualifications. Ethnic minorities living in Bearsden East also have more qualifications than those in the corresponding core settlement area of Woodlands. Almost 80 per cent of people of working age in the area are represented in social grades $\mathrm{AB}$ or $\mathrm{CI}$, twice that of Glasgow City. In line with this, there are two-thirds fewer people represented in social grade $\mathrm{E}$ compared to the city level. In terms of qualifications, again we see differences according to ethnic group in the area, with two-and-a-half times as many Pakistanis as white residents having no qualifications. This is 
Table 6.29 Occupancy rating by household (\%), Bearsden East

\begin{tabular}{ll}
\hline Occupancy rate* & $\%$ by households \\
\hline+2 or more & 69 \\
+1 & 20.1 \\
0 & 7.8 \\
-1 & 2.2 \\
-2 & 0.9 \\
\hline
\end{tabular}

Note: Population base 2,463

Source: 2001 Census; author's own analysis

Table 6.30 Household amenities by household (\%), Bearsden East

\begin{tabular}{|c|c|c|c|}
\hline & $\begin{array}{l}\% \text { of all } \\
\text { households }\end{array}$ & Of which: & \\
\hline \multirow{3}{*}{$\begin{array}{l}\text { Households } \\
\text { with central } \\
\text { heating }\end{array}$} & \multirow[t]{3}{*}{98.1} & $\begin{array}{l}\text { With shower/ } \\
\text { bath and toilet }\end{array}$ & 99.9 \\
\hline & & $\begin{array}{l}\text { Without shower/ } \\
\text { bath and toilet }\end{array}$ & 0.1 \\
\hline & & Total & 100 \\
\hline \multirow{3}{*}{$\begin{array}{l}\text { Households } \\
\text { without } \\
\text { central } \\
\text { heating }\end{array}$} & \multirow[t]{3}{*}{1.9} & $\begin{array}{l}\text { With shower/ } \\
\text { bath and toilet }\end{array}$ & 100 \\
\hline & & $\begin{array}{l}\text { Without shower/ } \\
\text { bath and toilet }\end{array}$ & 0 \\
\hline & & Total & 100 \\
\hline Total & 100 & & \\
\hline
\end{tabular}

Note: Population base 2,463

Source: 2001 Census; author's own analysis

again the case for those with the highest qualifications, with around I5 per cent more of white residents having group four qualifications than Indian and Pakistani residents. However, it is also worth noting that compared to Pakistanis in the inner-north core settlement of Woodlands, Pakistanis in Bearsden East are much more likely to have the highest level (four) of qualifications. This contrast does not hold for Indians or Chinese.

The percentage of working-age people who are economically active is Io per cent higher than the percentage for Glasgow City (55.4 per cent) and similarly, the percentage of economically inactive people in the area is also Io per cent less than that of Glasgow City and 3 per cent less than the Scottish average. Less than 5 per cent of children live in workless households, which is over 77 per cent lower as a percentage of the Scottish average. Car ownership in the area is very high, only nine per cent of all households do not own a car. The index of deprivation score for this area is 3.8 and all the data zones that comprise this area are represented amongst the top 15 per cent of least deprived data zones in the country. 
Table 6.31 Social grade all people over 16 (\%), Bearsden East

\begin{tabular}{ll}
\hline Social Grade & \% of all people over 16 \\
\hline $\mathrm{AB}$ & 45.2 \\
$\mathrm{C} 1$ & 33.9 \\
$\mathrm{C} 2$ & 6 \\
$\mathrm{D}$ & 4.9 \\
$\mathrm{E}$ & 10 \\
\hline
\end{tabular}

Note: Population base 5,221

Source: 2001 Census; author's own analysis

Table 6.32 Qualification by ethnic group, all people aged 16-74 (\%), Bearsden East

\begin{tabular}{lllllll}
\hline & All people & White & Indian & Pakistani & Chinese & Other \\
\hline \% of population aged 16-74 & 100 & 93.8 & 3.2 & 1.7 & 0.6 & 0.7 \\
No qualification & 15.4 & 14.5 & 25.6 & 36.6 & 37 & 24.2 \\
Group 1 & 15.1 & 15.6 & 17.1 & 14.7 & 22.2 & 10.3 \\
Group 2 & 19.7 & 19.7 & 19.7 & 17.1 & 25.9 & 10.3 \\
Group 3 & 7.7 & 7.6 & 9.9 & 2.4 & 3.7 & 6.9 \\
Group 4 & 42.1 & 42.6 & 27.7 & 29.2 & 11.3 & 48.3 \\
\hline
\end{tabular}

Note: Population base 4,691

Source: 2001 Census; author's own analysis

Table 6.33 Economic indicators, Bearsden East

\begin{tabular}{ll}
\hline Indicator & \% of people \\
\hline Economically active* & 65.9 \\
Economically inactive* & 34.1 \\
Unemployment claimants* & 1.3 \\
Income support claimants* & 3.3 \\
Children in workless households & 4.3 \\
Households without a car*** & 9.4 \\
\hline
\end{tabular}

Source: ScotPHO (2004); Census 2001

* All people aged 16-74

$* *$ All households

\section{Amenities and services}

Bearsden has no formal places of worship for faith groups other than Christian. There are two associations in the area for South Asian groups, one run by the council (The Minority Ethnic Forum in East Dunbartonshire) and one run by South Asian residents in the area (The Bearsden Asian Association), which provides education in Urdu and Arabic Studies in the local school hall. There are two primary schools and one secondary school in the area and a special needs school in the vicinity. There is also a language support team that operates within schools in the area to work with bilingual pupils. There are no libraries in the area, but in close proximity. Proximity to health 
services is also good; all households are within five minutes drive of a general practice doctor's surgery and a dental surgery and within at least a 30-minute drive to a hospital (SPHO 2004). Bearsden has a small number of retail and service outlets including three supermarkets, three banks, property services, specialist clothes shops, an alternative health therapy centre, a few delicatessens and cafes, several takeaway restaurants and a limited number of restaurants.

\section{Giffnock}

Giffnock is an affluent residential commuter suburb located five miles south of Glasgow's city centre in the district of East Renfrewshire. The population of the area is 82 per cent White Scottish with 8.5 per cent of the population comprised of minority ethnic groups (see Table 6.34). The area is also home to Scotland's largest Jewish community. The population of the area has a slightly younger age structure than that of Bearsden yet older than the two areas of core settlement, with 22.3 per cent of the population being over 60 and 33 per cent of the population being under 24 (see Table 6.35). The median age is $42 \mathrm{com}$ pared to 38 in Scotland as a whole.

\section{Housing}

The tenure structure of the area is almost wholly owner-occupied, like that of Bearsden and contrasting to that of Glasgow City and, indeed, Scotland (see Table 6.36). Again, on a parallel with Bearsden 92 per

Table 6.34 Population by ethnicity, Giffnock

\begin{tabular}{lrc}
\hline All people & 9,125 & \% of all people \\
\hline White Scottish & 7,553 & 82.8 \\
Other white British & 395 & 4.3 \\
White Irish & 195 & 2.2 \\
Other white background & 183 & 2 \\
Pakistani & 486 & 5.3 \\
Indian & 169 & 2 \\
Bangladeshi & 2 & 0.03 \\
Chinese & 62 & 0.7 \\
Other South Asian & 2 & 0.03 \\
African Caribbean & 3 & 0.04 \\
Black African & 5 & 0.1 \\
Other black & 0 & 0 \\
Any mixed background & 24 & 0.3 \\
Any other background & 21 & 0.2 \\
Total minority ethnic population & 774 & 8.5 \\
\hline Source: 2001 Census; authors & &
\end{tabular}

Source: 2001 Census; author's own analysis 
Table 6.35 Population by age structure (\% of all people), Giffnock

\begin{tabular}{ll}
\hline Age & \% of all people \\
\hline $0-15$ & 21 \\
$16-24$ & 11 \\
$25-29$ & 2.9 \\
$30-44$ & 19.9 \\
$45-59$ & 22.9 \\
$60-74$ & 13.9 \\
75 and over & 8.4
\end{tabular}

Note: Population base 9,125

Source: 2001 Census; author's own analysis

Table 6.36 Population by tenure (\% of all people), Giffnock

\begin{tabular}{|c|c|c|c|c|c|c|}
\hline \multicolumn{2}{|l|}{ Owned } & \multicolumn{2}{|l|}{ Social rented } & \multicolumn{2}{|l|}{ Private rented } & Live rent-free \\
\hline \multicolumn{2}{|l|}{97} & \multicolumn{2}{|l|}{0.8} & \multicolumn{2}{|l|}{1.4} & 0.8 \\
\hline \multicolumn{2}{|l|}{ Of which: } & \multicolumn{2}{|l|}{ Of which: } & \multicolumn{2}{|l|}{ Of which: } & \\
\hline \begin{tabular}{|l|} 
Owned \\
outright
\end{tabular} & 36.8 & $\begin{array}{l}\text { Rent from } \\
\text { council }\end{array}$ & 47 & $\begin{array}{l}\text { Private landlord/ } \\
\text { agency }\end{array}$ & 68 & \\
\hline $\begin{array}{l}\text { With } \\
\text { mortgage } \\
\text { or loan }\end{array}$ & 63.2 & $\begin{array}{l}\text { Other social } \\
\text { rented }\end{array}$ & 53 & Other & 32 & \\
\hline Shared ownership & 0 & & & & & \\
\hline
\end{tabular}

Note: Population base 9,125

Source: 2001 Census; author's own analysis

Table 6.37 Population by accommodation type (\% of all people), Giffnock

\begin{tabular}{lc}
\hline Accommodation type & \% of all people \\
\hline House/bungalow & 92 \\
Flat/maisonette/apartment & 8 \\
Caravan/mobile accommodation & 0 \\
\hline
\end{tabular}

Note: Population base 9,125

Source: 2001 Census; author's own analysis

Table 6.38 Occupancy rating by household (\%), Giffnock

\begin{tabular}{ll}
\hline Occupancy rate*: & \% of households \\
\hline+2 or more & 63.3 \\
+1 & 21.9 \\
0 & 11 \\
-1 & 2.9 \\
-2 & 0.9 \\
\hline
\end{tabular}

Note: Population base 3,402

Source: 2001 Census; author's own analysis 
Table 6.39 Household amenities by household (\%), Giffnock

\begin{tabular}{|c|c|c|c|}
\hline & $\begin{array}{l}\text { \% of all } \\
\text { households }\end{array}$ & Of which: & $\%$ \\
\hline $\begin{array}{l}\text { Households } \\
\text { with central }\end{array}$ & 98.4 & $\begin{array}{l}\text { With shower/ } \\
\text { bath and toilet }\end{array}$ & 99.94 \\
\hline \multirow[t]{2}{*}{ heating } & & $\begin{array}{l}\text { Without shower/ } \\
\text { bath and toilet }\end{array}$ & 0.06 \\
\hline & & Total & 100 \\
\hline $\begin{array}{l}\text { Households } \\
\text { without }\end{array}$ & 1.6 & $\begin{array}{l}\text { With shower/ } \\
\text { bath and toilet }\end{array}$ & 100 \\
\hline \multirow[t]{2}{*}{$\begin{array}{l}\text { central } \\
\text { heating }\end{array}$} & & $\begin{array}{l}\text { Without shower/ } \\
\text { bath and toilet }\end{array}$ & 0 \\
\hline & & Total & 100 \\
\hline Total & 100 & & \\
\hline
\end{tabular}

Note: Population base 3,402

Source: 2001 Census; author's own analysis

cent of people live in houses or bungalows. In terms of space, 85 per cent of households have more space than they need, less than 4 per cent are overcrowded (see Table 6.38) and less than 2 per cent of households are without central heating. The average (median) house price in the area is $£$ I75,000 (60 per cent higher than the Glasgow City average), with prices ranging between $£ 45,000$ and $£ \mathrm{I}, 250$,000 (Register of Sasines 2003; author's own analysis).

\section{Economic indicators, deprivation index social grades and qualifications}

Over three quarters of people of working age in the area are represented in social grades $\mathrm{AB}$ or $\mathrm{Cr}$ (See Table 6.40). Like Bearsden, there are twothirds fewer people represented in social grade E compared to Glasgow City. As in all of the other case study areas there are disparities amongst ethnic groups in qualification levels. However, this is less apparent in Giffnock amongst the Indian group who are well represented in group four with the highest level qualifications. Pakistanis in the area again fare badly in educational levels compared to their white counterparts, but markedly better than those Pakistanis living in the core. In Giffnock, twice as many white residents are represented in group four compared to Pakistanis, whereas in Pollokshields the ratio is four to one.

The percentage of working-age people who are economically active is almost 70 per cent, the highest in any of the case study areas, as levels of economic inactivity are lowest. Car ownership in the area is very high, but slightly lower than in Bearsden with only $\mathrm{I} 3$ per cent of all households not owing a car (see Table 6.42). The index of deprivation for this area is 4.9 and 70 per cent of data zones that comprise this area are represented amongst the highest 15 per cent of least deprived 
data zones in Scotland. Furthermore, Giffnock is home to the least deprived data zone in the country ranked in 6505 th place.

\section{Amenities and services}

The East Renfrewshire council is renowned for having a high achieving educational system. There are no nursery schools in the area but two in the neighbouring Thornliebank. There are two primary schools in the area and one secondary school, which is one of the top performing state secondary schools in Scotland. There is also a library in the area that provides several courses, including ICT. There are several places of

Table 6.40 Social grade, all people over 16 (\%), Giffnock

\begin{tabular}{lc}
\hline Social grade & \% of all people over 16 \\
\hline AB & 41.3 \\
C1 & 35.2 \\
C2 & 6.2 \\
D & 6.2 \\
E & 11.1 \\
\hline
\end{tabular}

Note: Population base 7,150

Source: 2001 Census; author's own analysis

Table 6.41 Qualification by ethnic group, all people aged 16-74 (\%), Giffnock

\begin{tabular}{lcccccc}
\hline & All people & White & Indian & Pakistani & Chinese & Other \\
\hline \% of population aged 16-74 & 100 & 91.8 & 1.8 & 5.4 & 0.5 & 0.5 \\
No qualification & 16.8 & 14.9 & 33.6 & 38.7 & 57.1 & 18.2 \\
Group 1 & 17.8 & 18 & 12.1 & 17.5 & 8.6 & 18.2 \\
Group 2 & 20.7 & 21.2 & 17.2 & 15.5 & 5.7 & 21.1 \\
Group 3 & 8 & 8.2 & 3.4 & 8.6 & 5.7 & 3 \\
Group 4 & 36.7 & 37.7 & 33.6 & 19.7 & 22.9 & 39.4 \\
\hline
\end{tabular}

Note: Population base 6,463

Source: 2001 Census; author's own analysis

Table 6.42 Economic indicators, Giffnock

\begin{tabular}{ll}
\hline Indicator & \% of people \\
\hline Economically active* & 67.6 \\
Economically inactive* & 32.4 \\
Unemployment claimants* & 1.2 \\
Income support claimants* & 3.4 \\
Children in workless households & 4.1 \\
Households without a car*** & 13.3 \\
\hline
\end{tabular}

Source: ScotPHO (2004); Census 2001

* All people aged 16-74

** All households 
worship in Giffnock for Christians as well as a synagogue and a Jewish community centre, but no places of worship for other faith groups. There are limited associations or facilitates representing/catering for other faiths in the area other than the Hindu Welfare and Cultural Association. Giffnock has more financial services and retail outlets than Bearsden. There are five banks in the area, a post office, several property services and developers, over ten restaurants, one large supermarket, as well as bakeries, butchers and confectionary shops, two car dealers, a sports centre, a wholesale catering outlet and a garden centre.

\section{South Asian housing transactions: Nam Pehchan results}

Following the case study selection, Sasines data (of housing transactions) for each of the areas was analysed using Nam Pehchan (names analysis software) to identify the housing transactions made by South Asians over the study period. The utility of this was twofold: first, it allowed us to identify households to be contacted as potential interviewees; and second, provided information on South Asian activity in each of the housing markets. Information was also generated from this analysis on the language and religious origin of the South Asians who had bought in these areas, which is presented in Tables 6.43 and 6.44.

The majority of South Asian housing transactions in three of the study areas were made by Muslims, as could be expected when considering their representation in each of these areas. Notably, however, in Bearsden the percentage of South Asian buyers who were Muslim was considerably lower than in the other areas whilst a higher percentage of South Asian buyers were from Sikh or Hindu origins (Table 6.43). Similarly, Nam Pehchan identified the South Asian names to be predominantly related to Muslim languages, especially so in Strathbungo/ Pollokshields and Giffnock. In Woodlands and Bearsden East, although more names were associated with Muslim languages than other languages, there was a significantly higher association with Punjabi and Hindi languages, most likely representative of the larger Indian populations in these areas (Table 6.44).

\section{Conclusion}

Over the ten years from I99I to 200I, Glasgow has seen localised changes in its South Asian population. Alongside continued patterns of ethnic clustering, we see notable dispersal to suburban areas as well as a more localised dispersal to the areas surrounding the traditional areas of core settlement. The analysis of the census found very 
Table 6.43 Percentage of South Asian buyers in study areas, 1991-2003, with breakdown by religious origin of name

\begin{tabular}{lcccc}
\hline & $\begin{array}{c}\text { Strathbungo/ } \\
\text { Pollokshields }\end{array}$ & Woodlands & Bearsden East & Giffnock \\
\hline Total number of transactions & 4,512 & 2,241 & 1,612 & 2,563 \\
\% of buyers from South & 24 & 18.5 & 6.2 & 7.13 \\
Asian origin & $\%$ & $\%$ & $\%$ & $\%$ \\
Of which: & 87.3 & 66.7 & 38.0 & 76.5 \\
Muslim & 1.1 & 5.8 & 17.0 & 2.2 \\
Hindu & 5.1 & 9.7 & 24.0 & 9.8 \\
Sikh & 0.0 & 0.0 & 0.0 & 0.0 \\
Buddhist & 0.0 & 0.0 & 0.0 & 0.0 \\
Other & 6.5 & 17.8 & 21.0 & 11.5 \\
Common & 100 & 100 & 100 & 100 \\
Total & & & & \\
\hline
\end{tabular}

Table 6.44 Percentage of South Asian buyers in study areas, 1991-2003, with breakdown by language origin of name

\begin{tabular}{lcccc}
\hline & $\begin{array}{c}\text { Strathbungo/ } \\
\text { Pollokshields }\end{array}$ & Woodlands & Bearsden & Giffnock \\
\hline \% of buyers from South Asian origin & 24 & 18.5 & 6.2 & 7.13 \\
Of which: & $\%$ & $\%$ & $\%$ & $\%$ \\
Bengali & 0.2 & 0.5 & 0.0 & 0.0 \\
Gujerati & 0.0 & 0.0 & 0.0 & 0.0 \\
Hindi & 0.0 & 0.0 & 0.0 & 0.0 \\
Punjabi & 2.3 & 6.0 & 15 & 3.8 \\
Pushtu & 0.0 & 0.0 & 0.0 & 0.0 \\
Singhalese & 0.0 & 0.0 & 0.0 & 0.0 \\
Sylheti & 0.0 & 0.0 & 0.0 & 0.0 \\
Tamil & 0.0 & 0.0 & 0.0 & 0.0 \\
Urdu & 16.5 & 13.5 & 5.0 & 10.9 \\
Muslim language & 70.5 & 54.8 & 40 & 68.3 \\
Hindu language & 3.7 & 14.0 & 20 & 7.1 \\
Common & 6.8 & 11.1 & 20 & 9.9 \\
Other & 0.0 & 0.0 & 0.0 & 0.0 \\
Total & 100 & 100 & 100 & 100 \\
\hline
\end{tabular}

different patterns in the area of core settlement north of the river to those in the areas to the south. In the areas of core settlement to the south of river, such as Strathbungo, Pollokshields and Pollokshaws, the South Asian population experienced considerable growth. The areas directly adjacent to and surrounding the area with the largest South Asian population in the city, in both I99I and 200I, experienced considerable expansion in their South Asian population. It is unclear as to whether or not this is related to overspill or whether it represents a smaller scale and 'closer to home' local dispersal to the periphery of 
the core. In the core settlement areas to the north, Woodlands and Garnethill, there was a decrease in the South Asian population as well as changes in the composition of ethnic groups that make up the areas populations. The same was verified in the areas neighbouring the core. It is possible that north-to-south movement has occurred between the areas of core settlement, but again this needs to be explored further.

The most evident change in South Asian residence during the census period was the extent to which South Asian households had begun to establish themselves in the suburbs. This is apparent through notable population shifts to suburbs that in I99I had very small South Asian populations and further to the suburbs surrounding them. Again, patterns differed between those areas to the north and south of the river, with the suburbs in the north-west experiencing a modest increase in the absolute number of South Asian households living there, in the context of a decreasing white population. In the southern suburbs, growth in the South Asian population was more significant, starting from a larger population base than in the northern suburbs, with an increase of 82 per cent across the East Renfrewshire district. The flows of suburban movers appear to have followed a similar trajectory out of the inner city to areas that can be easily accessed by the main transport routes out of the city centre, which pass through the areas of core settlement. Indeed, there was also an increase in the South Asian population in the intermediary areas along these routes between the core and the suburbs.

The results from the indices of dissimilarity and segregation point to a modest drop in segregation over time, being slight in the case of the Pakistanis. Despite this, the clustering analysis at output area was interesting. The majority of South Asians in the suburbs to the south, and intermediate areas between them and the core, live in output areas where at least 80 per cent of the population is white. Thus, although there is evidence of re-clustering in the suburbs, it is on a very small scale. This study also showed that Pakistanis and Indians exhibited different patterns of settlement. It appears that Pakistanis generally tend to reside in a narrow strip of the conurbation, forming a column out of the core to the south, albeit widening a bit into adjacent and intermediate areas. Whereas the Indian population are spread more widely across areas both in inner and outer Glasgow, forming more of a double arc of settlement rather than a column. As in previous periods, there was no movement of the South Asian population into the East End of the city, which is likely to reflect perceptions of safe places in the city. The ensuing three chapters, based on qualitative data collected in the four case study areas, will explore the causes and motivations underpinning the residential patterns outlined here. 


\section{The role of the neighbourhood in residential choice and re-location}

\section{Introduction}

Environmental factors and the role of the neighbourhood have been widely discussed in the literature as factors fundamental in decisions leading to residential change. Early attempts to theorise or explain residential mobility, more generally, saw movement as a result of rational decisions based upon both personal and environmental factors (Rossi I955). The ethnic cluster, or traditional area of core settlement, has been well documented in European literature; however, less has been written about the effects that these neighbourhoods and indeed personal differentials of those who live there have on forming residential choice. The literature has tended to focus more on the pull factors or advantages of the ethnic community and cultural facilities (Peach \& Smith I98I; Sanders \& Nee I996; Aldrich, Cater, Jones \& McEvoy I98I) or on the negative aspects of ethnic concentration in terms of its association with poverty and limited opportunities (Smith I989; Schill I992; Morris I987; Peach I992; Massey \& Denton I993; Phillips I998) or with its role in preventing integration (Independent Review Team 200I; Home Office 200I). It has focused less on the ways in which the core as a dynamic neighbourhood creates an impetus, acting as a push, for some households to move. In this instance, the area of core settlement and the social network there were found to act as both a pull factor and, less commonly discussed, a push factor in influencing residential decisions.

The suburbs have been presented in the literature as offering a refuge from the disadvantages of city living, yet criticised as places of conformity and for promoting status divisions. Perhaps above all, they have come to represent a symbol of upward mobility (Thorns I972). However, with the post-war expansion of British cities opened up a new type of suburb that offered both social rented property and more affordable owner-occupied housing, rendering them more accessible to the working classes. South Asian households were excluded from this process for several reasons, including institutional discrimination, discrimination in the housing market, fear of harassment, lack of resources or lack of interest for varying reasons. Indeed, it is not in 
either of the two aforementioned newer suburbs that they have begun to establish themselves, rather in the middle-class suburbs that have continued to signify progress or status.

This chapter aims to explore residential motivations related to the role of the specific core neighbourhoods and suburbs where the interviews were conducted and is structured as follows. The first section gives a brief outline of the different types of moves the participants made between neighbourhoods and discusses the paths along which migrating South Asian households moved through the city, as well as considering the accessibility of different areas. The second section looks specifically at the role of the area of core settlement and considers the ways in which it continues to attract new migrants, retain old ones and influences the decision of some households to move out. The third section explores factors that have seen suburbia emerge as a residential preference, both from the perspective of suburban residents and those who have remained in the area of core settlement.

\section{Moves between neighbourhoods: Paths through the city}

Traditionally, the area of core settlement acted as a reception area for new migrants to Glasgow and continues to play such a role even today. Some of the interviewees resident in the area of core settlement had moved straight to the core on arrival to Glasgow or earlier migrants had moved from the Gorbals, an area in Glasgow's inner city where the majority of minority ethnic groups lived before slum clearance. Others had moved within the area of core settlement, between core settlement areas or reverse moved from the suburbs. As for the suburban interviewees, the most common move made was from an area of core settlement in Glasgow. Several other households interviewed had moved within the suburbs and, much less commonly, a couple of households had moved from outside Glasgow straight to the suburbs.

The residential moves of the interviewees and their commentary on the moves of others they knew tended to take a similar path through the city depending on the core area of origin. For example, those interviewees living in the suburbs on the south of the city had, in the majority, moved from the core settlement on the south, whilst those living in the suburbs on the north-western edge of the city moved from the area of core settlement in the West End of the city north of the river Clyde. Past literature has documented the beginnings of similar patterns of movement to the suburbs (Binns 2002; Dalton \& Daghlian I989), which, from the qualitative evidence presented here, can be related to the closeness of the new area to the core, familiarity of the new area and its closeness to other family members. 
Examining the narratives of interviewees, both of those who had remained in the ethnic clusters and those who had dispersed, it is clear that a large number of them have a narrow sense of place(s) that they feel they can negotiate with or live in. This is related to several different factors at differing levels of importance, including: the sense that they would be accepted in the area; previous knowledge of that area (especially regarding types of neighbours and issues of safety); and the presence of other South Asians in the area. Additionally, it is likely that this is also related to the fact that the areas mentioned frequently by the interviewees are those with high status and good reputations, where it would be expected that a good proportion of the broader/general population would desire to live. There was a distinct generational element to this, as younger respondents had a much wider geographical sense of potential areas to live in. They were less restricted to areas that, with the moves of other South Asians, had become in some sense connected to the core. These interviewees felt they were able to maintain ties and negotiate their chosen lifestyle by living any distance away, as foremost they were willing to travel and had transportation (car ownership). The areas they aspired to live in branched beyond the suburbs to satellite commuting towns and in some instances much further to international destinations. One key factor that may explain this broader personal geography of the city is the fact that the majority had attended some type of higher education institution in other areas of the city. This served to increase their familiarity with other areas and confidence in travelling through the city. Areas of contact were also multiplied through social contacts made with fellow students. To the contrary, elderly and middle-aged respondents frequently expressed a preference to remain in the core and a large proportion of those middle-aged respondents who had future aspirations to move had only considered the few suburbs where South Asians were already established. Primarily, this was due to a fear of moving to an area without any prior knowledge of whether the neighbours were 'good'. Moreover, it was closely linked to sense of safety, the importance of the areas reputation and importantly with ties to the core settlement area, their home and the community.

\section{The role of the area of core settlement}

Cultural explanations have explained minority ethnic clustering as being a choice, based upon the desire to preserve culture and reflective of a rational decision to live in close proximity to others with the same ethnic and religious background and language and dietary needs (Dahya I974; Peach I998). Some of the older respondents who had lived in the core area for a long time and relied on the support of the ethnic 
and religious community exemplified this explanation. Similarly, the familiarity of the area of core settlement was most important for recent migrants still adjusting to a new country and language. Several of the interviewees highlighted language as a significant factor attracting new households to the areas of core settlement. Testament to this is the story of one man who had moved with his family from India just over one year ago. He depended on others in the area to help him to communicate in formal situations, such as banking and matters involving the state (normally relating to welfare and immigration issues), and to learn English. He had learned of areas which had developed Asian communities from a friend, who had lived in the UK in the past, and selected Pollokshields before his move from India. Longer established residents confirmed this and accentuated the important role of the neighbourhood in helping new migrants settle. In the words of one resident of the core area:

It is good (to live in the core) for your own basic needs, for your own religion and culture and things like that, places of worship, you know these kinds of things. I think there are more and more people actually moving into Pollokshields for these basic things, especially if you talking about people moving here from Pakistan. They want to come somewhere where they are not going to feel alienated, where they can speak the language and get the help to learn English.

(Mrs. Hussein, Strathbungo/Pollokshields, southern core)

Three men interviewed in the core settlement area, one who had moved relatively recently and two who had been living in the country for over ten years, felt that they were tied to the traditional area of settlement as their wives, who had moved later, could not speak English. Although believing that a better quality of life was available in other areas in the city, they were reluctant to move as they each worked outside of the area and felt that it was important for their wives to interact socially and receive support from neighbours. In the words of one of these men:

The thing is I go to work in another area where I have my business, but for my wife it's easier for her to get food because the shops are here and plus to give Islamic education to the kids it's easiest to stay here because she can't drive. I feel there is opportunity for a better life a wee bit farther out, but the only problem is she can't speak English, so we have to stay here.

(Mr. Dhaliwal, Strathbungo/Pollokshields, southern core) 
A key aspect of the area of core settlement that attracted or retained residents was the religious and cultural infrastructure that had developed over the past thirty years. Shops selling specialist Asian foods were considered the most necessary cultural facility. For Pakistani interviewees, all of whom were Muslim, the importance of cultural and religious facilities coincided, as access to establishments selling halal products was necessary for religious observance. For women in the child rearing stage of the life cycle and retired men, frequenting the local Asian shops provided daily social contact and a chance to socialise with others in the neighbourhood. Despite this, the majority of residents from the areas of core settlement said that the local Asian shops and other cultural facilities would not be a factor that would keep them in the area, whereas the mosque, the local social network and family might.

The importance of religious facilities and having easy access to them in making the core neighbourhoods attractive differed according to ethnic group, religion and personal religious observance. Indian interviewees considered it of less importance to have access to religious facilities in the area that they lived. This was related with the nature of worship, which more frequently involved private and personal reflection in the home and less public or congregational worship. Most frequented religious facilities no more than once a week - least frequently, once every two months - or for community celebrations such as weddings or religious festivals. In the words of one woman:

I feel religion is a very personal thing it's a private thing, it should not be paraded in front of everybody. I tend to make the children pray at home and then once a month or once every two months we go to the temple. We all get together and they see the community spirit, they see everything. But to go there everyday or even every week I feel it is too much you know because it starts in the home, you know at home, not just outside.

(Mrs. Singh, Giffnock, southern suburb)

Interestingly, among the Indian interviewees there was no desire to have temples or places of worship in areas where people lived outside of the core. This was related to a fear that having numerous local temples throughout the city would break the community into smaller groups, whereas travelling into a central place of worship would keep the community spirit stronger, as well as ensuring that people were 'integrated' throughout the city. As one Hindu couple commented:

I don't think there would be much benefit for us in having a temple in the local area, apart from as you grow older you may go to 
it occasionally. We just have one temple (Hindu) and there's no need for any more than that. Everybody has their own temple at home... we have an altar but you don't have to have an altar either. It's a different type of religion. We like to go to the temple but if there were lots temples here there and everywhere then the whole community would not all come together to meet and worship, we would be split up.

(Mr. and Mrs. Khan, Giffnock, southern suburb)

For the Pakistani interviewees, all of whom were Muslim, there was a very different need to be met due to the daily nature of worship. Some households made several trips to the mosque on a daily basis for different purposes, men for daily prayers and meetings and children for Koran school. This rendered a heavy commuting burden on those living outside of the core, seen by several families as a considerable draw back to living in the suburbs. It was for this reason that two interviewees had moved back to the core from the suburbs. As one of these interviewees describes:

I have six children and to trek back and forth, back and forth to bring the children to mosque school and then to go to daily prayers myself it was just too difficult, so I had to move back to Woodlands. We never got to relax in our house.

(Mr. Sood, Woodlands, northern core)

In both cases it was undoubtedly a practical issue, however, for one of the respondents the reverse move was also related with the desire to live close to their family again. More generally, however, the close social ties that frequenting the mosque fostered was important to all of those interviewed and was a positive aspect of living close to religious facilities and a drawback of living further away. A number of suburban residents had tried to resolve this by establishing informal facilities in local homes, whereby a class of students gathered in a neighbour's house for Koran school. Furthermore, several Pakistani interviewees thought that formal religious facilities in the suburbs would act as an impetus for people to leave the core, as they considered this the single most important factor in retaining households there. As one man commented:

If there was a mosque in Giffnock more people would move there because there is also a quality school and that is one thing that people want is a quality education for their children. But if the mosque is the top priority to yourself you can't have the best 
school or the best of both worlds.

(Mr. Saeed, Giffnock, southern suburb)

Informal religious facilities for teaching women and children in the suburbs had begun to act in a similar way to the formal religious facilities in the core area, as a factor that retained Pakistani Muslims in the area, discouraging them to move further out of the city, as explained by the following woman:

A teacher comes to somebody's house, it's handy, we pay him to come out this way. If we moved further out of Glasgow there wouldn't be as many people, so you just couldn't do it and you would spend half of your day in Glasgow, coming back, driving in and out to make sure the children received proper religious education.

(Mrs. Mir, Giffnock, southern suburb)

Despite the clear benefits of living in an ethnic cluster, there were aspects of living in the core settlement area which interacted with individual factors, such as increasing affluence and the birth of children, to compel some households to move. The close-knit nature of the social network in the core was seen as being invasive in the personal lives of some Pakistani and Indian interviewees, and a move to the suburbs was often tied-up with the desire for more privacy. Core residents also imparted stories of people moving to areas adjacent to the core to loosen ties with the community. Women especially felt that their behaviour was 'policed' and found it a struggle to keep their private life out of public conversation. In the words of a woman who had moved with her family to the suburbs:

You would go out to get a pint of milk and it would take about an hour because you would meet five people on the way to the shops. They're like that: 'God', you know, 'where have you been?' You know: 'I've just been out to get milk and oh god guess who I saw?' And you stop and you talk and it's like: 'Oh my god did you see that?’ Or whatever. We wanted to have privacy, you know?

(Miss Ali, Giffnock, southern suburb)

The desire to retreat to the suburbs for more privacy and autonomy was not a desire to completely disaffiliate with the ethnic community, or friends and neighbours, as community support, in its many forms, continued to be important and appreciated. As one woman explained: 
A lot of Indian people lived there (in the area of core settlement), we all went to the same temple and everyone knew what everyone else was doing. I think it is quite nice to be part of the community, my dad has been ill and our community has been absolutely brilliant. But you need your freedom, a wee bit of space as well. I still go to the temple and meet everybody, I keep in contact. But I wanted the freedom to sit in my own garden with my shorts on, whereas an Asian woman in the West End I wouldn't dare go out with my bare legs. Here it's just white people and they're not going to look at you and go uuuuh, if it was another Asian person they'd be thinking, 'Cover yourself up, what are you up to?'

(Mrs. Waseem, Bearsden, northern suburb)

In summary, the core area continues to play a central role as a place of reception for new migrants, as well as representing both ethnic and national (country of origin) identity and the ideals of community and family life. The association between ethnic identity and the core neighbourhood is also connected to the symbolic aspects of these communities in that the visual aspects of these areas, the shops, typefaces, colours, and the religious infrastructure and symbolism are part of the associations that supplement notions of simple needs related to going to a mosque or getting halal meat. Despite the continued importance of these associations, the 'stifling' and 'policing' effects of religiosity and close neighbouring led to the search for privatisation that many felt could be found in the suburbs.

\section{The suburbs: Aspirations, identity and 'peace and quiet'}

Akin to the long-standing correlation between the suburbs and the expression of social status, area reputation and the status indicators associated with particular suburban locales were influential in attracting people. It is difficult to decipher how much of this attraction was related to class values; rather what is clearer is the relationship between locale, lifestyle and identity as relating to social status. It was significant, to a certain degree, to the interviewees that the people living in the suburban areas were middle-class and white, as this was in some way synonymous with a feeling of having gained status not only within the ethnic community but within broader society. The boundaries of people's social standing widened and instead of feeling as if they were measured socially within the ethnic community they had stepped outside and had now expressed part of their identity in such a way (namely through the place that they lived) that allowed them to have status within the wider social system. Besides the attraction of a quieter 
and more secure environment with a more spacious house and garden, the suburbs and their residents were representative of the type of environment and values, especially educational ones, which were very much sought after:

People here are amicable, they are courteous, they are owner occupiers and they are well established. Therefore their children go to better schools and therefore their behaviour everything is better. (Mr. Gahier, Giffnock, southern suburb)

Social homogeneity also played a role in the respondent's sense of belonging, especially for Indian interviewees, who valued living in a neighbourhood with others who were more akin to them professionally and socially than residents in the core. There was evidence of a stratum within the Asian community in the core, as the social networks of several of these interviewees before moving to the suburbs were comprised of 'educated Asians' (Mrs. Raja, Bearsden). Living in the area of core settlement did not necessarily mean that everyone felt they were part of a community; some viewed it as a problem area, whilst living in the suburbs created some social distinction. This brings to mind the early writings of Gans (1972: 33) who questioned the extent to which spatial organisation and residential location are useful for explaining behaviour and ways of life. He argues that social phenomena cannot be understood entirely as a consequence of the ecological; instead ways of life are functions of class and lifestyle rather than of environmental factors of the neighbourhood. Thus, the feeling that people in the suburbs were more like them was something that gave these interviewees a sense that they fitted in. As well as the suburbs giving status, there was a sense that they were reflective of the personal identity of those who had moved from the area of core settlement. As Savage, Bagnall and Longhurst (2005: 207) argue:

One's residence is a crucial, probably the most crucial identifier of who you are. The sorting process by which people choose to live in certain places and others leave is at the heart of contemporary battles over social distinction.

Suburbanisation from the core was talked of as being an up-and-coming trend. A few of the residents of the core settlement highlighted materialist/status motives as being common drivers of suburbanising. In the words of one woman:

It is a prestige thing, you know, it is like another step up the ladder kind of thing. It is like just showing everybody, 'We've done 
well now, we can move out of a flat and get our own house, back garden and things'. That's what people kind of aspire to. Everyone says, 'Oh, they've got the money now.'

(Mrs. Al-Mufti, Strathbungo/Pollokshields, southern core)

To some degree, the moves of other economically successful families to the suburbs have established an escalating route, which for some is now perceived as a natural course. This appears to be related more with wealth than stage in the life cycle. Although the majority of families that had moved to the suburbs had experienced an increase in financial resources enabling their move, for some it was living in multi-earner extended households that created the financial capacity to move. To some extent, suburbanisation was described as becoming a norm signifying progress or status in ways that are reminiscent of the broader/majority population during the last century. As one man living in the core commented:

[When core residents see others moving to the suburbs] I think it makes them feel that, you know, they start to wonder, is this natural progression to move out of the city, they think, is it just the way it should be done? You know, you're used to people living here all their lives and you start to think, you know, why am I still here? Is it because am I not conforming to some thing you do, like they aren't keeping up... You do think that you are kind of stuck, still here.

(Mr. Mahmood, Woodlands, northern core)

Despite this, some economically successful professionals resident in the area of core settlement choose to remain there as they wanted to be in close contact with their families and found it convenient living within close access to places of worship and cultural amenities. Equally, others aspired to living in the suburbs but were limited by financial constraints.

In the case of some suburban movers, the contrast between the core and the suburbs led to feelings of isolation and alienation. This was more often the case for Pakistani women who were not in employment, could not drive and had no children of primary school age. As one woman, the fact that she had a disabled child was also a critical factor, who had moved back to Strathbungo/Pollokshields from the suburbs commented:

It was too secluded, you didn't see anyone, I mean, here for the kids they can play out in the park - it's only five minutes away, it's only across the road. I can keep an eye on them. When you have a 
young baby on your hands, you know if you don't have transport and that, then getting from Giffnock or anywhere else, you know, it's difficult to get things like milk and bread and things like that, it's a dilemma when you've got a disabled child. I felt out of it. (Mrs. Hussein, Strathbungo/Pollokshields, southern core)

Some women had become more dependent on their family for daily excursions or errands that they were able to manoeuvre entirely independently when they lived in the core area. Furthermore, they missed the close domestic arrangements and relationships with friends. Having children of school age seemed to give women a greater sense of being socially active in their new neighbourhood. This was due to shared interests and concerns for children as well as the interaction at school gates and events that fostered a sense of commonality between themselves and other mothers in the area. Educational facilities in general, in suburban middle-class areas, seemed to act as a strong bind to the area as well as being an expression of status and family aspirations. Educational services and their good reputation were key factors in determining residential location, especially for the Indian interviewees. Contrary to those who felt isolated, there were others, particularly several younger families interviewed, who felt that too many people they knew from the core were moving to the suburbs and the privacy and anonymity that they had moved in search of was being eroded. For instance, two young couples spoke of having to leave the area to go to the supermarket if they wanted to buy alcohol to avoid being discovered:

I would just like to get away... just having to bump into people who kind of watch when you are going out... we are young we are not like most Asians, we drink... it's just that sometimes if you pick up a can of beer you are worried who you are going to bump into, one of his family or one of my family, and not just that there are loads of friends and family within the community as well who might see you.

(Mrs. Mir, Giffnock, southern suburb)

For the majority of the interviewees who had suburbanised, an assessment of the advantages and disadvantages of living in a concentrated ethnic cluster was reflected in their decision-making processes about where they would move to. Alongside the advantages mentioned earlier, security was considered a key advantage and fear of harassment and hostility resulted in low mobility aspirations for some. The disadvantages of living in an area of ethnic concentration were related to the future effects of being distanced socially within broader society. This 
was normally related to aspirations for children. Several respondents, whose children attended the local, predominantly Asian, school, talked of concerns they had about their children being exposed to too little of the Scottish culture. As one mother commented:

I only have one son and I didn't want him to only mix with Asians. I wanted to move out to Bearsden [suburb] so that he wouldn't have problems in later life. Because I think if you have grown up with all Asian friends then getting a job with white British people can be hard because you have been in this wee [little] community all your life.

(Mrs. Waseem, Bearsden, northern suburb)

A substantial number of the interviewees located in both the suburbs and the core area expressed fears that a lack of ambition was developing amongst the youth living in the core. They felt that in general young people did not have to work as hard as the generation before to guarantee an income; instead they could rely on the family business and older members of the family for jobs or money. This concern was related to the disaffiliation of the Asian youth in the area and to gang membership. For households with children, worries about negative influences and the future of their children clearly influenced their residential choices. Furthermore, there were specific issues regarding their negative perception of the spatial concentration of Asian groups that had encouraged several of the Indian interviewees to relocate. These interviewees placed a strong emphasis on moving away from, not only the Muslim community but, the Asian community in general to an area where, in their own words, they would be more 'integrated'. Although concerns were usually centred upon aspirations for children, they were also indicative of unease that personal status and social identity be compromised by association with Pakistanis living in the core:

I'm Indian and I have got nothing against Muslims. I have got some very good friends who are Muslims but I just felt that because I have only got one son I'd either move or send him to private school. Now this sounds awful snobbish, but I didn't want him to go to the local [neighbourhood] school because I felt there were far too many Muslim children there. I didn't want him to pick up on the gangs or the habits. It [the area of core settlement] was getting more and more Muslim at the time and I would like to think I'm not a racist against my own type of people, but quite often with a lot of our people if one buys a house then we all do and get together, it wasn't a snobby thing I just didn't want him to 
only mix with Asians.

(Mrs. Singh, Giffnock, southern suburb)

There was an obvious concern among these interviewees with shirking the 'Asian' stereotype and distancing their own identity from what they felt was a lack of distinctiveness from the Pakistani Muslim community, seen as being the fabric of the stereotype. They resented their 'Scottishness' and various social and economic achievements being diluted or undermined by this association. Furthermore, the desire to create distance from the Pakistani community was tied up with issues around their low class position and negative conations related with increasing Islamophobia as a result of the global political situation. As one woman commented:

This is my country, my home... I feel when people see, or when the indigenous population see Asians or what they term as 'Asians' they start moving out... this is why we moved out [of the core area], it is all mostly Muslims now, people think we are all the same.

(Mrs. Singh, Giffnock, southern suburb)

In a sense, living in the suburbs negated the cultural and structural divides that clustering may suggest from the majority population, as certain social and material aspirations had been fulfilled. To a certain extent, this could be interpreted as an emulation of white middle-class aspirations as the arbiter of having achieved status or normality even. However, the importance of personal cultural and religious values, practised very much in private due to their very nature, perhaps reveals a more holistic picture of what living in the suburbs meant for these interviewees. These aspirations and the desire for privacy, along with the desire for a more individual identity that relied less heavily on their ethnicity or on being 'Asian', seem to coincide with a more general set of aspirations to be found in groups with growing resources.

\section{Conclusion}

The area of core settlement played an interesting role in both attracting new residents, retaining old ones and in creating an impetus for some households to move. The importance of the established community and the amenities of the core were different for different groups of people and the majority of core residents saw both advantages and disadvantages to living there. Despite its disadvantages that compelled some households to leave the area, the core area continued to play a 
significant function in the lives of out movers being the place they frequented most regularly in the city. Often, for Pakistani respondents, this was on a daily basis. So to a large degree, although people were attached to the area in very different ways, its function for cultural, religious or social reasons was something common to the vast majority of interviewees including those living in the suburbs. Although a choice for some, there were constraints, most commonly financial or cultural, that kept others in the core, regardless of their real residential preferences. In particular, the scarcity of religious facilities outside of the established core areas acted as a constraint for some depending on their ethnic group, religion, generation and age. Still, cultural and social factors compelled some people to move, as living in close proximity to the established community diminished their independence and compromised their sense of privacy and freedom.

The migration of households to the suburbs was clearly enabled by an increase in resources, which was in unison with, or perhaps a catalyst of, increased social aspirations. The types of services and markets that a large number of these households wanted to have access to were clearly available in the suburbs, most especially proximity to good schools and larger properties with private gardens. Although ties, in differing degrees, were maintained with the core, there was a sense that a move constituted a strategy to establish some social distance. In a sense, moving out, as well as creating distance socially also signified 'moving up', and was, in the opinions of some interviewees from the area of core settlement, something that was becoming to be thought of as a natural progression. There was a sense of belonging amongst several of the households interviewed in the suburbs that was fostered by common concerns and a sense of social affinity with residents, based on their children, status and having new and better housing markets and services open to them. Despite the importance of this in making people feel satisfied in their neighbourhood, a move to the suburb appeared to be less about gaining a sense of belonging to a place locally and more to do with being part of a system that is broader than location, which includes social identity. This involved a wider use of spaces on a daily basis than when they lived in the core, leading to daily commutes and increased mobility across the city. This wider use of space on a city level was juxtaposed with making personal and home life more private. Living in a more 'mixed' neighbourhood was a motivating factor for some, most especially Indian participants, to suburbanise. In a sense this was tied up with the desire to have more distinctiveness from the 'Asian' community, to move away from stereotypes and to 'integrate', which contradicts UK government views on minority ethnic residential choices. 


\section{Housing, households, families and safe places}

\section{Introduction}

This chapter is an exploration of three key interwoven issues found to shape the residential motivations of the interviewees: the role of family, the impact of housing and perceptions of safety. Household composition of South Asians has tended to be larger than the average in Britain. Extended family households or three generational living is common and has been maintained, to a large extent, as a traditional norm (Al Awad \& Songuga-Barke I992; Chang, Chen \& Somerville 2003), indicating that the residential choices of South Asian groups might be more complex than those of their white counter-parts. As Chang et al. (2003: 733) write, 'the decision to move involves changes in commuting times, neighbourhood amenities and social networks. These changes cannot be expected to have equal effects on the utility of each member of the household'. Indeed, the interplay of family hierarchies and more intricate generational roles is shown in the current research to have an impact on residential decision-making processes. The more complex household composition of South Asian households also has an influence on household housing needs and preferences. In general, the residential mobility literature lends itself to the assumption that households are bound to particular areas by ties to family members, jobs, neighbours and housing units (Speare I974; Bach \& Smith I977; Newman \& Duncan I979; Landale \& Guest I985; Deane I990). The strength of attachments may be measured as the degree of satisfaction expressed by members of the household, whilst it is argued that, in general, dissatisfaction rises as the family life cycle changes and the 'fit' of the house deteriorates. Due to the more complex household formations of the interviewees, there are often changes in different phases of the life cycle occurring at once within a household, meaning a greater variety of different housing needs may need to be addressed at any one time. Solutions to housing needs were not simply thought of as being structural, but, of course, related to key locational attributes. One such attribute is safety, a critical feature addressed in the housing literature specific to minority ethnic groups in contributing to housing outcomes (Bowes et al. I997; Sarre et al. I989). As the role of the 
neighbourhood (the people living there, the social ties that these create and the environment and services provided there) was discussed in the previous chapter, the safeness of a particular neighbourhood was also highlighted as an another decisive neighbourhood factor in choosing a place to live.

This chapter is structured as follows. The first section considers the role that the family plays in residential motivations and decisions. Some interesting changes in the traditional family structure are given attention, and the strong pull that family obligations create is discussed in the context of where people move to and the limitations that these may place on peoples housing choices. The second section considers housing issues, namely space and overcrowding, housing condition, affordability and house type. Finally, the third section considers the role that safety and feeling safe in an area has on influencing where people live, relating to the discussion in the previous chapter about accessible areas in the city.

\section{The family, proximity, space and changing cultural ideas}

Living in close proximity to the family, for the majority of interviewees but more so for Pakistani interviewees, was a decisive factor in choosing where to live. This motivation involved elements of the pressure of familial expectations and a need to be close to give or to receive financial, domestic and emotional support. For instance, one interviewee said that having his family close by made him feel, 'safe and confident' (Mr. Gutpa, Woodlands, northern core), whilst others described the limits that family obligations placed on the areas in which they could choose to live. The fact that people wanted to live close to their family was given a cultural inflection as some respondents felt that it was an 'Asian value', something that distinguished them from the Scottish. In the words of one interviewee:

I do enjoy having a big family, you get a lot of support with (maintaining) the cultural background and things as well. We are Asians so the family tends to stick together. The moral support may be financial as well. It's more of an obligation I think with us there's that closeness it's probably greater than among the Scottish.

(Mr. Bashir, Woodlands, northern core)

The pull of the family seemed to be more important than living close to neighbourhood amenities or the ethnic community. For almost all of those interviewed in the core, living there was, foremost, due to family ties before ties to the wider ethnic community. Recent migrants spoke 
of feelings of isolation in the community when it came to support for anything other than emergencies or in learning English. In the words of one man who had moved a few years before from India:

No, the other [Asian] families here don't support me. We have to support each other just me, my wife and two children here [in Pollokshields]. They are all family, cousins, sisters, brothers, you know they all support each other, I mean, they care but they support themselves, the big families. When my wife was in hospital they helped us.

(Mr. Sarwar, Strathbungo/Pollokshields, southern core)

The deeper support networks and more domestic social ties were described as operating more between relatives than amongst members of the ethnic community. The necessity to live in close proximity to the family due to the support it provided or obligations it imposed limited and constrained locational choices for some to the areas where their family live. As one interviewee commented:

No we didn't look far at all we just narrowed it down to these wee bits around here because we wanted to stay near the family. We really did not think of the possibility of living anywhere else, we couldn't really.

(Mrs. Fayad, Strathbungo/Pollokshields, southern core)

Likewise, it was very important for those moving to the suburbs to have the support of the extended family whether it was financially, emotionally or at least to have their overall approval. Few families moved without a prior discussion with their extended family about their future housing plans. This often resulted in the whole extended family deciding they would follow in a process of chain migration, hence a re-clustering of families within a few streets of each other in the suburbs. Earlier suburban movers relayed feelings of stress during their move relating to the uncertainty of how new neighbours would receive them, at such times the encouragement of the family was an important reinforcement.

\section{Household composition}

Despite the close ties between families, there was evidence of changes occurring in the household formation of some of those living in the suburbs, whereby several extended households had separated to form smaller nuclear families. The change in household formation appears to have been made viable due to several interrelated factors, including 
an increase in purchasing power within these families, a change in reasoning behind the extended family and changing cultural practices. The root of the extended family, according to a few interviewees, grew out of poverty and lack of resources that forced families to live together to save money. Despite being aware of the benefits it afforded, such as close family ties and a greater sense of responsibility for relatives, as greater wealth was accrued and combined with an increasing need for personal space and privacy, some of the interviewees began to question the need for it. As a man from the suburb of Bearsden who had moved out of the extended family home several years previously commented:

I'm very fortunate really I've got three brothers who actually live in Bearsden and my parents... everyone lived together in the one house, which just wasn't practical. I enjoy having a big family you do get a lot of support cultural as well and financial, we are fortunate that way. I mean a lot of that stems from the villages in Pakistan where people don't have a lot of money, so they had to live together... it was more out of necessity, but it became cultural. So a lot of Asians try to carry that scenario on... it just wasn't practical. (Mr. Sadiq, Bearsden, northern suburb)

The absorption of new family members, as the sons of the household began to marry and have children, was not an easy process for some. For others tension existed between different parts of the family, while others described feeling a lack of control over their lives and others a lack of privacy. In the words of one man who had recently moved from the extended family home in the core to a suburb:

When you have different sections of the family staying together there are always possibilities of tension. I could live with it if it was just my parents, it's my family, but my wife found it more difficult. I mean a good example is when relatives who visited, viewed it as my parents' house, so they didn't pay any sort of respect to our privacy or our children's in any way. It was like we might as well have been coming to visit. We were almost like guests in the house ourselves as well as lodgers, that played on my mind too... and it got to the stage when you think you should move on and take responsibility for your own life.

(Mr. Gahier, Giffnock, southern suburb)

The need for privacy or space among the interviewees was never a straightforward motivation, but complex in its juxtaposition with what was felt to be the value of the cultural practice of living together with 
the extended family. There were also other factors that complicated family life and living arrangements such as divorce.

Although the extended family was still valued, co-location to achieve its benefits was no longer seen as necessary by the majority of the younger interviewees. Despite this, proximity to the family related with specific obligations was still a significant determinant in specifying where these newly formed households decided to live, most remaining in the same area. It was more difficult for the older generation to accept this change and often a long and emotional process of negotiation preceded a change in the formation of the household:

My mum and dad took it very bad when my two older brothers moved out they fell out and everything. Initially it was really hard for my mother, it was the idea that the family could fall apart and now everything is finished.

(Mr. Dahliwal, Bearsden, northern suburb)

Thus, even in the light of changing family formations, the role of the family in the lives of the majority of those interviewed continued to be a crucial factor in determining choices made by the household around location and residential mobility. The influence that living within close proximity to the family had upon housing choice was related to values that the interviewees specified as having stemmed from ethnic practices and traditions, though had less to do with the ethnic community and its location. Most of the suburban Pakistani interviewees had moved to the suburbs and dispersed out of the core area of ethnic settlement because their families were also moving, to either the same house or the same neighbourhood. Equally, some remained in the core, despite the desire to move due to familial resistance. Whilst there were closer spatial ties amongst all generations of Pakistani families, Indian interviewees tended to live nearer family members of their own generation, whereas it was largely expected that the younger generation would move away to study or work.

\section{Housing issues}

Changes in the life cycle of the households interviewed did have influence on mobility decisions, based on an assessment of whether current housing met family needs. At times, households just made do as they could not afford to move or housing was swapped and shared between relatives to solve problems of overcrowding. Relating to the previous section, as the family structure of the interviewees changed, usually with the marriage of children, the absorption of relatives from abroad 
or the splitting of extended households into nuclear families, housing needs also changed. In general, however, in the case of the suburban movers a move was related more often with an increase in resources, aspirations and the ability to afford more space rather than a change in the life cycle.

\section{Space, housing condition and affordability}

Space, housing condition and affordability were three factors that acted in unison to add to a person's desire to move and to specify where they could move to, if at all. In the traditional areas of core settlement, space was not a push factor in isolation rather problems with the size and structure of the respondents' properties were discussed in conjunction with household condition. A few of the households interviewed, who where living in the core settlement area, had made their last move due to poor housing conditions characterised by severe damp and overcrowding. This is illustrated through the experience of one family who had been living in a damp one bedroom flat with five children for several years. Despite having preferred to stay in their previous neighbourhood, Govanhill, which is an area with a developed Asian community infrastructure, they moved to Strathbungo/Pollokshields to escape these conditions. This relocation was enabled by the prolonged financial support of the paternal grandparents, who had given their home to the family, moving to a smaller flat a few streets away in Pollokshields, to provide much required space and better conditions. A compromise was made between the desired location and a house that was of a tolerable standard and met housing needs and affordability.

The process of moving within the core was not easy due to increasing house prices; prices had increased by $\sigma_{3}$ per cent in Woodlands over the three years prior to the interviews and in Strathbungo/Pollokshields by 4I per cent (register of Sasines; author's own analysis). Other interviewees who had been living in homes of substandard condition were unable to afford the appropriate renovations or to buy in the same area. Several had been forced to move to the periphery of the area where house prices were slightly lower. In the words of one interviewee who had lived in the area since the mid-I97os:

My flat in [...] Street was in very, very poor condition; it was very damp and made me get asthma. I wasn't very happy to move because my flat is further away from Woodlands Road. I have to live near the mosque so that I can go there very often on foot. But now I feel ok because I can still see all of the same people everyday when I go back to the mosque or when I do my shopping. (Mr. Tabatabeyan, Woodlands, northern core) 
In several other instances, reflecting the experience of the two aforementioned respondents, there was a trade-off between housing condition, affordability and location, with location generally being the factor that was compromised. However, in most cases location was compromised within limits, as most households remained within reasonable access of the community and cultural facilities.

Affordability of owner-occupied properties, highlighted in the housing literature (Kearns 2002; Littlewood \& Kearns I998) as a key issue for minority ethnic groups, also appeared here as a critical factor. A few individuals had gone through periods when they could not manage their housing costs and had to move to less spacious and less expensive dwellings within the core, which often resulted in overcrowding. One older man had had his home repossessed due to difficulties in making mortgage payments and was forced to move into council housing on the outskirts of the city for a lengthy period before being able to afford another home in the core settlement area. Affordability was also an issue for the younger generation, upon marrying some of the children of long-term residents were forced to look for alternative accommodation due to limitations in space in the extended family home or to a desire for privacy. This proved difficult, especially in Woodlands, due to rising house prices. For instance, Mr. Abdoo and his wife bought a more reasonably priced house in Strathbungo/Pollokshields despite wanting to remain in Woodlands close to the family for the birth of their first child. They were currently 'making do' in the overcrowded family home and hadn't yet moved into the new property:

Nowadays it's difficult to move into the house in the area that you would like because the prices of the houses here are so high. We bought a house in Pollokshields and it was a good price it was a main door and had a garden so we took the opportunity. At this moment in time I'm still deciding what to do. I'm not sure if I will move in there yet. My wife is pregnant so at least for the first six months we will need the family around. Ideally I would have liked to stay here, I'm quite settled here, I've grown up here and it's convenient to have everything around you.

(Mr. Abdoo, Woodlands, northern core)

Although most of the suburban interviewees had moved from the core area, in some part, for more physical space in the home and a different house type (a house rather than a flat), several of those who had moved to semi-detached homes actually found physical space to be as constrained as it had been in their previous home. It was considered a worthwhile price to pay to have a smaller house in a better area, 
characterising the common trade-off amongst suburban interviewees between housing and location. As one woman commented:

This house has always been a bit small and whenever we can afford, we are going to move to a bigger house. We are very happy in this area; the only thing is the house is a bit small. We choose to have a smaller house though so that we could live here.

(Mrs. Aftab, Giffnock, southern suburb)

\section{House type}

In the traditional areas of core settlement studied, the predominant house type was the tenement, large Victorian sandstone terraced apartments typical of Glasgow. This house type tended to be more accommodating for the needs of an extended family household, in comparison with the kinds of terraced factory houses often occupied by minority ethnic groups in the north of England. Despite this, overcrowding was still found to be prevalent. However, for several of the interviewees, changing needs, mainly associated with the onset of old age, rendered the tenement, with its steep stairwell, unsuitable and acted as a push factor among the elderly to move to the suburbs. Several had previously been waiting on a ground floor flat coming on to the market in the core area but to no avail, which in each case was the preferred instance to moving out of the neighbourhood. This house type was also difficult for some young families, however, they were more able to manage and having children did not usually lead to a change in house type.

Age was a factor related to specific needs that made it necessary to change house type, but it was also important in terms of the reaction to this move. There were very different reactions between different generations within the household to a move out of the core area. Some of the families of the elderly individuals saw the situation as an opportunity, which may not have been negotiated if the need for more easily accessible housing was not present. To the contrary, the elderly members of households interviewed were more likely to experience difficulties upon moving and feel isolated and dependent. As one Indian woman who had moved to the suburbs with her parents commented:

My mum and dad they live in a bungalow [in Bearsden], they also came from the West End. So we had to look after my mum and dad, they couldn't get up and down the stairs in the closes [tenement flats]. My dad liked staying there and my mum liked it for the shops, she could go to all the local shops when she wanted, she's in Bearsden now, she is stuck, and she can't get out and 
about so she has to rely on us. It's not as easy as it was for her just to go round the corner and see her friends and do the shopping, there are Asian shops there as well.

(Mrs. Waseem, Bearsden, northern suburb)

Similarly, one young man talks of the difficulty of the move for his mother:

We were living in a top floor flat in Woodlands, so obviously hiking up and down the stairs was not good. My mum was getting on so her legs were not working too well and she had to climb up and down the stairs. I think though she would have preferred to stay where she was, it was so handy she could walk out and she had all the shops. Whereas here, you know, you can't exactly just walk out, you know, to the shops. You need a car to get to and fro. And because friends were nearby and you're just across the road you can just nip into [their] houses... we were [a] very close knit [family] her brothers' family were in walking distance.

(Mr. Bashir, Bearsden, northern suburb)

House type, was also often a pull factor, even if never in isolation, to the suburbs for those who were not elderly. This was often related to the desire to live in a bungalow or to have a house with a garden and with its own front door, as opposed to sharing a communal entrance. Property characteristics were in line with the common desire for more privatised living conditions.

\section{Safety and area reputation}

The influence of fear of or experience of racist crime and threats has been noted in the literature as having relevance in the housing choices and outcomes of the minority ethnic population (Bowes et al. I990a; Sarre et al. I989). Although not represented explicitly in any of the research questions, safety or more specifically feeling safe emerged from the interview data as a key exogenous factor influencing the actual moves of the interviewees, meriting its consideration in more detail here. In general terms, safety was one of the most significant neighbourhood characteristics in making an area desirable to live in. The specific individual experiences of a few of the respondents had led them to move in search of a place that felt safe. However, regardless of experience, the safeness of an area was a factor that all interviewees had considered carefully before choosing where to live. Specific criteria was applied to deduce if an area was a safe place to live, namely, area 
reputation, the socio-economic profile of residents, the fact that the area was 'multi-cultural' and tolerant and the experience of other South Asian households in the area. For early pioneering suburban movers knowing there were other Asian households in the area, regardless of their degree of contact with them, was a significant factor in making them feel safe in the area. This was true for more recent suburban movers, but in addition to the socio-economic background of the residents. Furthermore, there was evidence that feeling safe was further reinforced by the anonymity and privacy of the suburbs, along with quite notable security devices and fencing, which indeed was not unusual in the majority of houses in these areas. In contrast to recent research that suggested the more ethnically diverse an area is the less likely people are to trust neighbours or others within that area (Pennant 2005), several interviewees rated a cultural 'mix' as a positive aspect that provided evidence of a cohesive area, thus indicating it was a safe place to live. This was truer for the interviewees living in Woodlands where, being near the university and having quite a transient population, the mix is social as well as cultural.

For households who had moved to the suburbs from Strathbungo/ Pollokshields, safety featured not only as an important factor in choosing a new location in which to live but also in creating an impetus to move out of the core. Strathbungo/Pollokshields was considered to be an increasingly problematic area whose reputation was declining in response to problems with gangs (both white and Asian) in the area. One such example was the multiple robberies of Asian households by Asian youths. Mrs. Hussein who had been robbed on numerous occasions, due to the easy target her ground floor flat made, describes this:

Well there is a lot of this [robberies] about in the area. The majority of people that are living in Pollokshields are Asian and have got pure gold. It's a status symbol, the more you have shows your wealth, more or less. But people don't keep their gold in the bank they need it for easy access - to wear. So a lot of youngsters Asian, which I hate to admit, know where the money is... it's easier [to steal] and worth more than TVs and microwaves... [they] stick it in their pocket and walk out. It is increasing, they watch their mums with the gold and they know how much it is worth. (Mrs. Hussein, Strathbungo/Pollokshields, southern core)

The interviews with residents in Strathbungo/Pollokshields were conducted in the interim period between the brutal murder of a white youth and the trial, from which Asian youths were later convicted. At this time, shock was reverberating throughout the neighbourhood as well as a sense of insecurity in response to threats of British National 
Party (BNP) rallies in the area. Despite this, the interviewees from the area emphasised the benefits of the neighbourhood through accentuating the strength of social ties across both ethnic and religious groups as a critical response to the stigmatisation of the neighbourhood. Stigma was imposed more from outside, several of the interviewees who had suburbanised felt in some sense alienated from their past because of the difference between the area when they were younger and in the current period. As one Indian woman commented:

My dad still lives there and he tells me about the boys running around in cars at night racing and causing riots, there's a lot of police presence there now... not so long ago a boy was kidnapped and murdered there and that was something you know just round the corner from where we used to live with my parents. I used to play there, going to school, walking... it was like my home area and that kind of thing happening and the things that dad tells me I just cannot understand, I cannot imagine how it has changed. (Mrs. Singh, Giffnock, southern suburb)

The extent to which the area had changed was described as being more dramatic and over a shorter period of time by those who had moved out of the area than by those who continued to live there. A few interviewees left the core area and moved to Giffnock because they were worried about the impact of the area, and what they saw as a poor social environment, on their children. Residents in Strathbungo/Pollokshields, in general, as well as for prestige/status motivations, felt that the moves of people out of the area were for greater security. Other individuals, however, described how they preferred to remain in their current neighbourhood making a compromise between what they felt they needed in a neighbourhood (in terms of services and social support) and feelings of insecurity. As Wolpert (I966) argued in his theory of residential mobility, even if an individual makes a negative evaluation of their surroundings it may not necessarily result in residential change. He introduces the concept of a 'threshold effect' whereby a negative evaluation must reach a particular level before the individual begins to search for somewhere else to live, as people may find ways of decreasing their dissatisfaction that diminishes their inclination to move.

Many of the interviewees, unless they had a few incidents in their housing history in which they had experienced hostility or racism, usually took other measures to secure their homes, such as padlocks on their front doors. However, whenever feeling unsafe in an area was combined with poor or unsuitable housing, dissatisfaction often led to a household move. Thus it was a combination of factors, which of 
course simultaneously depended on financial means. For a few interviewees living in Strathbungo/Pollokshields, fear of crime and a desire for peace and less noise created a desire to move as part of their future housing plan. Particular neighbourhood benefits and assets, linked primarily to the religious and cultural infrastructure in the area and lack of financial resources, however, presently offset the move. Mr. Dahlwali highlights the negative and positive factors of living in the area:

My wife she likes Pollokshields because of the cloth shops and all the Asian shops. So she thinks she has to live in Pollokshields as she doesn't speak English, even though she is scared all of the time and spends most of the time in the house. But she doesn't want to leave [move], as she has two or three friends who live in nearby houses.

(Mr. Dahlwali, Strathbungo/Pollokshields, southern suburb)

In short, a compromise was made between feeling safe and area benefits. Still, a small number of interviewees had a strong desire to move out of Strathbungo/Pollokshields, but were constrained due to their financial position. In the words of an interviewee who was deeply dissatisfied with the area:

The robberies - everything - it's not safe... I am living here because there is no choice, that is why we are here. If you want to buy a house anywhere else it costs too much, I cannot afford it. I have even tried to get a council house but I can't get one anywhere. They tell me I have to wait for two years or something. So there is no choice. Some things are nice but some things are bad. The good things are the school and the everyday shops but it is not safe, you can't leave your house alone for long, you just worry...

(Mr. Sarwar, Strathbungo/Pollokshields, southern core)

This compromise was also reflected in the experiences of some interviewees who had negative experiences on first moving to the suburbs that had prolonged and made the settling in process more difficult. A concession was made between those initial feelings of being unsafe and the area benefits that they desired, including good schools, a neighbourhood with a good reputation and the right to live in an area that matched their socio-economic status.

For some interviewees, their move in pursuit of safety was a much more complex and decisive factor in the history of their housing career. Two interviewees, who had been living in an area adjacent to Woodlands, had moved back to the core after experiencing violent racially 
motivated attacks in their homes. In both instances injuries were sustained and their children witnessed the attacks. To some extent, this kind of discrimination and hostility still constrains people to the core. One such example is the housing career of one Indian man, which was characterised by multiple house moves in pursuit of safety. As a result of his negative experiences, the most important factor in creating not only neighbourhood satisfaction but personal contentment was linked with feeling safe, which was reflected in his desire for anonymity and privacy. He had begun his housing career in Scotland after his marriage to a White Scottish woman (since divorced). During his marriage he had lived in a predominantly white area in the east of the city, here he had the impression from his encounters with people (through body language and expression) that they were uncomfortable with him and the marriage. This was the cause of friction, creating severe household problems until the final divorce. After his divorce, he had moved into social rented housing in Sighthill, an area of the city that has absorbed many asylum seekers on their arrival to Glasgow and renowned for its social problems. Here, his experience was extreme, he was threatened and rarely left his flat unless he had arranged for someone to collect him and bring him home again by car. Even then he was nervous about using the elevators in the building because of what he described as loitering youths and drug users. He also had negative experiences with the housing authorities who offered little support or understanding:

I felt so unsafe there, many times I had requested to be moved out of there... they used to jag [inject drugs] in the lift. I was so fearful that I used to lock my door and never go out. I only went out when I needed to buy something. I stayed there for two years and the housing people they don't really bother with the coloured people. Every time I told them about the problems they would say everything was fine and it is the only thing we can do for you. Maybe they didn't realise the [severity of the] problem but they were a bit inconsiderate.

(Mr. Bhatt, Woodlands, northern core)

From here he moved into the private rented sector in the Strathbungo/ Pollokshields area of the city. He was reluctant to do so as he thought his experiences would be limited if he lived amongst other Asians and inhibit him from 'integrating with the culture'. This was mentioned frequently by other Indian respondents as being an important part of their housing choices. Despite this, he assumed that he would, at least, feel safe in the area. Although feeling safe in the building in which he was living, where the neighbours were all white, he felt unsafe living 
in the area due to the gang activity. As a result of sectarian tensions in the area, and its links with racist behaviour, he also felt alienated from both communities in the area, explaining his subsequent sense of isolation. Despite saying that he would feel safer in a more multicultural area, he still felt that if the Indian community was larger in Strathbungo/Pollokshields he would have had a greater sense of belonging to the area. In his own words:

I didn't feel safe in the area, and I didn't go out in the evening, there used to be fights. After the football matches the gangs would start throwing things, it was very unsafe. These people would use names and racist chants. So the Pakistani community they group together, I think because of this and other recent things, they are always like that anyway because of their religious attachment. I was a little bit out of there [isolated] because of the Pakistani community. These barriers, hidden barriers between communities, it was not easy to break those down in Pollokshields to be able to feel comfortable speaking to people. I tried to interact, but there I felt isolated.

(Mr. Bhatt, Woodlands, northern core)

\section{Conclusion}

The traditional role and structure of the family has been portrayed in the current chapter as dynamic and changing in both practical and philosophical ways, relating to individual experiences and other differentials, such as socio-economic class, increased affluence and generation. The increase in wealth among some of the interviewees not only enabled them to buy their own property and accrue their own assets but made changes in household formation viable. The decision-making process accompanying the fragmentation of extended family households was never uncomplicated in the light of familial and cultural pressures. Despite the dwindling importance of co-location amongst some of the younger generation, the importance of living nearby the family continued to be a decisive factor in attributing to residential motivations and choice. This was a stronger motivation than living in proximity to the ethnic community or to religious and cultural facilities, although these other factors continued to bear influence on family decisions. This not only has implications on the size of properties families need, but raises interesting questions about the importance that the extended family bears for Asian households in choosing where to live, especially if the right housing or resources were available. 
The prevailing poor quality and overcrowding of homes in the area of core settlement meant that some households, contrary to their area preferences, were forced to move out of necessity. Poorer households with less economic power or stability showed resourcefulness and flexibility in creating solutions to their housing problems. In the same vein, however, for housing needs to be met often a compromise was made between housing that was both affordable and of a tolerable standard and location (often these households were forced to move from the heart of the core to its periphery or to other adjacent areas). It was more common that the opposite compromise was made by suburban movers, and that the size and type of the house was compromised in order that they were able to afford to buy in their desired location. This led to many second moves within the suburbs or planned future moves as households pursued their ideal house type.

Security and fear of crime were issues relevant to the residential choices of many of the interviewees and more pertinent depending on the neighbourhood in which they lived and on past negative experiences. In the instance when safety did not act as a direct push factor from the neighbourhood of origin, the safety of a place was deliberated as an important issue in choosing destination areas. Perceptions of the safeness of a place, thus, acted as a filter to areas that were considered unsuitable across the city. The main elements considered to make a place safe were the reputation of the area, the class or socio-economic make-up of the area and the knowledge that other South Asian households had moved there before. For suburban residents, any safety measures taken to secure their home were to some degree about 'padding the bunker' (Davis I998). This, however, had an ethnic inflection as fear was based on an uncertainty of how residents in a new location would react to their 'colour' or ethnicity, indicating that space continues to be racialised in the city. 



\section{Residential outcomes: Settling in or moving on again?}

\section{Introduction}

The previous two chapters explored the residential motivations of the interviewees and considered the array of factors that compelled households to move from a particular area, alongside those factors that attracted them to a new locale. These 'push' and 'pull' factors were rarely forces distinct from one another and decisions were often about rationalising the two within the confines of constraints and other individual differentials. The current chapter advances to explore the outcome, rather than the motivations, of these residential decisions (to live in the core or the suburbs). If suburbanisation is an emerging preference among some South Asians, then the degree of their success in achieving this is significant in terms of wider issues of integration, social mobility and perceptions of safety in the city. The fact that moves to the suburbs have been relatively recent for this group and are increasing raises particular questions regarding their ease in settling-in and sense of belonging, considering the difference in the social and physical environment to that of the core area. Indeed, in popular culture and literature, contrary to the inner city, the suburbs have been represented as privatised retreats representing, 'a collective assertion of class, wealth and privilege' (Fishman I987: 3). The extent to which this is reflected in the reality of individual representations of life in the middleclass suburbs of Glasgow or emulated by the new suburban dwellers will be explored. In particular, we will see in this chapter how processes of belonging to the new residential area, through the meaning attached to place, are related to social identity construction and expression. Furthermore, general neighbourhood satisfaction and the impact of feeling safe and future residential aspirations will be explored.

\section{Settling into the suburbs: Privacy or inclusion?}

Pathways to incorporation in the suburbs of the migrating households were varied at the individual level, but related strongly to the fulfilment of expectations they had prior to the move. To a large extent, the 
meeting of these expectations acted as an indicator of having settled, meaning 'settling in' meant different things to different people. Further to the meeting of expectations, settling in or feeling a sense of belonging to the area was, in general, related to feeling akin to the residents, regardless of meaningful interaction with them, such as having similar aspirations for children. To some extent, this reflects the findings of Savage et al.'s (2005) recent study on attachment to place in the context of globalisation, in which they investigate the relationship between locale, lifestyles and identity in the middle classes. They found that a sense of belonging in their middle-class case study neighbourhoods was not shaped by having a history in the area, but rather through a process of 'electing to belong', through partaking in normal social processes in the area, which led to a sense of ordinariness. Pathways to belonging in the suburbs were, in general, less about building ties through active social interaction, but related to emulating or sharing the social norms of the suburban residents, such as educational values, shared concerns about children, keeping themselves to themselves, privacy, and a certain material standard of life. This was closely related to the fact that living in the suburban neighbourhood reflected more accurately the interviewees' social progress and achievements, whether related to class, education, economic resources or status. This illustrates how perceptions of identity are expressed through place of residence, as discussed in Chapter 7.

Savage et al. (2005) link 'elective belonging' with bringing up children. In their study in-migrants talked of how bringing up children in the area made them feel at home, as people living in these middle-class neighbourhoods had common concerns related to the local politics of schooling. The authors argued that to belong in the area was related to the 'wider spatial organisation of the educational field' (2005: 54) in which their children located them. This process rather than generating close social ties amongst residents was shown to generate detached social networks but acted as a means of 'performing belonging' (ibid.). As illustrated by the following mother, concerns about children - specifically, their participation in local schools and educational aspirations was something that suburban movers generally felt they had in common with other people in the area.

The school here is a very good school. It's got a very good reputation and the teachers are lovely and also the parents in the area really care about their children's education and behaviour. I feel very comfortable sending him to that school in that environment. (Mrs. Gahier, Giffnock, southern suburb) 
Pakistani interviewees, in comparison with Indian interviewees, were less likely to have considered the quality of schools before they moved, but it was an aspect of their new locale with which they were satisfied. As well as providing common values that generated a sense of belonging, more practically, mothers with children of school age were thrown into situations in which they had contact with other residents and fellow parents from the area. As one woman, from Bearsden, commented:

I was nervous about moving and getting to know people in the area and actually really it was when the boys started playgroup and things it made it much easier. We started to meet other people, at school, just like us with young children.

(Mrs. Waseem, Bearsden, northern suburb)

Further to providing a means of belonging to the neighbourhood in general, the school also acted as a pivotal point in creating intra-ethnic relations among Pakistani Muslims, especially women. Meetings at the school gates served as an informal information network that kept Pakistani Muslim families informed of any events or of new Koran classes starting in local homes. For the majority of the Pakistani Muslim respondents, living in the suburbs reflected their social trajectory without disrupting their cultural or religious field. They found ways to balance different aspects of their lives, for instance, through travelling back to the core for religious and cultural purposes or by establishing informal religious facilities in people's homes in the suburbs. Contrary to this, however, a few others began to doubt that they belonged, as their new place of residence, whilst reflecting their social trajectories, did not cater for their cultural and religious needs. This was less to do with the absence of facilities and more to do with the fact that other residents in the area (Giffnock), namely Jews and Christians, had religious facilities.

The process of adapting to life in a new neighbourhood was not entirely easy for some of the interviewees. Despite moving in pursuit of independence and privacy, a few interviewees felt quite isolated, as the quiet residential environment was at odds with the busy core where social interaction was higher. As one woman, from Giffnock, explained:

It was really hard when we first moved, I just thought it was so far away, that was my first thought and when we actually did move in I thought: 'Oh god, it's so quiet.' It took us quite a while to get used to that, before we lived in Pollokshields, where it's quite busy, we lived just off the main road, and you could hear cars all the time. Then here it was so quiet that the silence used to keep 
me awake. We hardly saw a soul on the street.

(Miss Ali, Giffnock, southern suburb)

A small number of households were unable to adapt and returned to the core from the suburbs after a couple of years. However, each of these households had members who had previously played central roles in the religious community. Living outside of the core gave them a sense that their influence and social role had diminished. One woman, who was the daughter of the head of the household, gave insight into some of the factors behind reverse moves:

Well, for us to move out to the suburbs it was really a novelty, you know and that really helped everyone to settle in, but after a while my dad started feeling out of the way of the community, feeling the quiet too much. He is one of the leaders in the Asian community and he was finding it difficult because people didn't know how to contact him. He was too out of the way and was always travelling back towards Pollokshields and Shawlands.

(Mrs. Mir, Strathbungo/Pollokshields, southern core)

The ease of settling-in differed according to age and stage in the life cycle. In general it was most difficult for the elderly and teenagers. The elderly more often became dependent on family members, whereas they had been more mobile in the core. There was also a sense amongst older, particularly Pakistani, respondents that the core area represented their ethnic identity in symbolic terms. For teenagers, the difficulty lay in moving away from friends and increased dependence on their parents for transport.

Initially, men were less worried about settling into the area than women. However, the majority of the men interviewed had been anxious about the move on behalf of their wives. The majority of men worked outside of the area in which they lived and had less need to worry about their everyday lives in the new neighbourhood as they tended only to be there in the evenings. The majority of the women, except two from the suburban households interviewed, did not work, and so being able to settle into the everyday life of the area was essential. A substantial number of the women of the households interviewed in the suburbs were unable to drive, so it was important that there were transport links to the core and that for those with children schools where in walking distance. As one man describes:

Yes, this area did, it felt like a natural choice to me, I really did not have any problems or worries at all, at least for myself. I was more concerned about how my wife would find it, but really she 
was $\mathrm{OK}$ in the end. And we managed to find a house close to the school. My wife she can't drive so she has to walk the kids to school and we made sure there were shops nearby so she is really happy here.

(Mr. Gahier, Giffnock, southern suburb)

In line with the discussion in the previous chapter, family was a much more important aspect in helping people settle in than the presence of members of the same ethnic group in the area. Although many interviewees knew of other Asian families living in the area, they did not seek them out neither did they have any substantial contact with them when they first moved. Instead, they came into contact with them on a random basis, whilst doing shopping or leaving the children to school, etc., as one man describes in the quote below. Despite this, a few interviewees said that just knowing other Asian families lived in the area gave them some sense of security that they too would settle into the area. As time went on, several of the Pakistani interviewees had developed relationships with each other, as discussed later.

I mean there were already a couple of Asian families who lived here when we moved, they stay quite local [nearby] and we knew of them through somebody else and eventually got to know them - not very well though - really we were on our own when we moved here, just the family. The other Asians in the area we just got to know in general, like meeting in the local Asda [supermarket], or the local school when dropping the kids off or something you know just in general.

(Mr. Bashir, Bearsden, northern suburb)

Feeling a sense of inclusion or belonging in the suburbs was often never really related to meaningful social interaction. Public space, to a great degree, was rarely utilised and very private due to several factors, the most important being the high dependency on cars, even to drive locally, which limited exposure between residents in the area. There were few people walking and no street activity, except a few residents mowing their lawns. In general, each property had high fences, garden hedges and gates at the entrance and between the house and its rear. The response of the interviewee below was common, most interviewees were happy to be friendly but preferred not to have direct contact with people in the area, reflecting the amiability but weakness of social ties:

I spend more time with my sister [who lived in the area), but I will say hello to them [other residents] if I meet them, like the wee women down the road... but sometimes they gabber, gabber, gabber. 
It's quite nice to be in the car [when passing them] because then you can just wave.

(Mrs. Kaur, Bearsden, northern suburb)

In line with this, several people placed more emphasis on the lack of interference that they had experienced when moving from the core to the suburb than on interactions in the suburbs. This weaker social interaction was completely ordinary in the suburbs, so people in a sense felt apart of what was considered to be normal social life there. As one man, who had moved from Strathbungo/Pollokshields, commented:

I mean I have freedom here they leave you alone you can walk with no disturbance, in Pollokshields people disturb each other all of the time, they stop you and are always talking to you, here there is peace, no interference and no noise, you can walk down the street and keep yourself to yourself.

(Mr. Lawanda, Giffnock, southern suburb)

Despite the infrequent social contact, the majority of the interviewees felt they had some kind of meaningful relationship with their neighbours. This tended to be based more on functional and practical support, which appeared to centre on either the security of the house, practical arrangements for taking children to school or help in emergencies, rather than day-to-day domestic or emotional relationships. In the words of one young woman, who had moved three years previous from Pollokshields:

It's like there is no community here. I got that in Pollokshields but not here. I think everybody just really keeps themselves to themselves. But if something happened then... like our next door neighbour she is really, really good because if we go down to England we give her one of our spare keys and she keeps an eye on the house. She is good like that she helped out a lot when my mum passed away, so if anything did happen you could rely on her.

(Miss Ali, Giffnock, southern suburb)

Reduced levels of support or social ties with neighbours in the suburb, when compared to neighbours in the core, was favourable for most, not only because, as already mentioned, it afforded them more privacy and less interference, but it meant they had less responsibility for others around them. The difference in the built environment and house type also meant they had to have less consideration for 
neighbours than whilst living in the close confines of a tenement building. As one woman who had moved to Bearsden commented:

It was very easy for us to settle when we first moved here, I didn't miss the West End [Woodlands] at all because I loved the garden for the children, it was so much better than the tenements, mostly because you didn't have to consider other people's preferences. I could let the children run around, hang the washing out, do anything without worrying about the neighbours (Mrs. Noor, Bearsden, southern suburb)

To the contrary, a small number of other respondents would have liked more involvement with their neighbours. Interviewees, in general, in Bearsden found it more difficult to interact with people in the area, as Mrs. Khan described the exclusive behaviour of women who had grown up in the area:

I find them really cliquey here, you know, they have like wee groups. I tried but they just keep themselves to themselves.

(Mrs. Khan, Bearsden, northern suburb)

\section{Religious links in the suburbs}

In both suburban areas, small Muslim communities had developed. As opposed to being the replication of social relations based on shared ethnicity and religious practices, which were visible in the core, primarily these groupings appeared to have developed to meet religious needs and for convenience sake. The difference in the nature of this re-gathering seemed to lie in the character of people's associations. There was less reliance on one another for day-to-day and emotional support and less social heterogeneity (in line with the class structure of the suburban areas); neither did the associations seem to have the same bearing on individuals private lives as they did in the core. Several people described having 'the best of both worlds': interaction with their religious or ethnic group and privacy. The Pakistani Muslim community was more developed, albeit in a more informal way, in Bearsden than in Giffnock. People had been meeting for several years in the local school to break their fast and pray at sunset during Ramadan. Although contact was somewhat infrequent, this was an element of peoples' lives which helped them to feel settled and supported. As one woman, who had moved from Woodlands to Bearsden, describes:

The community is very good here, you see people at the shop or at the schools. I am quite close to the people who live here. I had 
a couple of friends who lived here before I moved and slowly I met others... like during Ramadan when we are fasting we all get together in the night time to break our fast. We break our fast and pray once a day for a whole month so we really get to know each other and get close, there are not too many Muslims really in this area.

(Mrs. Raja, Bearsden, northern suburb)

The process of building a religious community in Giffnock was more difficult than in Bearsden. This was principally to do with the more formal plans of some active community actors to build a mosque and the refusal of the council to pass a building permit. This was a source of tension and alienation for some, especially when there were both Christian and Jewish places of worship and community centres in the area. A couple of interviewees, namely the proponents of the development, interpreted the denial to have a place of worship as a sign of rejection of their presence. A couple of other interviewees felt that it was important not only to have religious facilities for observances but also to create a central place for the Muslim community in the area. As one man, who had lived in Giffnock for over ten years, commented:

You know, if you have been to the mosque, it is not only a place for worship. The library is there and the reading room is there, so in other words, the five prayers only take one hour out of 24 hours. So the rest of the time you go there to socialise with people and see people. For instance, the old people they might go for one prayer and they stay socialising until the next one. So this is what is missing from this area.

(Mr. Sadiq, Giffnock, southern suburb)

To some extent, the desire to build a mosque was to do with localising the Muslim community, as people in the area attended different mosques in different areas in the city and, hence, had no real chance to get to know one another. This seems to be at odds with the desire for independence and privacy that a large number of the interviewees said motivated them to move. However, there was a sense that personal privacy would not be compromised as people did not live in close confines. The desire to establish facilities appeared to be an attempt to balance new residential patterns, integration into the new area and religious affiliations. One interviewee expressed this in the following way:

From an Asian point of view there is no community here it hasn't developed yet, well I don't know from the statistics but it's probably a recent thing really people living here in Giffnock, but I 
think we have got to establish a community sort of spirit here. I think the modern Asian as it were is trying to integrate more than the first generation, but I think there is still a desire to develop or to become more involved with each other in the area but this really hasn't happened yet.

(Mr. Gahier, Giffnock, southern suburb)

Desires to be involved in a community were for some more pertinent than for others, some of those interviewed would have appreciated the facilities but were less concerned about creating a 'community'. A woman from Bearsden illustrates a common feeling that several other interviewees expressed:

There are some groups here, we meet up for religious events; it is nice to speak Urdu, not that often but for special things in our calendar. The support is important and to go out and meet people, but the thing is even by going to these meetings I can still keep people out of my business. Well actually, even when I live out here people still know my business as they talk you know, but here at least I feel as if I have my privacy.

(Mrs. Raja, Bearsden, northern suburb)

Re-gathering in the suburbs appeared, for most, to be about convenience and facilitating simple religious needs without travelling to the central religious facilities. However, for a smaller number of interviewees there was a clear desire to rebuild a Muslim community in the suburbs as a means of increasing the opportunities to meet up and socialise together, which in a sense is contrary to the desire for privacy and space from the community. In some aspects, this desire perhaps renders social distance rather than distance from the close confines of religiosity in the core to be more prominent in influencing why some people want to move.

\section{The social environment, safety, fear of crime and lifestyle}

While in the last chapter the importance of safety was discussed in terms of its role in influencing where people lived, here it is discussed in terms of its impact on life in destination areas and future residential aspirations. While not commonplace, a few respondents had been victimised in their new residential location leading to quite serious constraints being placed upon their lifestyle and their sense of ease and safety in the neighbourhood. To a large extent, the reactions of these respondents were contingent on if the motivation of the incident was 
racial or more general, for instance, a robbery that may occur to any other resident in the area.

The most frequent incident experienced in the suburbs was robbery or crime against property, this type of crime not being entirely uncommon in quiet, affluent, middle-class suburbs. Naturally, those interviewees resident in the suburbs who had been robbed did feel insecure in their home and they had taken extra security precautions by way of fortressing their home or by simply changing more relaxed security habits. The more common nature of this crime made it easier to deal with; hearing of other families in the area in a similar situation eased any feelings of being singled out in the neighbourhood. Those who had experienced robberies still felt, in general, at ease in the neighbourhood. As Mrs. Waseem, who had been burgled a few months prior to the interview, described:

It was just unfortunate, the house is just so open and everybody can look into the house if they pass because we are just at the top of the hill and everyone can see what's happening. I feel quite comfortable staying here. It is just a bit creepy to know that somebody has been in my house, but I don't want to move. I've gotten comfortable with my neighbours. I don't really have any problem. (Mrs. Waseem, Bearsden, northern suburb)

To the contrary, a racially motivated threat was a personal threat, as experienced by few interviewees who had been amongst the earliest Asian incomers to the area. Two Indian families, quoted below, had moved from Woodlands to Bearsden and in the first week they arrived had received a threatening anonymous letter:

We had one racist letter, saying, 'Why are all of these people moving here bringing with them their pigs and their cows and their animals?' Actually, I don't know if I should tell you this but this was the kind of letter they used to use for Irish people, my friend told me. When I told my friend that's what she told me, it's not just us but it also happened to the Irish people... I just put it in the bin and it never happened again, but some people said I should have told the police. It really unsettled us because we were thinking all of the time which neighbour it could be and we didn't trust any of them.

(Mrs. Kaur, Bearsden, northern suburb)

We got a really nasty letter through the door. I don't know if they check and see who is moving in and if they are Asian or what they are, it was a horrible wee letter but nothing happened... It was ra- 
cist but nothing came out of it... We ignored it but it made you feel uncomfortable, you know is it this neighbour or that neighbour... we couldn't trust them. Now we have got to know them, it wouldn't have been any of them, it's stupid and silly, I don't know but it wasn't a nice letter anyway.

(Mrs. Raja, Bearsden, northern suburb)

Another family had received a prank phone call from teenagers in the area claiming to be from a racist group. This caused distress within the family, as the threat was very personal, describing their home and so on. The police had been involved and very supportive. While this incident was a prank it changed the amount of freedom that the family allowed their sons to have. As the mother of the household describes:

Someone got hold of our telephone number and pretended to be, they were called Combat I8 (A(I)dolf H(8)itler). They phoned the house and knew exactly what car we drove, which school the boys went to. It was called a prank but to me it wasn't a prank the boys were so frightened. I didn't want them going out or anything even though then they were about I5 or I6. Because of the colour you have to put up with so much... we've been lucky, but I know people who have had a lot more problems... this one girl I know she lives in Bearsden as well... her next door neighbour is really nasty to her. The neighbours don't like them because they are Asian. (Mrs. Khan, Bearsden, northern suburb)

Each of the families stayed in the area after the threats; however, it meant that the process of settling in was more difficult and led to them moderating their behaviour in some way, whether it was in levels of trust with the neighbours or in increasing the security of the house (some installed alarms, gates and cameras). All of these instances had been isolated and were over-written after long periods of time by positive experiences with neighbours. In the words of Mrs Kaur, who had been the recipient of a threatening letter:

It took us a long time to be able to settle in and trust the neighbours. Well there's one man Bob, and he was kind of funny, so we thought it could have been him but now he is great. But now they are actually all fine... it did take a long time to stop thinking...God you know who could it be that doesn't want us here, and we have every right to be here as any other person.

(Mrs. Kaur, Bearsden, northern suburb) 
In Strathbungo/Pollokshields, there was a more critical intra-community situation, whereby Asian youths in the area were intimidating residents. A significant number of the households interviewed had been robbed, some on more than one occasion, by Asian youths in the area. For many interviewees this had led to a change in levels of neighbourhood satisfaction, feelings of personal safety and significant behavioural changes. In some extreme cases a few interviewees never left their home unattended. One recent migrant from Kashmir described the disappointment, also commonplace among others, with the fact the perpetrators of the crime were Asian. As a consequence, the primary function of the community, as a safe and familiar place within the city, was altered for him:

I don't like living here. I don't feel safe because two years ago there was a robbery in my house. The young people in the neighbourhood are breaking in and thieving, they are our people. It is these youngsters who use drugs, so it is not safe; they are some of us [Pakistani]. Now I don't leave my house, unless I have to because I worry, I have to stay in the house a lot. My wife is scared all the time about what might happen to the house so she is always saying, 'hurry hurry' when we go shopping.

(Mr. Sarwar, Strathbungo/Pollokshields, southern core)

In specific parts of Strathbungo/Pollokshields, it was common to see the main doors of each flat within its close (stairwell) to be padlocked shut in addition to an ordinary Yale lock or the like, as people were attempting to protect their private space. Several people had installed imitation CCTV cameras, others had had iron bars made and fitted on to their windows, as Mrs. Hussein who had been burgled twice in her current flat and twice in the one previous had done:

There are so many break-ins, it used to be that you didn't have to bother about locking your doors and things like that but now you have to. I've had to put bars up because it's a big safety issue and now I think I am going to have to take them back down again because I don't think they meet with fire regulations for access out of the flat, but for safety it is the only way that I feel safe leaving the house for any amount of time.

(Mrs. Hussein, Strathbungo/Pollokshields, southern core)

The gangs of boys were more visible on the street in recent months and a couple of interviewees had friends who had been attacked at night on the way to the mosque for prayers. These incidents quite severely limited the personal freedom of several interviewees; some took 
security precautions at night and walked with friends or drove to the mosque, which was situated in the same neighbourhood. One interviewee highlights this through the experience of a friend:

My friend... he was beaten and they took some money from him at twelve o'clock at night. You can't walk at night on your own. If you are going to night prayers you have to walk with others or go by car. It is safe in the morning for morning prayers because they are sleeping!

(Mr. Dhaliwal, Strathbungo/Pollokshields, southern core)

What is interesting is the effect that length of residence appears to have in terms of those who are targeted, there was a sense amongst those who had lived in the area longer that they would be protected to a greater degree. This would suggest that community hierarchies are respected, at least to some degree. In the words of one resident from Pollokshields who had grown up in the area:

I think it makes a bit of a difference in terms of who is targeted. I mean, if someone had just moved into the area it would be different than someone living here for twenty-odd years. Also, the way you conduct yourself especially matters. If you are one of these people who is causing trouble all the time then people are going to be antagonised by you.

(Mrs. Mahmood, Strathbungo/Pollokshields, southern core)

It was difficult for the interviewees to talk overtly about these problems for fear of offending anyone in the community or shaming particular families. They took obvious care in any discussion of the issue, as one interviewee from Pollokshields illustrated:

There is a an underlying current of intolerance of all of this crime in the area, people don't like it, but nobody is going to come up and say anything in fear of saying something wrong... because you don't know if you are talking to the right person, when you are talking about these kind of things.

(Mrs. Anwar, Strathbungo/Pollokshields, southern core)

The majority were privately indignant with the parents of the gang members. They were held responsible for exerting a weak discipline on their sons and compensating for time spent away from the home at the family business with liberal amounts of money at the boys' disposal. In the words of one resident who felt very strongly about this topic of weak parenting: 
Their parents are not controlling them; they are not teaching them how to achieve a better life. If you don't water a plant then it will get dry... these parents have a greed for money, so they don't have time to look after their children... they give their children more money than they require... I watch who my boys are spending time with and where they are going. They just aren't controlling them... They are hiding their children from the police, if they are doing bad things they should tell the police.

(Mr. Sakinder, Strathbungo/Pollokshields, southern core)

The anger surrounding the current situation was evoked primarily by the disbelief that this unrest was being generated so openly from within the Asian, mostly Muslim population. Fear and anger were not the only reactions; interviewees were also ashamed, which was provoked further by media coverage of the situation and the abduction and murder of Kriss Donald, referred to earlier. Furthermore, the influence that this specific event had on the lifestyle and quality of life of the residents of the area was significant, in many cases people remained house bound for several days. This was due to the fear of retribution with the involvement of the BNP. As one woman commented:

There are a few gangs and a lot of rival gangs starting up in the area as well... starting up now that... you know, there's a lot of racial tension, and you'll have heard yourself about Kriss. When he was abducted and murdered there were a lot of people talking about reprisals and that... we've been lucky that nothing major has happened... It's down to Kriss' family that nothing happened in retribution because the BNP were up... they were wanting a rally up and down Kenmure Street [the street were the victim was abducted]. So that was scary, that was scary... and it was all over the papers

(Mrs. Mahmood, Strathbungo/Pollokshields, southern core)

Less can be said about the motivations behind the gang behaviour, without more in-depth interviewing. However, the increasing crime from within the community appeared to be a reaction to sectarian fighting between other white youths in the area and intolerance. Interestingly, although the youths were in breach of the ethnic and religious community, they had not completely forgone religious adherence, as some interviewees reported that they still attended the mosque for prayers. This brings to mind research conducted by Saeed, Blain and Forbes (1999) exploring identity among Pakistani teenagers, which found that they adopted religious labels as an element of their identity even when they did not practise the particular religion. To some 
degree, gang membership and subsequent territorial authority in the area appears to be mitigating a sense of identity that primarily deviates from societal, religious and cultural norms. In its essence, however, it encompasses some sense of how these boys feel both Asian and Scottish. On the one hand, the gang members are rejecting cultural and religious norms to achieve secular standing with their peers, which is illustrated through crime against the Asian community. On the other hand, they are using their background as a way to mark their identity or territory with rivals who are similarly identified by religious affiliation as a mark of sectarianism.

\section{Future aspirations}

The future residential aspirations of the interviewees reflected current levels of satisfaction, predicted changes in circumstances and also encompassed idealistic elements. Future aspirations in general were differentiated, to a large extent, by stage in the life cycle, by generation and by case study area. The younger interviewees and those who had been born in Scotland were more likely to aspire to move out of the core and farther away from the family or the community than more recent migrants or middle-aged and older respondents. Amongst the aforementioned groups, however, their plans involved remaining in Scotland or at least the UK. Still, interviewees who had married with someone from their parents' country of origin (Pakistan, except one from Dubai) often related their spouse's preference to return to their country of birth in the future.

The vast majority of interviewees from Woodlands wanted to remain in their current neighbourhood, showing high levels of attachment to the place and the community. This can be explained largely by both the general social environment of the area and the benefits of living close to cultural and religious facilities. Woodlands has become a desirable area to live, reflected in the rise in house prices, due to its social mix and proximity to the university, parklands, the city centre and other prestigious neighbourhoods. In general, a strong attachment to the area was positively correlated with a longer length of residence, as the younger interviewees were more willing to move in the future. Attachment to the area, however, was not solely related to characteristics of Woodlands itself, but to other exogenous factors such as safety and a fear of how people would be received in other areas. An older man seemed to capture the feelings of other interviewees who were his contemporaries: 
Here we've got everything, I mean, even more than the south side of the city. You don't want to be alone. You want to be with your friends and people who know you. I don't know what type of people I would live with if I moved. Here, I mean, if I'm feeling a little bit bored. I just put on my coat and pop out to see my friends or go to the local shops I know the people who work there ... I could never be happy away from here, so, no, I never want to move.

(Mr. Bashir, Woodlands, northern core)

The desire to stay was also often related to a sense of responsibility to the community. In particular, a small number of interviewees were involved in the running of the mosque on a daily basis, so felt they were needed as a community resource. In the words of the daughter of a couple who had lived in Woodlands for many years:

One thing that deters them from moving to other areas is that they've kind of built their life around here, you know, and obviously they would miss that. Just like the mosque is quite handy and everyone's going to that mosque and it is where they need to do their work in the mosque, they are needed.

(Mrs. Ahktar, Woodlands, northern core)

Place attachment, however, is not independent from the influence that proximity to family has on residential decisions, illustrated by the fact that all those households who wanted to remain in the area had family living nearby. Similarly, a large part of those respondents who aspired to leave the area did not have close family members in their immediate vicinity. For instance, the greater importance of family over neighbourhood is illustrated by Mr. Tabatabeyan:

I said to my wife we could move to the East End because it would be cheaper but she said no because there is no mosque or Asian community there. Well, I don't really have any plans at all at the moment, but maybe because of my children, like one of my sons has a job in Manchester and one of the other sons was thinking to move there because he was saying there are Muslim schools for girls and he was thinking to move for the education of the children. But if my children were in Glasgow I wouldn't move at all, I would stay in this area it is important to me.

(Mr. Tabatabeyan, Woodlands, northern core)

In Strathbungo/Pollokshields, over half of the interviewees had future plans to move out of the area. For the most part, this was due to social 
aspirations to suburbanise and issues related to rising crime in the area. However, several other interviewees who were active leaders or teachers in the local mosque or were involved in a local community group had a future vision for the area and were committed to it. These interviewees were engaged in dialogue with the police to develop strategies to make the community safer.

It has become clear throughout the discussion of the findings that both areas of core settlement continued to attract people to the area, whether to live or to make use of its facilities or social networks. This is best displayed through the fact that the majority of those interviewees living in a core area of settlement with future plans to move to the suburbs felt it to be important that they should live close to the core, as it had a high social and cultural value to them. The realisation of a move to the suburbs was inhibited by financial constraints for several interviewees; however, they hoped to be able to afford to move when their children began to work, illustrating the economic ties within families. Future plans for those middle-aged interviewees, excepting one man who had thought of moving to Manchester as some of his children lived there, involved remaining in Scotland and more specifically in the Glasgow suburbs of Giffnock, Bearsden, Newlands or Newton Mearns. There was a consensus that Scottish people were more friendly and tolerant than those who lived south of the border, this featured frequently as a reason to remain in Scotland. As the following interviewee, who had lived in England as a child, commented:

I think I wouldn't move down south, they depress me there; here the people are friendlier. I think there are more problems down south. I think Bearsden is a nice area; I would love it there, the size of the houses and peace and quiet. I would love a big house and a kitchen and a garden. Oh Giffnock is a nice area, actually my sister lived there that would be my second choice.

(Mrs. Raja, Woodlands, northern core)

Interviewees from the core areas, reflecting the experience of some of the suburban interviewees, were willing to live in a less than ideal property if it meant they were able to live in the location that they desired. Peace, quiet and safety were the most important aspects mentioned regarding desirable location. The feeling of being safe was related to the absence of gangs and the anonymity and the social status that the suburbs afforded. An example is the following account:

Yes. Yes, I want to move, my dream is Bearsden, Giffnock or Newton Mearns because they are very very quiet areas. I would like to live somewhere peaceful. Actually, there are some youngsters here 
creating problems and I'm not that sort of person I want a very peaceful life, plus I don't want to let my kids join them or to hear anything negative that they could pick up. I'm looking for peace, it doesn't matter - I could survive in a two bedroom. It doesn't matter, I don't want a big fancy house, just the peace.

(Mr. Dahlwali, Strathbungo/Pollokshields, southern core)

Length of residence in the UK and past housing experience had impact on aspirations, for instance, there was still a degree of uncertainty amongst several of the core residents, especially new migrants as to the safety of the suburbs. Moreover, only a couple of the core residents mentioned moving anywhere other than Glasgow's suburbs. However, suburban residents were more likely to have future plans to move greater distances away from both the core, and from the suburbs. This seemed to be endorsed by an increased confidence related to past housing history and a loosening of daily social ties with the core. An example of this is the desire expressed by a few families in Bearsden to retire to a smaller village in the countryside, being primarily attracted by the peace and increased isolation. The following interviewee had recently dissuaded her husband from wanting to return to India and convinced him to remain in Scotland, however, somewhere more rural as a compromise, as he had lived in a rural area in India:

My husband, he would love to move back home actually, to India but I wouldn't, it's OK for a holiday but I couldn't stay there. I'd miss all this here. I'd get a divorce before I moved. Ideally actually we will move to a lovely wee cottage somewhere, it would be brilliant just to get away from it all. You could go away and lose yourself there. Even somewhere like Drymen, it's not far from here; it's just a wee place. I love Scotland. I couldn't live anywhere else. I couldn't.

(Mrs. Khan, Bearsden, northern suburb)

This also highlights the extra dimension that trans-national marriages added to future residential plans. Two other women interviewed had spouses from Pakistan, in each of these instances there were tensions related with the fact the male partner wanted to return to his country of origin in the future. For the female interviewees, who were born in Britain, the idea of moving country was inconceivable, causing disagreement that had not yet been resolved within the household.

In some instances the suburbs did not afford privacy enough. Two young married couples with young children living in Giffnock were followed to the suburbs by family members and now wanted to move again for the same reasons. Despite the fact they were searching for 
complete privacy, it was important to be within easy access to their family:

East Kilbride was our ideal, wasn't it? It's kind of near enough but far enough from here. So we can have more privacy away from all the family living around here and live somewhere where nobody knows us but still be close to the family.

(Mr. and Mrs. Mir, Giffnock, southern suburb)

Material aspirations accounted for the desire to move to bigger houses within the suburbs for most. However, reasons for staying in the area rather than moving to another were, at large, associated with closeness to family and businesses, security and safety. To be in the catchment area of a good school was a further motivation, illustrated by the quote below, for future moves for a couple of interviewees in Giffnock:

Would I plan to move? It depends really, I suppose, when the kids are a wee bit older and thinking about secondary school, then a lot would depend on that. At the moment, everyone seems to want to send their children to a secondary school nearby, which has a good reputation, but we are just outside the catchment area. I think there is a sort of rundown school that they are spending I don't know how many millions fixing up. So we'll see how that improves and then take it from there. I don't really have a hard and fixed plan really. I don't know if living in this area has made me a wee bit of a snob... so if I moved it would be within a reasonable suburban atmosphere, a professional area. I think you want to be comfortable in your mind that it's a good area for the kids as well. (Mr. Gahier, Giffnock, southern suburb)

Given the differing motivations for moving within the suburbs to meet needs or aspirations the common determinant keeping people in the area, as alluded to by Mr. Gahier, was the status of the area.

\section{Conclusion}

The residential outcomes of the interviewees were diverse and dependent on numerous different factors, including personal and family circumstances, stage in the life cycle, economic status and gender. Inevitably a move to the suburbs was accompanied by a change in lifestyle, most notably the increased importance of home life over public life or neighbourhood life. The growth in the importance of private life was ironically accompanied by a greater use of spaces through out the city, as 
most had to commute for work, leisure, for worship and to access cultural facilities in the core. In general, the motivation stated by the majority of the interviewees was the desire for more privacy and security, as well as the importance of living close to the family. These expectations, in the most part, were met, resulting in satisfaction with the new area. However, for some these aspects were isolating and on leaving the core they had begun to value its public life more. Equally, others began to re-gather in the suburbs for religious events, albeit primarily for convenience sake, this provided an important form of support for some Muslim interviewees.

It is clear from the material presented that the interviewees' sense of belonging in the area was related to their sense of ordinariness. Social affinities with other residents were an important part of the interviewees' satisfaction with the area and shaped their sense of feeling apart of the neighbourhood. This was the case even though often it did not involve being particularly socially active or having close social ties with others around them. Having things in common, such as social status, was an aspect that created a sense of attachment to the new neighbourhood. This was enhanced for all members of the household, including grandparents, by having children at the local schools.

The extent to which individuals felt secure and safe in their neighbourhood was a key factor in determining residential outcomes and future residential aspirations. The intention of a threat or crime determined the impact it had upon the interviewee. Racially motivated crime created a feeling of isolation and alienation in an area, creating mistrust and insecurities with new neighbours. Responses to other types of crime varied, but mostly solicited changes in behaviour in order to increase personal safety, rather than alienating the family within the area as with racially motivated threats. When the crime was within the South Asian community it appeared to create in many ways more insecurity, as the community, which was once a safe place, became somewhere considered to be unsafe from the inside and stigmatised from the outside. It was the frustration of the increased crime from within the Asian community and the impact this had on the image of the area that was shaping the majority of the interviewees' from Pollokshields future plans to move out to the suburbs. This of course was coupled with suburbanisation as a growing trend. 


\title{
10 Conclusions
}

\begin{abstract}
Although the set of processes studied here are - firstly - ongoing and - secondly - at a young stage in their development, it is clear that minority ethnic groups are using space in a different way and that the suburban or core residential location is not an either/or choice for them. Rather many appear to be trying to balance an interest in social and material progression (including for their children), often through residential processes, with religious, cultural and family traditions. It is not clear to what extent the continuing values of culture and family are for practical or psychological reasons, but it is most likely for both. To a certain extent, these residential processes reflect a story of a social group that has become more affluent that mirrors the factors associated with the suburbanisation of wider society. However, there is an ethnic inflection to the causation that has led to these processes, mainly the critical influence of religiosity with its 'stifling' and 'policing' effects, as well as the continuing fear of discrimination specifying the areas in which people live. Until now, the discussion has been focused more or less exclusively on the qualitative or quantitative results in respective chapters, however, the purpose of this chapter is to draw both aspects together and elaborate the main conclusions along the lines of the three main categories of research objectives.
\end{abstract}

\section{Patterns of relocation}

Over the past ten years, Glasgow has seen localised changes in its South Asian population. In the traditional areas of core settlement in Glasgow we see continued clustering but little growth. Despite this, there were some interesting changes within the populations of these areas, revealing them to be dynamic and non-static. For instance, the South Asian population in Woodlands (the core area north of the river) as well as decreasing as a proportion of the expanding population of the area also changed internally, with new Pakistani residents (due to either in-movement or births) replacing a declining Indian population. The interviewees from the area attributed the lack of growth in the population to out migration, due both to the suburbanisation of mainly 
Indians and the increase in house prices that forced many younger Pakistani house buyers to move out of the area.

A similar pattern can be noted in the core area in the south of the city (Pollokshields/Strathbungo), which continues to be home to the largest absolute and relative South Asian population of any area in the city. The South Asian population, which is predominantly Pakistani, grew only slightly. However, again rather than being static, there appears to be population turnover, as evidence from the interviews suggests that the core area is still significant as a place of first settlement, whilst there was also notable movement by a significant number of Pakistani households into the areas adjacent to it. In fact, the major growth in the city was in these areas adjacent to and between the core settlement area and the suburbs to the south. This seemed to have little to do with overspill as the core is in no way saturated. The South Asian population makes up slightly more than a third of the area's total population and South Asians account for only a quarter of all house purchases in this locality over the past ten years. Rather, this appears to be related with a shift in cultural values, a loosening of daily ties with the community and with new ways of managing cultural expectations. Qualitative evidence also suggested that many of the younger generation of Pakistanis who could not afford to buy in Woodlands, where they had grown up, were buying in these areas crossing over from the more expensive West End core to cheaper areas adjacent to the southern core. The south more generally has become a buoyant property market in Glasgow and an alternative for many people from the popular West End (not just South Asians).

A further notable change in South Asian residence during the census period was the extent to which South Asian households had begun to suburbanise. The clear patterns of suburbanisation, though numerically small, can be seen through proportionately significant population shifts to suburbs that in I99I had very small South Asian populations. The most significant factor in explaining this relocation is the economic advancement of some South Asian households. There is clear evidence, from the qualitative work, of a growing South Asian middle class with social and material aspirations that have provided the motivation and resources to move. In addition to this, other extended households used the combined economic power of multiple earners in the family, who were not necessarily in professional positions, to finance the move.

The suburbs in the west (to the north of the river), which was one of the few areas outside of the core areas in I99I with a South Asian population, experienced little change in the absolute number of South Asian households living there. The opposite is true in the southern suburbs located in the district of East Renfrewshire, where there was a 
significant growth in the South Asian, mainly Pakistani, population, which increased by 85 per cent, from slightly over I,700 to over 3,I00. Despite increasing in visibility, it is important to emphasise the South Asian population only comprises 3 per cent of the district's total population. There appeared to be re-clustering of families and the re-gathering of Pakistanis along the lines of religious affiliation. Beyond this, it is clear that South Asian households have begun to move into suburban areas in the south of the city in which there were previously no or relatively few South Asian households, representing a wider dispersal.

Thus far the areas of core settlement in Glasgow have been home to Muslims, Sikhs, and Hindus, yet the research indicates a growing differentiation between and within South Asian groups. Despite the clear suburbanisation of Pakistani households, the out-migration of (the smaller) Indian population from the inner-city core areas has left the South Asian population there to be predominantly Pakistani and Mus$\mathrm{lim}$. This appears to be concentrating both those households who have less choice, due to cultural obligations and those who are disadvantaged financially in the core, whilst serving to widen class distinctions. Although there was clear evidence of limited choice and disadvantage, it must be highlighted that some people with high incomes chose to stay in the core area for religious and cultural reasons.

Finally, as in previous periods, despite the existence of a significant social rented stock and a previously expressed interest in moving into this sector, there was no movement of the South Asian population into the East End of the city. This, from qualitative evidence, reflects perceptions of the relative location of unsafe and stigmatised places in the city. Similarly, few South Asians lived in the north of the city which also appears to be a consequence of perceptions of areas that are open to them in the city and, also, because these areas are located too far away from the ethnic cores.

\section{Motivations and resources}

The general literature on suburbanisation and outward movement from the city alludes to several factors that instigate house moves. Traditionally, factors related with stage in the life cycle and other household factors were rendered as pertinent to why people move. More recently, emphasis has been placed on the pull of better services and environments to improve living conditions and to access better schools and job opportunities. There is also evidence from the literature that a move to the suburbs continues to represent a search for 'the good life' with socio-cultural underpinnings related to the expression of status and material gains. To the contrary, aspects of the inner city have been 
highlighted as push factors in instigating a move both in the early literature (Thorns I972) and more recently (Mumford \& Power I999; Champion et al. I998). Such factors include the impact of a poor quality environment, the unpopularity of a neighbourhood, urban decay, crime, congestion and the effects of other households moving out of the area on the perceived stability of the area (Rossi I955). In line with traditional patterns of residence, the literature pertaining to minority ethnic groups has, in general, been limited to the inner city, thus these groups have, at large, been excluded from discussions on residential mobility. The aim of this subsection of research objectives was to try to understand how broader motivations documented in the residential mobility literature are reflected in the migratory decisions of minority ethnic groups, given what has been documented in the past literature on minority ethnic housing and locational choices in the inner-city areas of settlement.

\section{Neighbourhood and family: Quality of life and time of life}

When we speak of push and pull factors we by no means see them as being separate or preserved aspects in the household decision-making process, rather the means in which they engage dialectally and are negotiated reflects the complexities in this process. Keeping this in mind, the neighbourhood context, both of origin and destination, worked together to influence people's decisions to move. The core area of settlement continued to be attractive to many households, confirming evidence presented in the literature relating to facilities and social and cultural networks. To the contrary, the perceived increase in crime in Strathbungo/Pollokshields, led to a diminishing sense that the 'community' was a safe place. This, in conjunction with fears of negative influences of youth culture on children, led to the desire among some to live in a quieter and safer place. The high density in the core areas as well as house type also created a desire for more space and privacy. Thus, to a certain degree, the decision to suburbanise was a response to the social and environmental deficits of living in the inner city consistent with earlier work by Champion et al. (1998) and Mumford and Power (1999). The pull factors of the suburbs related to the lifestyle that could be facilitated there, the socio-economic background of the residents, its reputation and the perception that it was safe. Furthermore, exclusive housing markets with particular stocks were available to movers, the schools and neighbours were seen as being better, the physical environment tidier, greener and quieter and more secure for children.

There was an ethnic dimension that acted as a pull factor to the suburbs, which was the role that the family or sometimes the wider social 
network played in housing and locational choices. Rossi's (I955) early study found that family and social networks had little or no influence on people's propensity to move or on their household decisions. However, the opposite is true in the experience of our interviewees. To the contrary, people were encouraged to suburbanise by informal information networks that provided them with information about the process and examples of successful residential outcomes. Contacts that encouraged people to move did not have to be actual but could be imagined. The knowledge alone that families with a similar ethnic background were living in the area gave them a sense of security, even if they did not know them or engage with them once they actually moved. Furthermore, there was evidence amongst the interviewees of chain migration amongst extended families who moved within a few streets of each other in the suburbs.

In contrast to early studies that found mobility to be greater in the stage in the life cycle when families had children and experienced growth, many of the interviewees moved at a later stage in the life cycle. Indeed, this was normally when the family was experiencing growth, but due to people marrying into the family or a member of the third generation being born into the household. In another common scenario, families moved when an elderly parent, who most likely established the family home in the core, had a change in their housing needs relating to their physical mobility. This is reflected in the age structure of the suburban households interviewed as in over half the head of the household was over 50. The younger suburban interviewees who had moved out of the extended family home and lived in nuclear families were most often professionals, whereas the members of extended family households often worked in the family business, which most likely reflects greater financial independence amongst the former.

\section{Occupational and economic class}

Although this thesis is a study of residential mobility, what has come to light is the extent to which social mobility is motivating the new residential patterns of South Asians in Greater Glasgow. Unsurprisingly, evidence from the interview data suggests that income is a significant driver behind processes of suburbanisation. In particular, the role that successful South Asian businesses have played in the process cannot be underrated. Over one-third of the suburban interviewees (seven out of twenty) had family businesses. Indeed, Bowes et al. (2002) highlight the significance of Pakistani business investment in Glasgow, not only in the niche economy but integrated into the wider economic structure of the city. Moving to the suburbs for these interviewees was 
significative of material success through hard work, which was reflected in a sense of pride, principally among older people interviewed. Similarly, success in the labour market is pertinent to the suburbanisation process as well over half of the suburban households interviewed had a household member with a professional job.

It is clear that income and employment are strong enabling and motivating factors in the process of suburbanisation. However, the variety of different ways in which families financed moves suggests that social trajectories and tendencies to disperse were not necessarily only linked to professional values but to aspirations for a better quality of life and a particular lifestyle. In saying this though, it is important to make clear that higher income or social/occupational mobility did not always correlate with the desire to move or increased mobility. The pull of the core proved strong for some who could have afforded to move, meaning that clustering need not always be associated with low income. However, the households interviewed in the core were more likely to have low-skilled jobs, work in the community, be unemployed or retired; also around one-fifth of interviewees had been or were currently self-employed. A further distinct factor between households who migrated to the suburbs and those who lived in the core was levels of car ownership. All suburban households had one or more cars per household, whereas almost half of the interviewees living in the core did not own a car. For most the daily commute to work was slightly increased by suburbanising, thus it did not appear that journey to work was a decisive factor in their migration decision.

Economic aspirations meant that for most households, regardless of their place of residence, owner occupation was in the long-term their ideal tenure choice. It was considered to make financial sense and a way of saving and widening future options. Despite this, confirming evidence in past literature (Third et al. I997; Bowes \& Sim I997; Bowes et al. I997; Sarre et al. I989), tenure choice was limited for some. Those struggling with housing costs (or who had in the past) would have liked to move into social rented accommodation in the short term. However, well-documented factors pertaining to location and long waiting lists once again created barriers. The future residential aspirations of several of those interviewees with lower incomes was to advance materially into better housing, which often meant moving away from the core to the suburbs, though this was truer for those living in the south of the city. It is interesting that the future residential aspirations of these particular interviewees were steered more so by material and quality of life aspirations rather than ties to the ethnic core or community. 


\section{Class, status and social identity}

The extent to which migration to the suburbs can be attributed to widening occupational class differences and aspirations related to social mobility within the South Asian group is clear. The degree to which it represents the adoption of middle-class values or class mobility, however, is a more complex issue. What can be argued with more certainty, though, is the extent to which a move to the suburbs was related to the desire for social status, representing social or material aspirations. This was often regardless of professional standing but, of course, dependent on economic advancement. Savage et al.'s (2005) recent work, which deals with the relationship between residential processes, location and class cultures in middle-class neighbourhoods, is useful here in helping to understand the association between the residential decisions, social trajectories and social identities of the interviewees. The authors explored the ways in which class cultures were linked to or formed through residential processes rather than being a product of occupation and employment. Indeed, they confirmed place of residence to be more pertinent as a key social identifier. The role of residential processes in forming or expressing social identity is prevalent in the current research, as movement to the suburbs for some was a strategy to create some social distance from the core and to live in place that they felt was a more accurate identifier of who they were. This could only be expressed through residential processes rather than solely through their professional life.

Despite the fact that the situation of the interviewees is similar to elements of Savage et al.'s (2005) work, there is an additional ethnic inflection, as in general the interviewees felt that their social identity was misconstrued or over determined by assumptions attached to their ethnicity. Thus the decision to suburbanise, for some, represented a clear effort to disperse from the ethnic cluster to re-establish identity on a basis that involved more than ethnicity and reflected better their values and social progress or more simply their desired lifestyle. This relates to the portrayal of core areas of ethnic settlement as being problematic and the politicisation of identity discussed in Chapter 2. In a sense, suburbanisation amongst some can be seen as a critical reaction to identities ascribed to them relating to ethnicity and religion, contrary to the preservation of religious or ethnic identity. The 'Asian' stereotype was seen, especially by the Indian interviewees, as specifically relating to Islam, a stereotype when relating to Pakistanis that they failed to question. Recent research in Scotland found that whilst Islamophobia has been on the rise since 9/II, Sikhs and Hindus have also been the subjects of increased victimisation in Scotland, relating to particular 
phenotypical features, namely skin colour, presumed to confirm their affiliation to Islam (Scottish Executive 2002c; Hopkins 2004).

There were clear inter-ethnic differences in the role that religion played in shaping personal identity. Pakistani respondents, in the majority, while moving to create social distance, felt that their Islamic background was a central part of their social identity. Their religion was generally a more assertive and public aspect of their identity compared to the Indian respondents who were concerned with keeping their religion private, partly due to its nature. This reflects previous studies which have shown Muslim identity to be the most assertive religious identity among the South Asian group (Hutnik I985; Vertovec \& Rodgers 1998). However, more recent studies have clearly shown both the ways in which Muslim identity is negotiated in line with other differences and the complexity of cultural identification (Phillips 2006). Hopkins (2006) explores the complex different ways in which masculinities of young Scottish Muslim men are articulated. Similarly, Dwyer (I998, 2000) highlights the diversity of ways in which Muslim women construct and contest their identities, specifically in relation to dominant racialised representations, changing familial gender ideals and gender relations.

The importance of being Muslim for the interviewees and of passing these values and beliefs on to their children, combined with the social aspirations highlighted earlier, points to a hybridisation of identity amongst the Pakistani Muslim interviewees. These interviewees appear to be trying to balance what it means to be Scottish, Pakistani and Muslim with class and career aspirations. This draws on debates in the literature that have contested the extent to which 'Asian' or ethnic identities are seen as being fixed and inward looking. Authors such as Amin (2002) and Dywer (1999) have highlighted the deficit in the ethnicisation of identity as failing to consider how ethnicity interrelates with class, education, gender, age, consumption and education. Harrison and Davis (200I) unpack this even further and point to the complexity of individual experiences that are indeed more complex than these broader categories of difference. Likewise, this echoes Phillip's (2006) assertion that the self-segregation debate sees the boundaries between religious and socio-cultural groups as being impermeable, overlooking the diversity of British Muslim's identifications. The strategies of those interviewed show that, to a large extent, expressing self identity was more important than expressing group identity. Furthermore, self-identities added depth to group identity and challenged prevailing stereotypes. For instance, some interviewees were proud that they were Pakistani and had suburbanised contrary to popular group stereotypes. 


\section{Self-segregation: Motivating residential choices?}

The insights provided by this thesis, to a large extent, contradict government views on the residential motivations of South Asian groups (The Independent Review Team 200I; Denham 200I; Ouseley 200I). Community cohesion is predicated on the myth of self-segregation that shifts the responsibility of integration on to the person living in the ethnic cluster. There are four main factors other than the sheer diversity of residential aspirations uncovered in this research that challenge the myth of self-segregation. The first is empowerment through socioeconomic advancement that has enabled many to move out of the core to the suburbs and other internal population movement in the city. The second is the constrained choices that keep many people in the area of core settlement despite alternative preferences. The accusation of self-segregation eclipses the role of material disadvantage and constraints in limiting residential choice, resonating, to a certain extent, elements of the underclass debate that has used behavioural explanations to explain inequality and exclusion, whilst acquitting structural explanations. The third is the way in which individuals use space and interact in different ways socially outside of the core area. Residential clustering in the context of this study certainly did not translate automatically or indeed easily into social segregation. Indeed, for several of the interviewees an assessment of the benefits of concentration and dispersal constituted part of their decision-making processes and motivations to suburbanise. Some interviewees, mostly Indian, moved to live in a more mixed neighbourhood. The fourth is the varied identities and motivations at play, which in turn impact residential choice, including Scottish national identity, social distinctions, parenting, gender, occupational class, changing cultural values and wider affiliations as well as religious beliefs and culture. Wider policy concerns would be better directed at the disadvantage and constraint that many households in the core face and in widening locational choices.

\section{Age and generation}

Age was found to be a factor that differentiated both residential preferences and levels of residential mobility. It also has a significant impact on the way in which people see the city, their levels of daily mobility, the geographical patterns of their social networks, their ethnic and social identity, their perceived opportunities in the labour and housing market and educational prospects for their children. In general, younger interviewees were second- or third-generation immigrants and had grown up in Glasgow in an area of core settlement. Amongst this small group of respondents, norms such as extended family living were 
questioned and seen by several as being a cultural tradition that had arisen from particular financial constraints, whereas co-location to achieve its benefits was no longer relevant in the context of their own lives. Despite this, they continued to comprehend its value in producing strong families and instilling a sense of responsibility in children. Individual experiences within any one extended family household were diverse and were influenced by intricate generational roles and cultural obligations. The younger generation, while some went into the family business, were more likely to have attended higher education. This not only increased their skills and confidence in the labour and housing markets, but also greatly widened their social contacts in the city and their mobility aspirations. When younger people did live in the extended family, especially sons, they often had important roles in the process of moving house. Frequently, it was a younger male member of the household that carried out the negotiations to buy new property, empowering them, to some extent, to influence household decisionmaking processes. The son's role in the house buying process was related to his higher level of education and greater confidence with professionals.

Furthermore, this group of younger interviewees had different social and educational aspirations for their children. Many wanted them to mix with other ethnic groups, most especially with other Scottish children and placed emphasis on the quality of local schooling, usually favouring schools outside the inner city, to escape particular negative influences. This had a direct influence on their locational choices or preferences. Similarly, those who had professional or semi-professional jobs had higher material expectations than their parents; they wanted more space and more privacy, which they were unable to buy in the core.

The importance of family and, for Muslims, even those who did not see themselves as very religious, of Koran education for their children was pronounced, despite their age or generation. These cultural factors did play a role in the residential decisions of these interviewees but had less influence in retaining them in the core than they did older people. With car ownership and more dynamic lifestyles the younger interviewees were quite mobile, travelling between several spaces in the city on a daily basis for leisure, work and cultural reasons. Thus, they were more prepared to consider relocation to the suburbs and beyond. In addition, age appears to produce a re-connection to the core as it continues to be strongly associated with ethnic and national identity on a symbolic and visual level appending more practical needs relating to religion and culture. 


\section{The role of the core settlement area and community}

The third group of research objectives focussed on the role of the core settlement area and the outcomes of migration in terms of its impact on community membership and new social network formations. The role that the core area and culture play in residential preferences and location is nuanced with other more general motivations discussed previously. The area of core settlement continued to be attractive as a residential location, primarily in relation to its social and cultural value more so than the physical environment. The value of the core area varied according to past housing history, length of residence in the city, religious observance, the strength of links to the local networks and a range of other individual factors, especially age. For several interviewees, living in the core was related to the advantages that they associated with clustering (i.e. cultural networks, language, facilities, friendship). This was especially true for new migrants, for whom the pre-existing minority ethnic community and cultural networks played a critical role in helping them settle and establish themselves. This was also highlighted by Robinson and Reeve (2006) in a recent report. Older people who had lived in the core for a long period of time attached a similar kind of importance to the ethnic community, but it also continued to be important for some middle-aged and younger interviewees. There was also a greater need amongst practising Muslims to be in close proximity to cultural and religious facilities. Furthermore, the commerce in the core areas of settlement attracted many visitors to area, including those who had suburbanised, creating a dynamic environment especially at the weekend. Over and above these practical and social reasons for remaining concentrated, the importance of family obligations and commitments was just as pertinent to locational choices as it was for suburban interviewees, showing that there were commonalities in interviewees' reasons for choosing where to live that transcended place and other differentials.

The qualitative findings contributed to our understanding of the role that culture plays in housing choices. The choice based literature focuses on clustering for cultural capital, whereas the current study found at times the constraining aspects of cultural obligations served to limit residential choices. Pakistani interviewees in particular said they were expected to live in close proximity to their families, regardless of their true residential preferences. Moreover, the impact of more intricate generational roles and hierarchies within extended families made residential decision making complicated and preferences very diverse, not to mention the matter of actual housing need. Cultural demands often led to inter-generational tensions, which in some instances resulted in the separation of extended families. As a means to 
solve the conflict between familial pressure and the perceived value of extended family living, some of the interviewees loosened daily ties by living in an adjacent area or even street, but remaining in close proximity. The change to nuclear family living was also driven by increased economic power and material aspirations, as some of the interviewees had specifically moved out of the family home so they could become owner occupiers in their own right. The changing attitude of younger respondents toward family and privacy contradicts earlier research conducted by Scottish Homes (I997). The study found that minority ethnic homeowners were much more likely to have left their last home, prior to becoming a homeowner, because they needed a bigger house, whereas white homeowners left because they wanted to live independently and to own their own home. Such changes may have implications for the size of properties minority ethnic families need in the future. Despite the changing role of cultural traditions within some families and the limitations which obligations placed on people, the pull of the family in shaping residential choices and preferences was still generally very strong, as highlighted throughout this chapter.

Beyond familial pressure and cultural expectations, some Pakistanis respondents' sense of privacy and autonomy was compromised due to high levels of public exposure and the feeling that personal behaviour was monitored through discourses of Islam. This is an aspect highlighted by Dwyer (I999) and in the Scottish context by Hopkins (2004). A move to suburbia loosened the hold that the local framework of public life had on the interviewees' private lives leading to increased personal freedom. Interestingly, Hopkins (2004) found that young $\mathrm{Pa}$ kistani Scots living in Glasgow also found alternative spaces to the area of core settlement as a means to attain greater freedom and personal choice. He illustrates this through the ways in which the young men in his sample negotiated their relationships with women in other areas in the city in order to keep them private. This is an aspect of the core that has been less commonly discussed in the literature and adds a new dimension to the role that we know clustering plays in the lives of some minority groups. This of course leads us to ask why re-clustering is occurring in the suburbs? It would appear, however, to be related more to the fact that other Asians living in the area provide an assurance of acceptance, without encroaching on their daily life. Thus clustering in the core and in the suburbs have aspects in common, but different affects in terms of impingement on private life.

Ethnicity played another role in constraining some to the core area due to a fear of not being accepted by new neighbours in other areas, confirming past literature that described the ethnic cluster as a refuge from hostility (Sarre et al. I989; Pacione I997; Van Kempen \& Ouzreken I998). Furthermore, evidence suggests that the areas in the city 
felt to be safe were few. The perceived safeness of an area and the likelihood that the residents there would accept them and be 'good' neighbours was one of the most decisive neighbourhood factors in determining residential location. This rendered location more important than the ideal property, on which people were willing to compromise. Of course, with few areas considered safe in the city the likelihood of reclustering outside of the core is greater.

\section{Residential outcomes and community}

In terms of residential outcomes for the migrating households, the suburban dwellers were overwhelmingly satisfied with their neighbourhood and related the change in the physical and social environment to an enhanced quality of life. A true sense of belonging in the suburbs came from the feeling of being 'ordinary' or like everyone else. This was a pronounced objective driving the residential choices of especially Indian interviewees. Again, parallels can be drawn with Savage et al.'s work of which a core concept was that of 'elective belonging' (2005: 203), were the feeling of belonging to an area was not characterised by historical roots one might have in an area. To the contrary, it involved a process in which 'people claimed ordinariness' (2005: II), rather than wanting to be distinctive they opted into a range of shared practices. In the current study these shared practices included equal material achievements, keeping a low profile and educational values for children. In a sense, these aspects were not expressed amongst neighbours but used to create what could arguably be described as imaginary bonds. In the instance of families with children, these aspects of belonging were activated in more practical ways relating to school events, play time and children's parties. Social affinity with other residents shaped the interviewees' sense of inclusion and attachment to the area, even though often this did not involve being particularly socially active with others around them. Indeed, settling into the suburban neighbourhood and developing a sense of belonging to the area appears to be less about integration in the sense of forming new social relationships and interdependencies across ethnic boundaries. There was little increase in social interaction to cause or lead to such associational or systematic integration (Lockwood I964), which is of course partly reflective of the privatised environment in the suburbs. It would appear that a move to the suburbs is akin to what we have seen in the majority population, and in a sense is 'integration' into 'normal' residential migratory patterns.

This has implications for the way in which the notion of integration is understood. Esser's (200I: 46) definition of social integration is perhaps a useful frame of reference here. He defines social integration as 
being 'the inclusion in already existing social systems'. In this instance, it is apparent that the interviewees felt they had socially integrated into an existing social system, but one that was characterised by limited social interdependencies. This to some extent suggests that the concept of 'integration' need not necessarily have a relational focus, which is distinct from the definition often adopted in migration and ethnic studies (Lindo 2005) involving the development of interdependencies between groups. This highlights a couple of issues pertinent to debates on integration. First, the extent to which wealth and property ownership in affluent areas as well as 'whiteness' or main stream values protects people from debates about needing to integrate or interact in social terms. The onus is placed on the responsibility of the minority ethnic resident living in less affluent areas, highlighting the hegemonic position of white and specifically middle-class values in the public sphere (see Back et al. 2002). Furthermore, the extent to which places of mixed residence may promote social integration or become places of engagement without pre-existing commonalities can be questioned.

\section{Drawbacks of the research and future research}

It is worthwhile at this point to acknowledge the weaknesses in the thesis. Substantive evidence from the qualitative research points to a clear heterogeneity and diversity of experience within the Asian population. This has implications for the way in which we think about and research the 'Asian community', as too often the term 'Asian' is used as a proxy for identity related to particular preconceived assumptions. The conception of this work did not focus enough on other differentials, which emerged during the research process. The inner workings and differences within this group are sometimes as stark as external differences, which has implications for the approach of work such as this.

The exclusion of the small Bangladeshi population from the qualitative interviews is a clear drawback to the breadth of this thesis' conclusions. The census analysis showed this population to be very small (just over 200 persons in Glasgow City). In hindsight, GROS estimate that this population may have been undercounted nationally by as many as a few thousand. Those who were recorded in the census appeared to be very segregated (this is probably also due to the very small population size), yet little is known about their housing experiences, tenure patterns, residential patterns and life chances more generally in Scotland.

The interviews revealed very distinct generational factors that had influence on housing and residential choices; however, the conclusions pertaining to this are limited in their scope as the sample size across 
generations was small. The inter-generational differences highlighted the dynamic nature of culture and the ways in which it interrelates with age and life experience in changing and shaping peoples cultural values. There would be value in a study that sampled purposively within a framework of age and generation to explore these factors in depth, as well as others, including household formation, housing choices and generational tensions.

In terms of mobility patterns and shifting residence, the focus here was limited to the suburbs and the ethnic core areas. However, future research is needed to further explore the processes underlying growth in the areas adjacent to the core. Motivations for such moves uncovered in the research were related to the loosening of daily ties with the religious and ethnic community and improving housing conditions and affordability. However, this was not a group that was targeted in the research, and research specifically targeting this group may provide more extensive knowledge into the drivers behind this changing residence and process of dispersal.

Although this study was specific to the owner-occupied sector, there was evidence from the interviewees that some households were being pushed into the private rented sector, due to the affordability of housing. Indeed, evidence from the census shows that South Asian representation in this tenure has grown. It is reputedly hard to access inhabitants in the private rented sector, but it appears to be an increasingly important aspect of South Asian housing experiences and/or choices. Future research may consider why this is the case, the impact of private renting on quality of life and opportunities, as well as considering minority ethnic experiences within this sector.

More evidence is needed relating to the relationship between residential segregation and social segregation. An important study would be one that explored, in more depth than there was scope to do in the current study, the use of space across the city and inter-ethnic relationships and types of interaction that people have with other ethnic groups.

Finally, there are certainly limitations to this case study in terms of its focus on one urban context, considering that there are clear differences between Scotland and the rest of the UK and subsequently between Glasgow and other UK cities. Despite the fact that local contexts and histories differ, some of the issues discussed here are likely to reflect to some degree experiences of South Asians within other urban contexts in the UK. 



\section{Appendix 1 \\ Semi-structured interview schedule \\ (core residents)}

\section{$1 \quad$ Residents of core settlement areas}

Themes to be explored

Housing histories; determine if housing location reflects residential preferences or more a result of constraints; investigate factors determining preferences; attraction of the core area, cultural, ethnicity, social class, age, life cycle; determine what they derive from current location; if reverse movers form the suburbs explore the pull factors that influenced both suburban and return move, investigate levels of neighbourhood satisfaction in each area; future residential aspirations; social networks.

\section{Housing history}

I. How long have you lived in this area?

2. Where did you live before moving here?

3. How did you find your current home?

4. Where do your friends and family live?

\section{Motivations}

5. What drew you to this area?

- Main attractions (neighbourhood/home/family/friends)?

6. Did you move because the area attracted you?

7. Did you move because this area attracted you or were there things about your last area/or house that you didn't like or that you found unsuitable for your needs?

8. Did this area feel like a natural choice to you? Were you at all anxious about moving here? Why was that?

9. Where there any other areas in Glasgow that you would have liked to move to? (Why not?)

Views on current neighbourhood

Io. What do you like about this area?

II. What things about this area do you like the most?

- Schools

- Shops 
- Places of worship

- Environment

- Friends/neighbours

- Family/relatives

- Closeness to work

- Sense of place/safety

I2. Are there any things that you don't like about living in this area?

Do you think they would have been better if you had moved somewhere else?

I3. How about other members of your family - how do they feel about living here?

Probe for reasons based around:

- Age

- Class

- Resources

- Ethnicity

I4. House - likes/dislikes:

- Space/facilities/structure/amenities/location?

I5. Who lives with you?

- How many generations/relations to one another?

Role of core settlement area

I6. What do you think makes an area a good place to live?

I7. Probe thoughts on relationships between people.

Do you think there are good relationships between people in the area?

Is there a sense of community? Who is apart of this? Who is outside of this?

I8. What do you think attracts new residents to the area?

I9. Do people tend to want to stay here? Why?

20. Have you noticed where families who move out of the area go to? Why do they move and why do they go where they go?

2I. Do you think people moving has an impact on the people who stay here or the sense of community in the area?

22 Do people who move away still keep in touch or keep using community facilities?

23. When you see people you know moving out of the area does it make you want to move?

24. What is your relationship like with neighbours/other members of the community? (levels of support - emotional/domestic/economic)

Future residential aspirations

25. Are you looking to move at all? When? Why? 
26. Where do you think you will realistically move to? Where would be your ideal place to live in the city?

- Differences between ideal and realistic moves

27. Are there any areas that you wouldn't want to move to?

28. Are there any particular barriers that a) might make you want to stay and b) might prevent you from moving?

29. What about the other people you live with would they consider moving?

30. Who would make the decision about if and where you should move? 



\section{Appendix 2 \\ Semi-structured interview schedule (suburban residents)}

\section{Suburban residents}

Themes to be explored

Housing histories; investigate factors determining preference and mobility, social class, age, stage in life cycle, pull factors; push factors from previous neighbourhood; investigate feelings of neighbourhood satisfaction in each area; relationships with the core settlement area; integration/in-group affiliation; future residential aspirations.

\section{Housing history}

I. How long have you lived in this area?

2. Where did you live before moving here?

3. How did you find your current home?

4. Where do you friends and family live?

\section{Motivations}

5. What drew you to this area?

- Main attractions

6. Did you move because this area attracted you or were there things about your last area/house that you didn't like or that you found unsuitable for your needs?

7. Were you at all anxious about moving here? Why was that?

8. Were there any other areas in Glasgow that you would have liked to move to? Any particular reason why you didn't end up there?

\section{Views on current neighbourhood}

9. How do you feel about living here?

Io. What things about this neighbourhood do you like the most?

- Schools

- Shops

- Environment

- Friends/neighbours

- Family/relatives

- Closeness to work

- Sense of place/safety 
- Space

- Privacy

II. Are there any things that you don't like about living in this area? Do you think it would have been better if you had moved somewhere else?

I2. How about other members of your family - how do they feel about living here?

Probe for reasons based around:

- Age

- Class

- Resources

- Ethnicity

I3. House - likes/dislikes:

- Space/facilities/structure/amenities/location

I4. Who lives with you?

- How many generations/relations to one another?

Community - New neighbourhood/connections with old neighbourhood

I5. Is this a good place? Does it match your ideas of a good place to live?

- Broach ideas on community

I6. Do you think there is a sense of community in this area? What are the relationships like between people?

I7. How easy was it for you to settle in here when you first moved?

I8. Did you already know anyone who moved here/or did anyone you know move here after you?

I9. How do you get on with your neighbours; is this different from the place that you lived before?

- Explore levels and type of contact

20. When you moved were there/or still are any things that you miss (ed) about your last neighbourhood?

- Draw out comparisons between suburban and core neighbourhoods

- Determine if expectations were met

2I. Do you still visit the last area that you lived in? Frequency? What for?

- Explore use of facilities and relationship with the community

Future residential aspirations

22. Would you consider moving house in the future? If yes where to? Why?

23. Are there any areas that you wouldn't want to move to?

24. Are there any particular barriers or things that would a) prevent you from moving? b) make you want to stay? 
25. What about the other people you live with (younger members of the family) would they consider moving?

26. Who would make the decision if and where you should move? 



\section{Appendix 3 Interviewee characteristics}

Interviewee Characteristics

$1 \quad$ A Pakistani Muslim, female, aged 26, who lived with her extended family (parents, uncle and aunt and children) in a small four-bedroom flat in an area of core settlement. All of the children of age were attending university. This interviewee studied computer sciences and worked in the family business. The main source of income for this household was the family convenience store which was located outside of the area. The family had one car and had recently moved from another area of core settlement.

2 A Kashmiri Muslim, male, aged between 30 and 40. The interviewee had moved straight from Kashmir to the core very recently. He was unemployed and receiving welfare benefits, but was looking for a job. He spoke English, but not fluently. He lived in a one bedroom flat with his wife and two children. $\mathrm{He}$ did not own a car

3 A Pakistani Muslim, male, aged between 30 and 40. He had only recently moved from another Scottish city to an area of core settlement. He was educated to Masters level in a Scottish university and had a prominent job working amongst the Muslim community in the area in which he lived. He lived in a spacious flat with his wife and three children and his parents-in-law. The household had one car.

$4 \quad$ An Indian Sikh, male, aged between 30 and 40. The interviewee had moved within the core out of the extended family home into a two-bedroom flat with his wife and two children. He worked in retail in an ethnic business in the city centre. The household had one car.

$5 \quad$ A Pakistani Muslim, female, aged 29. She had moved five years previously within the core area with her extended family (three generations including seven children) to a four bedroom flat. She was married and not working, but helping at home. The two main earners in the family were taxi drivers. The household had two cars.

6 An Indian Muslim, couple, aged between 40 and 50. They had moved within the core area ten years ago and lived with their child in a one bedroom flat. They owned a struggling business (convenience store) in a satellite town outside Glasgow. The family had one car.

7 A Pakistani Muslim, female, aged between 30 and 40. The interviewee had recently moved from the suburbs back to an area of core settlement where she had grown up. She was a housewife with three children living in a spacious flat. Her husband was from Pakistan and worked in the commercial sector. They had one car. 
Interviewee Characteristics

$8 \quad$ A Pakistani Muslim, female, aged between 20 and 30. The household had moved several years previously to a larger flat within the core. The interviewee had moved in the meantime from the north of England to marry one of the sons of the household, she subsequently had children. The household housed three generations and three married couples. The females did not work at present and the three males had manual jobs. The household had no car. A Pakistani Muslim, male, aged eighteen and currently attending college. The interviewee's parents had moved straight to the core from Pakistan before he was born had moved between the two countries since then. The household was comprised of a single family. The main earner of the household was a religious worker/teacher in the community with degree level education. The household had no car.

10 An Indian Sikh, male, aged between 60 and 70. He had moved from India straight to the core when his children were young. His, now grown up, children live in the suburbs. The interviewee had moved with his wife and son's family within the core to a better quality flat. The interviewee has a service sector job for a public institution. The household had one car.

11 A Pakistani Muslim, male, aged between 60 and 70. The interviewee had lived in a core area of settlement for 30 years. He now lives with his two children, their spouses and four grandchildren in a three bedroom flat. He was a retired bus driver. The main source of income for the household was his pension and his sons-in-laws incomes, both of whom work in an ethnic provisions shop in another area of core settlement. The household did not have a car.

12 A Pakistani Muslim, male, aged between 50 and 60. The interviewee had moved between core areas to be closer to a particular mosque where he did voluntary work at the Koran school. He lived in a single-family household with his wife, his children had moved away to the north of England to be married. He was not currently in employment and did not own a car.

13 A Pakistani Muslim, male, aged between twenty and 30. Lived in an extended family household in an area of core settlement. He was in the process of moving to another area of core settlement (with lower house prices than the current area) with his pregnant wife and their two children, as the family home was overcrowded. The main source of income was from the fathers pension (a retired shopkeeper), the interviewee who was a trainee solicitor and another son who worked in an administrative position in the public sector. The household had one car.

14 A Pakistani Muslim, male, aged between 30 and 40 . He had recently moved from an area outside of Glasgow back to the core to be closer to religious facilities and family. He lived in a two bedroom flat with his wife and five children. He worked in the voluntary sector as a carer. The household had no car.

15 An Indian Hindu, male, aged between 60 and 70. He lived in the core with his wife, they had recently moved to a smaller flat. His grown up children and grandchildren lived in the suburbs. He was a retired restaurateur. The household had no car. 
Interviewee Characteristics

16 A Pakistani Muslim, male, aged between 60 and 65. He had lived in the core for twenty years and recently moved to another flat to escape damp, which was causing illness in the family. He lived in a three bedroom flat with his wife, two children, their spouses and grandchildren. He was a retired train worker, who did voluntary work within the community and was very politically active. The main source of income for the household was the interviewee's pension and the income of one of his son-in-laws who was a taxi driver. The household had one car.

17 A Pakistani Muslim, female, aged between twenty and 30. The interviewee was single and a doctoral student. She lived with her parents and four siblings in an area of core settlement, in a three-bedroom flat, where they had lived for seventeen years. The main income of the family came from the fathers pension (a retired shop keeper) and the income of one of the sons who was a trainee doctor, the other children were in university. The household had one car.

18 A Pakistani Muslim, female, aged 40. The interviewee's husband had moved from Pakistan ten years previously to marry her and they had lived with her family in the core. The family had recently moved from the extended family household a few streets away to a two bedroom flat. The household income was from the extended family business, a convenience store outside of the area of core settlement. The household had no car.

19 A Pakistani Muslim, female, aged between twenty and 30. The interviewee lived in an extended family household in an area of core settlement with her husband's parents, his two brothers and their wives. She was the mother of two young children. The family owned three central Asian supermarkets in an area of core settlement, in which most members of the household worked, including the women. The household had two cars.

20 An Indian, Sikh, male, aged between 40 and 50. The interviewee was divorced and living alone in the core. He had moved from social housing in a peripheral area to the core a few years ago. He was educated to Masters level and worked in the public sector. He did not have a car.

21 A Pakistani, Muslim, male, aged between 50 and 60. The interviewee had moved straight to the suburbs from a northern English city to be close to his two children who had married into families in Glasgow. He owned a local confectionary shop and lived with his wife in a small house. He had one car. A Pakistani Muslim, couple, aged between twenty and 30. They lived in a small two bedroom terraced house in the suburbs with their two children and nearby their extended family. The main wage earner was an IT support worker whose wife was training to be a teacher. The household had one car.

23 A Pakistani Muslim, male, aged between 30 and 40 . He had moved from the extended family household in an area of core settlement to the suburbs. He lived in a semi-detached three bedroom house with his wife and two children. He was a computer programmer and was the sole wage earner. The household had one car.

24 A Pakistani Muslim, female, aged between 55 and 65. She was widowed had moved from an expensive villa on the periphery of the core to a small semidetached three bedroom house in the suburbs. The main household income was the pension of the deceased and equity from their previous home. The three children were studying at university. The household had one car. 
Interviewee Characteristics

$25 \quad$ An Indian Hindu female, aged between 30 and 40. She had moved several years previously from the core area, where her family live, to a three bedroom house in the suburbs with her husband and two children. The main household income comes from the family's restaurant in the city centre. The household had one car.

26 A Pakistani Muslim male, aged between 50 and 60. He had moved from the core with his parents and children to a four bedroom house in the suburbs. The main family income was from three thriving shops in two middle-class areas in the city. The household had three cars.

27 An Indian Sikh couple, aged between 50 and 60. The couple lived alone in a large four bedroom family home, where they moved to five years previously from the prosperous West End of the city. Their children, both doctors lived in other UK cities. The main earner was a surgeon. The household had two cars. An Indian Hindu male, aged between 40 and 50 . He had moved form the core to the suburbs ten years previously and had recently upgraded his suburban semi-detached home to a detached one. He lived with his wife and three young children. The interviewee was a university lecturer. The household had one car. A Pakistani Muslim female aged between twenty and 30 . She had recently moved to the suburbs with her father and siblings. Her extended family had followed and lived close by. The household income was from her father's job as a taxi driver and her brother who had a well paid professional job. The household had two cars.

30 A Pakistani Muslim, male, aged between 30 and 40 and single. He was in the process of moving out of the extended family home but currently lived with his parents and married brother in a spacious home in the suburbs. The main income was from the family business which consisted of several shops in villages outside of Glasgow. The household had three cars. A Pakistani Muslim male, aged between 30 and 40 . He had recently moved to the suburbs from an area of core settlement with his parents, married sibling and children. The household income was the pooled resources of the male family members who worked in a wholesale business in the core area. The household had one car.

32 A Pakistani Muslim male, aged between 35 and 45. He had recently moved out of the extended family home in the suburbs to another house in the same area with his wife and three children. The interviewee worked in his father's retail business in an area close by and was a small-scale real estate investor in the middle-east. The household had one car.

33 An Indian Hindu female, aged between 40 and 50 . When she had initially moved to the suburbs over ten years before, she, her husband and child shared a home with her sister's family. Recently they had bought another house a few streets away. The extended family owns a post office. The household had one car.

34 An Indian Sikh male, aged between 50 and 60. He had moved from the core to the suburb eight years previously with his wife and three children. Two of his children had moved to other areas in the city. The interviewee had a professional managerial job. The household had one car.

35 A Pakistani Muslim female, aged between 50 and 60. The interviewee had moved from the core area to the suburbs nine years before with her children. The house was overcrowded as two of the sons had recently married. One son worked as a manager in a large private company and the other as a manual labourer. The household had two cars. 
Interviewee Characteristics

36 A Pakistani Muslim male and Scottish Catholic woman, aged between 40 and 50. They had moved to the suburbs from an area close to the area of core settlement 6 years ago, before both their children were born. The male was a doctor and the female a nurse and travelled to work outside of the city. The household had two cars.

37 A Pakistani Muslim woman, aged between 50 and 60. She had moved five years ago from the core to the suburbs to a very large opulent six-bedroom home. She lived alone with her husband during the week, but her children returned home from university at the weekends. The household had two cars. The main income came from the family's very successful wholesale business that supplied Asian goods all over the country.

38 A Pakistani male, aged between 60 and 70. He had moved from another UK city straight to the suburbs with his wife and two sons to the home of his brother. He was a retired manual worker. The household had one car.

39 An Indian Sikh male, aged between twenty and 30. Lived in a single-family household in the suburbs with his parents and siblings. The interviewee was studying medicine. The main earner was his father who worked in a professional managerial job in the financial sector. The household had one car. An Indian Sikh female, aged between 40 and 50. She had moved to the suburbs over ten years ago and lived in a semi detached three bedroom house with her husband and child. The interviewee worked in IT support and her husband in a professional occupation. The household had one car. 



\section{Appendix 4 \\ Coding categories}

- Attractive attributes of 'core'

- Attractive attributes of suburban location

- Authorities - support

- Barriers to moving

- Changing values

- Decision-making process

- Definitions of the family/household

- Demographic and market changes

- Disadvantages of concentration

- Dissatisfaction with house

- Effect of out movers on community

- Employment status

- Family status

- Family visit during interview

- Forced moves

- Future aspirations

- Idea of ideal area

- Importance of family

- Independence of women

- Indian mobility

- Informal religious facilities

- Language

- Length of residence

- Neighbourhood dissatisfaction

- Other areas considered during purchase

- Out movers ties with community

- Poor environment for children

- Preference for other area than one moved to

- Privatised suburbs

- Religious facilities/lack of

- Residents view on core attractions

- Scotland

- Stigma - Pollokshields

- Strata within Asian community

- Teaching 
- Undesirable areas to live

- Younger generation

- Personal geography

- Closeness to work

- Place of study

- Mobility patterns

- Out of 'core'

- Back to 'core'

- Outside of country

- Core to core

- Within core

- Straight to suburbs

- Push factor

- Space

- Business

- Family

- High house prices

- Sense of safety

- Policing aspects of community

- To integrate

- House type

- Educational facilities

- Privacy

- Isolation/lack of independence

- Fear of crime

- Change in life cycle

- Resources

- Noise Reputation of area

- Social networks

- Type of support

- Community activity

- Changes in

- Wider community

- Dependence on or intrusiveness of community

- Location

- Relationships between Pakistanis and Indians

- Isolated

- Suburban movers relationships when in core

- Lack of Asian community in suburbs

- Development of Asian community in suburbs

- Sense of community (general)

- Importance of previous contacts in suburbs

- Importance of Asian community 
- Frequency of visits

- Indian

- Relationships women

- Mobility

- Transport

- Resources

- Sense of safety

- Fear of crime

- Victimisation

- Gangs

- Pull factors

- Religious facilities

- Educational facilities

- Space

- Asian community

- Cultural facilities

- Employment

- House type and price

- Status of woodlands

- Closeness to city centre

- General facilities

- Garden

- Peace and safety

- Reputation of area

- Family close by

- Familiarity of area

- Closeness to core

- Changes in family circumstances

- Problem in country of origin

- Process of buying home

- Submarket

- Sense of belonging/identity

- National

- Ethnic group

- Class

- Constraint

- House prices

- Need for religious facilities

- Lack of social housing

- Settling in

- Importance of Asian community

- Difficulty/Apprehension

- Housing history

- Life cycle 
- Marriage extended family growth

- Children grown up

- Building nuclear families

- Outmovers ties with community

- Core attributes missed by suburban mover

- Frequency of visits to core

- Sense that core has deteriorated - environmentally/social connections

- Motivations to suburbanise

- Resources and prestige

- Services

- Attractive environment and space

- Housing market

- Class/status issues 


\title{
Appendix 5 \\ Parent nodes
}

\author{
I. Personal geography \\ 2. Sense of safety \\ 3. Push factors \\ 4. Mobility patterns \\ 5. Social networks \\ 6. Pull factors \\ 7. Housing Issues \\ 8. Sense of belonging/Settling in \\ 9. Constraint \\ Io. Housing history \\ II. Religion \\ I2. Life cycle \\ I3. Out movers ties with community \\ I4. Motivations to suburbanise \\ I5. Neighbourhood Issues \\ I6. Future aspirations \\ I7. Residential outcomes \\ I8. Identity \\ I9. Resources
}





\section{Notes}

I The definition of a family adopted in the census is:

... a group of people consisting of a married or cohabiting couple with or without child(ren), or a lone parent with child(ren). Cohabiting couples include same sex couples. The 200I Census question asks for the relationship of each person in the household to every other member (except in large households). This enables the identification of concealed families (second or subsequent families in a household), families containing stepchildren and the relationship between families (living within one household). (GROS 200I)

2 The occupancy rating is worked out by relating the actual number of rooms in a household to the number of rooms needed by that household, which is calculated based on ages and relationships between the household members. An occupancy rating of I or $2+$ or more indicates that there are more rooms in the house than strictly needed by the household. An occupancy rating of $\circ$ indicates that the actual numbers of rooms is equal to the number needed, whereas a negative rating is indicative of fewer rooms than needed (GROS 200I).

3 The Other South Asian category and the Bangladeshi category are not represented here as they represent a very small fraction of the total group of South Asians.

4 Percentage of the postcode sectors South Asian population, living in output areas where South Asian populations are greater than 50 per cent, 20 per cent, Io per cent, 5 per cent, 2 per cent of the total population.

5 Percentage of the postcode sectors South Asian population, living in output areas where South Asian populations are greater than 50 per cent, 20 per cent, Io per cent, 5 per cent, 2 per cent of the total population, for postcode sectors with the most significant change in the South Asian population as a proportion of the total population (over 2 growth) during I99I-200I.

6 The case study areas are compared to Glasgow City as opposed to the Greater Glasgow study area in this section.

7 AB: Higher intermediate managerial/administrative/professional;

Cr: Supervisory, clerical, junior managerial/administrative;

C2: Skilled manual workers;

D: Semi-skilled and unskilled manual workers;

E: On state benefits

8 Group r: 'O' grade, Standard Grade, Intermediate ror 2, City and Guilds Craft, SVQ level I, 2 or equivalent;

Group 2: Higher Grade, CSYS, ONC, OND, City and Guild Advanced Craft, RSA Advanced Diploma, SVQ level 3 or equivalent;

Group 3: HND, HNC, RSA Higher Diploma, SVQ Level 4 or 5 or equivalent;

Group 4: First Degree, Higher Degree, Professional Qualification.

9 'Common' is the definition given to names when they are associated with three or more religions or languages. 



\section{References}

Al Awad, A. \& E. Songua-Barke (I992). 'Childhood problems in a Sudanese city: A comparison of extended and nuclear families', Child Development 63: 907-914.

Aldrich, H.E., J.C. Cater, T.P. Jones \& D. McEvoy (198I). 'Business development and selfsegregation: Asian enterprise in three British cities', in C. Peach, V. Robinson \& S. Smith (eds.). Ethnic segregation in cities, I79-I90. London: Croom Helm Ltd.

Allyene, B. (2002). 'An idea of community and its discontents: Towards a more reflexive sense of belonging in multicultural Britain', Ethnic and Racial Studies 25 (4): 607627.

Alexander, C. (2004). 'Imagining the Asian gang: Ethnicity, masculinity and youth after 'the riots', Critical Social Policy 24 (4): 526-549.

Amin, A. (2002). Ethnicity and the multicultural city, Report for the Department of Transport, Local Government and the Regions. London: DTLR.

Amin, A. (2002b). 'Ethnicity and the multicultural city: Living with diversity', Environment and Planning A 34 (6): 959-980.

Arshad, R. (2003). 'Race relations in Scotland', in Crowther, J.\& I. Martin (eds.). Renewing democracy in Scotland, I3I-I34. Leicester: NIACE.

Atkinson, R. (2006). 'Padding the bunker: Strategies of middle-class disaffiliation and colonisation in the city', Urban Studies 43 (4): 819-832.

Audrey, S. (2000). Multiculturalism in practise: Irish, Jewish, Italian and Pakistani migration to Scotland. Aldershot: Ashgate.

Bach, R.L. \& J. Smith (1977). 'Community satisfaction: Expectations of moving and migration', Demography I4: I47-I67.

Back, L., M. Keith, A. Khan, K. Shukra \& J. Solomos (2002). 'New Labours white heart: Politics, multiculturalism and the return of assimilation', Political Quarterly 73 (4): 445-454.

Bailey, N., I. Turok \& I. Docherty (1999). Edinburgh and Glasgow: Contrasts in competitiveness and cohesion. Glasgow: University of Glasgow.

Ballard, R. \& C. Ballard (I977). 'The Sikhs: The development of South Asian settlements in Britain', in Watson, J.L. (ed.). Between two cultures: Migrants and minorities in Britain. Oxford: Blackwell.

Barbour, R.S. (1998). 'Mixing qualitative methods: Quality assurance or qualitative quagmire?', Qualitative Health Research 8 (3): 352-36r.

Baxandall, R. \& E. Ewen (2000). Picture windows. New York: Basil Books.

Berce-Brathko, B. (2000). Can small urban communities survive: Culturological analysis in urban rehabilitation. London: Ashgate

Binns, C. (2002). Ethnic minorities, asylum seekers and refugees. Glasgow's local housing strategy: A topic paper. Glasgow: Glasgow City Council.

Bloor, M. (I997). 'Addressing social problems through qualitative research', in: Silverman, D. (ed.). Qualitative research: Theory, method and practice, 22I-238. London: Sage. 
Bourne, L. \& J. Simmons (1982). 'Defining the area of interest: Definitions of the city, metropolitan areas and extended urban regions', in Bourne, L. (ed) Internal structure of the city ( $2^{\text {nd }}$ Edition). Oxford: Oxford University Press.

Bowes, A.M., J. McCluskey. \& D.F. Sim (1989). Ethnic minority housing problems in Glasgow. Final Report to Glasgow District Council Housing Department.

Bowes, A.M., J. McCluskey \& D.F. Sim (I990a). 'Racism and harassment of Asians in Glasgow', Ethnic and Racial Studies I3 (I): 7I-9I.

Bowes, A., J. McCluskey \& D.F. Sim (I990b). 'Ethnic minorities and council housing in Glasgow', New Community I6 (4): 523-532.

Bowes, A. \& D.F. Sim (1997). Perspectives on welfare: The experience of minority ethnic groups in Scotland. Aldershot: Ashgate.

Bowes, A., N. Dar \& D.F. Sim (1997). 'Tenure preference and housing strategy: An exploration of Pakistani experiences', Housing Studies I2 (I): 63-84.

Bowes, A. \& D.F. Sim (2002). 'Patterns of residential settlement among black and minority ethnic groups', in Somerville, P. \& A. Steele (eds.). 'Race', housing and social exclusion. Jessica Kingsley.

Bowes, A.M., N.S. Dar \& D.F. Sim (2002). 'Differentiation in housing careers: The case of Pakistanis in the U.K', Housing Studies I7 (3): 38I-399.

Burgess, E. (1925). 'The growth of the city: An introduction to a research project', in Park, R.E., E. Burgess and R.D. McKenzie (eds.). The city. Chicago: University of Chicago Press.

Burnley Task Force (2002). Report of the Burnley Task Force. www.burnleytaskforce/org. uk/reports/taskforcereport.pdf.

Cabinet Office (2003). Ethnic minorities and the labour market. London: Cabinet Office.

Champion, T. (1996). 'Internal migration and ethnicity in Britain', in Ratcliffe P. (ed.). Ethnicity in the 1991 Census, volume 3, social geography and ethnicity in Britain: Geographical spread, spatial concentration and internal migration. Office for National Statistics. London: HSMO.

Champion, T. (I999). 'Migration and British cities in the I990s', National Institute Economic Review, I70: 60-77.

Champion, T. (200I) 'Urbanisation, surburbanisation, counterurbanisation and reurbanisation', in R. Paddison \& W. Lever (eds.). Handbook of urban studies, I43-16I. Sage, London.

Champion, T., D. Atkins, M. Coombes \& S. Fotheringham (1998) Urban exodus. London: CPRE.

Champion, T., S. Fotheringham, P. Rees, P. Boyle \& J. Stillwell (I998). The determinants of migration flows in England: A review of existing data and evidence. London: DETR.

Chang, C., S. Chen \& P. Somerville (2003). 'Economic and social status in household decision-making: Evidence relating to extended family mobility', Urban Studies 40 (4): 733-746.

Clapson, M. (1998). Invincible green suburbs, brave new towns. Manchester: Manchester University Press.

Communities Scotland (1996). Scottish house condition survey. Edinburgh: Communities Scotland.

Community Cohesion Panel (2004). The End of Parallel Lives? London: Home Office.

Central Rearch Unit (2002). City region boundaries study. Edinburgh: Scottish Executive.

Cummings, C., H. Winter, K.K. Cheng, R. Maric, P. Silcocks, \& C. Varghese (I999). 'An assessment of the Nam Pehchan computer programme for the identification of names of South Asian ethnic origin', Journal of Public Health Medicine 2I (4): 40I406. 
Dalton, M. \& S. Daghlian (1989). Race and Housing in Glasgow: The Role of Housing Associations. London: CRE.

Dalton, M. \& K. Hampton (I996). 'Housing needs of ethnic minorities in Govanhill: A community perspective', Scottish Ethnic Minorities Research Unit Research Paper, Series 2 (3). Glasgow Caledonian University: SEMRU.

Davis, M. (1998). Ecology of fear: Los Angeles and the imagination of disaster. New York: Henry Holts.

Dayha, B. (1974). 'The nature of Pakistani ethnicity in industrial cities in Britain', in Cohen, A. (ed.). Urban ethnicity. London: Tavistock.

Deane, G. (I990). 'Mobility and adjustments: Paths to the resolution of residential stress', in Demography 27 (I): 65-79.

De Jones, G.F. (I977.) 'Residential preferences and migration', in Demography I4 (2): 33I362.

Dorbiner, W. (1963). Class in suburbia. Chicago: Prentice-Hall.

Dorling, D. \& P. Rees (2003). 'A nation still dividing: The British census and social polarisation I97I-200I', Environment and Planning A 35: 287-1303.

Dwyer, C. (1998). 'Contested identities: Challenging dominant representations of young British Muslim women', in Skelton, T. \& G. Valentine (eds.). Cool places: Geographies of youth cultures, 50-65. London: Routledge.

Dwyer, C. (I999). 'Contradictions of community: Questions of identity for young British Muslim women', Environment and Planning A 31: 53-68.

Dwyer, C. (2000). 'Negotiating diasporic identities: Young British South Asian women', Womens Studies International Forum 23: 475-486.

Esser, H. (2003). 'Does new immigration require a theory of intergenerational integration?', MZES Working Paper No. 7I.

EuroDirect (2005). Millionaire neighbourhood report. www.eurodirect.co.uk/millionaire_report_2005html.

Fenton, M. (I977). 'Asian households in owner-occupation: A study of the pattern, costs and experiences of households in Greater Manchester', Working Paper on Ethnic Relations No. 2. Social Science Research Council Research Unit: University of Bristol.

Fernandez, P.M. \& J.C. Kulik (I98I). 'A multi-level model of life satisfaction: Effects of individual characteristics and neighbourhood composition', American Sociological Review $46(6): 840-850$

Fieldhouse, E. \& D. Cutts (2006). 'Voter turnout in British South Asian communities at the 200I general election', CCSR Working Paper 2006-02. Manchester: University of Manchester.

Fishman, R. (1987). Bourgeois utopias: The rise and fall of suburbia. New York: Basil Books.

Forrest, R. \& A. Kearns (200I). 'Social cohesion, social capital and the neighbourhood', Urban Studies 38(12): 2125-2I43.

Fox, K. (2004). Watching the English: The hidden rules of English behaviour. London: Hodder and Stoughton.

Gans, H. (1972). 'Urbanism and suburbanism as ways of life: A revaluation of definitions', in Kramer, J. (ed.). North American suburbs: Politics, diversity and change. New York: The Glendessary Press.

Gans, H. (1967). The Levittowners. New York: Pantheon.

Glasgow City Council (2002). The private rented sector: Glasgow's local housing strategy. Glasgow: GCC.

Gorard, S. \& C. Taylor (2002). 'What is segregation? A comparison of measures in terms of "strong" and "weak" compositional invariance', Sociology 36 (4): 875-895. 
GROS (2003). Scotland's Census 2001: Reference volume. SE/2003/69. Edinburgh: Scottish Executive.

GSPC (2003). Quarterly house price data. www.gspc.co.uk/sws.

Gwillian, M., C. Bourne, C. Swain \& A. Prat (1999). Sustainable renewal of suburban areas. York: Joseph Rowntree Foundation.

Harding, S., H. Dews \& S. Simpson (I999). 'The potential to identify South Asians using a computerised algorithm to classify names', Population Trends 97 (Autumn): 46-49.

Harris, P. \& P. Larkham (1999). Changing suburbs: Foundation form and function. London: E \& FN Spon.

Harrison, M. with C. Davis (200I). Housing, social policy and difference: Disability, ethnicity, gender and housing. Bristol: Policy Press.

Harrison, M. with D. Phillips (2003). Housing and black and minority ethnic communities: Review of the evidence base. London: Office of the Deputy Prime Minister.

Harrison, M., D. Phillips, K. Chahal, L. Hunt \& J. Perry (2005). Housing, 'race' and community cohesion. London: Chartered Institute of Housing.

Henderson, J. \& V. Karn (1987). Race, class and state housing: Inequality and the allocation of public housing in Britain. Aldershot: Gower.

Home Office (200I). Building cohesive communities (The Denham Report). London: HMSO.

Home Office (2004). Strength in diversity: Towards a community cohesion and race equality strategy. London: Home Office Communication Directorate.

Home Office (2004b). Religion in England and Wales: Findings from the 2001 Home Office Citizenship Survey. www.homeoffice.gov.uk/rds/index.htm.

Hopkins, P. (2004). 'Young Muslim men in Scotland: Inclusions and exclusions', Children's Geographies 2 (2): 257-272.

Hopkins, P. (2006). 'Youthful Muslim masculinities: Gender and generational relations', Transactions of the Institute of British Geographers 3I (3): 337-352.

Hutnik, N. (1985). Ethnic minority identity: The case of second generation South Asians in Britain. D.Phil Thesis: Oxford University.

Hyman, H. (1954). Interviewing in social research. Chicago: Chicago University Press.

Independent Review Team (200I). Community cohesion: A report of the independent review team. London: Home Office.

Johnston, R.J., J. Forrest \& M. Poulsen (2002). 'Are there ethnic enclaves/ghettos in British cities?' Urban Studies 39 (4): 59I-6I8.

Kasarda, J.D. \& M. Janowitz (I974). 'Community attachment in mass society', American Sociological Review 39: 328-339.

Kearns, A. (2002). 'Housing disadvantage and the inner city: the needs and preferences of ethnic minorities in sub-standard housing', in Somerville, P. \& A. Steele (eds.). 'Race', housing and social exclusion. London: Jessica Kingsley.

Kearns, A. \& R. Forrest (2000). 'Social cohesion and multi-level urban governance', Urban Studies 39 (4): 59I-IOI7.

Kearsley, G. \& S. Srivastava (I974). 'The spatial evolution of Glasgow's Asian community', Scottish Geographical Magazine 95: IIO-I24.

Kramer, J. (ed.) (1972). North American suburbs: Politics, diversity and change. New York: The Glendessary Press.

Landale, N.S. \& A.M. Guest (1985). 'Constraints, satisfaction and residential mobility: Speares' model reconsidered', Demography 22: 199-222. 
Lee, B.A., R.S. Oropesa \& J.W. Kanan (I994). 'Neighbourhood context and residential mobility', Demography 3I (2): 248-270.

Lee, E. (I966). 'A theory of migration', Demography 3: 47-57.

Lee, P. (I998). 'Housing policy, citizenship and social exclusion', in Marsh A. \& Mullins D. (eds.). Housing and public policy: Citizenship, choice and control. Buckingham: Open University Press.

Leonard, M. (2003). 'Interviews', in Miller R.L. \& J.D. Brewer (eds.). The A-Z of social research. London: Sage.

Lewis, P. (I994.) Islamic Britain: Religion, politics and identity among British Muslims. London: I.B. Tauris.

Liberson, S. (I96I). 'The impact of residential segregation on ethnic assimilation', Social Forces 40: 52-57.

Liberson, S. (1980). A piece of the pie: Black and White immigrants since 1880 . Berkley: University of California Press.

Liberson, S. (198I). 'An asymmetrical approach to segregation', in Peach, C., V. Robinson \& S. Smith (eds.). Ethnic segregation in cities, 6I-82. London: Croom Helm.

Lindo, F. (2005). 'The concept of integration: Theoretical concerns and practical meaning', in Social integration and mobility: Education, housing and health, IMISCOE Cluster B5 State of the Art Report. Universidade de Lisboa: Centro de Estudos Geograficos.

Littlewood, M. \& A. Kearns (1998). Below tolerable standard housing and ethnicity in Glasgow. Edinburgh: Scottish Homes.

Lockwood, D. (I964). 'Social integration and system integration', in Zollschan, G.K. \& W. Hirsch (eds.). Explorations in social change 244-25I. London: Routledge and Kegan.

Maan, B. (1992). The New Scots: The story of Asians in Scotland. Edinburgh: John Dinal.

Maan, B. (I994). No problem here: An investigation into racism in Scotland. Edinburgh: Scottish Office.

MacEwen, M., M. Dalton \& A. Murie (1994). 'Race' and housing in Scotland: A literature review and bibliography, SEMRU Research Paper No. 58. Edinburgh.

Massey, N. \& N.A Denton (I988). 'The dimensions of residential segregation', Social Forces 67 (3): 28I-3I5.

Massey, N. \& N.A. Denton (1993). American apartheid and the making of the underclass. Cambridge: Harvard University Press.

Massey, D., M. White \& V. Phua (I996) 'The dimensions of segregation revisited', Sociological Methods and Research 24 (2): 28I-292.

Miles, R. (I982) Racism and migrant labour. London: Routledge \& Kegan Paul.

Miles, R. \& A. Dunlop (1987) 'Racism in Britain: The Scottish dimension', in Jackson, P. (ed.). Race and racism II9-I4I. London: Unwin Hyman.

Miller, R.L. \& J.D. Brewer (2004) The A-Z of social research. London: Sage.

Mitchell, K. (2004). 'Geographies of identity: Multiculturalism unplugged', Progress in Human Geography 28 (5): 64I-65I.

Modood, T., R. Berthoud, J. Lakey, J. Nazroo, P. Smith, S. Virdee \& S. Beishon (I997). Ethnic minorities in Britain. London: Policy Studies Institute.

Modood, T. \& Werbner, P. (1997). The Politics of Multiculturalism in Northern Europe: Racism, Identity and Community. London: Zed Books.

MORI (2000). Assessing the market for new owner-occupied housing among Glasgow's Black and minority ethnic communities: Qualitative research study conducted for Scottish Homes. Edinburgh: MORI.

Morris, L.D. (1987). 'Local social polarisation: A case study of Hartlepool', International Journal of Urban and Regional Research II: 33I-350. 
Mumford, L. (I96I). The city in history: Its origins, its transformations and its prospects. New York: Harcourt, Brace and Ward.

Mumford, K. \& A. Power (I999). The slow death of great cities? Urban abandonment or urban renaissance. York: Joseph Rowntree Foundation.

Murdie, R. \& L. Borgegard (I998). 'Immigration, spatial segregation and housing segmentation of immigrants in metropolitan Stockholm, I960-95', Urban Studies 35 (Iо): I869-1888.

Musterd, S. \& W. Ostendorf, W. (1998). Urban segregation and the welfare state: Inequality and exclusion in western cities. London: Routledge.

Nanchchal, K., P. Mangtani, M. Alston \& I. Dos Santos Silva (200I). 'Development and validation of a computerised South Asian names and group recognition algorithm for use in British health related studies', Journal of Public Health Medicine 23 (4): 278 285 .

Newman, S.J. \& G. Duncan, G. (I979). 'Residential problems, dissatisfaction and mobility', Journal of the American Planning Association 45: I54-I66.

Newby, P. \& M. Turner (1999). 'British suburban taste, I880-1939', in Harris, P. \& P. Larkham (eds.). Changing suburbs: Foundation form and function. London: E \& FN Spon.

O'Leary, R. \& L. Dowds (2003). 'Questionnaire and structured interview schedule design', in Miller R.L \& J.D. Brewer (eds.). The A-Z of social research. London: Sage.

O'Loughlin, J. \& G. Glebe (I984). 'Intra-urban migration in West German cities', Geographical Review 74: I-23.

Ouseley, H. (200I) Community pride not prejudice. Bradford: Bradford City Council.

Ozuekren, A.S. \& R.Van Kempen (2002). 'Housing careers of minority ethnic groups: Experiences, explanations and prospects', Housing Studies I7 (3): 365-38I.

Pacione, M. (1997). Geographies of division in urban Britain. London: Routledge.

Pacione, M. (200I). Urban geography: A global perspective. London: Routledge.

Palen, J. (1995). The suburbs. McGraw-Hill.

Parekh, B. (2000). The future of multi-ethnic Britain. Runnymede Trust. London: Profile Books.

Park, R.E. (I926). 'The urban community as a spatial pattern and a moral order', in Burgess, W.E. (ed.). The urban community. Chicago: University of Chicago Press.

Park, R.E. (I928). 'Human migration and the marginal man', American Journal of Sociology 33 (6): 88I-893.

Park, R. (I952). Human communities: The city and human ecology. New York: Free Press.

Pawson, H., H. Third \& S. Wainwright (1996). Housing needs and preferences of minority ethnic households in Leith. Report to Scottish Homes by Edinburgh College of Art/Heriot-Watt University.

Peach, C. (1992). 'Urban concentration and segregation in Europe since I945', in Cross, M. (ed.). Ethnic minorities and industrial change in Europe and North America. Cambridge: Cambridge University Press.

Peach, C. (1996). 'Does Britain have ghettos?', Transactions of the Institute of British Geographers, New series 2I (I): 216-235.

Peach, C. (1998). 'South Asian and Caribbean ethnic minority housing choice in Britain', Urban Studies 35 (го): I657-1680.

Peach, C. \& S. Smith (I98I). 'Introduction', in Peach C., V.R. Robinson \& S. Smith (eds.). Ethnic segregation in cities, 9-22. London: Croom Helm Ltd.

Peach, C. \& D, Rossiter (I996). 'Level and nature of spatial concentration and segregation of minority ethnic populations in Great Britain, I99I', in Ratcliffe, P. (ed.). Social geo- 
graphy and ethnicity in Britain: Geographical spread, spatial concentration and internal migration, Volume 3 of Ethnicity in the 1991 Census. Office for National Statistics, London HMSO.

Pennant, R. (2005). Diversity, trust and community participation in England. London: Home Office.

Phillips, D. (1998). 'Black and ethnic minority concentration, segregation and dispersal in Britain', Urban Studies 35 (I0): I68I-I702.

Phillips, D. (200I). Movement to opportunity: South Asian relocation in northern cities. End of award report, ESRC Ro0238038. Leeds: University of Leeds School of Geography.

Phillips, D. (2003). 'Experiences and interpretations of segregation, community and neighbourhood', in Harrison, M. with D. Phillips (eds.). Housing Black and minority ethnic communities: A review of the evidence base, 36-49. London: ODPM.

Phillips, D. (2005). 'Housing achievements, diversity and constraints', in Harrison, M., D. Phillips, K. Chahal, L. Hunt \& J. Perry (eds.). Housing, 'race' and community cohesion, 25-46.. London: Chartered Institute of Housing.

Phillips, D. (2006). 'Parallel lives? Challenging discourses of British Muslim self-segregation', Environment and Planning D: Society and Space 24: 25-40.

Phillips, D. \& V. Karn (I99I). 'Racial segregation in Britain: Patterns, processes and policy approaches', in Huttman, E.D. (ed.). Urban housing segregation of minorities in Western Europe and the United States. Duke University Press.

Phillips, D. \& R. Unsworth (2002). 'Changing minority ethnic housing choices in the social rented sector', in Sommerville, P. \& A. Steele (eds.). 'Race', housing and social exclusion. London: Kingsley.

Phillips, D., P. Ratcliff \& C. Davis (2003). Asian mobility in Leeds and Bradford. www.geog. leeds.ac.uk/projects/mobility.

Phillips, T. (2005). Sleep walking into segregation. www.cre.gov.uk.

Platt, L. (2005). Migration and social mobility: The life chances of Britain's minority ethnic communities. York: Joseph Rowntree Foundation.

Putman, R. (2000). Bowling alone: The collapse and revival of American community. New York: Simon and Schuster.

Ratcliffe, P. (I996). 'Methodological refinement, policy formulation and the future research agenda: Some brief reflections', in Ratcliffe, P (ed.). Social geography and ethnicity in Britain: Geographical spread, spatial concentration and internal migration, volume 3 of ethnicity in the 1991 Census. Office for National Statistics, London: HMSO.

Ratcliffe, P. (2002). 'Theorising ethnic and 'racial' exclusion in housing', in Somerville, P. \& A. Steele (eds.) 'Race', housing and social exclusion. London: Jessica Kingsley.

Ratcliffe, P. (2004). 'Race', ethnicity and difference: Imagining the inclusive society. Maidenhead: Open University Press.

Ratcliffe, P. with M. Harrison, R. Hogg, B. Line, D. Phillips \& R. Tomlins. R. (200I) Breaking down the barriers: Improving Asian access to social rented housing. Coventry: $\mathrm{CIH}$, on behalf of Bradford MDC, Bradford Housing Forum, The Housing Corporation and FBHO.

Rees, P. \& F. Butt (2004). 'Ethnic change and diversity in England, I98I-200I', Area 36: I74-I86.

Rees, P. \& D. Philips (1996). 'Geographical spread: The national picture’, in Ratcliffe, P. (ed) Social geography and ethnicity in Britain: Geographical spread, spatial concentration and internal migration, volume 3 of ethnicity in the 1991 Census. Office for National Statistics, London: HMSO.

Rex, J. \& R. Moore (I967). Race, community and conflict. London: Oxford University Press. Ritchie, D. (200I). Oldham independent review: One Oldham, one future. Government Office for the North West. 
Robinson, D. (2005). 'The search for community cohesion: Key themes and dominant concepts of the public policy agenda', Urban Studies 42 (8): I4II-I428.

Robinson, D. \& K. Reeve (2006). The experiences and consequences of new immigration at the neighbourhood level: A review of the evidence. York: Joseph Rowntree Foundation.

Rossi, P.H. (I955). Why families move: A study of the social psychology of urban residential mobility. Glencoe: Free Press.

Rothblatt, D. \& D. Garr (1986). Suburbia: An international assessment. London: Croom Helm.

Runnymede Trust (1997). Islamaphobia: A challenge for us all. London: Runnymede Trust.

Saeed, A., N. Blain \& D. Forbes (1999). 'New ethnic and national questions in Scotland: Post-British identities among Glasgow Pakistani teenagers', Ethnic and Racial Studies 22 (5): $82 \mathrm{I}-844$.

Saltman, J. (I99I). 'Theoretical orientation: Residential segregation', in Huttman, E.D. (ed.). Urban housing segregation of minorities in Western Europe and the United States. Duke University Press.

Sanders, J. M. \& V. Nee (I996). 'Immigrant self-employment: The family as social capital and the value of human capital', American Sociological Review 6r: 23I-246.

Sarre, P., D. Philips \& R. Skellington (I989). Ethnic minority housing: Explanations and policies. Aldershot: Gower.

Savage, M., G. Bagnall \& B. Longhurst (2005). Globalisation and belonging. London: Sage.

Savage, M. (2002). 'Class and labour history', in Van Voss, L.H. \& M. Vander Linden (eds.). Class and other identities. Oxford: Berghahn.

Schill, M.H. (I992). 'De-concentrating the inner-city poor', Chicago-Kent Law Review 67: $795-853$.

Schmidt, C. (2000). 'The analysis of semi-structured interviews', in Flich. U., E. von Kerdoff \& I. Stienke (eds.). A Companion to Qualitative Research. London: Sage.

Schoon, N. (200I). The chosen city. London: Spon Press.

Scottish Executive (I999). A Scotland where everyone matters. Edinburgh: Scottish Executive.

Scottish Executive (200I). Audit of research on minority ethnic issues in Scotland from a 'race' perspective. Edinburgh: Scottish Executive.

Scottish Executive (2002a). New Scots: Attracting fresh talent to meet the challenge of growth. Edinburgh: Scottish Executive.

Scottish Executive (2002b). Housing Scotland Act, 2001: Housing lists and allocations. SE Circulari/2002. Edinburgh: Scottish Executive.

Scottish Executive (2002c). Tackling religious hatred. Edinburgh: Scottish Executive.

Scottish Executive (2004). Analysis of ethnicity in the 2001 Census. Summary Report. Edinburgh: Scottish Executive.

Scottish Executive (2005). Using the Scottish index of multiple deprivation, 2004: Guidance. www.scotland.gov.uk/Publications/2005/01/20458/49127.

Scottish Office (I99I). Ethnic minorities in Scotland. SCPR, Central Research Unit, Edinburgh: Scottish Office.

Sennett, R. (1970). The uses of disorder. New York: Vintage.

Shevky, E. \& W. Bell (I955). Social area analysis. Stanford, CA: Stanford University Press.

Silverman, D. (ed.) (I997). Qualitative research: Theory, method and practice. London: Sage.

Sim, D. (I99I). 'Ethnic minority access to housing associations', in Bowes, A. \& D. Sim (eds.). Demands and constraints: Ethnic minorities and social services in Scotland. Edinburgh: SCVO.

Simpson, L. (2004). 'Statistics of racial segregation: Measures, evidence and policy', Urban Studies 4I (3): 66I-68I. 
Simpson, L. (2005). Measuring residential segregation. Presentation to ESRC. www.ccsr.ac. uk/research/migseg.htm.

Smith, S. (1989). The politics of 'race' and residence: Citizenship, segregation and white supremacy in Britain. Cambridge: Polity Press.

Somerville, P. (1998). 'Explanations of social exclusion: Where does housing fit in?', Housing Studies I3 (6): 76I-780.

Sonuga-Barke, E.J.S. \& M. Mistry (2000). 'The effect of extended family living on the mental health of three generations within two Asian communities', British Journal of Clinical Psychology 39: I29-I4I.

Speare, A.J. (I970). 'Home ownership lifecycle stage and residential mobility', Demography 7 (4): 449-458.

Speare. A.J. (I974). 'Residential satisfaction as an intervening variable in residential mobility', Demography II: I73-I88.

SPHO (2004). Community Profiles. www.scotpho.org.uk/web/site/home/Comparativehealth/Profiles/CommunityProfiles/CommunityProfiles.asp.

Stearns, L \& J. Logan (I986). 'Measuring trends in segregation', Urban Affairs Quarterly 22 (I): I24-I5O.

The Strategy Unit (2003). Ethnic minorities and the labour market: Final report. London: Cabinet Office.

Third, H., S. Wainwright \& H. Pawson (1997a). Constraint and choice for minority ethnic homeowners in Scotland. Research Report No. 54. Edinburgh: Scottish Homes.

Third, H. \& MacEwen (1997b). 'The housing experience of minority ethnic groups in Scotland', in Bowes, A. \& D. Sim (eds.). Perspectives on welfare: The experience of minority ethnic groups in Scotland. Aldershot: Ashgate.

Thomlinson, R. (1969). Urban structure: The social and spatial characteristics of cities. New York: Random House.

Thompson, F.M.L. (1985). The rise of suburbia. New York: Leicester University Press.

Thorns D. (1972). The suburbs. London: Batnam Press.

Tomlins, M., M.R.D. Johnson \& D. Owen (2002). 'The resource of ethnicity in the housing careers and preferences of Vietnamese communities in London', Housing Studies I7 (3): 505-519.

Van Kempen, R. \& S. Ozuekren (1998). 'Ethnic segregation in cities: New forms and explanations in a dynamic world', Urban Studies 35 (I0): 1631-I656.

Vertovec, S. \& A. Rodgers (1998). European muslim youth: Reproducing religion, ethnicity and culture. London: Aldershot.

Wainwright, S., A. Murie \& M. MacEwen (1994). The experience of households from minority ethnic groups in the Scottish housing system: A report to Scottish Homes. Edinburgh: Scottish Homes.

Weitzman, E. A. (2000). 'Software and qualitative research', Sociological Focus I8: I07-II7.

Wolpert, J. (1966). 'Migration as an adjustment to environmental stress', Journal of Social Issues 22 (4): 92-IO2. 



\section{Other IMISCOE titles}

\section{IMISCOE Research}

Rinus Penninx, Maria Berger, Karen Kraal, Eds.

The Dynamics of International Migration and Settlement in Europe:

A State of the Art

2006 (ISBN 9789053568668 )

(originally appearing in IMISCOE Joint Studies)

Leo Lucassen, David Feldman, Jochen Oltmer, Eds.

Paths of Integration: Migrants in Western Europe (1880-2004)

2006 (ISBN 9789053568835 )

Rainer Bauböck, Eva Ersbøll, Kees Groenendijk, Harald Waldrauch, Eds. Acquisition and Loss of Nationality: Policies and Trends in 15 European Countries, Volume 1: Comparative Analyses

2006 (ISBN 9789053569207 )

Rainer Bauböck, Eva Ersbøll, Kees Groenendijk, Harald Waldrauch, Eds. Acquisition and Loss of Nationality: Policies and Trends in 15 European Countries, Volume 2: Country Analyses 2006 (ISBN 978905356 921 4)

Rainer Bauböck, Bernhard Perchinig, Wiebke Sievers, Eds.

Citizenship Policies in the New Europe

2007 (ISBN $978905356922 \mathrm{I}$ )

Veit Bader

Secularism or Democracy? Associational Governance of Religious Diversity 2007 (ISBN 9789053569993 )

Holger Kolb, Henrik Egbert, Eds.

Migrants and Markets: Perspectives from Economics and the Other

Social Sciences

2008 (ISBN 9789053566848 )

Ralph Grillo, Ed.

The Family in Question: Immigrant and Ethnic Minorities in

Multicultural Europe

2008 (ISBN 9789053568699 ) 
Corrado Bonifazi, Marek Okólski, Jeannette Schoorl, Patrick Simon, Eds. International Migration in Europe: New Trends and New Methods of Analysis 2008 (ISBN 978905356894 I)

Maurice Crul, Liesbeth Heering, Eds.

The Position of the Turkish and Moroccan Second Generation in Amsterdam and Rotterdam: The TIES Study in the Netherlands 2008 (ISBN 978908964 06I I)

Marlou Schrover, Joanne van der Leun, Leo Lucassen, Chris Quispel, Eds. Illegal Migration and Gender in a Global and Historical Perspective 2008 (ISBN 9789089640475 )

Gianluca P. Parolin

Citizenship in the Arab World: Kin, Religion and Nation-State 2009 (ISBN 978908964045 I)

Rainer Bauböck, Bernhard Perchinig, Wiebke Sievers, Eds. Citizenship Policies in the New Europe: Expanded and Updated Edition 2009 (ISBN 978908964 I08 3)

\section{IMISCOE Reports}

Rainer Bauböck, Ed.

Migration and Citizenship: Legal Status, Rights and Political Participation 2006 (ISBN 978905356888 o)

Michael Jandl, Ed.

Innovative Concepts for Alternative Migration Policies:

Ten Innovative Approaches to the Challenges of Migration in the 21st Century 2007 (ISBN 978905356990 o)

Jeroen Doomernik, Michael Jandl, Eds.

Modes of Migration Regulation and Control in Europe

2008 (ISBN 9789053566893 )

Michael Jandl, Christina Hollomey, Sandra Gendera, Anna Stepien, Veronika Bilger

Migration and Irregular Work in Austria. A Case Study of the Structure and Dynamics of Irregular Foreign Employment in Europe at the Beginning of the 21st Century 2008 (ISBN 9789089640536 ) 
Heinz Fassmann, Ursula Reeger, Wiebke Sievers, Eds.

Statistics and Reality: Concepts and Measurements of Migration in Europe 2009 (ISBN 9789089640529$)$

Karen Kraal, Judith Roosblad, John Wrench, Eds.

Equal Opportunities and Ethnic Inequality in European Labour Markets:

Discrimination, Gender and Policies of Diversity

2009 (ISBN 978908964 I26 7)

\section{IMISCOE Dissertations}

Panos Arion Hatziprokopiou

Globalisation, Migration and Socio-Economic Change in Contemporary

Greece: Processes of Social Incorporation of Balkan Immigrants

in Thessaloniki

2006 (ISBN 9789053568736 )

Floris Vermeulen

The Immigrant Organising Process: Turkish Organisations in Amsterdam and Berlin and Surinamese Organisations in Amsterdam, 1960-2000 2006 (ISBN 978905356875 ㅇ)

Anastasia Christou

Narratives of Place, Culture and Identity: Second-Generation

Greek-Americans Return 'Home'

2006 (ISBN 978905356878 I)

Katja Rušinović

Dynamic Entrepreneurship: First and Second-Generation Immigrant

Entrepreneurs in Dutch Cities

2006 (ISBN 9789053569726 )

Ilse van Liempt

Navigating Borders: Inside Perspectives on the Process of Human Smuggling into the Netherlands

2007 (ISBN 9789053569306 )

Myriam Cherti

Paradoxes of Social Capital: A Multi-Generational Study of Moroccans

in London

2008 (ISBN 978905356032 7) 
Marc Helbling

Practising Citizenship and Heterogeneous Nationhood: Naturalisations in Swiss Municipalities

2008 (ISBN 978908964034 5)

Inge Van Nieuwenhuyze

Getting by in Europe's Urban Labour Markets: Senegambian Migrants'

Strategies for Survival, Documentation and Mobility

2009 (ISBN 978908964050 5)

Nayla Mourkabel

Sri Lankan Housemaids in Lebanon: A Case of 'Symbolic Violence' and 'Every Day Forms of Resistance'

2009 (ISBN 978908964 O5I 2)

Jérôme Jamin

L'imaginaire du complot: Discours d'extrême droite en France et aux Etats-Unis

2009 (ISBN 978908964048 2)

John Davies

'My Name Is Not Natasha': How Albanian Women in France Use

Trafficking to Overcome Social Exclusion (1998-2001)

2009 (ISBN 9789053567074 )

Dennis Broeders

Breaking Down Anonymity: Digital Surveillance of Irregular Migrants in Germany and the Netherlands

2009 (ISBN 978908964 I59 5)

Arjen Leerkes

Illegal Residence and Public Safety in the Netherlands

2009 (ISBN 978908964049 9)

João Sardinha

Immigrant Associations, Integration and Identity: Angolan, Brazilian and Eastern European Communities in Portugal

2009 (ISBN 9789089640369 ) 